\title{
Three Essays in Applied Econometrics: Agricultural and Energy Economics
}

\author{
Kuan-Ming Huang \\ West Virginia University, kh0060@mix.wvu.edu
}

Follow this and additional works at: https://researchrepository.wvu.edu/etd

Part of the Behavioral Economics Commons, Econometrics Commons, Environmental Studies

Commons, Food Security Commons, Other Economics Commons, and the Regional Economics

Commons

\section{Recommended Citation}

Huang, Kuan-Ming, "Three Essays in Applied Econometrics: Agricultural and Energy Economics" (2021). Graduate Theses, Dissertations, and Problem Reports. 8058.

https://researchrepository.wvu.edu/etd/8058

This Dissertation is protected by copyright and/or related rights. It has been brought to you by the The Research Repository @ WVU with permission from the rights-holder(s). You are free to use this Dissertation in any way that is permitted by the copyright and related rights legislation that applies to your use. For other uses you must obtain permission from the rights-holder(s) directly, unless additional rights are indicated by a Creative Commons license in the record and/ or on the work itself. This Dissertation has been accepted for inclusion in WVU Graduate Theses, Dissertations, and Problem Reports collection by an authorized administrator of The Research Repository @ WVU.

For more information, please contact researchrepository@mail.wvu.edu. 
Three Essays in Applied Econometrics: Agricultural and Energy Economics

Kuan-Ming Huang

Dissertation to be submitted to the

Davis College of Agriculture, Natural Resources, and Design

West Virginia University

In partial fulfillment of the requirement for the degree of

\section{Doctor of Philosophy}

In

Natural Resource Economics (Sustainability Studies)

Xiaoli L. Etienne, Ph.D., Chair

Alan R. Collins, Ph.D.

Victor K. Chow. Ph.D.

Ana Claudia Sant'Anna, Ph.D.

Division of Resource Economics and Management

Morgantown, West Virginia

2021

Keywords: Natural Gas, Shale Boom, Natural Hazard, Economic Impact, Covid-19, Food Expenditure 


\begin{abstract}
Three Essays in Applied Econometrics: Agricultural and Energy Economics Kuan-Ming Huang
\end{abstract}

This dissertation examines three empirical issues in energy and agricultural economics using econometrics models whose titles are: 1) Do Natural Hazards in the Gulf Coast Still Matter for State-Level Natural Gas Prices in the US? Evidence After the Shale Gas Boom; 2) Do Exploitations of Marcellus and Utica Shale Formations Improve Regional Economy in Ohio, Pennsylvania, and West Virginia? A Synthetic Control Analysis; and 3) How Did Covid-19 Impact US Household Food Spending? An Analysis Six Months In.

The first essay assesses the impact of natural hazards on state-level natural gas prices and evaluates the effects of the shale gas boom on the hazard-price relationship. Property losses due to natural hazards in Texas and Louisiana are used to represent supply shocks in US natural gas market from the Gulf area. Panel distributed lag models are applied to a state-level panel data set from 1995 to 2016. Estimation results show that natural gas prices in both importing and exporting states have become less responsive to natural hazards in Texas, but more sensitive to hazard events in Louisiana since the shale boom. These results are robust to the break dates used, the geographical location of states considered, and the empirical specifications employed. The increasing importance of Louisiana in natural gas pricing is perhaps due to its role as the benchmark pricing location for US natural gas and its expansive pipeline networks.

The second essay examines the impact of shale gas development on various economic outcomes in three Appalachian states: Ohio, Pennsylvania, and West Virginia. Four key economic indicators (poverty rate, population growth, employment growth, and income per capita growth) are considered. Estimation results obtained from the synthetic control method using 2002-2017 data are mixed. The shale development decreased the poverty rate and increased the employment growth rate in Pennsylvania and West Virginia in the short-run (2010 to 2013). In West Virginia, shale development also increased personal income per capita growth in the short run. However, most of the positive impacts disappeared or turned negative in the later post-boom period (2014 to 2017). The shale development did not bring significant economic benefits to Ohio. 
Nonetheless, shale development exerts a potential long-term negative effect on population growth in all three states.

The third essay exploits a nationwide survey of primary grocery shoppers to estimate the impact of Covid-19 on household spending behavior. The survey was conducted in August 2020 when the economy had partially reopened in many areas of the country and consumers had different spending opportunities compared to when the Covid-19 lockdown began. Various sociodemographic information such as household income, age, Covid-19 severity level, access to grocery stores, and farmers markets were collected. Findings based on ordered Probit models show that food insecurity problems impacted middle-class households (those with income below $\$ 50,000$ and those with income between $\$ 50,000$ and $\$ 99,999$ ). Households with children and/or the elderly (i.e., those that usually require higher food quality and nutrition intakes) had a higher probability of increasing their spending during Covid-19 than before. Furthermore, consumers' food safety practice levels and the Covid-19 severity level within the country of their residences significantly affected their overall food grocery and local produce shopping behaviors. 


\section{Acknowledgment}

As a transfer student from Washington State University, I truly appreciate everyone I met at West Virginia University. First of all, the greatest appreciation goes to my advisor, Dr. Xiaoli Etienne. She spent tremendous time and effort guiding and training me to be a qualified scholar. She always shows great care and patience since the very first day we met in her class. She has been doing everything she can to help me succeed. I can't get this close to the finish line without her guidance. Thank you.

I am truly grateful to my committee members, Dr. Alan Collins, Dr. Victor Chow, and Dr. Ana Claudia Sant'Anna. Together with Dr. Gerard D'Souza, Dr. Collins admitted me into the program when I was not doing very well in my previous department. The mentorship, supports, and resources he provided throughout the years allow me to complete this journey. I thank Dr. Chow for not only providing comments on research but also giving me career advice. I am also very grateful to Dr. Sant'Anna, who helped me tremendously with my research and shared everything she knows about how to be successful in the early career stage.

I am truly thankful to the Division for providing financial supports throughout the years, without which I would not have been made it so far. Dr. Dee Singh-Knights taught me a lot about teaching and offered me opportunities to practice my teaching skills. Dr. Cheryl Brown provided many helpful suggestions and comments during my survey design process. Dr. Mark Sperow, Dr. Heather Stephens, and Dr. Elizabeth Byrd shared their experiences on job searching. Lisa and Barry helped me a lot with administrative-related tasks. Dr. Feng Yao and Dr. Adam Nowak were always very responsive and helped me a lot with econometrics.

Of course, I do not forget about my friends at WVU. Fellow REM graduate students Marziyeh, Shabani, Alex, Anica, Ritika, Douglas, Sara, Elham, Fahad, Bolar, Chris, Zach, Lisa, and many more. My buddies in the finance department, Shengru, and Yang, the math and econometrics gurus! I had a great time taking classes and discussing research ideas with all of you. I am also grateful to all friends and families I met in Morgantown, particularly the help from Dr. Chang, Dr. Chen, Dr. Kang, Dr. Lin, Dr. Wang, Kelley, and their families more. Also, the young folks, Angel, Chiang, Felicity, Lily, and Elena. 
I also thank my master committee members at Washington State University and the University of Idaho, Dr. Mark Gibson, Dr. Andrew Cassey, and Dr. Philip Watson. All of you were very inspiring and provided me great advice and mentorships. Of course, my Pullmans/Moscow wolf pack, Jacky(s), Hao, Ricky, Steve, Steven(s), Chris, Jin, Oscar, Banford, Ernest, Anita, Josie, Hermosa, Victoria, Winnie, Richard, Derrick, James, and more. Thank you all for showing up at different stages of my life and being a part of my good old times.

To Fred and Ginny, thank you for being my host parents when I first came to the U.S. in 2005. You and April took great care of me and taught me a lot about American cultures and traditions. To my dear father, Dr. Shou-Tzuoo Huang, thank you for being my excellent role model and supporting me both mentally and financially throughout the years. As a finance expert, you should have known that investing in S\&P500 or Nasdaq would have generated way more return than investing in me. However, you still choose to believe in me. Thank you.

To my dear mother, Shafei Chen, thank you for taking care of and educating me since day -266 (approximately). You taught me not just academics but also how to be a kind person. Thank you.

To my oldest brother, David, thank you for being my cool brother and role model since childhood.

To my middle brother, Champ, sister-in-law, Frannie, and their two lovely kiddos, Ming and Bao, thank you for taking good care of our parents and showing me great care and supports. To my relatives and family friends, thank you for all the kind words and heartwarming encouragement.

To my lovely cat daughter, Tiny. Thanks for accompanying me day and night 24/7, especially during the pandemic. Even if you can't read and write, you still helped typing my dissertation with your paws. Thank you for always by my side during this long journey.

To my future girlfriend/wife, even if I am not sure who you are, as a believer in happy wife happy life, I feel I should reserve a spot for you on this one of the most important stacks of papers in my life. Thank you.

Finally, I truly appreciate everyone who helped me directly and indirectly throughout the journey. Even if I am not able to list each one of you, please accept my sincere appreciation. Thank you! 


\section{Table of Contents}

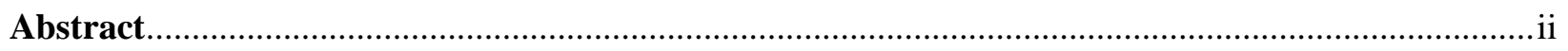

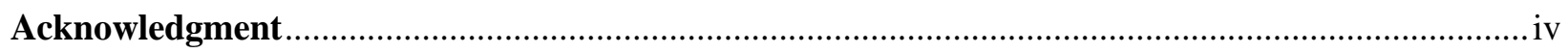

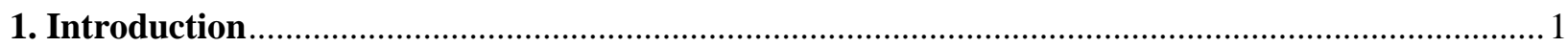

2. Do Natural Hazards in the Gulf Coast Still Matter for State-Level Natural Gas Prices in the US?

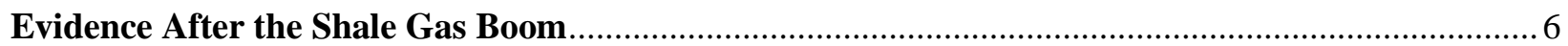

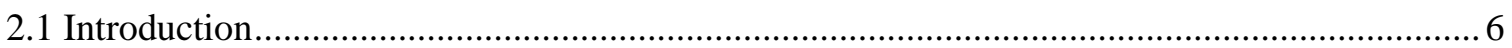

2.2 Recent Development in the US Natural Gas Industry and Related Literature ......................... 9

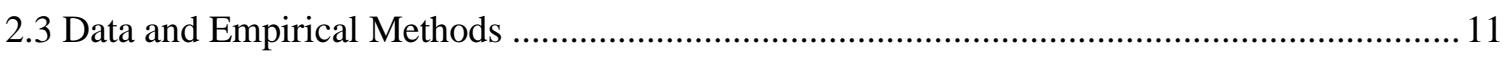

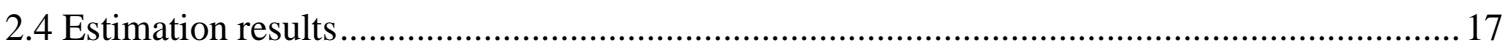

2.4.1 The average effect of natural hazards on natural gas prices .......................................... 18

2.4.2 Do natural gas prices in importing/exporting states respond differently to natural hazards?

2.4.3 How do natural gas prices in states of different regions respond to natural hazards? ......21

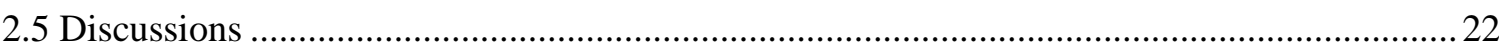

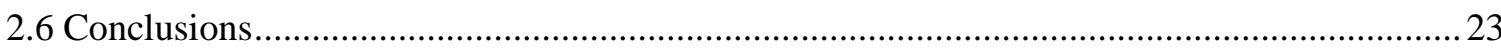

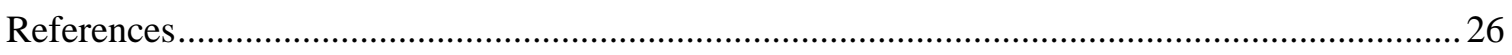

3. Do Exploitations of Marcellus and Utica Shale Formations Improve Regional Economy in Ohio, Pennsylvania, and West Virginia? A Synthetic Control Analysis ................................................52

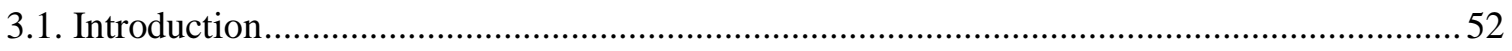

3.2. Impact of Marcellus and Utica shale development ...........................................................5

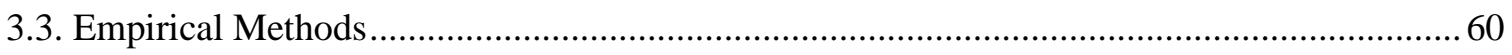

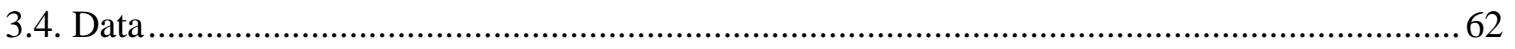

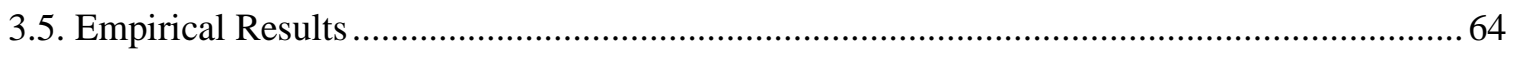

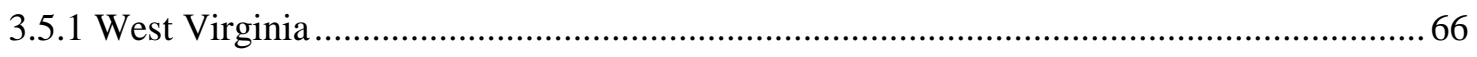

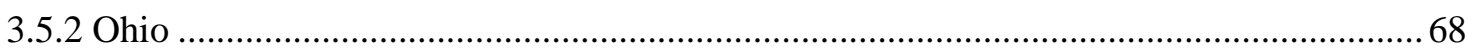

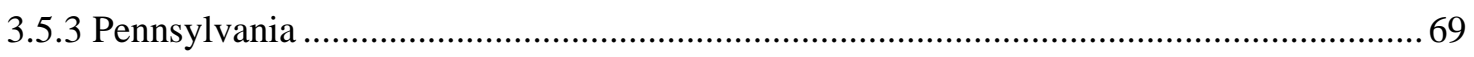

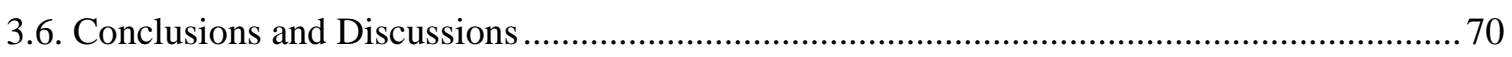

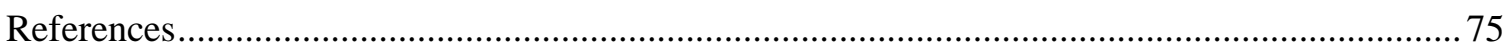

4. How Did Covid-19 Impact US Household Food Spending? An Analysis Six Months In ...............99

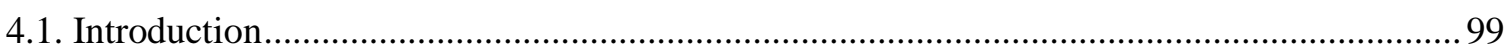

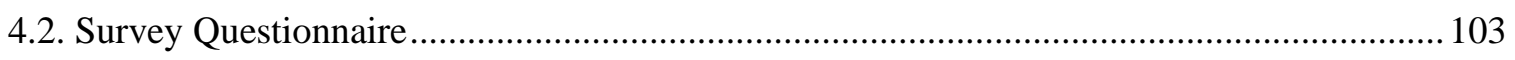

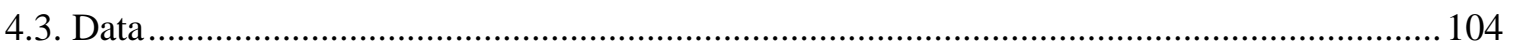

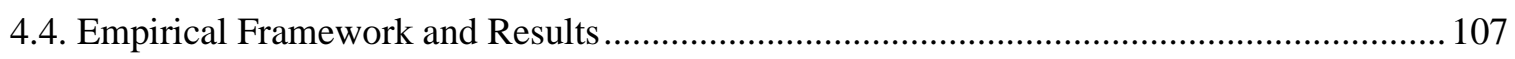




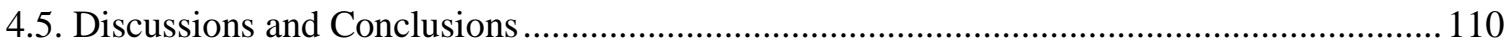

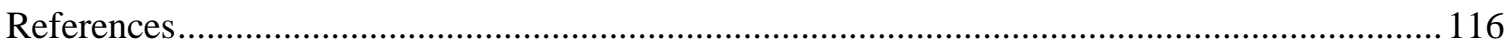

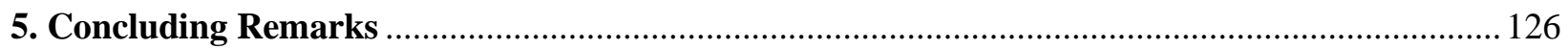




\section{List of Figures}

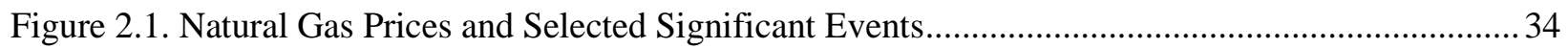

Figure 2.2. Natural Gas Gross Withdrawals in Lower 48 States and Selected Regions .............................35

Figure 2.3. In-state Property Damages and City Gate Prices in Selected States...................................... 36

Figure 2.4. Number of States Experienced Structural Break by Year .................................................... 37

Figure 2.5. Annual Natural Hazard Occurrences in LA and TX before and after 2010 .......................... 37

Figure 2.6. Cumulative Effects of One-Unit Shock to In-state, Texas, and Louisiana Natural Hazards for

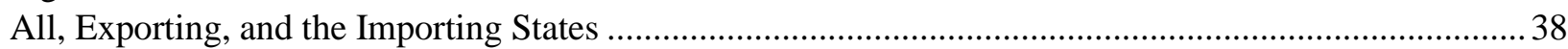

Figure 2.7. Cumulative Effects of One-Unit Shock to In-state, TX, and LA Natural Hazards on States in

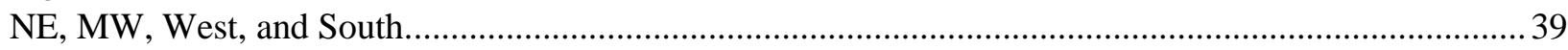

Figure 3.1. Monthly Natural Gas Production of Ohio, Pennsylvania, and West Virginia, 2000-2018....... 85

Figure 3.2. Production by Shale Play and Marcellus \& Utica Production Share...................................... 86

Figure 3.3. West Virginia (upper left), Ohio (upper right), and Pennsylvania (low) Top Coal and Oil \&

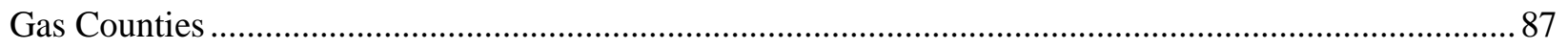

Figure 3.4. Optimal Weight Matrix for Top Oil and Gas Producing Counties in WV, OH, and PA. ........ 88

Figure 3.5. Estimated Impacts of Shale Boom on Top Oil \& Gas Counties in West Virginia ...................90

Figure 3.6. Estimated Impacts of Shale Boom on Top Oil \& Gas Counties in Ohio...............................91

Figure 3.7. Estimated Impacts of Shale Boom on Top Oil \& Gas Counties in Pennsylvania ....................92

Figure 3.A1. Leave-one-out Robustness Test Results for WV4 …......................................................93

Figure 3.A2. Leave-one-out Robustness Test Results for WV15 .........................................................94

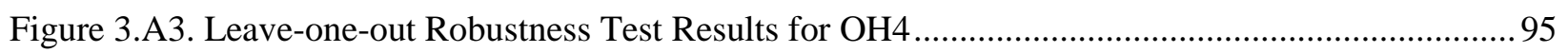

Figure 3.A4. Leave-one-out Robustness Test Results for $\mathrm{OH} 15$............................................................96

Figure 3.A5. Leave-one-out Robustness Test Results for PA4 ..............................................................97

Figure 3.A6. Leave-one-out Robustness Test Results for PA15 ….......................................................98

Figure 4.1. Grocery shopping and fresh produce expenses, and the share of locally grown fresh produce purchased by income level: Before vs. During Covid-19 124 


\section{List of Tables}

Table 2.1. Summary Statistics of Variables Considered in the Analysis ................................................ 30

Table 2.2. Estimation results for scenario 1 (46 states combined) and 2 (Export \& Import) .................... 31

Table 2.3. $P$-values for $F$-tests: the Impacts of In-state, Texas, and Louisiana Property Damages and

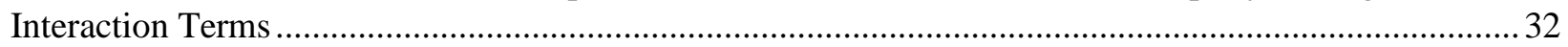

Table 2.4. Estimation results for scenario 3: Northeast, Midwest, West, and South ................................. 33

Table 2.A1. Estimation results when using alternative policy variables for scenario 1: All States ............40

Table 2.A2. Estimation results when using alternative policy variables for scenario 2: Export States .......41

Table 2.A3. Estimation Results when using alternative policy variables for scenario 2: Import States..... 42

Table 2.A4. Results when using alternative policy variables for scenario 3: Northeast States ................. 43

Table 2.A5. Results when using alternative policy variables for scenario 3: Midwest States .................... 44

Table 2.A6. Results when using alternative policy variables for scenario 3: West States..........................45

Table 2.A7. Results when using alternative policy variables for scenario 3: South States.........................46

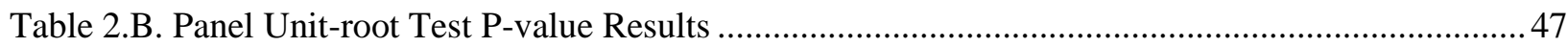

Table 2.C1. Estimation results when property damages from TX \& LA vs. all Gulf states are considered:

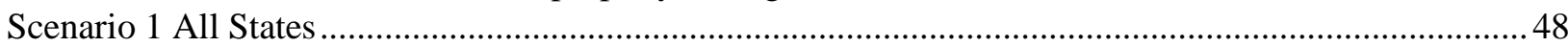

Table 2.C2. Estimation results when property damages from TX \& LA vs. all Gulf states are considered:

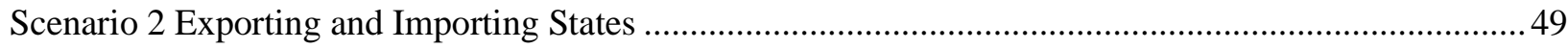

Table 2.C3. Estimation results when property damages from TX \& LA vs. all Gulf states are considered:

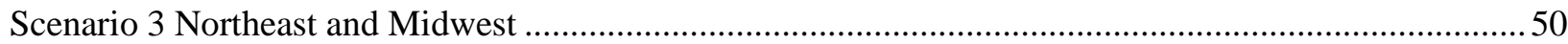

Table 2.C4. Estimation results when property damages from TX \& LA vs. all Gulf states are considered:

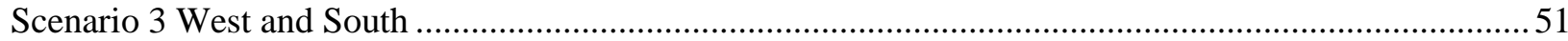

Table 3.1. Summary Statistics: West Virginia, Ohio, and Pennsylvania Top 4 and 15 Oil \& Gas Aggregates of Nonmetropolitan Counties (ANC) and 27-Donor ANCs ................................................81

Table 3.2. Match Quality of All Variables (Comparison with 27-state Average) ....................................82

Table 3.3. Joint Impact P-values for Post-boom period, 2010-2017 ...................................................... 83

Table 3.4. Estimated Impacts of Shale Boom on Top Oil \& Gas Counties in PA, OH, and WV .............. 84

Table 4.1. Demographic information of the survey respondents and descriptions of the variables ......... 120

Table 4.2. Summary of Dependent Variable: Changes in Consumption Pattern................................... 121

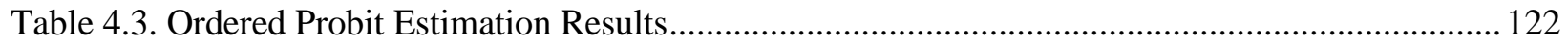

Table 4.4. Marginal Effects of Variables on Overall Food Grocery Spending, Fresh Produce Expenditure, and Share of Locally Grown Fresh Produce Purchased...................................................................... 123

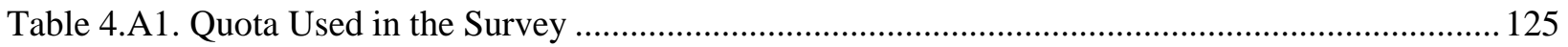




\section{Chapter 1}

\section{Introduction}

Traditionally, the majority of natural gas in the United States was produced in states along the Gulf of Mexico and their offshore areas. Of the states sharing the Gulf Coast (Alabama, Florida, Louisiana, Mississippi, and Texas), Louisiana (LA) and Texas (TX) are the two main net exporting states. The combined gross withdrawals from the two states accounted for approximately $95 \%$ of total withdrawals by the Gulf states during the sample period (EIA, 2018). In the late 1990s, spurred by high natural gas prices and a shortage of supply, the oil and gas industry in the US started to combine horizontal drilling and hydraulic fracturing techniques to extract natural gas from shale formations. The dramatic rise in shale production has lowered natural gas prices throughout the US. The price at Henry Hub, a major natural gas distribution hub in the US, decreased from \$8.69 in 2005 to \$3.15 per million BTU in 2018.

The shale gas boom involves multiple states and numerous wells, and the exploration and operation conditions of these states and wells all vary. Several new natural gas exporting states, most notably Pennsylvania (PA), West Virginia (WV), and Ohio (OH), which withdraw from the Marcellus and Utica shale plays, as well as North Dakota (ND), which withdraws from the Bakken Region, witnessed their combined gross withdrawals rose from less than $5 \%$ of the total US production before mid-2010 to more than $30 \%$ in 2018.

With the rise of production from shale resources, several important questions emerge. First, how has the shale revolution changed the natural gas price dynamics in the United States? Previous studies have extensively analyzed how the rise of unconventional oil and gas production have affected natural gas prices. However, none of the previous studies have systematically how natural gas prices respond to supply and demand disruptions due to natural hazards, and how the relationship might have changed after the shale revolution. Second, with the extensive drilling activities taken place throughout the Marcellus and Utica shale plays, has the shale gas boom created positive economic impacts to the regional economies of the shale states and counties? Although previous studies have analyzed how shale gas development affected the regional economy in various regions and states, surprisingly limited attention has 
been paid to West Virginia and Ohio, the two states that are playing an increasingly important role in US natural gas supply.

On the question relating to disasters-price relationship, I focus in particular on the disaster-related disruptions in the Gulf Coast. Prior to 1997 , nearly $80 \%$ of the lower 48 -state gross withdrawals came from LA and TX. The federal offshore production in the Gulf of Mexico accounted for approximately $21 \%$ of the total US natural gas withdrawals in 1997 . Not surprisingly, natural hazards in the Gulf area that caused supply disruptions could dramatically affect the US natural gas market as most of the production took place in that region. However, with the rise of fracking and the declining production from federal offshore, natural gas production centers in the US began to shift inland in the late 2000s. Since the inland states are subject to almost no tropical storms or hurricanes which, in the past, had caused severe natural gas supply disruptions, it is expected that natural gas prices have become less responsive to natural hazards in the Gulf states in the shale era.

In the first paper, I analyze how natural hazard events affect state-level natural gas prices in the United States and how the relationship has changed in light of the shale revolution. In addition to natural hazards within each state, the hazard events in two traditional exporting states in the Gulf Coast (Texas and Louisiana) are considered to determine whether shale production growth has made natural hazards in the Gulf region less important to natural gas pricing. Using a state-level panel data set from 1995 to 2016, I estimate fixed-effect panel distributed lag models to empirically examine these relationships. Property losses due to natural hazards in Texas and Louisiana are used to represent supply shocks from the Gulf area, while in-state natural hazardrelated property losses are used to measure the exogenous shocks from weather-related events originated within the state.

Results show that natural gas prices in both importing and exporting states have become less responsive to natural hazards in Texas but more sensitive to hazard events in Louisiana since the shale boom. These results are robust to the break dates used, the geographical location of states considered, and the empirical specifications employed. The more diversified production regions in the post-shale era have mitigated the effect of Texas' hazard events on state-level natural gas prices across the US. The increasing importance of Louisiana in natural gas pricing is perhaps due to its role as the benchmark pricing location for US natural gas and its expansive 
pipeline networks. I also show that natural gas prices in importing states have become less sensitive to their in-state natural hazards. Overall, findings from the present paper suggest that the impacts of supply or demand disruptions due to weather-related events have diminished in the post-shale era, although Louisiana continues to play an important role.

Regarding the second question on the impact of the shale development of the Marcellus and Utica formations on local economies, I focus on the economic impacts on each of the three shale states, Ohio, Pennsylvania, and West Virginia, separately. Although nationally, the shale boom started in the mid-2000s, natural gas production in these states did not begin to take off in the late 2000s. The combined output from Marcellus and Utica plays accounted for only $1 \%$ of total shale gas production in November 2008, reaching 3\% in August 2009 and over 5\% in April 2010. The average monthly natural gas production has increased by $889 \%, 2,174 \%$, and $393 \%$ from the pre-shale era (2002-2009) to the shale boom period (2010-2018) in Ohio, Pennsylvania, and West Virginia, receptively. The dramatical increase in drilling activities can create employment opportunities and incentive local economic growth. Nonetheless, natural resource extractions often create negative externalities such as air and water pollutions and further cause environmental degradations. It is unclear whether shale boom generated net positive impact to the three Appalachian states, and the magnitudes and length of these impacts in each state.

In the second essay, I examine how the recent shale boom has affected several key economic indicators in the top oil and gas counties in Pennsylvania, Ohio, and West Virginia using the synthetic control method. I find mixed results depending on the regions and time periods considered, highlighting the importance of conducting region-specific analysis when evaluating the impact of the recent boom in the unconventional oil and gas sector.

Specifically, in WV the shale development significantly decreased the poverty rate, but the impact fails to persist in the long run. The shale boom also created short-term positive effects on both employment growth rate and per capita personal income in the first few post-boom years (2010 to 2013), but the effects became negative in the later post-boom period (2014 to 2017). Furthermore, shale development negatively affected population growth in top oil and gas counties in $\mathrm{WV}$, with the negative effect strengthens in the later post-boom period. In Ohio, counties with extensive drilling activities in $\mathrm{OH}$ fail to enjoy most of economic benefits from shale development. Meanwhile, the negative externalities associated with shale drilling may have 
depressed the population growth rate in the region. In Pennsylvania, the shale boom decreased the poverty rate, but as in WV the impact diminished in 2016. Estimation results further suggest that shale development increased employment growth in 2010-2013, but the impacts subsequently turned negative in the following years. For population growth, I again find shale drilling to exert a negative impact that persists and is enhanced in the long run.

While completing my Ph.D. at West Virginia University, one of the biggest sudden exogenous shocks that occurred to the global economy is the Covid-19 pandemic. Countries including US began to restrict border entries and global air travels in February 2020, and Covid19 was later declared as a global pandemic by the World Health Organization in March 2020. President Trump declared national emergency and states started to issue stay-at-home orders at the same month. The economic recovery package, CARES Act was passed and signed into law at late March. By the end of May, the Covid-19 death reached 100,000 in the US. The daily new cases in the US spiked to over 50,000 in July. At the beginning of the pandemic, concerns about food shortage led to panic buying as consumers stocked up on groceries. During Covid-19, the closure and limited access to restaurant dining, as well as the lifestyle changes (e.g., working from home), have led consumers to change their grocery shopping habits. Consumers are also facing higher food prices due to issues in the supply chain such as labor shortage and reduced shipments.

Amid this backdrop, in the third essay I estimate how Covid-19 has affected US household grocery spending behavior, in particular fresh produce and local food purchase and factors driving such changes. Earlier studies have analyzed the consumer behaviors in the early pandemic stage between mid-March and June 2020. However, the US economy was partially reopened in August. The store and restaurant operation restrictions were not as strict as the early lockdown period. Furthermore, consumers who received financial assistance from government in the early pandemic stage may had exhausted their extra incomes. It is expected that the consumers' shopping behaviors may differ from their pre-pandemic and early stage pandemic shopping behaviors.

In my third essay, using a nationwide survey of primary grocery shoppers conducted in August 2020, I examine household food spending when the economy had partially reopened, using interval and Order Probit regressions. Findings show that food insecurity problems impacted 
middle-class households (those with income below $\$ 50,000$, and those with income between $\$ 50,000$ and $\$ 99,999$ ). Households with children or elderlies (i.e., those that usually require higher food quality and nutrition intakes) had a higher probability of increasing their spending during Covid-19 than before. Consumers who practice food safety procedures more thoughtfully and the ones who live in a county with a higher Covid-19 severity level were also more likely to increase their spending. Furthermore, food accessibility significantly affected consumer grocery spending and local fresh produce consumption.

A revised version of the first essay co-authroed with Dr. Xiaoli Etienne is published in Energy Economics volume 98, 2021. The revised version of the second essay co-authored with Dr. Xiaoli Etienne was submitted to Papers in Regional Science. The revision requested from the initial review had been completed, and the paper had been resubmmited to the journal for reconsideration. The revised version of the third essay co-authored with Dr. Ana Claudia Sant'Anna and Dr. Xiaoli Etienne was submitted to PLOS ONE, and it is currently under review. 


\section{Chapter 2}

\section{Do Natural Hazards in the Gulf Coast Still Matter for State-Level Natural Gas Prices in the US? Evidence After the Shale Gas Boom}

\subsection{Introduction}

The short- and long-term negative effects of natural disasters such as earthquakes, hurricanes, tsunamis on the economic system are well-documented in the literature. In 1992, Hurricane Iniki caused approximately 7.4 billion US dollars in direct damage, generated longterm negative impacts on the local economy, and resulted in population loss in the Kauai Island of Hawaii (Coffman and Noy 2012). The estimated monetary damages caused by the 2010 Haiti Earthquake were at least 8.1 billion US dollars (Cavallo, Powell, and Becerra 2010). Norio et al. (2011) note that the 2011 Eastern Japan Earthquake not only disrupted agricultural production and automobile manufacturing in Japan, but also resulted in dramatic fluctuations in financial markets and the appreciation of the Japanese Yen which is harmful to an exporting country like Japan. In Vietnam, Noy and Vu (2010) find that natural disasters that caused more deaths lowered the output growth, while the natural disasters that destroyed more properties and facilities created short-term positive economic impacts.

In addition to affecting the overall economy, natural disasters may also create unexpected short-term fluctuations in energy prices. Hartley, Medlock, and Rosthal (2008) find that tropical storms at the Gulf Coast caused the short-term US natural gas prices to deviate from their longrun equilibrium values. When Hurricanes Katrina and Rita hit the Gulf of Mexico in 2005, the daily offshore natural gas supply decreased by about 6.7 billion cubic feet, as many offshore natural gas platforms, major processing facilities, and major pipeline segments were destroyed (Kumins and Bamberger 2005). Natural gas prices then rose by nearly $48 \%$ in the two months ${ }^{1}$

\footnotetext{
${ }^{1}$ The percentage is calculated by comparing the post-hurricane price (October US citygate price) and the price before hurricane (August US citygate price): $(\$ 12.16-\$ 8.20) / \$ 8.20=0.4829$, based on US Natural Gas Citygate Price, see https://www.eia.gov/dnav/ng/hist/n3050us3m.htm, accessed on 12/15/2019.
} 
after the hurricanes. Figure 2.1 shows the correspondence between natural gas price fluctuations in the US and some noteworthy supply disruptions, including the California energy crisis of 2000-2001, Hurricane Ivan in 2004, Hurricanes Katrina and Rita in 2005, and freeze-offs in 2011 (Mchich 2018).

Despite the anecdotal evidence that natural hazards can cause significant fluctuations in energy prices, few empirical studies have systematically investigated the magnitude and duration of these effects and how they may have changed due to the rise of shale gas production and the resulting shift in production centers. $\mathrm{Mu}$ (2007) finds that weather shocks, defined as the deviation in degree days from the average level, significantly affect natural gas price volatility. Wiggins and Etienne (2017) attribute most of the price fluctuations in the US natural gas market between mid-2005 and mid-2006 to Hurricanes Katrina and Rita. Nick and Thoenes (2014) highlight the importance of temperature shocks on natural gas prices in Germany. Brigida (2019) finds that natural gas price volatility was higher in winter due to weather effects and fluctuating storage levels.

The existing literature on the effect of weather-related events on natural gas prices is limited on at least four fronts. First, demand and supply shocks due to weather events are often used as control variables in the empirical analysis when estimating the effect of other variables on natural gas price movements. For instance, cooling degree days (CDDs) and heating degree days (HDDs) are used to control the weather and seasonal effects when analyzing the relationship between natural gas and oil prices (Brown and Yücel 2008) and the impact of nonweather-related shocks on natural gas price volatility (Wiggins and Etienne 2017). Although Mu (2007) explicitly discusses the effects of CDDs and HDDs on natural gas price dynamics, the analysis is limited to temperature deviations.

Second, some previous studies use dummy variables to represent extreme events such as financial crises, wars, and catastrophes in regression models when estimating energy price volatility (Hartley and Medlock 2014, Hartley, Medlock, and Rosthal 2008). The events considered in the analysis are often limited to those that either created substantial losses or received extensive media attention. However, some smaller and less well-publicized hazard events may as well pose significant risks to the energy market and cause considerable price fluctuations. The dummy variable approach also does not differentiate between the magnitudes 
of these weather events, which could lead to upward or downward bias depending on the severity of the events.

Third, most previous studies only focus on national prices without considering regional data. Natural gas prices in the US are primarily affected by regional supply-and-demand factors due to the large spatial discrepancies in the demand and production regions, transportation bottlenecks, weather differences, and other region-specific factors. Recent empirical studies further show that the US natural gas market has become less integrated in the shale era due to the slower pace in pipeline capacity expansion than the production growth (Scarcioffolo and Etienne 2019). Ignoring regional heterogeneity may result in biased estimation results on how natural gas prices respond to natural hazards.

Finally, none of the earlier studies consider how the shale gas development in Marcellus, Utica, and Bakken shale plays and the resulting rising unconventional gas production in inland regions may have affected the relationship between weather-related events and natural gas price volatility. Given the production center shifts, it is likely that supply disruptions in the Gulf coast and in-state natural hazards play a less important role in regional natural gas pricing.

Our paper seeks to fill these gaps in the literature by analyzing how natural hazard events affect state-level natural gas prices in the United States and how the relationship has changed in light of the shale revolution. In addition to natural hazards within each state, the hazard events in two traditional exporting states in the Gulf Coast (Texas and Louisiana) are considered to determine whether shale production growth has made natural hazards in the Gulf region less important to natural gas pricing. Using a state-level panel data set from 1995 to 2016, we estimate fixed-effect panel distributed lag models to empirically examine these relationships. Property losses due to natural hazards in Texas and Louisiana are used to represent supply shocks from the Gulf area, while in-state natural hazard-related property losses are used to measure the exogenous shocks from weather-related events originated within the state.

Results show that natural gas prices in both importing and exporting states have become less responsive to natural hazards in Texas but more sensitive to hazard events in Louisiana since the shale boom. These results are robust to the break dates used, the geographical location of states considered, and the empirical specifications employed. The more diversified production regions in the post-shale era have mitigated the effect of Texas' hazard events on state-level 
natural gas prices across the US. The increasing importance of Louisiana in natural gas pricing is perhaps due to its role as the benchmark pricing location for US natural gas and its expansive pipeline networks. We also show that natural gas prices in importing states have become less sensitive to their in-state natural hazards. Overall, findings from the present paper suggest that the impacts of supply or demand disruptions due to weather-related events have diminished in the post-shale era, although Louisiana continues to play an important role.

The remainder of the paper is organized as follows. Section two briefly discusses the recent development in the US natural gas industry and some related literature. Section three discusses the data and empirical methods. Estimation results are presented in section four. Section five discusses the results and the last section concludes the paper.

\subsection{Recent Development in the US Natural Gas Industry and Related Literature}

Traditionally, the majority of natural gas in the United States was produced in states along the Gulf of Mexico and their offshore areas. Of the states sharing the Gulf Coast (Alabama, Florida, Louisiana, Mississippi, and Texas), Louisiana (LA) and Texas (TX) are the two main net exporting states. ${ }^{2}$ The combined gross withdrawals from the two states accounted for approximately $95 \%$ of total withdrawals by the Gulf states during the sample period (EIA, 2018). In the late 1990s, spurred by high natural gas prices and a shortage of supply, the oil and gas industry in the US started to combine horizontal drilling and hydraulic fracturing techniques to extract natural gas from shale formations. The dramatic rise in shale production has lowered natural gas prices throughout the US. The price at Henry Hub, a major natural gas distribution hub in the US, decreased from $\$ 8.69$ in 2005 to $\$ 3.15$ per million BTU in $2018 .^{3}$

The shale gas boom involves multiple states and numerous wells, and the exploration and operation conditions of these states and wells all vary. Several new natural gas exporting states, most notably Pennsylvania (PA), West Virginia (WV), and Ohio $(\mathrm{OH})$, which withdraw from the

\footnotetext{
${ }^{2}$ Although in some years Alabama's production exceeded its consumption, it is only a minor natural gas producer in the US. In other years, the natural gas consumption in Alabama was higher than its production.

${ }^{3}$ See EIA Henry Hub spot prices: https://www.eia.gov/dnav/ng/hist/rngwhhdm.htm, accessed on 12/15/2019.
} 
Marcellus and Utica shale plays, as well as North Dakota (ND), which withdraws from the Bakken Region, witnessed their combined gross withdrawals rose from less than $5 \%$ of the total US production before mid-2010 to more than $30 \%$ in 2018.

Figure 2.2 illustrates the shift in the production centers of the US natural gas supply. Prior to 1997 , nearly $80 \%$ of the lower 48-state gross withdrawals (Federal Offshore-Gulf of Mexico excluded) came from LA and TX. The federal offshore production in the Gulf of Mexico accounted for approximately $21 \%$ of the total US natural gas withdrawals in 1997 . Not surprisingly, natural hazards in the Gulf area that caused supply disruptions could dramatically affect the US natural gas market as most of the production took place in that region.

However, natural gas production from TX and LA declined in the following years due to the depletion of several large gas fields (Swindell 1999). Although much of the shale gas drilling activities have taken place in Texas's Barnett Shale, the combined share of natural gas production from TX and LA has declined to approximately $45 \%$ of the total US natural gas supply in recent years. Furthermore, federal offshore output in the Gulf dramatically declined over the past two decades. By the end of 2017, it only accounted for less than $3 \%$ of the total US natural gas withdrawals. Figure 2.2 suggests that natural gas production centers began to shift inland in the late 2000s as shale production becomes increasingly prevalent. Since the inland states are subject to almost no tropical storms or hurricanes which, in the past, had caused severe natural gas supply disruptions, it is expected that natural gas prices have become less responsive to natural hazards in the Gulf states in the shale era.

Several studies have analyzed the effect of weather-related events on natural gas price fluctuations. Nick and Thoenes (2014) find that in Germany, temperature and supply shocks strongly affect short-term natural gas price fluctuations, while in the long-term crude oil and coal prices are the main determinants of natural gas price volatility. In the United States, Mu (2007) notes that about $50 \%$ of the natural gas demand depends on the weather as natural gas is used for both heating and electricity generation. Additionally, short-term US natural gas prices were found to deviate from their long-run equilibrium values because of the tropical storms in the Gulf Coast and other seasonal factors (Hartley and Medlock 2014, Hartley; Medlock, and Rosthal 2008). In particular, Wiggins and Etienne (2017) attribute most of the price fluctuations in the US natural gas market between mid-2005 and mid-2006 to Hurricanes Katrina and Rita. In a 
recent study, Brigida (2019) modeled the volatility in the US natural gas market, finding it to be considerably higher in the winter due to temperature fluctuations and changing storage levels.

In this paper, we investigate how natural hazard events, quantified as the dollar amount of the property damage losses, affect state-level natural gas prices in the United States. In addition to natural hazards within each state, the hazard events in two major net-producing states in the Gulf Coast, Texas, and Louisiana, are evaluated to determine whether the rise of shale production has made natural hazards in the Gulf region less relevant to natural gas pricing. Since weather disruptions can cause both demand and supply shocks in the natural gas market, especially at the regional level, we expect natural gas prices to respond significantly to hazard events that occurred both within the state and in the major production centers. Furthermore, as the Gulf area has lost its dominance in the US natural gas supply, we expect state-level natural gas prices to become less sensitive to hazard events in the Gulf region after the rise of unconventional gas production.

\subsection{Data and Empirical Methods}

We collect state-level natural gas prices at citygate from the US Energy Information Administration (EIA hereinafter). The citygate refers to the point where natural gas is transferred from inter- or intra-state pipelines to a local natural gas utility, and therefore the price at this point should mainly reflect the wholesale or wellhead prices plus the transportation cost and region-specific premiums/discounts. Unlike the representative price at a given hub used in previous studies (e.g., Wiggins and Etienne 2017), the state-level prices allow us to examine the heterogeneous effect of weather-related events depending on the underlying characteristics of the state. The citygate prices could vary substantially depending on the regional weather events and other region-specific supply and demand factors.

One difficulty when addressing the proposed research questions is to find an appropriate measure for natural hazards that could impact natural gas supply or demand. As discussed earlier, the conventional approach of using dummy variables to represent well-known natural hazards or other supply disruptions (Hamilton 2003, Hartley and Medlock 2014, Hartley; Medlock, and Rosthal 2008, Kilian 2008a) suffers from several shortcomings_-assigning a 
numerical value of one to each event not only masks the differential effect of various natural hazards but also ignores the impact of smaller or less publicized events. Even for the same natural hazard that struck more than one state, it could affect the natural gas market somewhat differently depending on its damages to each state.

To remedy these problems, we use the property damages (in monetary values) caused by natural hazards as a proxy for the potential supply or demand disruptions due to weather-related events. The data are obtained from the Spatial Hazard Events and Losses Database for the United States (SHELDUS), currently maintained by the Arizona State University. The damage values are adjusted to 2016 levels to account for inflation. The types of natural hazards considered in the data include avalanches, coastal, drought, earthquakes, floods, fog, hail, heat, hurricanes and tropical storms, landslides, lightning, severe thunderstorms, tornados, tsunami and seiches, volcanos, wildfires, wind, and winter weather (Center for Emergency Management and Homeland Security, CEMHS hereinafter 2018). According to the CEMHS (2018), the property damage data are prepared by the National Weather Services based on estimates from insurance companies or other qualified sources. Hazard-related damages inflicted on both private properties and public infrastructure or facilitates are included in the estimates.

We use monthly in-state property damages to measure the supply or demand shocks that occurred within each state, and property damages in Texas and Louisiana to represent supply disruptions due to natural hazards in the Gulf Coast. We only consider property damages in TX and LA since the other states (Alabama, Florida, and Mississippi) were consuming more than their in-state productions in 1995-2016. Meanwhile, TX and LA production accounted for approximately $95 \%$ of the total Gulf State production in 1995-2016. For these reasons, property damages in TX and LA should convey information on the natural hazards in the two states and the Gulf Coast.

Figure 2.3 plots the in-state property damages and citygate natural gas prices (dollars per Mcf) in selected states. The top panel plots the two sequences for California and New York, the two states with the highest consumption, while the bottom graphs show the relationship between the two variables in TX and LA, the two main gas-exporting states. As can be seen, natural hazard events occurred more frequently in Louisiana than in the other three states. The peaks of 
property damages due to natural hazards were often followed by subsequent price increases, although sometimes with a delay.

To quantify the ceteris paribus effect of natural hazards on natural gas prices, it is necessary to include other supply and demand variables in the empirical analysis. The majority of the natural gas in the US is used for electricity generation and residential use, which is strongly correlated with the demand for heating and cooling. We hence follow previous studies (Hartley and Medlock 2014, Hartley, Medlock, and Rosthal 2008, Mu 2007) and use heating degree days (HDDs) and cooling degree days (CDDs) to measure natural gas demand. CDDs (HDDs) refer to the sum of daily temperatures below (above) 65 degrees Fahrenheit each month and are collected from the Climate Prediction Center at the National Oceanic and Atmospheric Administration (NOAA).

State-level natural gas prices may also be affected by the declining share of Gulf Coast production, or equivalently the rising importance of inland supply. We include the percentage of Gulf Coast and Federal Offshore production in the total US production (GCFO) as an additional control variable. The average percentage from the preceding three years is used in the model to minimize the endogeneity problem. The production data are collected from the EIA.

Annual state-level GDP, collected from the US Bureau of Economic Analysis, is included to control the effects of economic growth on natural gas prices. Since natural hazards of the same magnitude may cause different levels of property losses in each state, including state-level GDP also helps filter out the effect of regional economic conditions on the dollar amount of property losses due to natural hazards. The GDP data are adjusted to 2016 dollars to account for inflation.

Previous literature notes that crude oil prices tend to influence natural gas prices but not vice versa (Ramberg and Parsons 2012). We therefore include oil refiners' acquisition costs (adjusted to 2016 dollars) as an exogenous variable to capture the effects of oil market shocks on natural gas prices. Since oil price fluctuations also reflect business cycles and other economic factors (Barsky and Kilian 2004, Kilian 2008a, 2018b, 2009), including oil prices in the analysis also helps control other exogenous factors not explicated accounted for in the analysis.

Natural gas prices are affected by stock market volatility due to the linkage between the energy market and the overall US economy. We include the Volatility Index (VIX) of the Chicago Board of Exchange (CBOE), the leading indicator of the US stock market volatility, as 
an additional control variable. Since the shale boom period overlaps with the 2007-2009 great recession, including VIX helps control the potential impacts of macroeconomic fluctuations on natural gas prices. Following previous studies (Ahoniemi 2008), we use the first difference of VIX in the regression analysis.

State-level energy policies and environmental regulations may significantly affect the natural gas sector. ${ }^{4}$ Policies on the distance between wells and property lines, waste management, and health and safety regulations could raise production costs (Colborn et al. 2011). Further, energy policies favoring the renewable sector over fossil fuels discourage natural gas production and consumption (Shearer et al. 2014). To account for the time-varying effect of state-level policies on natural gas prices, we include the achieved Renewable Portfolio Standards (RPS) in Megawatt-hours (MWh) per million population as a control variable in the model. Policymakers often use RPS to achieve multiple policy goals, such as reducing greenhouse gas emissions and increasing renewable energy production (Yin and Powers 2010). Since states with a stronger preference for renewable energies are more likely to pursue environmentally-friendly policies (Dong 2012, Thombs and Jorgenson 2020), the RPS should also contain information on the stringency of environmental regulations in a given state. Considine and Manderson (2014) and Kydes (2007) show that state-level energy and electricity prices are significantly affected by RPS. To construct the achieved RPS variable, we collect the total annual RPS obligation (in MWh) and the annual RPS obligation achievement rate (\%) from the Lawrence Berkeley National Laboratory. Since the amount of obligation depends highly on the state population, we further divide the achieved obligation by the state population (in million people).

Data for the variables described above are combined into a monthly state-level panel data set. Due to their geographic locations, Alaska and Hawaii are excluded from the analysis. The District of Columbia is also excluded due to data availability. The sample period runs from January 1995 to December 2016, resulting in 264 monthly observations for each state and 12,672 observations for all states combined. Regarding the frequency of the data, the state-level data in monthly frequency is used in this study. Population, state GDP, and achieved renewable portfolio

\footnotetext{
${ }^{4}$ We appreciate the suggestion from a reviewer to include the state policy variable and the production variable discussed earlier. Several other variables for environmental regulations are considered, including the RPS obligation by state, the percentage of RPS obligation achieved, a binary RPS variable (RPS Dummy $=1$ when a state has RPS in a given year; 0 otherwise), and per capita energy-related carbon intensity. The results (available in Appendix A) are qualitatively similar regardless of the policy variable used.
} 
standard (RPS) obligation are only available in yearly frequency. For population, we transform the data from yearly frequency to monthly frequency assuming constant monthly growth rate. For state GDP, the yearly data was adjusted with monthly deflator. For achieved RPS obligation, the year-end data is used to represent every month throughout a year. For the natural gas and oil prices, the monthly level data represents the monthly average rather than the month-end closing price. The cooling (heating) degree days represent the sum of cooling (heating) degree days in a month rather than the average of daily cooling (heating) degrees. Property damage loss data represents the total monthly property damage. For the CBOE Volatility Index, the monthly closing price is used. We use various panel unit root tests (the Levin-Lin-Chu test, the Breitung test, and the Im-Persaran-Shun test) to determine the stationarity of key variables used in the paper. Testing results (available in Appendix B) suggest that the dependent variable, natural gas prices, and key independent variables (in-state, Texas, and Louisiana property damages) are all stationary under the panel setting.

Table 2.1 presents the summary statistics for each variable considered in the analysis. The maximum state property damage (60,316 million dollars) was caused by Hurricane Katrina in 2005. The highest natural gas citygate price occurred in Maine in June 2008, reaching $\$ 24.87 /$ Mcf, while the lowest price (\$0.75/Mcf) occurred in July 2001 in North Dakota. Further examination of the data suggests that natural gas prices in most states peaked a few months after the landfall of Hurricane Katrina in 2005. Oil prices peaked at $\$ 147.67$ per barrel in July 2008 and hit bottom at $\$ 13.26$ per barrel in December 1998. Additionally, CDDs appear to be more volatile than HDDs, as the standard deviation of CDDs is much higher than its mean.

We use fixed-effects panel data models to estimate the impact of natural hazard events on state-level natural gas prices. Specifically, consider the following regression equation:

$$
P_{i, t}=\operatorname{Hazard}_{i, t} \gamma+\operatorname{Hazard}_{i, t} D_{t} \delta+X_{i, t} \beta+\alpha_{i}+\varepsilon_{i, t}
$$

where $P_{i, t}$ represents the price of natural gas in state $i$ at month $t, \operatorname{Hazard}_{i, t}$ is a measure of supply/demand disruptions due to natural hazards in the major natural gas-producing states in the Gulf area, $D_{t}$ is a dummy variable indicating the shift in production center due to the rise of shale production, $X_{i, t}$ is a vector of control variables for state $i$ at time $t$, and $\gamma, \delta$, and $\beta$ are parameters to be estimated. The control variables include, among others, the in-state supply or 
demand shocks due to natural hazards, CDDs, HDDs, Gulf states and federal offshore production share, GDP, VIX, the achieved RPS, and oil prices. The interaction term, $\operatorname{Hazard}_{i, t} D_{t}$, allows the effect of natural hazards to vary before and after the shift in the production center in the US natural gas industry. If the rise of unconventional gas production has weakened the effect of Gulf-area supply disruptions, the coefficient of the interaction term $(\delta)$ should be negatively significant.

The composite error term in equation (1) consists of two parts, where $\alpha_{i}$ is the fixed effect representing the state-level characteristics that affect natural gas prices but are relatively constant over time, and the idiosyncratic factors $\left(\varepsilon_{i, t}\right)$ for each state that varies across time. These time-varying unobserved factors may include improvement in natural gas-related facilities, unobserved policies, and other state-specific factors uncorrelated with property losses and other control variables. The fixed effects transformation drops out independent variables that are constant over time for each state.

To allow natural hazards to have a long-term impact on natural gas prices, we include lagged property losses for both in-state and Gulf area natural hazards. The regression equation (1) essentially becomes a fixed-effects panel distributed lag model. Since the cross-sectional unit of the model is "state," the standard i.i.d. assumption for the error term in equation (1) may be violated due to correlations over time within a given state. For this reason, we consider clusterrobust standard errors that allow for correlations across time within a state but not across different states (Cameron and Miller 2015). However, Cameron, Gelbach, and Miller (2008) show that when the number of clusters is small, asymptotic tests based on cluster-robust standard errors may suffer from the over-rejection problem. As a remedy, we calculate the cluster-robust bootstrap standard errors following Cameron, Gelbach, and Miller (2008).

Since one of the objectives of the present paper is to analyze whether the rise of shale gas production has altered how natural gas prices respond to natural hazard events at the Gulf coast, it is necessary to identify when this shift occurred. In other words, we need to determine the break date in the regression analysis, or when $D_{t}$ in equation (1) takes on a value of one. Although drilling activities in the shale formations started in the late 1990s, the shale gas boom did not begin until the late 2000s. As can be seen in figure 2.1, the dramatic rise of shale production in fact began in 2010, when the combined monthly dry gas production from Bakken 
and Marcellus' formations reached 1 billion cubic feet and the combined production of Pennsylvania, West Virginia, Ohio, and North Dakota exceeded 5\% of the total US production.

As a formal test, we apply Andrews (1993) structural break test with a single unknown break date to empirically determine when the break occurred. We consider various specifications, including the baseline model with all variables, the baseline model excluding natural hazard loss-related variables, the baseline model with only current-period hazard-related variables. Figure 2.4 shows the estimation results for the structural break test. As can be seen, most of the states experienced a structural break in 2009 regardless of the specifications considered. Based on the structural break test results, we define the following:

$$
D_{t}=\left\{\begin{array}{l}
0, \text { for years prior to } 2009 \\
1, \text { for years after } 2009
\end{array}\right.
$$

One concern with dividing the data into two sub-periods is that one sub-period might have experienced more frequent hazard events than the other, which may lead to over- or underestimation of the true effects of the hazard events. As shown in figure 2.5, the monthly natural hazard occurrences in TX and LA are rather comparable before and after 2009. We also conduct a two-sample $t$-test of the two hazard variables during the two sub-periods, finding no significant differences before and after the break date.

\subsection{Estimation results}

To examine how states of different characteristics respond to natural hazards, we consider the following scenarios in the empirical analysis:

i) Scenario 1: all 46 states (ALL, excluding TX and LA) are considered in the estimation to obtain the average effect of natural hazards on state-level natural gas prices.

ii) Scenario 2: states are divided into exporting and importing states based on their total consumption and production levels. A state is considered a net-exporting (importing) state if its average withdrawals in 1995-2016 are higher (lower) than its average consumption. In total, the exporting and importing groups include 12 and 34 states, 
respectively. Scenario 2 allows us to examine if natural gas prices at exporting and importing states respond to natural hazards differently.

iii) Scenario 3: the states are divided into sub-groups based on their geographic locations: Northeast (NE), Midwest (MW), South (South), and West (West). ${ }^{5}$ The numbers of states in each region are 10,11, 11, and 14, respectively. Previous studies suggest an east-west split in the US gas market due to pipeline capacity constraints (King and Cuc 1996, Serletis and Herbert 1999). Scenario 3 allows us to test this hypothesis by examining whether states in different regions respond to natural hazards differently.

Using AIC and BIC, six lags for property losses in Texas and Louisiana and three lags for in-state property losses are used in the analysis. Estimation results are qualitatively similar when alternative lag lengths are considered. ${ }^{6}$ For each model, we test for over-identifying restrictions to determine whether a fixed- or random-effects model is preferred for the data. Compared to the standard Hausman Test, the over-identifying restriction test can be used in conjunction with clustered standard errors (Schaffer and Stillman 2006). Testing results suggest that the null hypothesis is rejected in all scenarios, providing strong evidence in favor of a fixed-effects specification.

\subsubsection{The average effect of natural hazards on natural gas prices}

Table 2.2 model (1) presents the estimation results for scenario 1 when all 46 states are considered. HDDs significantly increase natural gas prices, as the increasing demand for heating on cold days tightens the supply and demand relationship. Gulf coast production share significantly decreases state-level natural gas prices. GDP, a proxy for the aggregate demand, is positive but significant. Oil prices and VIX positively affect gas prices, collaborating findings from earlier studies that oil and stock markets play an important role in natural gas pricing (Hartley and Medlock 2014, Zhang, Chevallier, and Guesmi 2017). Achieved RPS negatively affects prices, although the effect is non-significant. The dummy variable indicating the post-

\footnotetext{
${ }^{5}$ The states in Northeast include Connecticut, Maine, Massachusetts, Michigan, New Hampshire, New Jersey, New York, Pennsylvania, Rhode Island, and Vermont. The Midwest includes Illinois, Indiana, Iowa, Kansas, Minnesota, Missouri, Nebraska, North Dakota, Ohio, South Dakota, and Wisconsin. The South includes Alabama, Arkansas, Florida, Maryland, Delaware, Georgia, Kentucky, Louisiana, Mississippi, North Carolina, Oklahoma, South Carolina, Tennessee, Texas, Virginia, and West Virginia. The states in the West include Montana, Wyoming, $\underline{\text { Colorado, }}$ New Mexico, Idaho, Utah, Arizona, Nevada, Washington, Oregon, California.

${ }^{6} \mathrm{We}$ also estimate models when the property damages from other Gulf states (Alabama, Florida, and Mississippi) are included, and the results (available in Appendix C tables C1-C4) are qualitatively similar to those presented.
} 
shale period is negatively significant, suggesting that on average, state-level prices were lower after 2009 after accounting for various explanatory variables.

For the natural hazard variables, table 2.2 model (1) suggests that in-state property damages on average do not significantly affect natural gas prices. This effect remains unchanged in the second sub-period despite the dramatic growth in shale production after 2009. Estimation results further suggest that in the pre-shale period, recent natural hazards in TX (from the current month to three months prior) positively affect state-level prices. However, this effect dramatically weakens in the post-shale era as the coefficients for the TX interaction terms are mostly negatively significant. By contrast, natural gas prices have become more responsive to natural hazards in LA in the second sub-period - the positive and significant coefficients associated with the LA interaction terms reinforce the positive effects of LA natural hazards on state-level prices in the pre-shale era.

Direct interpretation of the estimated coefficients in a distributed lag model is difficult due to the dynamics involved. To facilitate the discussion, we plot the cumulative effect of a oneunit temporary shock to the property damage variable on state-level natural gas prices, as shown in the first row of figure 2.6. The mean cumulative effects of a unit shock to TX natural hazards in the pre-shale period are greater than those in the post-boom period. Furthermore, while the effects of a unit increase in TX hazards was positively significant in the pre-shale period, the effects become mostly non-significant after 2009.

By contrast, the cumulative effects of a unit shock to LA natural hazards are positively significant in both sub-periods, with larger magnitudes observed in the post-shale era. In other words, natural hazards in LA play a more important role after the rise of shale production. For in-state property damages, the magnitudes of their cumulative effects are small and mostly nonsignificant during both sub-periods.

Since TX and LA are neighboring states, natural hazard damages from the two states may be correlated if they are subject to the same hazard event, making it difficult to disentangle the effect of one from the other. We perform $F$-tests to see if the impacts of natural hazards in the two states are statistically different. As shown in table 2.3 (last row of each panel), the null hypothesis of equal impacts from the two states is rejected at $1 \%$ level, providing strong 
evidence that the natural hazards in TX and LA exert differential effects on state-level natural gas prices.

\subsubsection{Do natural gas prices in importing/exporting states respond differently to natural hazards?}

We next consider whether prices in net exporting and importing states respond differently to natural hazards (scenario 2), the results of which are presented in the models (2)-(3) table 2.2. In the pre-shale period, in-state natural hazards negatively affect natural gas prices in exporting states. For these states, in-state natural hazards could damage pipelines, limiting their ability to transport natural gas out of states and depressing prices in the state. However, the negative impacts of in-state natural hazards diminished in the shale era, as illustrated by the positive interaction terms at lag 2. Meanwhile, prices in importing states respond positively to in-state hazard events with a one-month lag. Th positive effect declined in the post-shale era as suggested by the negatively significant coefficient for the interaction term associated with lag 2 . For importing states, the loss of natural gas supply during in-state hazard events may be recovered more quickly in the post-shale era due to the increased production from inland regions.

Estimation results in table 2.2 and the cumulative response functions in figure 2.6 (rows 2 and 3) further suggest that an increase in TX natural hazards significantly increases natural gas prices in both exporting and importing states in the pre-shale period, while after 2009 it plays a much less important role. Consistent with the findings for all states, the cumulative effects of TX hazard events are mostly non-significant in the second sub-period in both importing and exporting states.

By contrast, the effects of LA hazard events have increased after the shale boom, a result corroborating the findings from scenario 1. Prior to 2009, LA natural hazards only exerted a small positive effect on prices in both importing and exporting states, and the effects are significant starting from four months after the shock occurs. After 2009, prices in both groups of states respond positively to natural hazards in LA at the month when the shock occurs. The effects are also of larger magnitudes compared to those in the first sub-period. 


\subsubsection{How do natural gas prices in states of different regions respond to natural hazards?}

We further estimate the panel distributed lag models for different regions in the US (scenario 3) to determine whether states in different geographical locations respond differently to natural hazards. Estimation results are presented in table 2.4 and figure 2.7.

As shown in table 2.4, natural gas prices in the West respond negatively to in-state property damages with a three-month lag in the pre-shale era. The effect diminishes after 2009 as shown by the positively significant interaction term at lag 2 . Furthermore, prices in the South respond positively to in-state property damages in the pre-shale era, and this effect continues into the post-shale era. Data from the EIA show that the South had the highest average ratio of underground natural gas in storage over total consumption compared to other regions in the first sub-period. ${ }^{7}$ Since inventory plays a vital role in regulating prices and the storage systems are sometimes vulnerable to natural disasters, hazard events in these regions may temporarily limit storage facilities' ability to transport natural gas to industrial and residential customers, raising state-level natural gas prices.

For the first sub-period, state-level natural gas prices in all regions respond significantly to TX natural hazards before 2010. Since the rise of unconventional oil and gas production, however, the significant effect of TX hazard events on natural gas prices have weakened for all regions. Figure 2.7 further suggests that for all regions, the cumulative effects of an increase in TX hazard events turned from positively significant in the first sub-period to non-significant or slightly negatively in the shale era. Data from the EIA show that for all four regions, the average ratio of natural gas production over consumption, an indicator for self-sufficiency level, has increased significantly from the first to the latter sub-period. ${ }^{8}$ The increased natural gas availability may have mitigated the impact of TX natural hazards on state-level prices.

We further find that the four regions respond similarly to natural hazards occured in LA. As shown in figures 2.7, prior to 2009 a shock to LA natural hazards overall exerts a nonsignificant or slightly positive effect on natural gas prices. In the post-shale period, a one-unit shock to LA hazard events significantly increases natural gas prices in all regions, and the

\footnotetext{
${ }^{7}$ See EIA state-level natural gas underground storage data https://www.eia.gov/dnav/ng/ng_stor_wkly_s1_w.htm and consumption: https://www.eia.gov/dnav/ng/ng_cons_sum_dcu_nus_m.htm, accessed on 12/15/2019.

${ }^{8}$ See EIA state-level natural gas consumption: https://www.eia.gov/dnav/ng/ng_cons_sum_dcu_nus_m.htm and production: https://www.eia.gov/dnav/ng/ng_prod_sum_a_EPG0_FGW_mmcf_m.htm, accessed on 12/15/2019.
} 
magnitudes of the effects have all increased dramatically compared to the pre-shale period. The only exception is perhaps the Midwest, where the magnitude of the mean cumulative effect at month 6 is comparable between the two sub-periods.

\subsection{Discussions}

Taken together, for most of the models considered, natural hazards in TX significantly increased state-level natural gas prices in the first sub-period. However, the impacts of TX hazard events either diminished or became slightly negative in the post-shale period. By contrast, natural hazards in LA had smaller effects on natural gas prices compared to those in TX prior to 2009 , but their impacts significantly increased in the post-shale era. Even though Texas is still one of the major producing states since the shale boom, the impact of supply/demand disruptions in the state is mitigated by rising production from inland states such as Pennsylvania, Ohio, West Virginia, North Dakota, and Colorado. These inland states are less likely to be affected by the same hazard events as in TX.

Cost of drilling and pipeline capacity constraints may also play a role in the declining importance of natural hazards in Texas. Data from the EIA suggest that the average well drilling and completion costs in the two main inland shale plays, Marcellus and Bakken, are lower than those in Eagle Ford and Midland shale plays (the two main TX shale plays) in 2006-2015 (EIA 2016). The higher drilling cost in TX may have made the state less competitive than the in-land states, lowering the impact of TX natural hazards on natural gas prices in other states.

Furthermore, the Permian region in western Texas, which produces a large amount of natural gas (mostly in the form of associated gas) from oil wells, suffered from significant pipeline capacity constraints in the shale era (Skarzynski 2018, McRae 2018). Skarzynski (2018) notes that the natural gas price at Waha Hub in western Texas had been consistently lower than the Henry Hub price due to the region's ability to transport natural gas to consumption states. The pipeline capacity constraints in Texas may be another reason why supply disruptions in the region due to natural hazards are less relevant to state-level natural gas prices in the shale era.

The increasing importance of Louisiana in natural gas pricing in most of the specifications is perhaps due to its role as the leading trading and distribution center in the 
country. Henry Hub, a distribution hub on the natural gas pipeline system in Louisiana, is the official delivery location for futures contracts traded on the New York Mercantile Exchange (NYMEX). Prices in Henry Hub are commonly used as the pricing benchmark for natural gas traded in the US due to its strategic location and logistical infrastructure (CME Group 2020). The expansive pipeline network in LA directly connects the state to various storage facilities and several major pipelines, allowing it to move the excess natural gas in the gas-rich Southwest to major consumption markets in the US. In recent years, Henry Hub has become even more important in natural gas pricing as the average daily futures trading volume on CME had dramatically increased. Damaged hubs and infrastructure due to natural hazards could shut down the pipeline system, limiting the state's ability to transport gas from producing states to consumption markets and leading to higher natural gas prices across the US.

Relative to other regions, states in the Midwest witnessed a slightly lower increase in their responses to LA natural hazards in the second sub-period. Furthermore, comparing the results across different regions, we fail to identify a clear "east-west" split in the US natural gas market proposed by King and Cuc (1996) either before or after the rise of shale production.

In August 2017, Hurricane Harvey struck the Gulf Coast area and shut down approximately $50 \%$ of the daily natural gas production in TX. ${ }^{9}$ The Federal Offshore area lost $12.61 \%$ of the natural gas production during the same period (DOE 2017). When Hurricanes Katrina and Rita hit TX and LA in 2005, the supply disruptions caused a $48 \%$ price increase. By contrast, US natural gas prices decreased a day after Hurricane Harvey's landfall, and the prices remained low in the following months. The post-Harvey natural gas price behavior echoes the main finding of this paper that the impacts of natural hazards in TX on natural gas prices have diminished since the growth of inland production due to the shale revolution.

\subsection{Conclusions}

Traditionally, natural hazards in the Gulf coast heavily impact natural gas prices in the US due to its dominant role in the country's natural gas supply. This paper revisits this

\footnotetext{
${ }^{9} 50 \%$ is calculated by post-storm natural gas daily production of $3.0 \mathrm{Bcf}$ divided by pre-storm natural gas daily production $6.0 \mathrm{Bcf}$.
} 
hypothesis in the context of the recent shale boom where much of the US natural gas production has taken place in inland states. Using fixed-effects panel distributed lag models, we find that for most of the states, natural hazards in the Gulf Coast still matter in the post-shale era, significantly affecting their natural gas prices. However, supply disruptions due to natural hazards in TX have become less important, while hazard events in LA have played a more important role in the shale era. The rising production in inland states has reduced most states' dependency on natural gas from TX. The increasing importance of LA is perhaps due to its role as a leading trading and distribution center in the US and its expansive pipeline network, which connects the Southwest US with the rest of the country. Additionally, we find that importing states have become less sensitive to in-state natural hazards after the shale boom.

Our results highlight the importance of expanding pipeline capacity and improving the resilience of the natural gas supply system in the US to mitigate the negative effect of natural hazards. Adding pipeline capacity could enable more natural gas from shale-rich regions to reach the interstate pipeline system, providing additional sources of supply to importing states and alleviating the effects of natural hazards in one region on natural gas prices. This diversification of natural gas supply is important in stabilizing regional natural gas prices. At the national level, the Federal Energy Regulatory Commission (FERC) and the US Department of Transportation (DOT) may also wish to re-evaluate natural gas storage levels, pipelines, transportation regulations, and risk-management strategies to cope with the new development in the natural gas market. The interstate gas and hazardous liquid transport regulations from the DOT are especially important because most states do not have stringent state-level interstate transportation regulations (Pless 2011).

State regulatory agencies may wish to enforce their state regulations and inspections to be at the same level as or more stringent than federal regulations (Pless 2011), in particular new natural-gas producing states such as Pennsylvania, Ohio, West Virginia, and North Dakota. Given the increasing importance of Louisiana in the post-shale era, efforts should be taken to improve the infrastructure in the state so that the adverse effects of natural hazards may not cause a large-scale natural gas price spike. In the short-term, before more stringent federal or state regulations take place, inspections and renovations of aging pipelines and storage facilities are needed to improve the resilience of the natural gas transportation system. 
The paper has two limitations. First, our indicators for natural hazards may contain measurement errors since some natural hazards may not affect either natural gas supply or demand. This may introduce noise into the regression model and bias our estimates downward. Therefore, the estimated results provided in this paper may be considered a lower-bound for the effect of natural hazard events on state-level natural gas prices. Another drawback is that losses due to natural hazards do not differentiate between supply and demand shocks. Some natural hazards can create positive demand shocks. For example, more electricity is needed to pump water for irrigation when there is a severe drought, and more natural gas is required for defrosting when a blizzard hits. Including temperature variables, HDDs and CDDs which are used to quantify the energy demand for heating and cooling, can help differentiate demand shocks from supply shocks. Further study is needed to more accurately document the role of natural hazards in energy pricing. 


\section{References}

Ahoniemi, Katja. 2008. "Modeling and forecasting the VIX index." Available at SSRN 1033812.

Andrews, Donald WK. 1993. "Tests for parameter instability and structural change with unknown change point." Econometrica: Journal of the Econometric Society:821-856.

Barsky, Robert B, and Lutz Kilian. 2004. "Oil and the Macroeconomy since the 1970s." Journal of Economic Perspectives 18 (4):115-134.

Brigida, Matthew. 2019. "Parameter Variation and the Components of Natural Gas Price Volatility." Journal of Energy Markets 12 (1).

Brown, Stephen P. A., and Mine K. Yücel. 2008. "Deliverability and regional pricing in U.S. natural gas markets." Energy Economics 30 (5):2441-2453. doi: https://doi.org/10.1016/j.eneco.2007.12.015.

Cameron, A Colin, Jonah B Gelbach, and Douglas L Miller. 2008. "Bootstrap-based improvements for inference with clustered errors." The Review of Economics and Statistics 90 (3):414-427.

Cameron, A Colin, and Douglas L Miller. 2015. “A practitioner's guide to cluster-robust inference.” Journal of human resources 50 (2):317-372.

Cavallo, Eduardo, Andrew Powell, and Oscar Becerra. 2010. "Estimating the direct economic damages of the earthquake in Haiti.” The Economic Journal 120 (546):F298-F312.

Center for Emergency Management and Homeland Security (CEMHS). 2018. Spatial Hazard Events and Losses Database for the United States. edited by Arizona State University.

CME Group. 2020. Introduction to Energy: Understanding Henry Hub.

https://www.cmegroup.com/education/courses/introduction-to-energy/introduction-tonatural-gas/understanding-henry-hub.html.

Coffman, Makena, and Ilan Noy. 2012. "Hurricane Iniki: measuring the long-term economic impact of a natural disaster using synthetic control." Environment and Development Economics 17 (2):187-205.

Colborn, Theo, Carol Kwiatkowski, Kim Schultz, and Mary Bachran. 2011. "Natural gas operations from a public health perspective." Human and ecological risk assessment: An International Journal 17 (5):1039-1056. 
Considine, Timothy, and Edward Manderson. 2014. "The role of energy conservation and natural gas prices in the costs of achieving California's renewable energy goals." Energy economics 44:291-301.

Department of Energy (DOE). 2017. Tropical Depression Harvey Event Report.

Dong, CG. 2012. "Feed-in tariff vs. renewable portfolio standard: An empirical test of their relative effectiveness in promoting wind capacity development." Energy Policy 42:476485.

Hamilton, James D. 2003. "What is an oil shock?” Journal of Econometrics 113 (2):363-398. doi: https://doi.org/10.1016/S0304-4076(02)00207-5.

Hartley, Peter R, and Kenneth B Medlock. 2014. "The relationship between crude oil and natural gas prices: The role of the exchange rate." The Energy Journal 35 (2).

Hartley, Peter R, Kenneth B Medlock, and Jennifer E Rosthal. 2008. “The relationship of natural gas to oil prices." The Energy Journal 29 (3).

Kilian, Lutz. 2008a. "The Economic Effects of Energy Price Shocks.” Journal of Economic Literature 46 (4):871-909.

---. 2008b. "Exogenous oil supply shocks: how big are they and how much do they matter for the US economy?” The Review of Economics and Statistics 90 (2):216-240.

---. 2009. "Not All Oil Price Shocks Are Alike: Disentangling Demand and Supply Shocks in the Crude Oil Market.” American Economic Review 99 (3):1053-69.

King, Marlin, and Milan Cuc. 1996. "Price convergence in North American natural gas spot markets.” The Energy Journal 17 (2).

Kumins, Lawrence C, and Robert Bamberger. 2005. "Oil and gas disruption from Hurricanes Katrina and Rita."

Kydes, Andy S. 2007. "Impacts of a renewable portfolio generation standard on US energy markets." Energy Policy 35 (2):809-814.

Mchich, Adila 2018. “Are Crude Oil \& Natural Gas Prices Linked?”. CME Group. https://www.cmegroup.com/education/articles-and-reports/are-crude-oil-natural-gasprices-linked.html.

McRae, Shaun. 2018. Crude oil price differentials and pipeline infrastructure. National Bureau of Economic Research. 
Mu, Xiaoyi. 2007. "Weather, storage, and natural gas price dynamics: Fundamentals and volatility." Energy Economics 29 (1):46-63.

Nick, Sebastian, and Stefan Thoenes. 2014. "What drives natural gas prices?-A structural VAR approach.” Energy Economics 45:517-527.

Norio, Okada, Tao Ye, Yoshio Kajitani, Peijun Shi, and Hirokazu Tatano. 2011. "The 2011 eastern Japan great earthquake disaster: Overview and comments.” International Journal of Disaster Risk Science 2 (1):34-42.

Noy, Ilan, and Tam Bang Vu. 2010. "The economics of natural disasters in a developing country: The case of Vietnam.” Journal of Asian Economics 21 (4):345-354.

Pless, Jacquelyn. 2011. Making State Gas Pipelines Safe and Reliable: An Assessment of State Policy. National Conference of State Legislatures (NCSL).

Ramberg, David J, and John E Parsons. 2012. "The weak tie between natural gas and oil prices." The Energy Journal 33 (2).

Scarcioffolo, Alexandre Ribeiro, and Xiaoli L Etienne. 2019. "How connected are the US regional natural gas markets in the post-deregulation era? Evidence from time-varying connectedness analysis.” Journal of Commodity Markets 15:100076.

Schaffer, Mark E, and Steven Stillman. 2006. "XTOVERID: Stata module to calculate tests of overidentifying restrictions after xtreg, xtivreg, xtivreg2, xthtaylor."

Serletis, Apostolos, and John Herbert. 1999. "The message in North American energy prices." Energy Economics 21 (5):471-483.

Shearer, Christine, John Bistline, Mason Inman, and Steven J Davis. 2014. "The effect of natural gas supply on US renewable energy and CO2 emissions." Environmental Research Letters 9 (9):094008.

Skarzynski, Nicholas. 2018. "Permian region natural gas prices fall as production continues to grow."

Swindell, Gary S. 1999. "Texas Production data show rapid gas depletion.” Oil and Gas Journal 97 (25):51-53.

Thombs, Ryan P, and Andrew K Jorgenson. 2020. "The political economy of renewable portfolio standards in the United States.” Energy Research \& Social Science 62:101379.

U.S. Energy Information Administration (EIA). 2016. "Trends in U.S. Oil and Natural Gas Upstream Costs." 
Wiggins, Seth, and Xiaoli L. Etienne. 2017. "Turbulent times: Uncovering the origins of US natural gas price fluctuations since deregulation.” Energy Economics 64:196-205. doi: https://doi.org/10.1016/j.eneco.2017.03.015.

Wiser, Ryan, and Mark Bolinger. 2007. "Can deployment of renewable energy put downward pressure on natural gas prices?” Energy Policy 35 (1):295-306.

Yin, Haitao, and Nicholas Powers. 2010. "Do state renewable portfolio standards promote instate renewable generation?" Energy Policy 38 (2):1140-1149.

Zhang, Yue-Jun, Julien Chevallier, and Khaled Guesmi. 2017. ““'De-financialization” of commodities? Evidence from stock, crude oil and natural gas markets.” Energy Economics 68:228-239. 


\section{Tables and Figures}

Table 2.1. Summary Statistics of Variables Considered in the Analysis

\begin{tabular}{|c|c|c|c|c|c|c|c|}
\hline Variable & & Unit & Obs & Mean & Std. Dev. & Min & $\operatorname{Max}$ \\
\hline NGP & $\begin{array}{l}\text { State-level natural gas } \\
\text { prices }\end{array}$ & $\$ / \mathrm{Mcf}$ & 12,672 & 6.65 & 2.78 & 0.75 & 24.87 \\
\hline CDDs & Cooling degree days & degree & 12,672 & 93.10 & 146.51 & 0 & 804 \\
\hline HDDs & Heating degree days & degree & 12,672 & 427.52 & 422.82 & 0 & 2029 \\
\hline GSFO & $\begin{array}{l}\text { Lagged 3-year average } \\
\text { share of Gulf Coast } \\
\text { production }\end{array}$ & percent $(\%)$ & 12,672 & 60.48 & 12.12 & 40.79 & 87.62 \\
\hline GDP & State-level GDP & million $\$$ & 12,672 & 311.35 & 374.49 & 19.56 & 2656.16 \\
\hline OILP & State-level oil price & \$/barrel & 12,672 & 58.26 & 32.84 & 13.26 & 147.67 \\
\hline VIX & CBOE Volatility Index & index & 12,672 & 20.45 & 7.78 & 10.42 & 59.89 \\
\hline $\begin{array}{l}\text { Achieved } \\
\text { RPS }\end{array}$ & $\begin{array}{l}\text { Achieved RPS } \\
\text { obligation }\end{array}$ & $\begin{array}{l}\text { MWh/million } \\
\text { population }\end{array}$ & 12,672 & 0.20 & 0.49 & 0 & 3.5 \\
\hline ISdmg & $\begin{array}{l}\text { In-state natural hazard } \\
\text { damage }\end{array}$ & million $\$$ & 12,672 & 33.24 & 708.34 & 0 & 60316.71 \\
\hline TXdmg & $\begin{array}{l}\text { Texas natural hazard } \\
\text { damage }\end{array}$ & million $\$$ & 12,672 & 142.29 & 568.74 & 0 & 7054.44 \\
\hline LAdmg & $\begin{array}{l}\text { Louisiana natural } \\
\text { hazard damage }\end{array}$ & million \$ & 12,672 & 321.39 & 3765.75 & 0 & 60316.71 \\
\hline
\end{tabular}

Notes: prices, GDP, and property damages are adjusted to 2016 dollars. 
Table 2.2. Estimation results for scenario 1 (46 states combined) and 2 (Export \& Import)

\begin{tabular}{|c|c|c|c|}
\hline DV= state-level natural gas prices & $\begin{array}{l}\text { (1) } \\
\text { All }\end{array}$ & $\begin{array}{l}\text { (2) } \\
\text { Export }\end{array}$ & $\begin{array}{l}\text { (3) } \\
\text { Import }\end{array}$ \\
\hline Cooling degree days & 0.0000 & $0.0002 * *$ & -0.0001 \\
\hline Heating degree days & $0.0001 * * *$ & $0.0001 * * *$ & $0.0001^{* * *}$ \\
\hline Gulf Coast production share & $-1.0355^{* * *}$ & $-1.0543 * * *$ & $-1.0695 * * *$ \\
\hline Log(State GDP) & 0.1326 & 0.1626 & 0.0735 \\
\hline VIX first difference & $0.0408^{* * *}$ & 0.0126 & $0.0473^{* * *}$ \\
\hline $\log ($ Oil price $)$ & $0.4646^{* * *}$ & $0.4723^{* * *}$ & $0.4658 * * *$ \\
\hline Achieved RPS obligation & -0.0164 & 0.0020 & -0.0169 \\
\hline $\mathrm{D}(=1$ if Year $\geq 2010)$ & $-0.4153 * * *$ & -0.3624 & $-0.4048 * * *$ \\
\hline Log(In-state Dmg) & 0.0010 & 0.0007 & 0.0015 \\
\hline Log(In-state Dmg: Lag 1) & 0.0008 & -0.0003 & $0.0014 *$ \\
\hline Log(In-state Dmg: Lag 2) & 0.0001 & $-0.0017 *$ & 0.0007 \\
\hline Log(In-state Dmg: Lag 3) & -0.0003 & -0.0016 & 0.0000 \\
\hline Log(TX Dmg) & $0.0070^{* * *}$ & $0.0046^{* *}$ & $0.0079 * * *$ \\
\hline Log(TX Dmg: Lag 1) & $0.0096^{* * *}$ & $0.0086^{* * *}$ & $0.0101 * * *$ \\
\hline Log(TX Dmg: Lag 2) & $0.0054 * * *$ & 0.0038 & $0.0061 * * *$ \\
\hline Log(TX Dmg: Lag 3) & $0.0033^{* * *}$ & 0.0008 & $0.0043^{* * *}$ \\
\hline Log(TX Dmg: Lag 4) & $-0.0017 *$ & -0.0017 & -0.0016 \\
\hline Log(TX Dmg: Lag 5) & $-0.0069 * * *$ & -0.0025 & $-0.0084 * * *$ \\
\hline Log(TX Dmg: Lag 6) & $-0.0109 * * *$ & $-0.0068 * *$ & $-0.0123 * * *$ \\
\hline Log(LA Dmg) & $-0.0030 * * *$ & -0.0020 & $-0.0034 * * *$ \\
\hline Log(LA Dmg: Lag 1) & 0.0000 & 0.0001 & 0.0000 \\
\hline Log(LA Dmg: Lag 2) & $-0.0017 * * *$ & 0.0005 & $-0.0025 * * *$ \\
\hline Log(LA Dmg: Lag 3) & $0.0032 * * *$ & $0.0043^{* * *}$ & $0.0027 * * *$ \\
\hline Log(LA Dmg: Lag 4) & $0.0035^{* * *}$ & $0.0054^{* * *} *$ & $0.0028 * * *$ \\
\hline Log(LA Dmg: Lag 5) & $0.0077 * * *$ & $0.0068 * * *$ & $0.0080^{* * *}$ \\
\hline Log(LA Dmg: Lag 6) & $0.0101 * * *$ & $0.0099 * * *$ & $0.0102 * * *$ \\
\hline D $* \log ($ In-State Dmg $)$ & -0.0021 & -0.0010 & -0.0023 \\
\hline D* $\log ($ In-State Dmg: Lag 1) & -0.0016 & 0.0021 & $-0.0028 * *$ \\
\hline D* Log(In-State Dmg: Lag 2) & -0.0004 & $0.0040 * *$ & -0.0018 \\
\hline D * Log(In-State Dmg: Lag 3) & -0.0021 & 0.0009 & $-0.0030 *$ \\
\hline $\mathrm{D} * \log (\mathrm{TX}$ Dmg $)$ & $-0.0101 * * *$ & $-0.0067 * * *$ & $-0.0115^{* * *}$ \\
\hline D * Log(TX Dmg: Lag 1) & $-0.0127 * * *$ & $-0.0146^{* * *}$ & $-0.0123^{* * *}$ \\
\hline D * Log(TX Dmg: Lag 2) & $-0.0062 * * *$ & $-0.0065^{* * *}$ & $-0.0066^{* * *}$ \\
\hline D * Log(TX Dmg: Lag 3) & $-0.0044 * *$ & -0.0029 & $-0.0053 * *$ \\
\hline D* Log(TX Dmg: Lag 4) & $0.0030 * *$ & 0.0020 & $0.0031 *$ \\
\hline D* Log(TX Dmg: Lag 5) & 0.0020 & -0.0009 & $0.0030 *$ \\
\hline D * Log(TX Dmg: Lag 6) & 0.0016 & 0.0003 & 0.0019 \\
\hline $\mathrm{D} * \log (\mathrm{LA}$ Dmg $)$ & $0.0067 * * *$ & $0.0051 *$ & $0.0072 * * *$ \\
\hline D* $\log ($ LA Dmg: Lag 1$)$ & $0.0063^{* * *}$ & $0.0063^{* * *} *$ & $0.0062^{* * *}$ \\
\hline D* $\log ($ LA Dmg: Lag 2) & $0.0093 * * *$ & $0.0086^{* * *}$ & $0.0096^{* * *}$ \\
\hline D * Log(LA Dmg: Lag 3) & $0.0033^{* * *} *$ & 0.0019 & $0.0039 * * *$ \\
\hline D * Log(LA Dmg: Lag 4) & $0.0028 * * *$ & -0.0006 & $0.0040 * * *$ \\
\hline D* $\log ($ LA Dmg: Lag 5) & 0.0014 & 0.0013 & 0.0014 \\
\hline D * $\log ($ LA Dmg: $\operatorname{Lag} 6)$ & -0.0006 & -0.0020 & -0.0002 \\
\hline Constant & -1.3818 & -1.8269 & -0.6311 \\
\hline R-squared & 0.6104 & 0.6070 & 0.6179 \\
\hline N. of observations & 11868 & 3096 & 8772 \\
\hline
\end{tabular}

Notes: $* \mathrm{p}<0.10, * * \mathrm{p}<0.05, * * * \mathrm{p}<0.01$. 
Table 2.3. $P$-values for $F$-tests: the Impacts of In-state, Texas, and Louisiana Property Damages and Interaction Terms

\begin{tabular}{|c|c|c|c|c|c|c|c|}
\hline Null Hypothesis & All & Export & Import & NE & MW & West & South \\
\hline \multicolumn{8}{|c|}{ Panel A. Pre-shale period, for Years prior to 2009} \\
\hline $\operatorname{ISDmg}_{t-i}=0$, for $\mathrm{i}=0,1, \ldots, 3$ & 0.31 & 0.36 & 0.32 & 0.00 & 0.89 & 0.18 & 0.00 \\
\hline $\operatorname{TXDmg}_{\mathrm{t}-\mathrm{i}}=0$, for $\mathrm{i}=0,1, \ldots, 6$ & 0.00 & 0.00 & 0.00 & 0.00 & 0.00 & 0.00 & 0.00 \\
\hline $\operatorname{LADmg}_{\mathrm{t}-\mathrm{i}}=0$, for $\mathrm{i}=0,1, \ldots, 6$ & 0.00 & 0.00 & 0.00 & 0.00 & 0.00 & 0.00 & 0.00 \\
\hline$\sum_{\mathrm{i}=0}^{6} \operatorname{TXDmg}_{\mathrm{t}-\mathrm{i}}=\sum_{\mathrm{i}=0}^{6} \operatorname{LADmg}_{\mathrm{t}-\mathrm{i}}$ & 0.09 & 0.26 & 0.23 & 0.23 & 0.00 & 0.67 & 0.10 \\
\hline $\operatorname{TXDmg}_{\mathrm{t}-\mathrm{i}}=\mathrm{LADmg}_{\mathrm{t}-\mathrm{i}}=0$, for $\mathrm{i}=0,1, \ldots, 6$ & 0.00 & 0.00 & 0.00 & 0.00 & 0.00 & 0.00 & 0.00 \\
\hline
\end{tabular}

Panel B. Post-shale period, for years after 2009

\begin{tabular}{|c|c|c|c|c|c|c|c|}
\hline $\operatorname{ISDmg}_{\mathrm{t}-\mathrm{i}}+\operatorname{ISDmg}_{\mathrm{t}-\mathrm{i}} * \mathrm{D}=0$, for $\mathrm{i}=0,1, \ldots, 3$ & 0.01 & 0.03 & 0.00 & 0.97 & 0.00 & 0.04 & 0.00 \\
\hline $\mathrm{TXDmg}_{\mathrm{t}-\mathrm{i}}+\mathrm{TXDmg}_{\mathrm{t}-\mathrm{i}} * \mathrm{D}=0$, for $\mathrm{i}=0,1, \ldots, 6$ & 0.00 & 0.00 & 0.00 & 0.00 & 0.00 & 0.00 & 0.00 \\
\hline $\mathrm{LADmg}_{\mathrm{t}-\mathrm{i}}+\mathrm{LADmg}_{\mathrm{t}-\mathrm{i}} * \mathrm{D}=0$, for $\mathrm{i}=0,1, \ldots, 6$ & 0.00 & 0.00 & 0.00 & 0.00 & 0.00 & 0.00 & 0.00 \\
\hline $\begin{array}{l}\sum_{\mathrm{i}=0}^{6}\left(\mathrm{TXDmg}_{\mathrm{t}-\mathrm{i}}+\mathrm{TXDmg}_{\mathrm{t}-\mathrm{i}} * \mathrm{D}\right)=\sum_{\mathrm{i}=0}^{6}\left(\mathrm{LADmg}_{\mathrm{t}-\mathrm{i}}+\right. \\
\left.\mathrm{LADmg}_{\mathrm{t}-\mathrm{i}} * \mathrm{D}\right)\end{array}$ & 0.00 & 0.09 & 0.00 & 0.44 & 0.00 & 0.00 & 0.00 \\
\hline $\begin{array}{l}\text { TXDmg }_{t-i}+\text { TXDmg }_{t-i} * D=\text { LADmg }_{t-i}+\text { LADmg }_{t-i} * \\
D=0, \text { for } \mathrm{i}=0,1, \ldots, 6\end{array}$ & 0.00 & 0.00 & 0.00 & 0.00 & 0.00 & 0.00 & 0.00 \\
\hline
\end{tabular}

Notes: this table tests the null hypothesis specified in the first column for each estimated model presented in tables 2 and 4. 
Table 2.4. Estimation results for scenario 3: Northeast, Midwest, West, and South

\begin{tabular}{|c|c|c|c|c|}
\hline DV = state-level natural gas prices & $\begin{array}{l}(4) \\
\text { Northeast }\end{array}$ & $\begin{array}{l}\text { (5) } \\
\text { Midwest }\end{array}$ & $\begin{array}{l}(6) \\
\text { West }\end{array}$ & $\begin{array}{l}\text { (7) } \\
\text { South }\end{array}$ \\
\hline Cooling Degree Days & $0.0004 * * *$ & $0.0004 * * *$ & -0.0001 & 0.0000 \\
\hline Heating Degree Days & $0.0001 * * *$ & $0.0001 * * *$ & $0.0002 * * *$ & $0.0001 * *$ \\
\hline $\log ($ State GDP $)$ & 0.0293 & 0.0938 & -0.0257 & 0.3026 \\
\hline VIX first difference & $0.0679 *$ & -0.0063 & 0.0378 & $0.0634 * * *$ \\
\hline $\mathrm{D}(=1$ if $Y e a r \geq 2010)$ & -0.2642 & $-0.3696 * * *$ & -0.0058 & $-0.6263 * * *$ \\
\hline Log(In-state Dmg) & -0.0013 & -0.0001 & -0.0001 & $0.0033 * *$ \\
\hline Log(In-state Dmg: Lag 1) & 0.0010 & -0.0003 & 0.0002 & 0.0001 \\
\hline Log(In-state Dmg: Lag 2) & -0.0001 & -0.0007 & -0.0012 & 0.0015 \\
\hline Log(In-state Dmg: Lag 3) & -0.0028 & -0.0003 & $-0.0019 *$ & $0.0027 * *$ \\
\hline Log(TX Dmg: Lag 4) & -0.0006 & $-0.0061 * * *$ & 0.0010 & -0.0013 \\
\hline Log(TX Dmg: Lag 5) & $-0.0056 * * *$ & $-0.0082 * * *$ & -0.0023 & $-0.0086 * * *$ \\
\hline Log(TX Dmg: Lag 6) & $-0.0091 * * *$ & $-0.0159 * * *$ & $-0.0093 * * *$ & $-0.0082 * * *$ \\
\hline Log(LA Dmg) & $-0.0046 * * *$ & $-0.0048 * * *$ & -0.0016 & $-0.0035^{* *}$ \\
\hline Log(LA Dmg: Lag 1) & $-0.0032 *$ & $0.0032 * *$ & -0.0023 & 0.0012 \\
\hline Log(LA Dmg: Lag 2) & $-0.0033 * * *$ & 0.0011 & $-0.0030 * *$ & -0.0013 \\
\hline Log(LA Dmg: Lag 3) & 0.0026 & $0.0058 * * *$ & 0.0018 & $0.0027 * * *$ \\
\hline Log(LA Dmg: Lag 4) & 0.0018 & $0.0067 * * *$ & $0.0031 *$ & $0.0029 * * *$ \\
\hline Log(LA Dmg: Lag 5) & $0.0065 * * *$ & $0.0110 * * *$ & $0.0052 * * *$ & $0.0085 * * *$ \\
\hline Log(LA Dmg: Lag 6) & $0.0085 * * *$ & $0.0142 * * *$ & $0.0092 * * *$ & $0.0090 * * *$ \\
\hline D * Log(In-State Dmg) & 0.0011 & 0.0005 & -0.0007 & -0.0045 \\
\hline D * Log(TX Dmg: Lag 4) & 0.0004 & $0.0098 * * *$ & -0.0021 & $0.0038 *$ \\
\hline D * Log(TX Dmg: Lag 5) & $-0.0059 *$ & $0.0084 * * *$ & -0.0023 & $0.0040 *$ \\
\hline D * Log(TX Dmg: Lag 6) & -0.0033 & $0.0095 * * *$ & -0.0013 & -0.0004 \\
\hline D * Log(LA Dmg) & $0.0064 * * *$ & $0.0066 * * *$ & 0.0036 & $0.0093 * * *$ \\
\hline D * Log(LA Dmg: Lag 1) & $0.0098 * * *$ & 0.0015 & $0.0088 * * *$ & $0.0063 * * *$ \\
\hline D * Log(LA Dmg: Lag 2) & $0.0101 * * *$ & $0.0061 * * *$ & $0.0109 * * *$ & $0.0104 * * *$ \\
\hline D * Log(LA Dmg: Lag 3) & 0.0031 & 0.0002 & $0.0051 * * *$ & $0.0041 * * *$ \\
\hline D * Log(LA Dmg: Lag 4) & $0.0059 * * *$ & $-0.0038 * *$ & $0.0050 * * *$ & $0.0027 * * *$ \\
\hline D * Log(LA Dmg: Lag 5) & 0.0047 & $-0.0050 * * *$ & $0.0054 * * *$ & 0.0003 \\
\hline D * Log(LA Dmg: Lag 6) & 0.0035 & $-0.0067 * * *$ & -0.0017 & 0.0006 \\
\hline Constant & -0.3627 & -0.7822 & 0.3061 & -3.3972 \\
\hline R-squared & 0.5964 & 0.6265 & 0.636 & 0.6521 \\
\hline N. of observations & 2580 & 2838 & 2838 & 3612 \\
\hline
\end{tabular}

Notes: $* \mathrm{p}<0.10,{ }^{* *} \mathrm{p}<0.05, * * * \mathrm{p}<0.01$ 


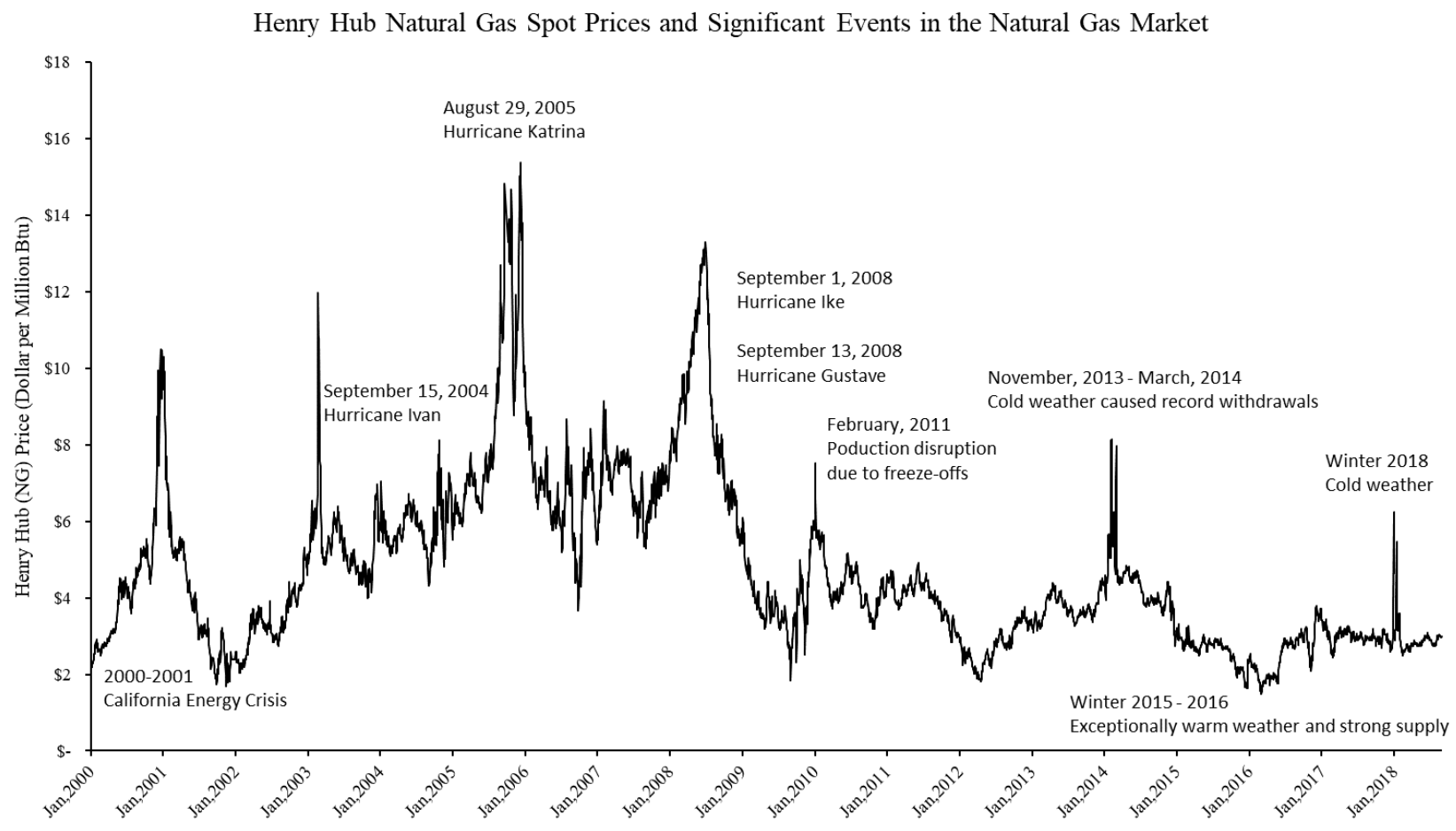

Source: Mchich, A. (2018). Are Crude Oil \& Natural Gas Prices Linked? Retrieved and Reproduced from https://www.cmegroup.com/education/articles-and-reports/are-crude-oil-natural-gas-prices-linked.html

Figure 2.1. Natural Gas Prices and Selected Significant Events 


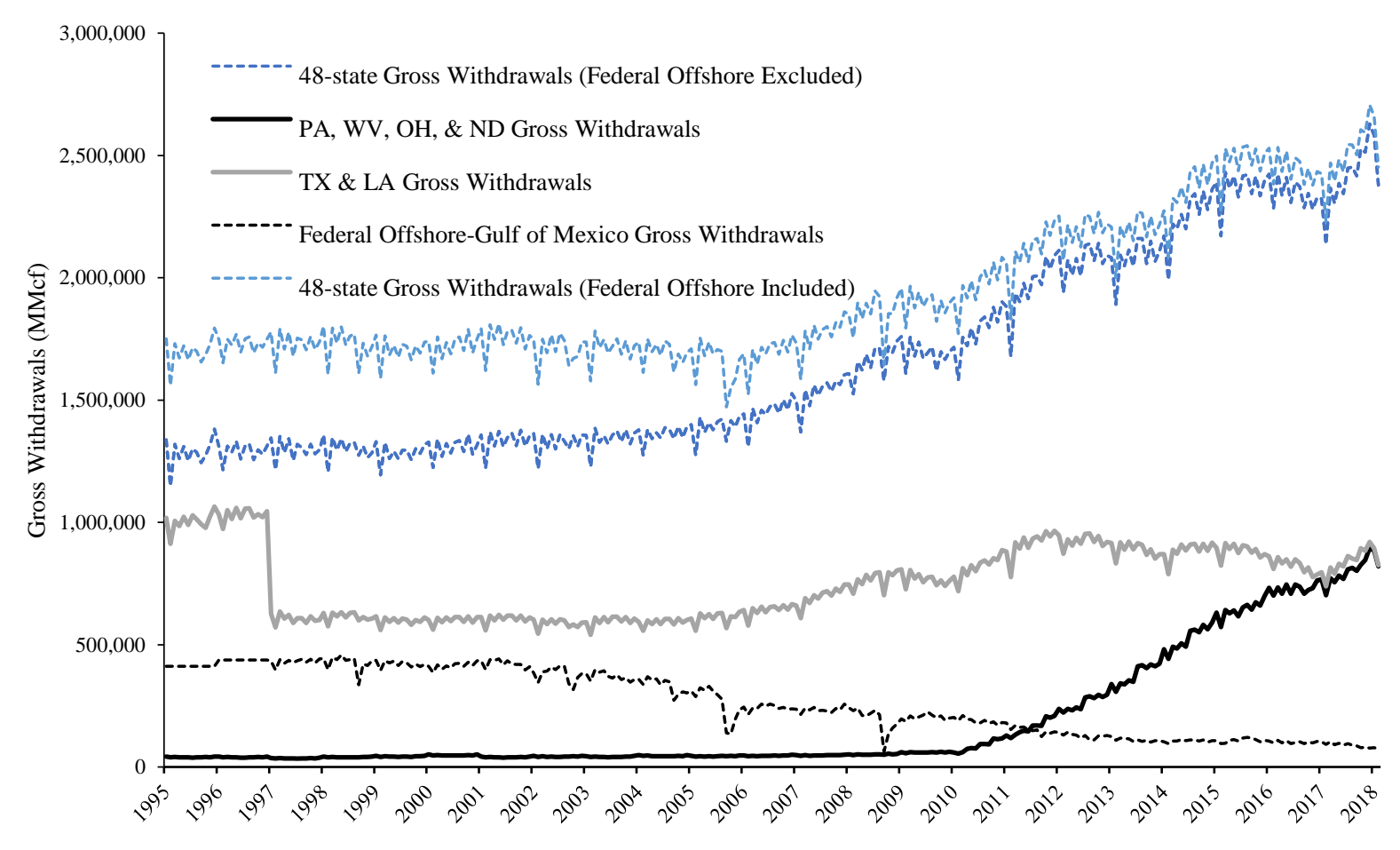

Source: US Energy Information Administration (EIA, 2018). Natural Gas Gross Withdrawals.

Figure 2.2. Natural Gas Gross Withdrawals in Lower 48 States and Selected Regions 

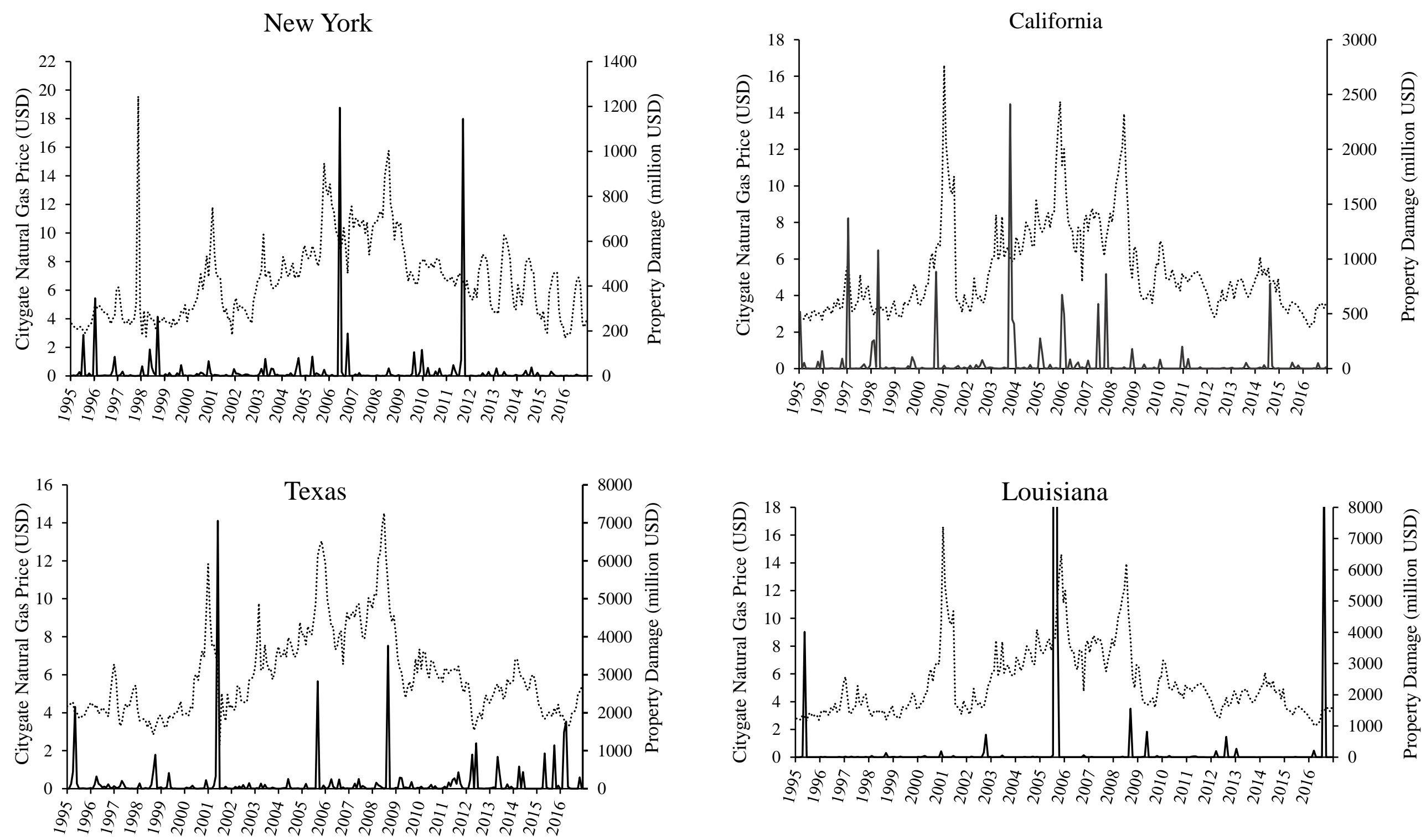

Note: dash line $=$ prices $($ left $)$, solid line $=$ property damages $($ right $)$

Figure 2.3. In-state Property Damages and City Gate Prices in Selected States 


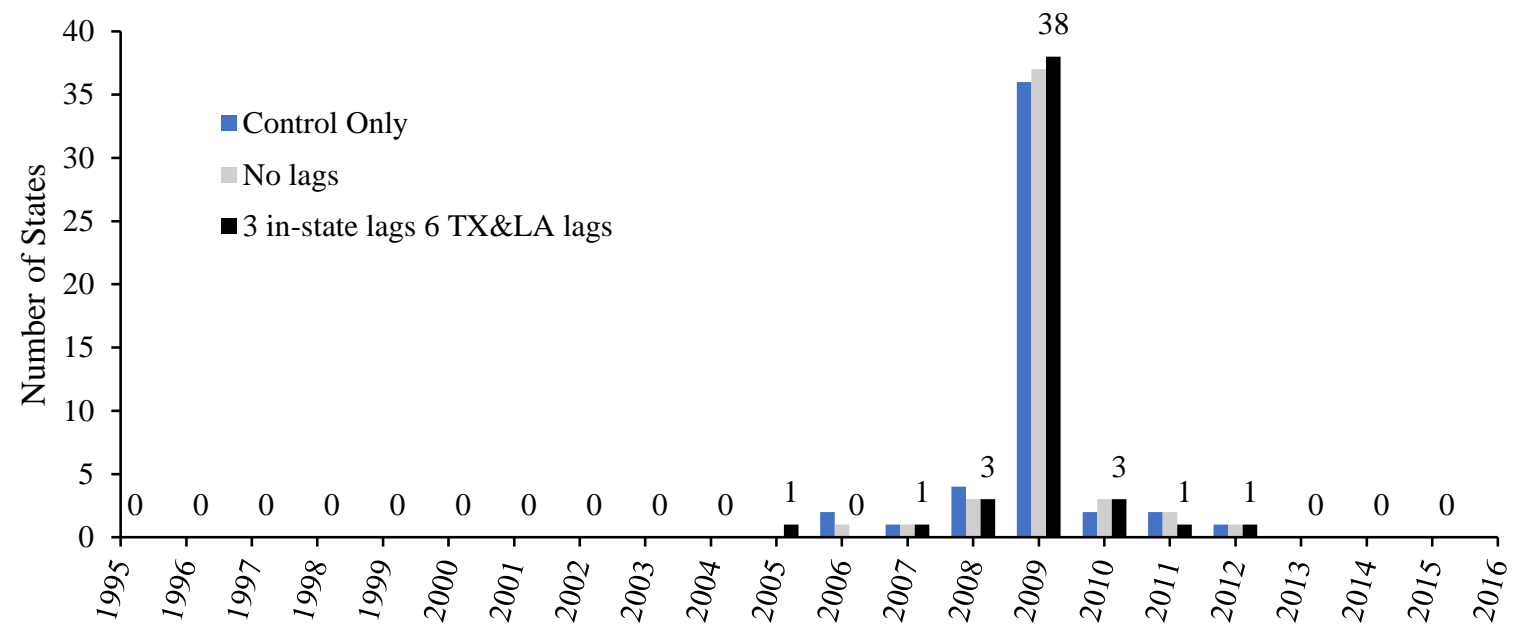

Figure 2.4. Number of States Experienced Structural Break by Year

\section{Louisiana}

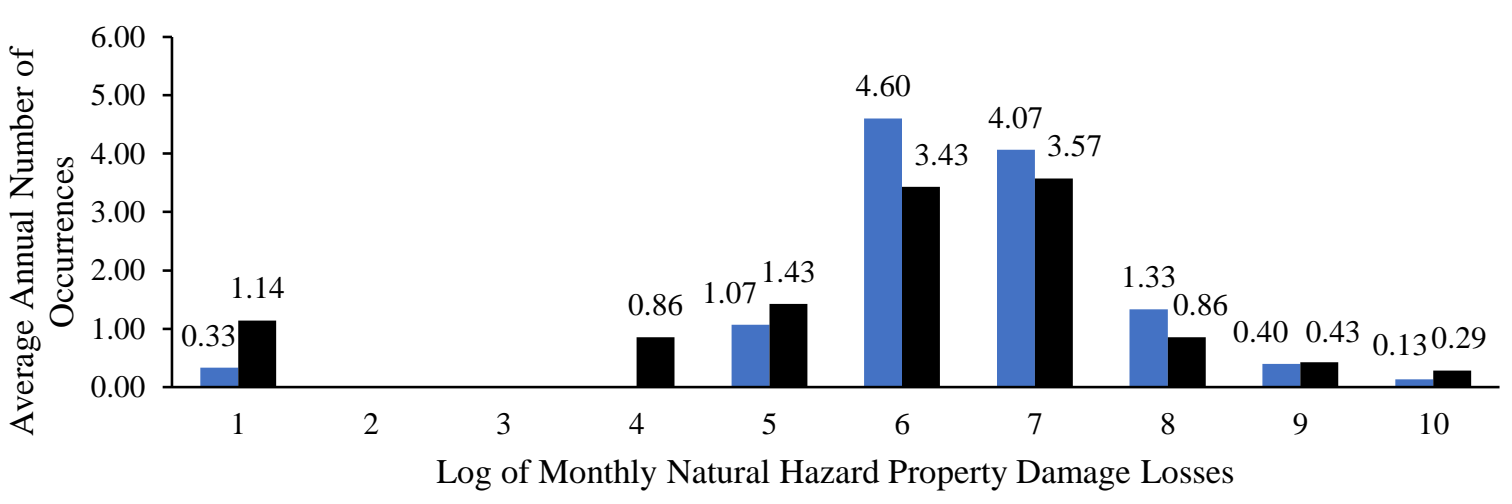

Texas

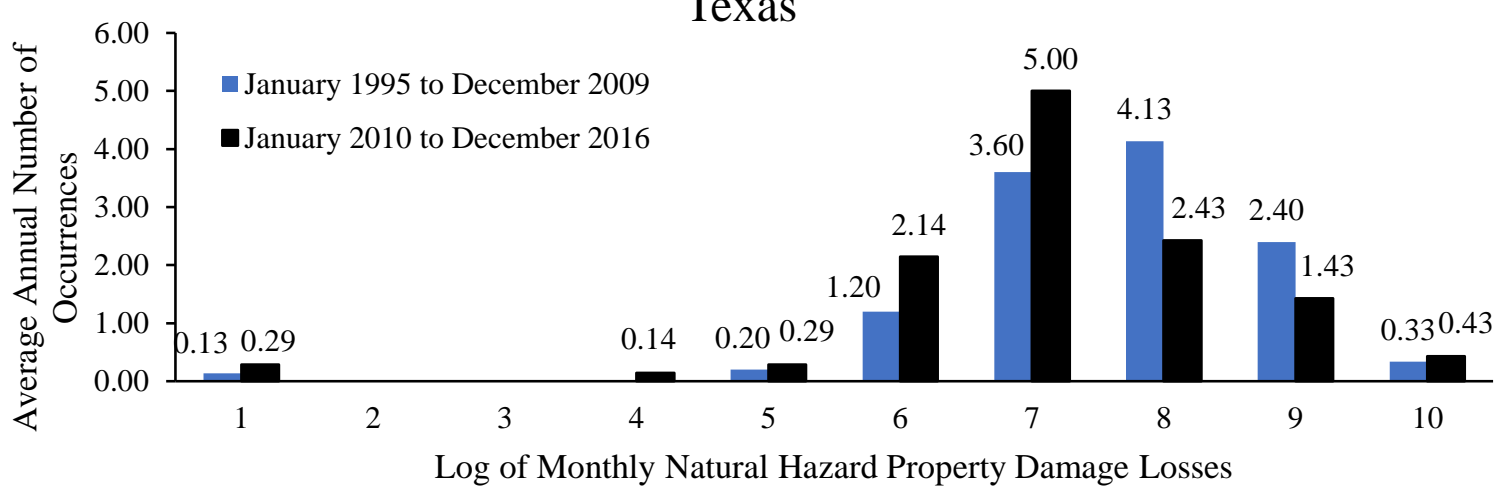

Figure 2.5. Annual Natural Hazard Occurrences in LA and TX before and after 2010 

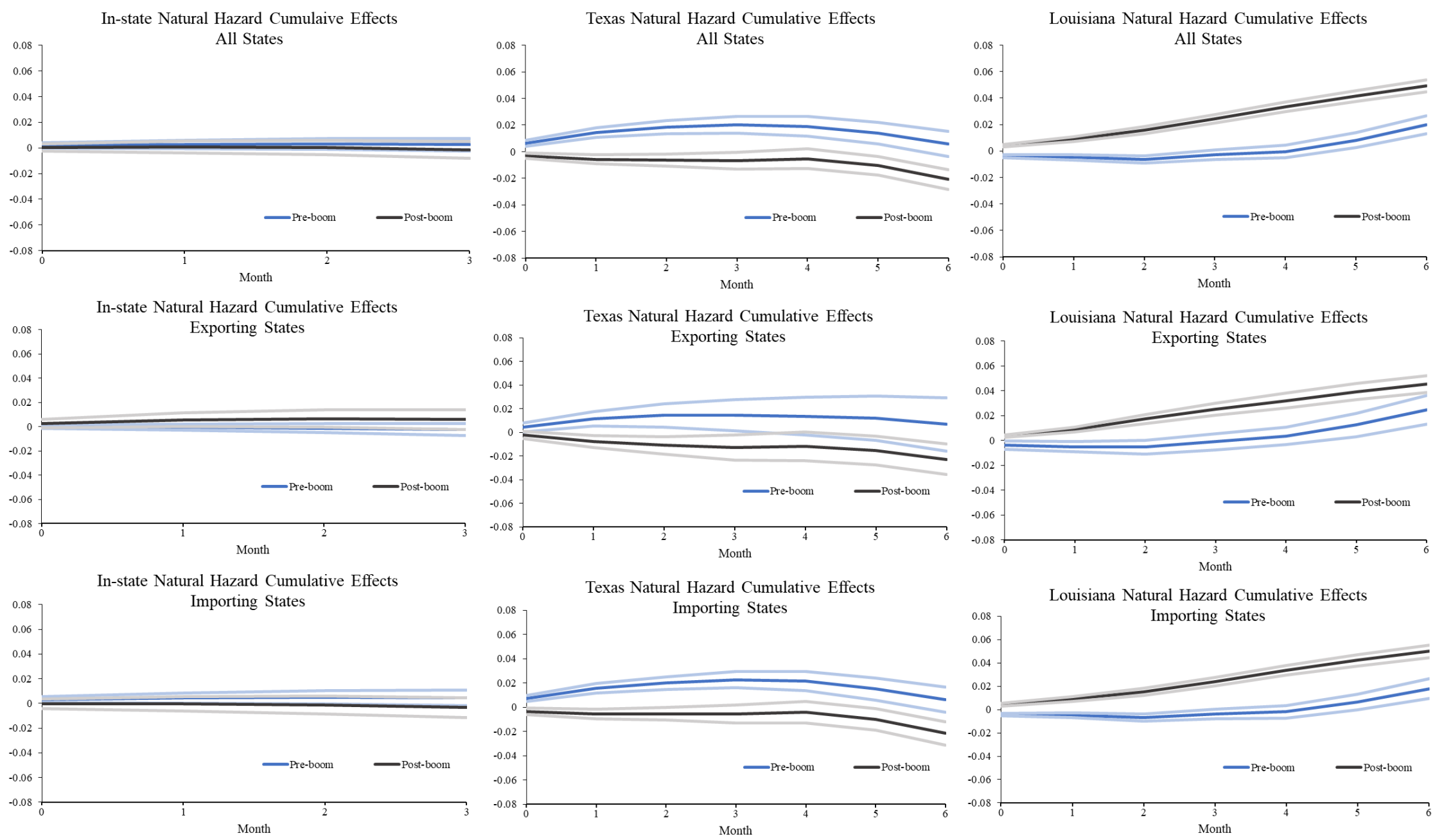

Note: The lighter blue and gray lines indicate the $95 \%$ confidence intervals of pre-boom and post-boom cumulative effect, respectively.

Figure 2.6. Cumulative Effects of One-Unit Shock to In-state, Texas, and Louisiana Natural Hazards for All, Exporting, and the Importing States 

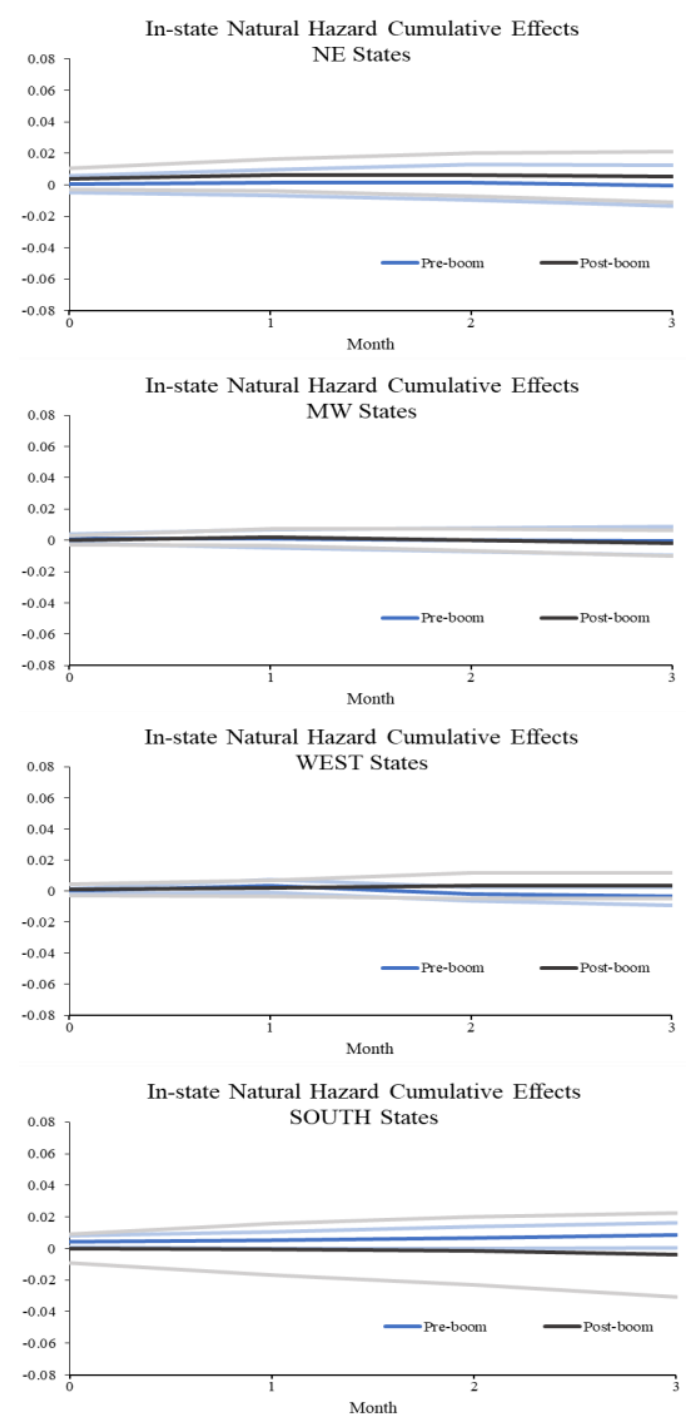

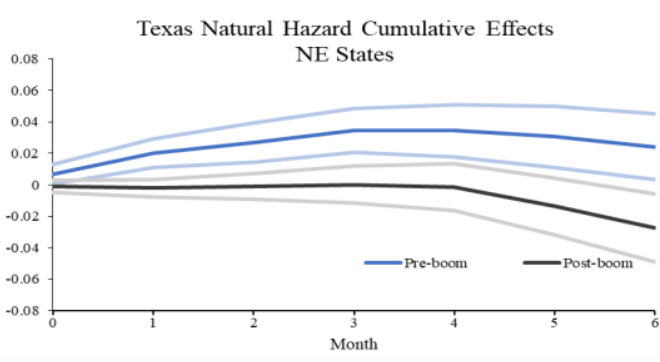

Texas Natural Hazard Cumulative Effects

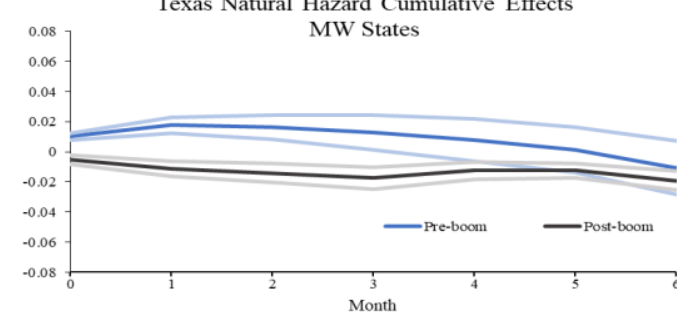

Texas Natural Hazard Cumulative Effects

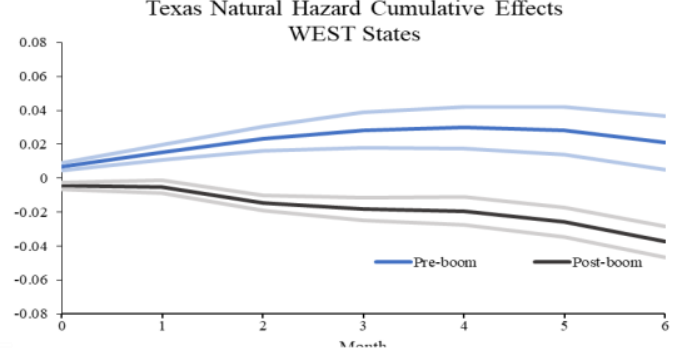

Texas Natural Hazard Cumulative Effects

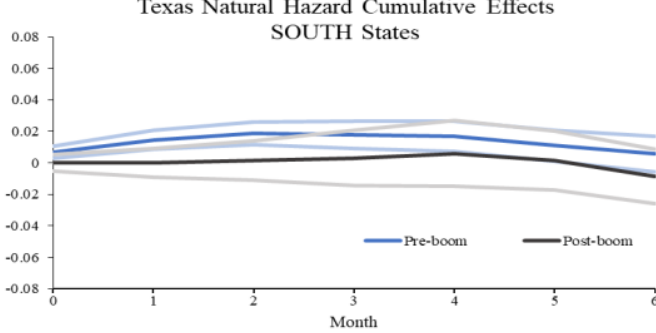

Louisiana Natural Hazard Cumulative Effects

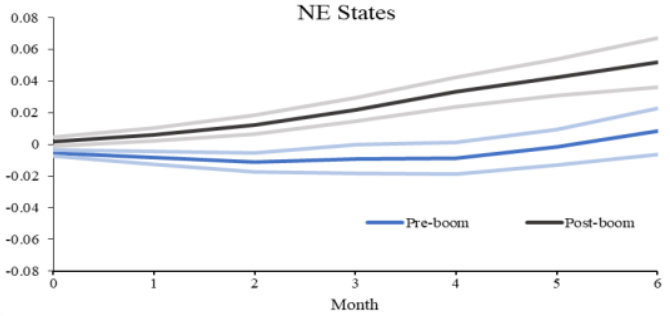

Louisiana Natural Hazard Cumulative Effects MW States

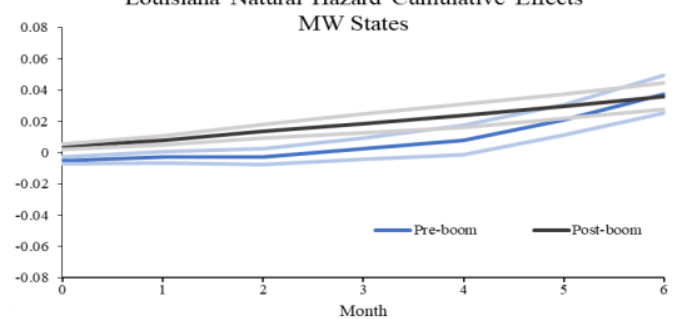

Louisiana Natural Hazard Cumulative Effects WEST States

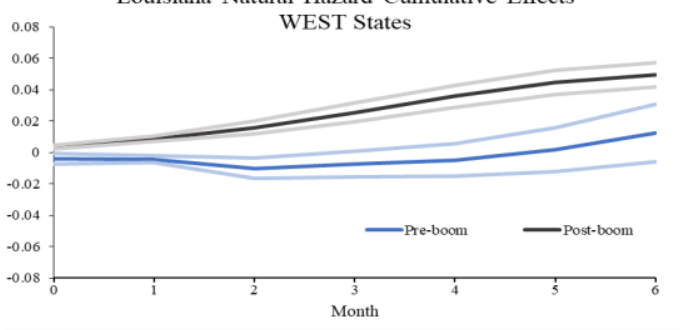

Louisiana Natural Hazard Cumulative Effects

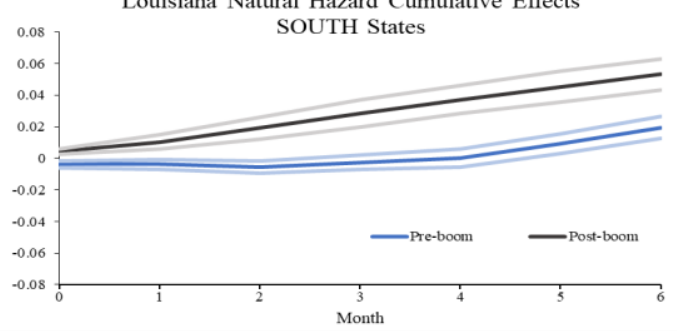

Note: The lighter blue and gray lines indicate the $95 \%$ confidence intervals of pre-boom and post-boom cumulative effect, respectively.

Figure 2.7. Cumulative Effects of One-Unit Shock to In-state, TX, and LA Natural Hazards on States in NE, MW, West, and South. 


\section{Appendix A}

Table 2.A1. Estimation results when using alternative policy variables for scenario 1: All States

\begin{tabular}{|c|c|c|c|c|c|}
\hline & Model 1 & Model 2 & Model 3 & Model 4 & Model 5 \\
\hline ARPSMP & -0.0164 & & & & \\
\hline RPS Obligation ${ }^{b}$ & & 0.0000 & & & \\
\hline RPS Dummy $^{c}$ & & & -0.0243 & & \\
\hline ARPS $\%$ d & & & & 0.0386 & \\
\hline Energy Carbon $^{\mathrm{e}}$ & & & & & $0.0110 * *$ \\
\hline Gulf Coast production share & $-1.0355 * * *$ & $-1.0276 * * *$ & $-1.0390 * * *$ & $-1.0435^{* * *}$ & $-1.0035^{* * *}$ \\
\hline Cooling degree days & 0.0000 & 0.0000 & 0.0000 & 0.0000 & 0.0000 \\
\hline Heating degree days & $0.0001 * * *$ & $0.0001 * * *$ & $0.0001 * * *$ & $0.0001 * * *$ & $0.0001 * * *$ \\
\hline $\log ($ State GDP $)$ & 0.1326 & 0.1401 & 0.1346 & 0.1356 & 0.1653 \\
\hline VIX first difference & $0.0408 * * *$ & $0.0414 * * *$ & $0.0401 * *$ & $0.0396 * *$ & $0.0360 * *$ \\
\hline Log(Oil price) & $0.4646 * * *$ & $0.4637 * * *$ & $0.4680 * * *$ & $0.4695^{* * *}$ & $0.4605 * * *$ \\
\hline $\mathrm{D}(=1$ if Year $\geq 2010)$ & $-0.4153 * * *$ & $-0.4148 * * *$ & $-0.4159 * * *$ & $-0.4047 * * *$ & $-0.3652 * * *$ \\
\hline Log(In-state Dmg) & 0.0010 & 0.0009 & 0.0010 & 0.0011 & 0.0011 \\
\hline Log(In-state Dmg: Lag 1) & 0.0008 & 0.0007 & 0.0008 & 0.0008 & 0.0009 \\
\hline Log(In-state Dmg: Lag 2) & 0.0001 & 0.0000 & 0.0001 & 0.0001 & 0.0001 \\
\hline Log(In-state Dmg: Lag 3) & -0.0003 & -0.0004 & -0.0003 & -0.0003 & -0.0003 \\
\hline $\log (\mathrm{TX}$ Dmg) & $0.0070 * * *$ & $0.0070 * * *$ & $0.0071 * * *$ & $0.0071 * * *$ & $0.0072 * * *$ \\
\hline Log(TX Dmg: Lag 1) & $0.0096 * * *$ & $0.0096 * * *$ & $0.0097 * * *$ & $0.0097 * * *$ & $0.0097 * * *$ \\
\hline Log(TX Dmg: Lag 2) & $0.0054 * * *$ & $0.0054 * * *$ & $0.0055^{* * *}$ & $0.0055^{* * *}$ & $0.0056 * * *$ \\
\hline Log(TX Dmg: Lag 3) & $0.0033 * * *$ & $0.0034 * * *$ & $0.0034 * * *$ & $0.0034 * * *$ & $0.0036 * * *$ \\
\hline Log(TX Dmg: Lag 4) & $-0.0017 *$ & $-0.0017 *$ & $-0.0016^{*}$ & $-0.0016^{*}$ & -0.0013 \\
\hline Log(TX Dmg: Lag 5) & $-0.0069 * * *$ & $-0.0069 * * *$ & $-0.0068 * * *$ & $-0.0068 * * *$ & $-0.0065^{* * *}$ \\
\hline Log(TX Dmg: Lag 6) & $-0.0109 * * *$ & $-0.0109 * * *$ & $-0.0108 * * *$ & $-0.0107 * * *$ & $-0.0105 * * *$ \\
\hline Log(LA Dmg) & $-0.0030 * * *$ & $-0.0030 * * *$ & $-0.0031 * * *$ & $-0.0031 * * *$ & $-0.0031 * * *$ \\
\hline Log(LA Dmg: Lag 1) & 0.0000 & 0.0000 & 0.0000 & -0.0001 & 0.0000 \\
\hline Log(LA Dmg: Lag 2) & $-0.0017 * * *$ & $-0.0016 * * *$ & $-0.0017 * * *$ & $-0.0018^{* * *}$ & $-0.0018 * * *$ \\
\hline Log(LA Dmg: Lag 3) & $0.0032 * * *$ & $0.0032 * * *$ & $0.0031 * * *$ & $0.0031 * * *$ & $0.0028 * * *$ \\
\hline Log(LA Dmg: Lag 4) & $0.0035^{* * *}$ & $0.0035 * * *$ & $0.0035^{* * *}$ & $0.0034 * * *$ & $0.0032 * * *$ \\
\hline Log(LA Dmg: Lag 5) & $0.0077 * * *$ & $0.0077 * * *$ & $0.0077 * * *$ & $0.0076^{* * *}$ & $0.0075^{* * *}$ \\
\hline Log(LA Dmg: Lag 6) & $0.0101 * * *$ & $0.0101 * * *$ & $0.0100 * * *$ & $0.0100 * * *$ & $0.0098 * * *$ \\
\hline $\mathrm{D} * \log (\mathrm{In}-$ State Dmg $)$ & -0.0021 & -0.0017 & -0.0020 & -0.0021 & -0.0021 \\
\hline D * Log(In-State Dmg: Lag 1) & -0.0016 & -0.0014 & -0.0016 & -0.0016 & -0.0016 \\
\hline D * Log(In-State Dmg: Lag 2) & -0.0004 & -0.0001 & -0.0003 & -0.0004 & -0.0004 \\
\hline D * Log(In-State Dmg: Lag 3) & -0.0021 & -0.0018 & -0.0020 & -0.0021 & -0.002 \\
\hline $\mathrm{D} * \log (\mathrm{TX}$ Dmg $)$ & $-0.0101 * * *$ & $-0.0102 * * *$ & $-0.0102 * * *$ & $-0.0103^{* * *}$ & $-0.0103 * * *$ \\
\hline D * Log(TX Dmg: Lag 1) & $-0.0127 * * *$ & $-0.0127 * * *$ & $-0.0128 * * *$ & $-0.0129 * * *$ & $-0.0129 * * *$ \\
\hline D * Log(TX Dmg: Lag 2) & $-0.0062 * * *$ & $-0.0063 * * *$ & $-0.0063 * * *$ & $-0.0064 * * *$ & $-0.0066^{* * *}$ \\
\hline D * Log(TX Dmg: Lag 3) & $-0.0044 * *$ & $-0.0045 * * *$ & $-0.0044 * *$ & $-0.0045^{* *}$ & $-0.0047 * * *$ \\
\hline $\mathrm{D} * \log (\mathrm{TX}$ Dmg: Lag 4) & $0.0030 * *$ & $0.0029 * *$ & $0.0030^{* *}$ & $0.0029 * *$ & $0.0025^{*}$ \\
\hline $\mathrm{D} * \log (\mathrm{TX}$ Dmg: Lag 5) & 0.0020 & 0.0020 & 0.0019 & 0.0018 & 0.0016 \\
\hline D * Log(TX Dmg: Lag 6) & 0.0016 & 0.0017 & 0.0016 & 0.0014 & 0.0012 \\
\hline $\mathrm{D} * \log (\mathrm{LA}$ Dmg $)$ & $0.0067 * * *$ & $0.0067 * * *$ & $0.0068 * * *$ & $0.0068 * * *$ & $0.0068 * * *$ \\
\hline $\mathrm{D} * \log (\mathrm{LA}$ Dmg: Lag 1$)$ & $0.0063 * * *$ & $0.0062 * * *$ & $0.0064 * * *$ & $0.0064 * * *$ & $0.0062 * * *$ \\
\hline D * Log(LA Dmg: Lag 2) & $0.0093 * * *$ & $0.0092 * * *$ & $0.0094 * * *$ & $0.0095 * * *$ & $0.0094 * * *$ \\
\hline $\mathrm{D} * \log (\mathrm{LA}$ Dmg: Lag 3$)$ & $0.0033 * * *$ & $0.0032 * * *$ & $0.0034 * * *$ & $0.0034 * * *$ & $0.0035^{* * *}$ \\
\hline D * Log(LA Dmg: Lag 4) & $0.0028 * * *$ & $0.0027 * * *$ & $0.0029 * * *$ & $0.0029 * * *$ & $0.0031 * * *$ \\
\hline D * Log(LA Dmg: Lag 5) & 0.0014 & 0.0013 & 0.0015 & 0.0015 & 0.0015 \\
\hline$D * \log ($ LA Dmg: Lag 6) & -0.0006 & -0.0007 & -0.0005 & -0.0005 & -0.0005 \\
\hline Constant & -1.3818 & -1.4724 & -1.4154 & -1.4322 & -2.0556 \\
\hline R-squared & 0.6104 & 0.6107 & 0.6106 & 0.611 & 0.6126 \\
\hline N. of observations & 11868 & 11868 & 11868 & 11868 & 11868 \\
\hline $\begin{array}{l}\text { Notes: } \\
\text { a Achieved Renewable Portfolio Standard } \\
{ }^{b} \text { Renewable Portfolio Standard Obligation } \\
{ }^{c} \text { Binary Renewable Portfolio Standard Va } \\
\text { d Renewable Portfolio Standard Obligation } \\
\text { e Per Capita Energy-related Carbon Intensi } \\
{ }^{*} \text { p }<0.10 \text {, ** }<<0.05, * * * \text { p }<0.01 \text {. }\end{array}$ & $\begin{array}{l}1 \text { when a st } \\
\text { ement Perce }\end{array}$ & $\begin{array}{l}\text { on Populatic } \\
\mathrm{S} \text { in a given }\end{array}$ & erwise) & & \\
\hline
\end{tabular}


Table 2.A2. Estimation results when using alternative policy variables for scenario 2: Export States

\begin{tabular}{|c|c|c|c|c|c|}
\hline & Model 1 & Model 2 & Model 3 & Model 4 & Model 5 \\
\hline ARPSMP $^{\text {a }}$ & 0.0020 & & & & \\
\hline RPS Obligation ${ }^{b}$ & & 0.0000 & & & \\
\hline RPS Dummy ${ }^{c}$ & & & -0.0023 & & \\
\hline ARPS \% ${ }^{d}$ & & & & 0.0005 & \\
\hline Energy Carbon ${ }^{\mathrm{e}}$ & & & & & 0.0107 \\
\hline Gulf Coast production share & $-1.0543 * * *$ & $-1.0551 * * *$ & $-1.0541 * * *$ & $-1.0543 * * *$ & $-1.0411 * * *$ \\
\hline Cooling degree days & $0.0002 * *$ & $0.0002 * *$ & $0.0002 * *$ & $0.0002 * *$ & $0.0002 * *$ \\
\hline Heating degree days & $0.0001 * * *$ & $0.0001 * * *$ & $0.0001^{* * *}$ & $0.0001 * * *$ & $0.0001 * * *$ \\
\hline $\log ($ State GDP $)$ & 0.1626 & 0.1586 & 0.1621 & 0.1626 & 0.1853 \\
\hline VIX first difference & 0.0126 & 0.0132 & 0.0126 & 0.0126 & 0.004 \\
\hline $\log ($ Oil price $)$ & $0.4723 * * *$ & $0.4728 * * *$ & $0.4728 * * *$ & $0.4722 * * *$ & $0.4649 * * *$ \\
\hline $\mathrm{D}(=1$ if $Y e a r \geq 2010)$ & -0.3624 & -0.3318 & -0.3613 & -0.3626 & -0.2426 \\
\hline Log(In-state Dmg) & 0.0007 & 0.0005 & 0.0007 & 0.0007 & 0.0008 \\
\hline Log(In-state Dmg: Lag 1) & -0.0003 & -0.0005 & -0.0003 & -0.0003 & -0.0003 \\
\hline Log(In-state Dmg: Lag 2) & $-0.0017 *$ & $-0.0019 *$ & $-0.0017 *$ & $-0.0017 *$ & $-0.0017 *$ \\
\hline Log(In-state Dmg: Lag 3) & -0.0016 & -0.0018 & -0.0016 & -0.0016 & -0.0016 \\
\hline $\log (\mathrm{TX}$ Dmg) & $0.0046^{* *}$ & $0.0047 * *$ & $0.0046^{* *}$ & $0.0046 * *$ & $0.0050 * * *$ \\
\hline Log(TX Dmg: Lag 1) & $0.0086^{* * *}$ & $0.0087 * * *$ & $0.0086^{* * *}$ & $0.0086^{* * *}$ & $0.0088 * * *$ \\
\hline Log(TX Dmg: Lag 2) & 0.0038 & $0.0039 *$ & 0.0038 & 0.0038 & $0.0041 *$ \\
\hline Log(TX Dmg: Lag 3) & 0.0008 & 0.0009 & 0.0008 & 0.0008 & 0.0014 \\
\hline Log(TX Dmg: Lag 4) & -0.0017 & -0.0016 & -0.0017 & -0.0017 & -0.001 \\
\hline Log(TX Dmg: Lag 5) & -0.0025 & -0.0025 & -0.0025 & -0.0025 & -0.0018 \\
\hline Log(TX Dmg: Lag 6) & $-0.0068 * *$ & $-0.0068 * *$ & $-0.0068 * *$ & $-0.0068 * *$ & $-0.0060 * *$ \\
\hline Log(LA Dmg) & -0.0020 & -0.0020 & -0.0021 & -0.0020 & -0.0020 \\
\hline Log(LA Dmg: Lag 1) & 0.0001 & 0.0001 & 0.0001 & 0.0001 & 0.0002 \\
\hline Log(LA Dmg: Lag 2) & 0.0005 & 0.0004 & 0.0004 & 0.0005 & 0.0003 \\
\hline Log(LA Dmg: Lag 3) & $0.0043 * * *$ & $0.0043 * * *$ & $0.0043^{* * *}$ & $0.0043 * * *$ & $0.0037 * * *$ \\
\hline Log(LA Dmg: Lag 4) & $0.0054 * * *$ & $0.0053 * * *$ & $0.0054 * * *$ & $0.0054 * * *$ & $0.0049 * * *$ \\
\hline Log(LA Dmg: Lag 5) & $0.0068 * * *$ & $0.0067 * * *$ & $0.0067 * * *$ & $0.0068 * * *$ & $0.0064 * * *$ \\
\hline Log(LA Dmg: Lag 6) & $0.0099 * * *$ & $0.0098 * * *$ & $0.0098 * * *$ & $0.0099 * * *$ & $0.0094 * * *$ \\
\hline $\mathrm{D} * \log (\mathrm{In}-$ State Dmg $)$ & -0.001 & -0.0006 & -0.001 & -0.001 & -0.0013 \\
\hline D * Log(In-State Dmg: Lag 1) & 0.0021 & $0.0024 *$ & 0.0021 & 0.0021 & 0.0020 \\
\hline D * Log(In-State Dmg: Lag 2) & $0.0040 * *$ & $0.0044 * * *$ & $0.0040 * *$ & $0.0040 * *$ & $0.0039 * *$ \\
\hline D * Log(In-State Dmg: Lag 3) & 0.0009 & 0.0013 & 0.0009 & 0.0009 & 0.0008 \\
\hline $\mathrm{D} * \log (\mathrm{TX}$ Dmg $)$ & $-0.0067 * * *$ & $-0.0068 * * *$ & $-0.0067 * * *$ & $-0.0067 * * *$ & $-0.0073^{* * *}$ \\
\hline D * Log(TX Dmg: Lag 1) & $-0.0146 * * *$ & $-0.0149 * * *$ & $-0.0147 * * *$ & $-0.0146^{* * *}$ & $-0.0152 * * *$ \\
\hline D * Log(TX Dmg: Lag 2) & $-0.0065 * * *$ & $-0.0068 * * *$ & $-0.0065 * * *$ & $-0.0065 * * *$ & $-0.0073 * * *$ \\
\hline D * Log(TX Dmg: Lag 3) & -0.0029 & -0.0031 & -0.0029 & -0.0029 & -0.0036 \\
\hline D * Log(TX Dmg: Lag 4) & 0.0020 & 0.0019 & 0.0020 & 0.0020 & 0.0009 \\
\hline D * Log(TX Dmg: Lag 5) & -0.0009 & -0.001 & -0.0009 & -0.0009 & -0.0018 \\
\hline D * Log(TX Dmg: Lag 6) & 0.0003 & 0.0002 & 0.0003 & 0.0003 & -0.0008 \\
\hline $\mathrm{D} * \log (\mathrm{LA}$ Dmg $)$ & $0.0051^{*}$ & $0.0049^{*}$ & $0.0051^{*}$ & $0.0051 *$ & $0.0050^{*}$ \\
\hline D * Log(LA Dmg: Lag 1) & $0.0063 * * *$ & $0.0062 * * *$ & $0.0063^{* * *}$ & $0.0063 * * *$ & $0.0062 * * *$ \\
\hline D * Log(LA Dmg: Lag 2) & $0.0086^{* * *}$ & $0.0084 * * *$ & $0.0086^{* * *}$ & $0.0086 * * *$ & $0.0088 * * *$ \\
\hline D * Log(LA Dmg: Lag 3) & 0.0019 & 0.0018 & 0.0019 & 0.0019 & $0.0025 *$ \\
\hline D * Log(LA Dmg: Lag 4) & -0.0006 & -0.0007 & -0.0006 & -0.0006 & 0.0001 \\
\hline D * Log(LA Dmg: Lag 5) & 0.0013 & 0.0010 & 0.0013 & 0.0013 & 0.0015 \\
\hline D * Log(LA Dmg: Lag 6) & -0.002 & -0.0022 & -0.0019 & -0.002 & -0.0017 \\
\hline Constant & -1.8269 & -1.7806 & -1.8228 & -1.8271 & -2.5528 \\
\hline $\mathrm{R}$-squared & 0.6070 & 0.6081 & 0.6070 & 0.6070 & 0.6114 \\
\hline N. of observations & 3096 & 3096 & 3096 & 3096 & 3096 \\
\hline $\begin{array}{l}\text { Notes: } \\
{ }^{a} \text { Achieved Renewable Portfolio } \\
{ }^{b} \text { Renewable Portfolio Standard O } \\
{ }^{c} \text { Binary Renewable Portfolio Sta } \\
{ }^{d} \text { Renewable Portfolio Standard O } \\
{ }^{\text {e }} \text { Per Capita Energy-related Carbc } \\
{ }^{*} \text { p }<0.10, * * p<0.05, * * * p<0.01 .\end{array}$ & $\begin{array}{l}\text { Obligation } \\
\text { n (in MWh) } \\
\text { ariable (=1 } \\
\text { on Achieveme } \\
\text { sity }\end{array}$ & $\begin{array}{l}\text { (Wh) per Mi } \\
\text { a state has } \\
\text { ercentage }\end{array}$ & $\begin{array}{l}\text { pulation } \\
\text { a given ye }\end{array}$ & otherwise) & \\
\hline
\end{tabular}


Table 2.A3. Estimation Results when using alternative policy variables for scenario 2: Import States

\begin{tabular}{|c|c|c|c|c|c|}
\hline & Model 1 & Model 2 & Model 3 & Model 4 & Model 5 \\
\hline ARPSMP $^{a}$ & -0.0169 & & & & \\
\hline RPS Obligation ${ }^{b}$ & & 0.0000 & & & \\
\hline RPS Dummy $^{c}$ & & & -0.0228 & & \\
\hline ARPS $\% d$ & & & & -0.0461 & \\
\hline Energy Carbon $^{\mathrm{e}}$ & & & & & 0.0148 \\
\hline Gulf Coast production share & $-1.0695 * * *$ & $-1.0584 * * *$ & $-1.0727 * * *$ & $-1.0790 * * *$ & $-1.0326 * * *$ \\
\hline Cooling degree days & -0.0001 & -0.0001 & -0.0001 & -0.0001 & -0.0001 \\
\hline Heating degree days & $0.0001 * * *$ & $0.0001 * * *$ & $0.0001 * * *$ & $0.0001 * * *$ & $0.0001 * * *$ \\
\hline $\log ($ State GDP $)$ & 0.0735 & 0.079 & 0.0781 & 0.0857 & 0.1063 \\
\hline VIX first difference & $0.0473 * * *$ & $0.0480 * * *$ & $0.0465 * *$ & $0.0455 * *$ & $0.0425 * *$ \\
\hline $\log ($ Oil price $)$ & $0.4658 * * *$ & $0.4650 * * *$ & $0.4687 * * *$ & $0.4709 * * *$ & $0.4645^{* * *}$ \\
\hline $\mathrm{D}(=1$ if Year $\geq 2010)$ & $-0.4048 * * *$ & $-0.4120 * * *$ & $-0.4075 * * *$ & $-0.3929 * * *$ & $-0.3554 * * *$ \\
\hline Log(In-state Dmg) & 0.0015 & 0.0014 & 0.0015 & 0.0016 & 0.0016 \\
\hline Log(In-state Dmg: Lag 1) & $0.0014 *$ & 0.0013 & 0.0014 & $0.0014 *$ & $0.0015 *$ \\
\hline Log(In-state Dmg: Lag 2) & 0.0007 & 0.0007 & 0.0007 & 0.0008 & 0.0008 \\
\hline Log(In-state Dmg: Lag 3) & 0.0000 & -0.0001 & 0.0000 & 0.0001 & 0.0001 \\
\hline Log(TX Dmg) & $0.0079 * * *$ & $0.0079 * * *$ & $0.0079 * * *$ & $0.0080 * * *$ & $0.0081 * * *$ \\
\hline Log(TX Dmg: Lag 1) & $0.0101 * * *$ & $0.0101 * * *$ & $0.0101 * * *$ & $0.0102 * * *$ & $0.0103 * * *$ \\
\hline Log(TX Dmg: Lag 2) & $0.0061 * * *$ & $0.0061 * * *$ & $0.0062 * * *$ & $0.0062 * * *$ & $0.0063 * * *$ \\
\hline Log(TX Dmg: Lag 3) & $0.0043^{* * *}$ & $0.0043^{* * *}$ & $0.0044 * * *$ & $0.0044 * * *$ & $0.0046^{* * *}$ \\
\hline Log(TX Dmg: Lag 4) & -0.0016 & -0.0016 & -0.0015 & -0.0015 & -0.0012 \\
\hline Log(TX Dmg: Lag 5) & $-0.0084 * * *$ & $-0.0084 * * *$ & $-0.0084 * * *$ & $-0.0083 * * *$ & $-0.0081 * * *$ \\
\hline Log(TX Dmg: Lag 6) & $-0.0123 * * *$ & $-0.0123 * * *$ & $-0.0122 * * *$ & $-0.0121 * * *$ & $-0.0119 * * *$ \\
\hline Log(LA Dmg) & $-0.0034 * * *$ & $-0.0034 * * *$ & $-0.0034 * * *$ & $-0.0035 * * *$ & $-0.0036^{* * *}$ \\
\hline Log(LA Dmg: Lag 1) & 0.0000 & 0.0000 & 0.0000 & -0.0001 & -0.0001 \\
\hline Log(LA Dmg: Lag 2) & $-0.0025 * * *$ & $-0.0024 * * *$ & $-0.0025 * * *$ & $-0.0026 * * *$ & $-0.0027 * * *$ \\
\hline Log(LA Dmg: Lag 3) & $0.0027 * * *$ & $0.0027 * * *$ & $0.0026^{* * *}$ & $0.0026 * * *$ & $0.0022 * * *$ \\
\hline Log(LA Dmg: Lag 4) & $0.0028 * * *$ & $0.0028 * * *$ & $0.0028 * * *$ & $0.0027 * * *$ & $0.0025 * * *$ \\
\hline Log(LA Dmg: Lag 5) & $0.0080 * * *$ & $0.0081 * * *$ & $0.0080 * * *$ & $0.0079 * * *$ & $0.0078^{* * *}$ \\
\hline Log(LA Dmg: Lag 6) & $0.0102 * * *$ & $0.0102 * * *$ & $0.0101 * * *$ & $0.0100 * * *$ & $0.0099 * * *$ \\
\hline D * Log(In-State Dmg $)$ & -0.0023 & -0.002 & -0.0022 & -0.0024 & -0.0022 \\
\hline D * Log(In-State Dmg: Lag 1) & $-0.0028 * *$ & $-0.0026 *$ & $-0.0028 * *$ & $-0.0028 * *$ & $-0.0027 *$ \\
\hline D * Log(In-State Dmg: Lag 2) & -0.0018 & -0.0016 & -0.0017 & -0.0018 & -0.0017 \\
\hline D * Log(In-State Dmg: Lag 3) & $-0.0030^{*}$ & -0.0028 & $-0.0030 *$ & $-0.0031 *$ & -0.0029 \\
\hline $\mathrm{D} * \log (\mathrm{TX}$ Dmg $)$ & $-0.0115 * * *$ & $-0.0115 * * *$ & $-0.0115 * * *$ & $-0.0116 * * *$ & $-0.0116^{* * *}$ \\
\hline D * Log(TX Dmg: Lag 1) & $-0.0123 * * *$ & $-0.0123 * * *$ & $-0.0124 * * *$ & $-0.0125 * * *$ & $-0.0127 * * *$ \\
\hline D * Log(TX Dmg: Lag 2) & $-0.0066 * * *$ & $-0.0067 * * *$ & $-0.0067 * * *$ & $-0.0068 * * *$ & $-0.0070 * * *$ \\
\hline D * Log(TX Dmg: Lag 3) & $-0.0053 * *$ & $-0.0054 * *$ & $-0.0053 * *$ & $-0.0054 * *$ & $-0.0056^{* *}$ \\
\hline D * Log(TX Dmg: Lag 4) & $0.0031 *$ & $0.0031 *$ & $0.0031 *$ & $0.0030 *$ & 0.0027 \\
\hline $\mathrm{D} * \log (\mathrm{TX}$ Dmg: Lag 5) & $0.0030^{*}$ & $0.0031 *$ & $0.0030 *$ & $0.0029 *$ & 0.0027 \\
\hline D * Log(TX Dmg: Lag 6) & 0.0019 & 0.0020 & 0.0019 & 0.0017 & 0.0016 \\
\hline $\mathrm{D} * \log (\mathrm{LA}$ Dmg $)$ & $0.0072 * * *$ & $0.0072 * * *$ & $0.0073 * * *$ & $0.0073 * * *$ & $0.0073 * * *$ \\
\hline D * Log(LA Dmg: Lag 1) & $0.0062 * * *$ & $0.0061 * * *$ & $0.0062 * * *$ & $0.0063 * * *$ & $0.0062 * * *$ \\
\hline D * Log(LA Dmg: Lag 2) & $0.0096 * * *$ & $0.0095 * * *$ & $0.0096^{* * *}$ & $0.0097 * * *$ & $0.0097 * * *$ \\
\hline D * Log(LA Dmg: Lag 3) & $0.0039 * * *$ & $0.0039 * * *$ & $0.0040 * * *$ & $0.0041 * * *$ & $0.0042 * * *$ \\
\hline D * Log(LA Dmg: Lag 4) & $0.0040 * * *$ & $0.0040 * * *$ & $0.0041 * * *$ & $0.0042 * * *$ & $0.0043^{* * *}$ \\
\hline $\mathrm{D} * \log (\mathrm{LA}$ Dmg: Lag 5) & 0.0014 & 0.0013 & 0.0014 & 0.0015 & 0.0014 \\
\hline D * Log(LA Dmg: Lag 6) & -0.0002 & -0.0003 & -0.0002 & -0.0001 & -0.0002 \\
\hline Constant & -0.6311 & -0.6997 & -0.6935 & -0.7924 & -1.3178 \\
\hline R-squared & 0.6179 & 0.6179 & 0.618 & 0.6188 & 0.6203 \\
\hline N. of observations & 8772 & 8772 & 8772 & 8772 & 8772 \\
\hline
\end{tabular}

Notes:

a Achieved Renewable Portfolio Standard Obligation (in MWh) per Million Population

${ }^{\mathrm{b}}$ Renewable Portfolio Standard Obligation (in MWh)

${ }^{\mathrm{c}}$ Binary Renewable Portfolio Standard Variable (= 1 when a state has RPS in a given year; 0 otherwise)

${ }^{\mathrm{d}}$ Renewable Portfolio Standard Obligation Achievement Percentage

e Per Capita Energy-related Carbon Intensity

$* \mathrm{p}<0.10, * * \mathrm{p}<0.05, * * * \mathrm{p}<0.01$. 
Table 2.A4. Results when using alternative policy variables for scenario 3: Northeast States

\begin{tabular}{|c|c|c|c|c|c|}
\hline & Model 1 & Model 2 & Model 3 & Model 4 & Model 5 \\
\hline $\begin{array}{l}\text { ARPSMP }{ }^{\mathrm{a}} \\
\text { RPS Obligation }{ }^{\mathrm{b}} \\
\text { RPS Dummy }{ }^{\mathrm{c}} \\
\text { ARPS \% }{ }^{\mathrm{d}} \\
\text { Energy Carbon }{ }^{\mathrm{e}}\end{array}$ & -0.0731 & $-0.000 * *$ & $-0.1470^{*}$ & $-0.1955 * * *$ & $0.0355^{*}$ \\
\hline $\begin{array}{l}\text { Gulf Coast production share } \\
\text { Cooling degree days } \\
\text { Heating degree days } \\
\text { Log(State GDP) } \\
\text { VIX first difference } \\
\text { Log(Oil price) } \\
\text { D (=1 if Year } \geq 2010)\end{array}$ & $\begin{array}{l}-1.0452 * * * \\
0.0004 * * * \\
0.0001 * * * \\
0.0293 \\
0.0679 * \\
0.5303 * * * \\
-0.2642 \\
\end{array}$ & $\begin{array}{l}-0.8687 * * * \\
0.0004 * * * \\
0.0001 * * * \\
0.2119 \\
0.0783 * \\
0.5107 * * * \\
-0.2080 \\
\end{array}$ & $\begin{array}{l}-0.8580 * * * \\
0.0004 * * * \\
0.0001 * * * \\
0.2545 \\
0.0631 * \\
0.5548 * * * \\
-0.3044 \\
\end{array}$ & $\begin{array}{l}-0.8895 * * * \\
0.0004 * * * \\
0.0001 * * * \\
0.2705 \\
0.0593 \\
0.5576 * * * \\
-0.2614 \\
\end{array}$ & $\begin{array}{l}-0.9731 * * * \\
0.0004 * * * \\
0.0001 * * * \\
0.0267 \\
0.0621 \\
0.5374 * * * \\
-0.2405 \\
\end{array}$ \\
\hline $\begin{array}{l}\text { Log(In-state Dmg) } \\
\text { Log(In-state Dmg: Lag 1) } \\
\text { Log(In-state Dmg: Lag 2) } \\
\text { Log(In-state Dmg: Lag 3) }\end{array}$ & $\begin{array}{l}-0.0013 \\
0.0010 \\
-0.0001 \\
-0.0028 \\
\end{array}$ & $\begin{array}{l}-0.002 \\
0.0004 \\
-0.0007 \\
-0.0035^{* *}\end{array}$ & $\begin{array}{l}-0.0013 \\
0.0010 \\
-0.0001 \\
-0.0029 *\end{array}$ & $\begin{array}{l}-0.0011 \\
0.0011 \\
0.0000 \\
-0.0027 *\end{array}$ & $\begin{array}{l}-0.0013 \\
0.001 \\
-0.0003 \\
-0.0030 *\end{array}$ \\
\hline $\begin{array}{l}\text { Log(TX Dmg) } \\
\text { Log(TX Dmg: Lag 1) } \\
\text { Log(TX Dmg: Lag 2) } \\
\text { Log(TX Dmg: Lag 3) } \\
\text { Log(TX Dmg: Lag 4) } \\
\text { Log(TX Dmg: Lag 5) } \\
\text { Log(TX Dmg: Lag 6) }\end{array}$ & $\begin{array}{l}0.0090 * * * \\
0.0150 * * * \\
0.0071 * * * \\
0.0084 * * * \\
-0.0006 \\
-0.0056 * * * \\
-0.0091 * * * \\
\end{array}$ & $\begin{array}{l}0.0089 * * * \\
0.0149 * * * \\
0.0072 * * * \\
0.0087 * * * \\
-0.0003 \\
-0.0054 * * * \\
-0.0091 * * * \\
\end{array}$ & $\begin{array}{l}0.0092 * * * \\
0.0155 * * * \\
0.0078 * * * \\
0.0088 * * * \\
-0.0003 \\
-0.0052 * * \\
-0.0085 * * * \\
\end{array}$ & $\begin{array}{l}0.0093 * * * \\
0.0156 * * * \\
0.0078 * * * \\
0.0088 * * * \\
-0.0003 \\
-0.0050 * * \\
-0.0082 * * * \\
\end{array}$ & $\begin{array}{l}0.0096 * * * \\
0.0158 * * * \\
0.0079 * * * \\
0.0092 * * * \\
0.0003 \\
-0.0049 * * \\
-0.0084 * * * \\
\end{array}$ \\
\hline $\begin{array}{l}\text { Log(LA Dmg) } \\
\text { Log(LA Dmg: Lag 1) } \\
\text { Log(LA Dmg: Lag 2) } \\
\text { Log(LA Dmg: Lag 3) } \\
\text { Log(LA Dmg: Lag 4) } \\
\text { Log(LA Dmg: Lag 5) } \\
\text { Log(LA Dmg: Lag 6) }\end{array}$ & $\begin{array}{l}-0.0046 * * * \\
-0.0032 * \\
-0.0033 * * * \\
0.0026 \\
0.0018 \\
0.0065 * * * \\
0.0085 * * * \\
\end{array}$ & $\begin{array}{l}-0.0045 * * * \\
-0.0032 * \\
-0.0033 * * * \\
0.0027 * \\
0.0018 * \\
0.0065 * * * \\
0.0087 * * * \\
\end{array}$ & $\begin{array}{l}-0.0053 * * * \\
-0.0039 * * \\
-0.0041 * * * \\
0.0021 \\
0.0013 \\
0.0060 * * * \\
0.0080 * * * \\
\end{array}$ & $\begin{array}{l}-0.0054 * * * \\
-0.0039 * * \\
-0.0042 * * * \\
0.0019 \\
0.0012 \\
0.0058 * * * \\
0.0077 * * * \\
\end{array}$ & $\begin{array}{l}-0.0051 * * * \\
-0.0037 * * \\
-0.0040 * * * \\
0.0017 \\
0.0011 \\
0.0060 * * * \\
0.0080 * * * \\
\end{array}$ \\
\hline $\begin{array}{l}\text { D * Log(In-State Dmg) } \\
\text { D * Log(In-State Dmg: Lag 1) } \\
\text { D * Log(In-State Dmg: Lag 2) } \\
\text { D * Log(In-State Dmg: Lag 3) }\end{array}$ & $\begin{array}{l}0.0011 \\
-0.0011 \\
-0.0003 \\
0.0029 \\
\end{array}$ & $\begin{array}{l}0.0042 \\
0.0016 \\
0.0023 \\
0.0059 *\end{array}$ & $\begin{array}{l}0.0012 \\
-0.001 \\
-0.0001 \\
0.0032 \\
\end{array}$ & $\begin{array}{l}0.0009 \\
-0.0012 \\
-0.0002 \\
0.0030 \\
\end{array}$ & $\begin{array}{l}0.0012 \\
-0.0009 \\
-0.0002 \\
0.0030 \\
\end{array}$ \\
\hline $\begin{array}{l}\text { D * Log(TX Dmg) } \\
\text { D * Log(TX Dmg: Lag 1) } \\
\text { D * Log(TX Dmg: Lag 2) } \\
\text { D * Log(TX Dmg: Lag 3) } \\
\text { D * Log(TX Dmg: Lag 4) } \\
\text { D * Log(TX Dmg: Lag 5) } \\
\text { D* Log(TX Dmg: Lag 6) }\end{array}$ & $\begin{array}{l}-0.0097 * * * \\
-0.0170 * * * \\
-0.0072 * * \\
-0.0088 * \\
0.0004 \\
-0.0059 * \\
-0.0033 \\
\end{array}$ & $\begin{array}{l}-0.0104 * * * \\
-0.0173 * * * \\
-0.0074 * * \\
-0.0093 * * \\
0.0002 \\
-0.0058 * \\
-0.0035 \\
\end{array}$ & $\begin{array}{l}-0.0103 * * * \\
-0.0176^{* * *} \\
-0.0079 * * \\
-0.0093^{* *} \\
0.0000 \\
-0.0063 * \\
-0.0036 \\
\end{array}$ & $\begin{array}{l}-0.0109 * * * \\
-0.0181 * * * \\
-0.0083 * * \\
-0.0096 * * \\
-0.0003 \\
-0.0067 * * \\
-0.0042 \\
\end{array}$ & $\begin{array}{l}-0.0102 * * * \\
-0.0177 * * * \\
-0.0077 * * \\
-0.0089 * * \\
0.0000 \\
-0.0059 * \\
-0.003 \\
\end{array}$ \\
\hline $\begin{array}{l}\text { D * Log(LA Dmg) } \\
\text { D * Log(LA Dmg: Lag 1) } \\
\text { D * Log(LA Dmg: Lag 2) } \\
\text { D * Log(LA Dmg: Lag 3) } \\
\text { D * Log(LA Dmg: Lag 4) } \\
\text { D * Log(LA Dmg: Lag 5) } \\
\text { D } * \log (\text { LA Dmg: Lag 6) }\end{array}$ & $\begin{array}{l}0.0064 * * * \\
0.0098 * * * \\
0.0101 * * * \\
0.0031 \\
0.0059 * * * \\
0.0047 \\
0.0035\end{array}$ & $\begin{array}{l}0.0060 * * \\
0.0093 * * * \\
0.0086 * * * \\
0.0016 \\
0.0048 * * * \\
0.0028 \\
0.0017 \\
\end{array}$ & $\begin{array}{l}0.0074 * * \\
0.0107 * * * \\
0.0111 * * * \\
0.0038 \\
0.0067 * * * \\
0.0054 \\
0.0041 \\
\end{array}$ & $\begin{array}{l}0.0076 * * * \\
0.0110 * * * \\
0.0114 * * * \\
0.0040 \\
0.0070 * * * \\
0.0055 \\
0.0043 \\
\end{array}$ & $\begin{array}{l}0.0071 * * \\
0.0102 * * * \\
0.0106 * * * \\
0.0038 * \\
0.0066 * * * \\
0.0047 \\
0.0032 \\
\end{array}$ \\
\hline $\begin{array}{l}\text { Constant } \\
\text { R-squared } \\
\text { N. of observations } \\
\end{array}$ & $\begin{array}{l}-0.3627 \\
0.5964 \\
2580 \\
\end{array}$ & $\begin{array}{l}-2.5791 \\
0.6017 \\
2580 \\
\end{array}$ & $\begin{array}{l}-3.2362 \\
0.602 \\
2580 \\
\end{array}$ & $\begin{array}{l}-3.4215 \\
0.6087 \\
2580 \\
\end{array}$ & $\begin{array}{l}-0.9392 \\
0.5971 \\
2580 \\
\end{array}$ \\
\hline
\end{tabular}

Notes:

a Achieved Renewable Portfolio Standard Obligation (in MWh) per Million Population

${ }^{\mathrm{b}}$ Renewable Portfolio Standard Obligation (in MWh)

${ }^{\mathrm{c}}$ Binary Renewable Portfolio Standard Variable (= 1 when a state has RPS in a given year; 0 otherwise)

${ }^{\mathrm{d}}$ Renewable Portfolio Standard Obligation Achievement Percentage

e Per Capita Energy-related Carbon Intensity

$* \mathrm{p}<0.10, * * \mathrm{p}<0.05, * * * \mathrm{p}<0.01$. 
Table 2.A5. Results when using alternative policy variables for scenario 3: Midwest States

\begin{tabular}{|c|c|c|c|c|c|}
\hline & Model 1 & Model 2 & Model 3 & Model 4 & Model 5 \\
\hline ARPSMP a & 0.0033 & & & & \\
\hline RPS Obligation ${ }^{b}$ & & 0.0000 & & & \\
\hline RPS Dummy $^{\mathrm{c}}$ & & & $-0.0995 *$ & & \\
\hline ARPS $\%$ d & & & & -0.0985 & \\
\hline Energy Carbon ${ }^{\mathrm{e}}$ & & & & & 0.0068 \\
\hline Gulf Coast production share & $-0.9679 * * *$ & $-0.9853 * * *$ & $-1.1237 * * *$ & $-1.1186 * * *$ & $-0.9788 * * *$ \\
\hline Cooling degree days & $0.0004 * * *$ & $0.0004 * * *$ & $0.0004 * * *$ & $0.0004 * * *$ & $0.0004 * * *$ \\
\hline Heating degree days & $0.0001 * * *$ & $0.0001 * * *$ & $0.0001 * * *$ & $0.0001 * * *$ & $0.0001 * * *$ \\
\hline $\log ($ State GDP $)$ & 0.0938 & 0.0837 & 0.0232 & 0.0286 & 0.0749 \\
\hline VIX first difference & -0.0063 & -0.0061 & -0.0075 & -0.0072 & -0.0088 \\
\hline Log(Oil price) & $0.4229 * * *$ & $0.4242 * * *$ & $0.4428 * * *$ & $0.4403 * * *$ & $0.4205 * * *$ \\
\hline $\mathrm{D}(=1$ if $Y$ ear $\geq 2010)$ & $-0.3696 * * *$ & $-0.3439 * * *$ & $-0.2764 * * *$ & $-0.2540 * * *$ & $-0.3039 * *$ \\
\hline Log(In-state Dmg) & -0.0001 & 0.0000 & -0.0004 & -0.0004 & -0.0001 \\
\hline Log(In-state Dmg: Lag 1) & -0.0003 & -0.0003 & -0.0006 & -0.0007 & -0.0003 \\
\hline Log(In-state Dmg: Lag 2) & -0.0007 & -0.0007 & -0.001 & -0.0011 & -0.0008 \\
\hline Log(In-state Dmg: Lag 3) & -0.0003 & -0.0003 & -0.0009 & -0.0009 & -0.0004 \\
\hline $\log (T X$ Dmg) & $0.0111 * * *$ & $0.0112 * * *$ & $0.0118 * * *$ & $0.0119 * * *$ & $0.0113 * * *$ \\
\hline Log(TX Dmg: Lag 1) & $0.0095 * * *$ & $0.0096 * * *$ & $0.0104 * * *$ & $0.0104 * * *$ & $0.0097 * * *$ \\
\hline Log(TX Dmg: Lag 2) & 0.001 & 0.001 & 0.0018 & 0.0019 & 0.0012 \\
\hline Log(TX Dmg: Lag 3) & -0.0019 & -0.0019 & -0.0013 & -0.0011 & -0.0016 \\
\hline Log(TX Dmg: Lag 4) & $-0.0061 * * *$ & $-0.0061 * * *$ & $-0.0056 * * *$ & $-0.0055 * * *$ & $-0.0058 * * *$ \\
\hline Log(TX Dmg: Lag 5) & $-0.0082 * * *$ & $-0.0081 * * *$ & $-0.0078 * * *$ & $-0.0077 * * *$ & $-0.0079 * * *$ \\
\hline Log(TX Dmg: Lag 6) & $-0.0159 * * *$ & $-0.0158 * * *$ & $-0.0158 * * *$ & $-0.0156 * * *$ & $-0.0156 * * *$ \\
\hline $\log (\mathrm{LA}$ Dmg) & $-0.0048 * * *$ & $-0.0048 * * *$ & $-0.0050 * * *$ & $-0.0051 * * *$ & $-0.0048 * * *$ \\
\hline Log(LA Dmg: Lag 1) & $0.0032 * *$ & $0.0032 * *$ & $0.0029 * *$ & $0.0029 * *$ & $0.0032 * *$ \\
\hline Log(LA Dmg: Lag 2) & 0.0011 & 0.0011 & 0.0007 & 0.0007 & 0.0011 \\
\hline Log(LA Dmg: Lag 3) & $0.0058 * * *$ & $0.0058 * * *$ & $0.0053 * * *$ & $0.0053 * * *$ & $0.0057 * * *$ \\
\hline Log(LA Dmg: Lag 4) & $0.0067 * * *$ & $0.0066 * * *$ & $0.0062 * * *$ & $0.0062 * * *$ & $0.0065 * * *$ \\
\hline Log(LA Dmg: Lag 5) & $0.0110 * * *$ & $0.0110 * * *$ & $0.0108 * * *$ & $0.0108 * * *$ & $0.0109 * * *$ \\
\hline Log(LA Dmg: Lag 6) & $0.0142 * * *$ & $0.0142 * * *$ & $0.0138 * * *$ & $0.0138 * * *$ & $0.0141 * * *$ \\
\hline D * Log(In-State Dmg) & 0.0005 & 0.0005 & 0.0012 & 0.0011 & 0.0005 \\
\hline D * Log(In-State Dmg: Lag 1) & 0.0016 & 0.0017 & 0.0023 & 0.0023 & 0.0017 \\
\hline D * Log(In-State Dmg: Lag 2) & 0.0000 & 0.0000 & 0.0008 & 0.0007 & 0.0001 \\
\hline D * Log(In-State Dmg: Lag 3) & -0.004 & -0.0039 & -0.0031 & -0.0032 & -0.0039 \\
\hline $\mathrm{D} * \log (\mathrm{TX} \mathrm{Dmg})$ & $-0.0158 * * *$ & $-0.0160 * * *$ & $-0.0166 * * *$ & $-0.0167 * * *$ & $-0.0161 * * *$ \\
\hline D * Log(TX Dmg: Lag 1) & $-0.0158 * * *$ & $-0.0160 * * *$ & $-0.0170 * * *$ & $-0.0172 * * *$ & $-0.0163 * * *$ \\
\hline D * Log(TX Dmg: Lag 2) & $-0.0030 *$ & $-0.0031 *$ & $-0.0040 * * *$ & $-0.0043 * * *$ & $-0.0035 * * *$ \\
\hline D * Log(TX Dmg: Lag 3) & -0.0017 & -0.0018 & -0.0026 & -0.0029 & -0.0021 \\
\hline D * Log(TX Dmg: Lag 4) & $0.0098 * * *$ & $0.0098 * * *$ & $0.0093 * * *$ & $0.0090 * * *$ & $0.0093 * * *$ \\
\hline D * Log(TX Dmg: Lag 5) & $0.0084 * * *$ & $0.0083 * * *$ & $0.0079 * * *$ & $0.0077 * * *$ & $0.0080 * * *$ \\
\hline D * Log(TX Dmg: Lag 6) & $0.0095 * * *$ & $0.0093 * * *$ & $0.0092 * * *$ & $0.0088 * * *$ & $0.0090 * * *$ \\
\hline $\mathrm{D} * \log (\mathrm{LA}$ Dmg $)$ & $0.0066 * * *$ & $0.0066 * * *$ & $0.0064 * * *$ & $0.0064 * * *$ & $0.0066 * * *$ \\
\hline D * Log(LA Dmg: Lag 1) & 0.0015 & 0.0015 & 0.0015 & 0.0015 & 0.0014 \\
\hline D * Log(LA Dmg: Lag 2) & $0.0061 * * *$ & $0.0061 * * *$ & $0.0062 * * *$ & $0.0063 * * *$ & $0.0061 * * *$ \\
\hline D * Log(LA Dmg: Lag 3) & 0.0002 & 0.0002 & 0.0003 & 0.0004 & 0.0003 \\
\hline D * Log(LA Dmg: Lag 4) & $-0.0038 * *$ & $-0.0038 * *$ & $-0.0038 * *$ & $-0.0036 * *$ & $-0.0036 * *$ \\
\hline D* Log(LA Dmg: Lag 5) & $-0.0050 * * *$ & $-0.0051 * * *$ & $-0.0051 * * *$ & $-0.0050 * * *$ & $-0.0051 * * *$ \\
\hline D * Log(LA Dmg: Lag 6) & $-0.0067 * * *$ & $-0.0068 * * *$ & $-0.0068 * * *$ & $-0.0066 * * *$ & $-0.0068 * * *$ \\
\hline Constant & -0.7822 & -0.6636 & 0.0616 & -0.0062 & -0.7542 \\
\hline R-squared & 0.6265 & 0.6266 & 0.6318 & 0.6312 & 0.6273 \\
\hline N. of observations & 2838 & 2838 & 2838 & 2838 & 2838 \\
\hline
\end{tabular}

Notes:

a Achieved Renewable Portfolio Standard Obligation (in MWh) per Million Population

${ }^{\mathrm{b}}$ Renewable Portfolio Standard Obligation (in MWh)

${ }^{\mathrm{c}}$ Binary Renewable Portfolio Standard Variable (= 1 when a state has RPS in a given year; 0 otherwise)

${ }^{\mathrm{d}}$ Renewable Portfolio Standard Obligation Achievement Percentage

e Per Capita Energy-related Carbon Intensity

$* \mathrm{p}<0.10, * * \mathrm{p}<0.05, * * * \mathrm{p}<0.01$. 
Table 2.A6. Results when using alternative policy variables for scenario 3: West States

\begin{tabular}{|c|c|c|c|c|c|}
\hline & Model 1 & Model 2 & Model 3 & Model 4 & Model 5 \\
\hline ARPSMP a & -0.0519 & & & & \\
\hline RPS Obligation ${ }^{b}$ & & 0.0000 & & & \\
\hline RPS Dummy $^{\mathrm{c}}$ & & & 0.0006 & & \\
\hline ARPS $\%$ d & & & & -0.0128 & \\
\hline Energy Carbon ${ }^{\mathrm{e}}$ & & & & & 0.0047 \\
\hline Gulf Coast production share & $-1.5889 * * *$ & $-1.5921 * * *$ & $-1.5807 * * *$ & $-1.5823 * * *$ & $-1.5278 * * *$ \\
\hline Cooling degree days & -0.0001 & -0.0001 & -0.0001 & -0.0001 & -0.0001 \\
\hline Heating degree days & $0.0002 * * *$ & $0.0002 * * *$ & $0.0002 * * *$ & $0.0002 * * *$ & $0.0002 * * *$ \\
\hline $\log ($ State GDP $)$ & -0.0257 & -0.0222 & -0.0424 & -0.0382 & 0.0002 \\
\hline VIX first difference & 0.0378 & 0.0382 & 0.0379 & 0.0376 & 0.0356 \\
\hline Log(Oil price $)$ & $0.5051 * * *$ & $0.5059 * * *$ & $0.5056^{* * *}$ & $0.5077 * * *$ & $0.4999 * * *$ \\
\hline $\mathrm{D}(=1$ if $Y$ ear $\geq 2010)$ & -0.0058 & -0.024 & -0.0722 & -0.0598 & -0.0606 \\
\hline Log(In-state Dmg) & -0.0001 & -0.0007 & -0.0001 & -0.0001 & 0.0000 \\
\hline Log(In-state Dmg: Lag 1) & 0.0002 & -0.0002 & 0.0003 & 0.0003 & 0.0003 \\
\hline Log(In-state Dmg: Lag 2) & -0.0012 & $-0.0016 * *$ & -0.0012 & -0.0012 & -0.0011 \\
\hline Log(In-state Dmg: Lag 3) & $-0.0019 *$ & $-0.0024 * * *$ & $-0.0018 *$ & -0.0018 & -0.0017 \\
\hline $\log (T X$ Dmg) & $0.0070 * * *$ & $0.0071 * * *$ & $0.0068 * * *$ & $0.0069 * * *$ & $0.0067 * * *$ \\
\hline Log(TX Dmg: Lag 1) & $0.0098 * * *$ & $0.0099 * * *$ & $0.0097 * * *$ & $0.0098 * * *$ & $0.0096 * * *$ \\
\hline Log(TX Dmg: Lag 2) & $0.0088 * * *$ & $0.0090 * * *$ & $0.0087 * * *$ & $0.0088 * * *$ & $0.0087 * * *$ \\
\hline Log(TX Dmg: Lag 3) & $0.0058 * * *$ & $0.0061 * * *$ & $0.0057 * * *$ & $0.0057 * * *$ & $0.0057 * * *$ \\
\hline Log(TX Dmg: Lag 4) & 0.0010 & 0.0013 & 0.0009 & 0.0009 & 0.0010 \\
\hline Log(TX Dmg: Lag 5) & -0.0023 & -0.0022 & -0.0025 & -0.0025 & -0.0025 \\
\hline Log(TX Dmg: Lag 6) & $-0.0093 * * *$ & $-0.0095 * * *$ & $-0.0096 * * *$ & $-0.0095 * * *$ & $-0.0095 * * *$ \\
\hline $\log ($ LA Dmg) & -0.0016 & -0.0015 & -0.0016 & -0.0017 & -0.0016 \\
\hline Log(LA Dmg: Lag 1) & -0.0023 & -0.0022 & -0.0022 & -0.0023 & -0.0022 \\
\hline Log(LA Dmg: Lag 2) & $-0.0030 * *$ & $-0.0030 * *$ & $-0.0029 * *$ & $-0.0030 * *$ & $-0.0030 * *$ \\
\hline Log(LA Dmg: Lag 3) & 0.0018 & 0.0018 & 0.0018 & 0.0018 & 0.0017 \\
\hline Log(LA Dmg: Lag 4) & $0.0031 *$ & $0.0031 *$ & $0.0032 *$ & $0.0031 *$ & $0.0030 *$ \\
\hline Log(LA Dmg: Lag 5) & $0.0052 * * *$ & $0.0052 * * *$ & $0.0053 * * *$ & $0.0052 * * *$ & $0.0052 * * *$ \\
\hline Log(LA Dmg: Lag 6) & $0.0092 * * *$ & $0.0093 * * *$ & $0.0093 * * *$ & $0.0092 * * *$ & $0.0091 * * *$ \\
\hline D * Log(In-State Dmg) & -0.0007 & 0.0008 & -0.0008 & -0.0009 & -0.0010 \\
\hline D * Log(In-State Dmg: Lag 1) & 0.0000 & 0.0011 & -0.0002 & -0.0002 & -0.0003 \\
\hline D * Log(In-State Dmg: Lag 2) & $0.0033 *$ & $0.0044 * * *$ & $0.0031 *$ & $0.0031 *$ & 0.0030 \\
\hline D * Log(In-State Dmg: Lag 3) & 0.0016 & $0.0030 * * *$ & 0.0014 & 0.0014 & 0.0012 \\
\hline $\mathrm{D} * \log (\mathrm{TX}$ Dmg $)$ & $-0.0110 * * *$ & $-0.0113 * * *$ & $-0.0108 * * *$ & $-0.0109 * * *$ & $-0.0107 * * *$ \\
\hline D * Log(TX Dmg: Lag 1) & $-0.0171 * * *$ & $-0.0172 * * *$ & $-0.0168 * * *$ & $-0.0169 * * *$ & $-0.0166 * * *$ \\
\hline D * Log(TX Dmg: Lag 2) & $-0.0140 * * *$ & $-0.0142 * * *$ & $-0.0135 * * *$ & $-0.0136 * * *$ & $-0.0135 * * *$ \\
\hline D * Log(TX Dmg: Lag 3) & $-0.0105 * * *$ & $-0.0109 * * *$ & $-0.0101 * * *$ & $-0.0101 * * *$ & $-0.0100 * * *$ \\
\hline D * Log(TX Dmg: Lag 4) & -0.0021 & -0.0024 & -0.0018 & -0.0018 & -0.0018 \\
\hline D * Log(TX Dmg: Lag 5) & -0.0023 & -0.0024 & -0.0019 & -0.0020 & -0.0019 \\
\hline D * Log(TX Dmg: Lag 6) & -0.0013 & -0.0009 & -0.0007 & -0.0008 & -0.0007 \\
\hline $\mathrm{D} * \log (\mathrm{LA}$ Dmg $)$ & 0.0036 & 0.0035 & $0.0038 *$ & $0.0038 *$ & 0.0037 \\
\hline D * Log(LA Dmg: Lag 1) & $0.0088 * * *$ & $0.0086 * * *$ & $0.0089 * * *$ & $0.0090 * * *$ & $0.0089 * * *$ \\
\hline D * Log(LA Dmg: Lag 2) & $0.0109 * * *$ & $0.0105 * * *$ & $0.0109 * * *$ & $0.0110 * * *$ & $0.0110 * * *$ \\
\hline D * Log(LA Dmg: Lag 3) & $0.0051 * * *$ & $0.0050 * * *$ & $0.0052 * * *$ & $0.0052 * * *$ & $0.0053 * * *$ \\
\hline D * Log(LA Dmg: Lag 4) & $0.0050 * * *$ & $0.0049 * * *$ & $0.0050 * * *$ & $0.0050 * * *$ & $0.0051 * * *$ \\
\hline D * Log(LA Dmg: Lag 5) & $0.0054 * * *$ & $0.0051 * * *$ & $0.0054 * * *$ & $0.0054 * * *$ & $0.0054 * * *$ \\
\hline D * Log(LA Dmg: Lag 6) & -0.0017 & -0.0019 & -0.0017 & -0.0016 & -0.0016 \\
\hline Constant & 0.3061 & 0.2635 & 0.503 & 0.4451 & -0.1337 \\
\hline R-squared & 0.636 & 0.6397 & 0.6345 & 0.6346 & 0.6351 \\
\hline N. of observations & 2838 & 2838 & 2838 & 2838 & 2838 \\
\hline
\end{tabular}

Notes:

a Achieved Renewable Portfolio Standard Obligation (in MWh) per Million Population

b Renewable Portfolio Standard Obligation (in MWh)

${ }^{c}$ Binary Renewable Portfolio Standard Variable (= 1 when a state has RPS in a given year; 0 otherwise)

d Renewable Portfolio Standard Obligation Achievement Percentage

e Per Capita Energy-related Carbon Intensity

$* \mathrm{p}<0.10, * * \mathrm{p}<0.05, * * * \mathrm{p}<0.01$. 
Table 2.A7. Results when using alternative policy variables for scenario 3: South States

\begin{tabular}{|c|c|c|c|c|c|}
\hline & Model 1 & Model 2 & Model 3 & Model 4 & Model 5 \\
\hline ARPSMP a & 0.0015 & & & & \\
\hline RPS Obligation ${ }^{b}$ & & 0.0000 & & & \\
\hline RPS Dummy $^{\mathrm{c}}$ & & & -0.0074 & & \\
\hline ARPS $\%$ d & & & & -0.0062 & \\
\hline Energy Carbon $^{\mathrm{e}}$ & & & & & $0.0301 * * *$ \\
\hline Gulf Coast production share & $-0.8968 * * *$ & $-0.8453 * * *$ & $-0.8931 * * *$ & $-0.8935 * * *$ & $-0.8209 * * *$ \\
\hline Cooling degree days & 0.0000 & 0.0000 & 0.0000 & 0.0000 & -0.0001 \\
\hline Heating degree days & $0.0001 * *$ & $0.0001 * *$ & $0.0001 * *$ & $0.0001 * *$ & $0.0001 * *$ \\
\hline $\log ($ State GDP $)$ & 0.3026 & $0.3608 * *$ & 0.3059 & 0.3055 & $0.4483 * * *$ \\
\hline VIX first difference & $0.0634 * * *$ & $0.0633 * * *$ & $0.0631 * * *$ & $0.0632 * * *$ & $0.0430 *$ \\
\hline Log(Oil price) & $0.4345 * * *$ & $0.4273 * * *$ & $0.4346 * * *$ & $0.4346 * * *$ & $0.4232 * * *$ \\
\hline $\mathrm{D}(=1$ if $Y$ ear $\geq 2010)$ & $-0.6263 * * *$ & $-0.6100 * * *$ & $-0.6244 * * *$ & $-0.6247 * * *$ & $-0.4056 * * *$ \\
\hline Log(In-state Dmg) & $0.0033^{* *}$ & $0.0032 * *$ & $0.0033 * *$ & $0.0033 * *$ & $0.0042 * * *$ \\
\hline Log(In-state Dmg: Lag 1) & 0.0001 & 0.0001 & 0.0002 & 0.0001 & 0.0009 \\
\hline Log(In-state Dmg: Lag 2) & 0.0015 & 0.0015 & 0.0015 & 0.0015 & 0.0021 \\
\hline Log(In-state Dmg: Lag 3) & $0.0027 * *$ & $0.0027 * *$ & $0.0027 * *$ & $0.0027 * *$ & $0.0033 * *$ \\
\hline $\log (T X$ Dmg) & $0.0077 * * *$ & $0.0076 * * *$ & $0.0077 * * *$ & $0.0077 * * *$ & $0.0083 * * *$ \\
\hline Log(TX Dmg: Lag 1) & $0.0098 * * *$ & $0.0096 * * *$ & $0.0098 * * *$ & $0.0098 * * *$ & $0.0102 * * *$ \\
\hline Log(TX Dmg: Lag 2) & $0.0052 * * *$ & $0.0051 * * *$ & $0.0052 * * *$ & $0.0052 * * *$ & $0.0057 * * *$ \\
\hline Log(TX Dmg: Lag 3) & 0.0009 & 0.0008 & 0.0009 & 0.0009 & 0.0019 \\
\hline Log(TX Dmg: Lag 4) & -0.0013 & -0.0013 & -0.0013 & -0.0013 & 0.0001 \\
\hline Log(TX Dmg: Lag 5) & $-0.0086 * * *$ & $-0.0086 * * *$ & $-0.0086 * * *$ & $-0.0086 * * *$ & $-0.0073 * * *$ \\
\hline Log(TX Dmg: Lag 6) & $-0.0082 * * *$ & $-0.0082 * * *$ & $-0.0082 * * *$ & $-0.0082 * * *$ & $-0.0066^{* *}$ \\
\hline $\log (\mathrm{LA}$ Dmg) & $-0.0035 * *$ & $-0.0035 * *$ & $-0.0035 * *$ & $-0.0035 * *$ & $-0.0039 * * *$ \\
\hline Log(LA Dmg: Lag 1) & 0.0012 & 0.0013 & 0.0012 & 0.0012 & 0.0012 \\
\hline Log(LA Dmg: Lag 2) & -0.0013 & -0.0012 & -0.0013 & -0.0013 & $-0.0020 * * *$ \\
\hline Log(LA Dmg: Lag 3) & $0.0027 * * *$ & $0.0027 * * *$ & $0.0027 * * *$ & $0.0027 * * *$ & $0.0012 *$ \\
\hline Log(LA Dmg: Lag 4) & $0.0029 * * *$ & $0.0029 * * *$ & $0.0029 * * *$ & $0.0029 * * *$ & $0.0018 * *$ \\
\hline Log(LA Dmg: Lag 5) & $0.0085 * * *$ & $0.0085 * * *$ & $0.0085 * * *$ & $0.0085 * * *$ & $0.0074 * * *$ \\
\hline Log(LA Dmg: Lag 6) & $0.0090 * * *$ & $0.0090 * * *$ & $0.0090 * * *$ & $0.0090 * * *$ & $0.0077 * * *$ \\
\hline D * Log(In-State Dmg) & -0.0045 & -0.005 & -0.0046 & -0.0046 & -0.0062 \\
\hline D * Log(In-State Dmg: Lag 1) & -0.003 & -0.0034 & -0.0031 & -0.0031 & -0.0044 \\
\hline D * Log(In-State Dmg: Lag 2) & -0.0017 & -0.0021 & -0.0018 & -0.0018 & -0.0027 \\
\hline D * Log(In-State Dmg: Lag 3) & -0.0059 & -0.0066 & -0.0061 & -0.0061 & -0.007 \\
\hline $\mathrm{D} * \log (\mathrm{TX}$ Dmg $)$ & $-0.0091 * * *$ & $-0.0088 * * *$ & $-0.0091 * * *$ & $-0.0091 * * *$ & $-0.0092 * * *$ \\
\hline D * Log(TX Dmg: Lag 1) & $-0.0097 * * *$ & $-0.0095 * * *$ & $-0.0097 * * *$ & $-0.0097 * * *$ & $-0.0103 * * *$ \\
\hline D * Log(TX Dmg: Lag 2) & -0.0034 & -0.0032 & -0.0033 & -0.0033 & -0.0041 \\
\hline D * Log(TX Dmg: Lag 3) & 0.0007 & 0.0010 & 0.0008 & 0.0008 & 0.0000 \\
\hline D * Log(TX Dmg: Lag 4) & $0.0038 *$ & $0.0039 *$ & $0.0038 *$ & $0.0038 *$ & 0.0025 \\
\hline D * Log(TX Dmg: Lag 5) & $0.0040 *$ & $0.0040 *$ & $0.0039 *$ & $0.0039 *$ & 0.0023 \\
\hline D * Log(TX Dmg: Lag 6) & -0.0004 & -0.0004 & -0.0004 & -0.0004 & -0.0024 \\
\hline $\mathrm{D} * \log (\mathrm{LA}$ Dmg $)$ & $0.0093 * * *$ & $0.0093 * * *$ & $0.0093 * * *$ & $0.0093 * * *$ & $0.0094 * * *$ \\
\hline D * Log(LA Dmg: Lag 1) & $0.0063 * * *$ & $0.0063 * * *$ & $0.0063 * * *$ & $0.0063 * * *$ & $0.0062 * * *$ \\
\hline D * Log(LA Dmg: Lag 2) & $0.0104 * * *$ & $0.0105 * * *$ & $0.0104 * * *$ & $0.0104 * * *$ & $0.0111 * * *$ \\
\hline D * Log(LA Dmg: Lag 3) & $0.0041 * * *$ & $0.0041 * * *$ & $0.0041 * * *$ & $0.0041 * * *$ & $0.0051 * * *$ \\
\hline D * Log(LA Dmg: Lag 4) & $0.0027 * * *$ & $0.0027 * * *$ & $0.0027 * * *$ & $0.0027 * * *$ & $0.0035 * * *$ \\
\hline D * Log(LA Dmg: Lag 5) & 0.0003 & 0.0002 & 0.0003 & 0.0003 & 0.0009 \\
\hline D * Log(LA Dmg: Lag 6) & 0.0006 & 0.0005 & 0.0006 & 0.0006 & 0.0011 \\
\hline Constant & -3.3972 & $-4.0904 *$ & -3.4395 & -3.4342 & $-5.9451 * * *$ \\
\hline R-squared & 0.6521 & 0.6537 & 0.6521 & 0.6521 & 0.6683 \\
\hline N. of observations & 3612 & 3612 & 3612 & 3612 & 3612 \\
\hline
\end{tabular}

Notes:

a Achieved Renewable Portfolio Standard Obligation (in MWh) per Million Population

${ }^{\mathrm{b}}$ Renewable Portfolio Standard Obligation (in MWh)

${ }^{c}$ Binary Renewable Portfolio Standard Variable (= 1 when a state has RPS in a given year; 0 otherwise)

d Renewable Portfolio Standard Obligation Achievement Percentage

e Per Capita Energy-related Carbon Intensity

$* \mathrm{p}<0.10, * * \mathrm{p}<0.05, * * * \mathrm{p}<0.01$. 


\section{Appendix B}

Table 2.B. Panel Unit-root Test P-value Results

\begin{tabular}{ccccc}
\hline & $\begin{array}{l}\text { Log(Natural Gas } \\
\text { Price) }\end{array}$ & $\begin{array}{l}\text { In-state Property } \\
\text { Damage }\end{array}$ & $\begin{array}{l}\text { Texas Property } \\
\text { Damage }\end{array}$ & $\begin{array}{l}\text { Louisiana Property } \\
\text { Damage }\end{array}$ \\
\hline LLC $^{\text {a }}$ & & & & \\
1 & 0.0000 & 0.0000 & 0.0000 & 0.0000 \\
2 & 0.0000 & 0.0000 & 0.0000 & 0.0000 \\
3 & 0.0000 & 0.0000 & 0.0000 & 0.0000 \\
4 & 0.0000 & 0.0000 & 0.0000 & 0.0000 \\
5 & 0.0001 & 0.0000 & 0.0000 & 0.0000 \\
6 & 0.0071 & 0.0000 & 0.0000 & 0.0000 \\
\hline Breitung & & & & \\
$\mathrm{b}$ & 0.0000 & 0.0000 & 0.0000 & 0.0000 \\
1 & 0.0000 & 0.0000 & 0.0000 & 0.0000 \\
2 & 0.0000 & 0.0000 & 0.0000 & 0.0000 \\
3 & 0.0000 & 0.0000 & 0.0000 & 0.0000 \\
4 & 0.0000 & 0.0000 & 0.0000 & 0.0000 \\
5 & 0.0000 & 0.0000 & 0.0000 & 0.0000 \\
6 & & & & 0.0000 \\
\hline IPS & c & & 0.0000 & 0.0000 \\
1 & 0.0000 & 0.0000 & 0.0000 & 0.0000 \\
2 & 0.0000 & 0.0000 & 0.0000 & 0.0000 \\
3 & 0.0000 & 0.0000 & 0.0000 & 0.0000 \\
4 & 0.0000 & 0.0000 & 0.0000 & 0.0000 \\
5 & 0.0000 & 0.0000 & 0.0000 &
\end{tabular}

Note:

${ }^{a}$ Levin-Lin-Chu Unit-root Test. Ho: Panels contain unit roots; Ha: Panels are stationary

${ }^{\mathrm{b}}$ Breitung Unit-root Test. Ho: Panels contain unit roots; Ha: Panels are stationary

${ }^{c}$ Im-Pesaran-Shun Unit-root Test. Ho: All panels contain unit roots; Ha: At least one panel is stationary 


\section{Appendix C}

Table 2.C1. Estimation results when property damages from TX \& LA vs. all Gulf states are considered: Scenario 1 All States

\begin{tabular}{|c|c|c|}
\hline & All (TX \& LA) & All (All 5 Gulf States) \\
\hline Achieved RPS obligation & -0.0164 & -0.0151 \\
\hline Gulf Coast production share & $-1.0355 * * *$ & $-0.8614 * * *$ \\
\hline Cooling degree days & 0.0000 & 0.0001 \\
\hline Heating degree days & $0.0001 * * *$ & $0.0001 * * *$ \\
\hline $\log ($ State GDP $)$ & 0.1326 & 0.0337 \\
\hline VIX first difference & $0.0408 * * *$ & $0.0342 *$ \\
\hline Log(Oil price) & $0.4646^{* * *}$ & $0.4658 * * *$ \\
\hline $\mathrm{D}(=1$ if Year $\geq 2010)$ & $-0.4153 * * *$ & $-0.5797 * * *$ \\
\hline Log(In-state Dmg) & 0.0010 & 0.0008 \\
\hline Log(In-state Dmg: Lag 1) & 0.0008 & 0.0007 \\
\hline Log(In-state Dmg: Lag 2) & 0.0001 & 0.0000 \\
\hline Log(In-state Dmg: Lag 3) & -0.0003 & -0.0008 \\
\hline $\log (\mathrm{TX}$ Dmg) & $0.0070 * * *$ & $0.0047 * * *$ \\
\hline Log(TX Dmg: Lag 1) & $0.0096^{* * *}$ & $0.0080 * * *$ \\
\hline Log(TX Dmg: Lag 2) & $0.0054 * * *$ & 0.0010 \\
\hline Log(TX Dmg: Lag 3) & $0.0033 * * *$ & -0.0004 \\
\hline Log(TX Dmg: Lag 4) & $-0.0017 *$ & $-0.0062 * * *$ \\
\hline Log(TX Dmg: Lag 5) & $-0.0069 * * *$ & $-0.0107 * * *$ \\
\hline Log(TX Dmg: Lag 6) & $-0.0109 * * *$ & $-0.0162 * * *$ \\
\hline $\log ($ LA Dmg) & $-0.0030 * * *$ & $-0.0018 * *$ \\
\hline Log(LA Dmg: Lag 1) & 0.0000 & 0.0014 \\
\hline Log(LA Dmg: Lag 2) & $-0.0017 * * *$ & $-0.0031 * * *$ \\
\hline Log(LA Dmg: Lag 3) & $0.0032 * * *$ & 0.0003 \\
\hline Log(LA Dmg: Lag 4) & $0.0035^{* * *}$ & $0.0028 * * *$ \\
\hline Log(LA Dmg: Lag 5) & $0.0077 * * *$ & $0.0071 * * *$ \\
\hline Log(LA Dmg: Lag 6) & $0.0101 * * *$ & $0.0089 * * *$ \\
\hline D * Log $($ In-State Dmg $)$ & -0.0021 & $-0.0035 * *$ \\
\hline D * Log(In-State Dmg: Lag 1) & -0.0016 & $-0.0022 *$ \\
\hline D * Log(In-State Dmg: Lag 2) & -0.0004 & -0.0007 \\
\hline D * Log(In-State Dmg: Lag 3) & -0.0021 & 0.0002 \\
\hline $\mathrm{D} * \log (\mathrm{TX}$ Dmg $)$ & $-0.0101 * * *$ & $-0.0136 * * *$ \\
\hline D * Log(TX Dmg: Lag 1) & $-0.0127 * * *$ & $-0.0116^{* * *}$ \\
\hline D * Log(TX Dmg: Lag 2) & $-0.0062 * * *$ & $-0.0062 * * *$ \\
\hline D * Log(TX Dmg: Lag 3) & $-0.0044 * *$ & $-0.0048 * *$ \\
\hline D * Log(TX Dmg: Lag 4) & $0.0030 * *$ & 0.0013 \\
\hline $\mathrm{D} * \log (\mathrm{TX}$ Dmg: Lag 5) & 0.0020 & 0.0027 \\
\hline D * Log(TX Dmg: Lag 6) & 0.0016 & $0.0052 *$ \\
\hline $\mathrm{D} * \log (\mathrm{LA}$ Dmg $)$ & $0.0067 * * *$ & $0.0073 * * *$ \\
\hline D * Log(LA Dmg: Lag 1) & $0.0063 * * *$ & $0.0084 * * *$ \\
\hline D $* \log ($ LA Dmg: Lag 2) & $0.0093 * * *$ & $0.0145 * * *$ \\
\hline D * Log(LA Dmg: Lag 3) & $0.0033 * * *$ & 0.0032 \\
\hline$D * \log ($ LA Dmg: Lag 4) & $0.0028 * * *$ & $0.0138 * * *$ \\
\hline$D * \log ($ LA Dmg: Lag 5) & 0.0014 & 0.0021 \\
\hline $\mathrm{D} * \log (\mathrm{LA}$ Dmg: $\operatorname{Lag} 6)$ & -0.0006 & $0.0087 * * *$ \\
\hline Constant & -1.3818 & -0.3729 \\
\hline R-squared & 0.6104 & 0.6403 \\
\hline N. of observations & 11868 & 11094 \\
\hline
\end{tabular}

Notes: $* \mathrm{p}<0.10, * * \mathrm{p}<0.05, * * * \mathrm{p}<0.010$. In column 1 , only property damages from LA and TX are used on the right-hand side. In column 2, property damages in LA, TX, FL, AL, and MS are used. Coefficient estimates for variables associated with LA, TX, and FL are omitted from the table as they are not the paper's main interest. 
Table 2.C2. Estimation results when property damages from TX \& LA vs. all Gulf states are considered: Scenario 2 Exporting and Importing States

\begin{tabular}{|c|c|c|c|c|}
\hline & $\begin{array}{l}\text { Export } \\
\text { (TX \& LA) }\end{array}$ & $\begin{array}{l}\text { Export } \\
\text { (All } 5 \text { Gulf States) }\end{array}$ & $\begin{array}{l}\text { Import } \\
(\text { TX \&LA) }\end{array}$ & $\begin{array}{l}\text { Import } \\
\text { (All } 5 \text { Gulf States) }\end{array}$ \\
\hline Achieved RPS obligation & 0.0002 & -0.0544 & -0.0169 & -0.0048 \\
\hline Gulf Coast production share & $-1.0543 * * *$ & $-1.2319 * * *$ & $-1.0695 * * *$ & $-0.7900 * * *$ \\
\hline Cooling degree days & $0.0002 * *$ & $0.0002 * *$ & -0.0001 & 0.0000 \\
\hline Heating degree days & $0.0001 * * *$ & $0.0001 * * *$ & $0.0001 * * *$ & $0.0001 * * *$ \\
\hline Log(State GDP) & 0.1626 & -0.1437 & 0.0735 & 0.0254 \\
\hline VIX first difference & 0.0126 & 0.0147 & $0.0473 * * *$ & 0.0389 \\
\hline Log(Oil price) & $0.4723 * * *$ & $0.5150 * * *$ & $0.4658 * * *$ & $0.4594 * * *$ \\
\hline $\mathrm{D}(=1$ if $Y$ ear $\geq 2010)$ & -0.3624 & -0.4160 & $-0.4048 * * *$ & $-0.5814 * * *$ \\
\hline Log(In-state Dmg) & 0.0007 & 0.0007 & 0.0015 & 0.0013 \\
\hline Log(In-state Dmg: Lag 1) & -0.0003 & -0.0003 & $0.0014 *$ & 0.0012 \\
\hline Log(In-state Dmg: Lag 2) & $-0.0017 *$ & $-0.0019 * * *$ & 0.0007 & 0.0007 \\
\hline Log(In-state Dmg: Lag 3) & -0.0016 & $-0.0027 * * *$ & 0.0000 & -0.0003 \\
\hline $\log (\mathrm{TX}$ Dmg) & $0.0046 * *$ & $0.0039 *$ & $0.0079 * * *$ & $0.0051 * * *$ \\
\hline Log(TX Dmg: Lag 1) & $0.0086 * * *$ & $0.0085 * * *$ & $0.0101 * * *$ & $0.0080 * * *$ \\
\hline Log(TX Dmg: Lag 2) & 0.0038 & 0.0011 & $0.0061 * * *$ & 0.0012 \\
\hline Log(TX Dmg: Lag 3) & 0.0008 & -0.0011 & $0.0043 * * *$ & 0 \\
\hline Log(TX Dmg: Lag 4) & -0.0017 & $-0.0065 * * *$ & -0.0016 & $-0.0060 * * *$ \\
\hline Log(TX Dmg: Lag 5) & -0.0025 & $-0.0054 * * *$ & $-0.0084 * * *$ & $-0.0125 * * *$ \\
\hline Log(TX Dmg: Lag 6) & $-0.0068 * *$ & $-0.0107 * * *$ & $-0.0123 * * *$ & $-0.0177 * * *$ \\
\hline $\log ($ LA Dmg) & -0.0020 & -0.0017 & $-0.0034 * * *$ & $-0.0020 * *$ \\
\hline Log(LA Dmg: Lag 1) & 0.0001 & 0.0008 & 0.0000 & 0.0014 \\
\hline Log(LA Dmg: Lag 2) & 0.0005 & -0.0018 & $-0.0025 * * *$ & $-0.0038 * * *$ \\
\hline Log(LA Dmg: Lag 3) & $0.0043 * * *$ & 0.0017 & $0.0027 * * *$ & -0.0004 \\
\hline Log(LA Dmg: Lag 4) & $0.0054 * * *$ & $0.0056 * * *$ & $0.0028 * * *$ & 0.0017 \\
\hline Log(LA Dmg: Lag 5) & $0.0068 * * *$ & $0.0064 * * *$ & $0.0080 * * *$ & $0.0071 * * *$ \\
\hline Log(LA Dmg: Lag 6) & $0.0099 * * *$ & $0.0083 * * *$ & $0.0102 * * *$ & $0.0090 * * *$ \\
\hline D * Log(In-State Dmg) & -0.001 & $-0.0041 * * *$ & -0.0023 & $-0.0035 * *$ \\
\hline D * Log(In-State Dmg: Lag 1) & 0.0021 & -0.0003 & $-0.0028 * *$ & $-0.0029 * *$ \\
\hline D * Log(In-State Dmg: Lag 2) & $0.0040 * *$ & $0.0027 * *$ & -0.0018 & -0.0019 \\
\hline D * Log(In-State Dmg: Lag 3) & 0.0009 & 0.0028 & $-0.0030 *$ & -0.0009 \\
\hline $\mathrm{D} * \log (\mathrm{TX}$ Dmg $)$ & $-0.0067 * * *$ & $-0.0125 * * *$ & $-0.0115 * * *$ & $-0.0141 * * *$ \\
\hline D * Log(TX Dmg: Lag 1) & $-0.0146 * * *$ & $-0.0149 * * *$ & $-0.0123 * * *$ & $-0.0108 * * *$ \\
\hline D * Log(TX Dmg: Lag 2) & $-0.0065 * * *$ & $-0.0086 * * *$ & $-0.0066 * * *$ & $-0.0056 * * *$ \\
\hline D * Log(TX Dmg: Lag 3) & -0.0029 & -0.0058 & $-0.0053 * *$ & $-0.0048 *$ \\
\hline D * Log(TX Dmg: Lag 4) & 0.0020 & -0.0004 & $0.0031 *$ & 0.0017 \\
\hline D * Log(TX Dmg: Lag 5) & -0.0009 & -0.0043 & $0.0030 *$ & $0.0047 * * *$ \\
\hline D * Log(TX Dmg: Lag 6) & 0.0003 & -0.0030 & 0.0019 & $0.0074 * *$ \\
\hline $\mathrm{D} * \log (\mathrm{LA}$ Dmg $)$ & $0.0051 *$ & $0.0062 * *$ & $0.0072 * * *$ & $0.0078 * * *$ \\
\hline D * Log(LA Dmg: Lag 1) & $0.0063 * * *$ & $0.0074 * *$ & $0.0062 * * *$ & $0.0089 * * *$ \\
\hline D * Log(LA Dmg: Lag 2) & $0.0086 * * *$ & $0.0091 * * *$ & $0.0096 * * *$ & $0.0162 * * *$ \\
\hline D * Log(LA Dmg: Lag 3) & 0.0019 & -0.0035 & $0.0039 * * *$ & $0.0055 * *$ \\
\hline D * Log(LA Dmg: Lag 4) & -0.0006 & $0.0058 * * *$ & $0.0040 * * *$ & $0.0166 * * *$ \\
\hline D * Log(LA Dmg: Lag 5) & 0.0013 & 0.0005 & 0.0014 & $0.0028 *$ \\
\hline D * Log(LA Dmg: Lag 6) & -0.002 & $0.0068 * * *$ & -0.0002 & $0.0093 * * *$ \\
\hline Constant & -1.8269 & 1.3149 & -0.6311 & -0.2052 \\
\hline R-squared & 0.607 & 0.6529 & 0.6179 & 0.6479 \\
\hline N. of observations & 3096 & 2838 & 8772 & 8256 \\
\hline
\end{tabular}

Notes: $* \mathrm{p}<0.10, * * \mathrm{p}<0.05$, $* * * \mathrm{p}<0.010$. In column 1 , only property damages from LA and TX are used on the right-hand side. In column 2, property damages in LA, TX, FL, AL, and MS are used. Coefficient estimates for variables associated with LA, TX, and FL are omitted from the table as they are not the paper's main interest. 
Table 2.C3. Estimation results when property damages from TX \& LA vs. all Gulf states are considered: Scenario 3 Northeast and Midwest

\begin{tabular}{|c|c|c|c|c|}
\hline & $\begin{array}{l}\text { Northeast } \\
\text { (TX\&LA) }\end{array}$ & $\begin{array}{l}\text { Northeast } \\
\text { (All } 5 \text { Gulf States) }\end{array}$ & $\begin{array}{l}\text { Midwest } \\
\text { (TX\&LA) }\end{array}$ & $\begin{array}{l}\text { Midwest } \\
\text { (All } 5 \text { Gulf States) }\end{array}$ \\
\hline Achieved RPS obligation & -0.0731 & -0.0484 & 0.0033 & 0.0118 \\
\hline Gulf Coast production share & $-1.0452 * * *$ & $-0.7790 * * *$ & $-0.9679 * * *$ & $-0.6286 * *$ \\
\hline Cooling degree days & $0.0004 * * *$ & $0.0003 * *$ & $0.0004 * * *$ & $0.0004 * * *$ \\
\hline Heating degree days & $0.0001 * * *$ & $0.0001 * * *$ & $0.0001 * * *$ & $0.0001 * * *$ \\
\hline $\log ($ State GDP $)$ & 0.0293 & 0.0463 & 0.0938 & 0.0704 \\
\hline VIX first difference & $0.0679 *$ & 0.0616 & -0.0063 & -0.0477 \\
\hline Log(Oil price) & $0.5303 * * *$ & $0.5013 * * *$ & $0.4229 * * *$ & $0.4219 * * *$ \\
\hline $\mathrm{D}(=1$ if $Y$ ear $\geq 2010)$ & -0.2642 & -0.1616 & $-0.3696 * * *$ & $-1.0922 * * *$ \\
\hline Log(In-state Dmg) & -0.0013 & -0.0012 & -0.0001 & 0.0000 \\
\hline Log(In-state Dmg: Lag 1) & 0.0010 & 0.0005 & -0.0003 & 0.0005 \\
\hline Log(In-state Dmg: Lag 2) & -0.0001 & -0.0002 & -0.0007 & -0.0001 \\
\hline Log(In-state Dmg: Lag 3) & -0.0028 & $-0.0030 *$ & -0.0003 & -0.0001 \\
\hline $\log ($ TX Dmg) & $0.0090 * * *$ & 0.0038 & $0.0111 * * *$ & $0.0079 * * *$ \\
\hline Log(TX Dmg: Lag 1) & $0.0150 * * *$ & $0.0109 * * *$ & $0.0095 * * *$ & $0.0074 * * *$ \\
\hline Log(TX Dmg: Lag 2) & $0.0071 * * *$ & 0.0014 & 0.0010 & $-0.0025 * *$ \\
\hline Log(TX Dmg: Lag 3) & $0.0084 * * *$ & $0.0046 * *$ & -0.0019 & $-0.0045 * * *$ \\
\hline Log(TX Dmg: Lag 4) & -0.0006 & $-0.0047^{*}$ & $-0.0061 * * *$ & $-0.0101 * * *$ \\
\hline Log(TX Dmg: Lag 5) & $-0.0056 * * *$ & $-0.0113 * * *$ & $-0.0082 * * *$ & $-0.0116 * * *$ \\
\hline Log(TX Dmg: Lag 6) & $-0.0091 * * *$ & $-0.0145 * * *$ & $-0.0159 * * *$ & $-0.0222 * * *$ \\
\hline $\log ($ LA Dmg) & $-0.0046 * * *$ & -0.0029 & $-0.0048 * * *$ & $-0.0029 * *$ \\
\hline Log(LA Dmg: Lag 1) & $-0.0032 *$ & -0.0021 & $0.0032 * *$ & $0.0065 * * *$ \\
\hline Log(LA Dmg: Lag 2) & $-0.0033 * * *$ & $-0.0063 * * *$ & 0.0011 & -0.0006 \\
\hline Log(LA Dmg: Lag 3) & 0.0026 & $-0.0030 *$ & $0.0058 * * *$ & $0.0037 * * *$ \\
\hline Log(LA Dmg: Lag 4) & 0.0018 & 0.0010 & $0.0067 * * *$ & $0.0068 * * *$ \\
\hline Log(LA Dmg: Lag 5) & $0.0065 * * *$ & $0.0044 * * *$ & $0.0110 * * *$ & $0.0118 * * *$ \\
\hline Log(LA Dmg: Lag 6) & $0.0085 * * *$ & $0.0068 * * *$ & $0.0142 * * *$ & $0.0142 * * *$ \\
\hline D * Log(In-State Dmg) & 0.0011 & -0.0003 & 0.0005 & -0.0015 \\
\hline D * Log(In-State Dmg: Lag 1) & -0.0011 & -0.0006 & 0.0016 & -0.0001 \\
\hline D * Log(In-State Dmg: Lag 2) & -0.0003 & -0.0003 & 0.0000 & -0.0007 \\
\hline D * Log(In-State Dmg: Lag 3) & 0.0029 & 0.0040 & -0.004 & -0.0014 \\
\hline $\mathrm{D} * \log (\mathrm{TX}$ Dmg $)$ & $-0.0097 * * *$ & $-0.0108 * * *$ & $-0.0158 * * *$ & $-0.0169 * * *$ \\
\hline D * Log(TX Dmg: Lag 1) & $-0.0170 * * *$ & $-0.0138 * * *$ & $-0.0158 * * *$ & $-0.0139 * * *$ \\
\hline D * Log(TX Dmg: Lag 2) & $-0.0072 * *$ & $-0.0077 * *$ & $-0.0030 *$ & $-0.0035^{* *}$ \\
\hline D * Log(TX Dmg: Lag 3) & $-0.0088 *$ & $-0.0117 *$ & -0.0017 & -0.0009 \\
\hline D * Log(TX Dmg: Lag 4) & 0.0004 & 0.0007 & $0.0098 * * *$ & $0.0062 * * *$ \\
\hline D * Log(TX Dmg: Lag 5) & $-0.0059 *$ & 0.0017 & $0.0084 * * *$ & $0.0056 * * *$ \\
\hline D * Log(TX Dmg: Lag 6) & -0.0033 & 0.0052 & $0.0095 * * *$ & $0.0128 * * *$ \\
\hline $\mathrm{D} * \log (\mathrm{LA} \mathrm{Dmg})$ & $0.0064 * * *$ & 0.0025 & $0.0066 * * *$ & $0.0082 * * *$ \\
\hline D * Log(LA Dmg: Lag 1) & $0.0098 * * *$ & $0.0119 * * *$ & 0.0015 & 0.0015 \\
\hline $\mathrm{D} * \log (\mathrm{LA}$ Dmg: Lag 2) & $0.0101 * * *$ & $0.0217 * * *$ & $0.0061 * * *$ & $0.0097 * * *$ \\
\hline D * Log(LA Dmg: Lag 3) & 0.0031 & $0.0138 * * *$ & 0.0002 & -0.0020 \\
\hline D * Log(LA Dmg: Lag 4) & $0.0059 * * *$ & $0.0209 * * *$ & $-0.0038 * *$ & 0.0022 \\
\hline $\mathrm{D} * \log (\mathrm{LA}$ Dmg: Lag 5) & 0.0047 & $0.0075 * *$ & $-0.0050 * * *$ & -0.0022 \\
\hline D* Log(LA Dmg: Lag 6) & 0.0035 & $0.0135 * * *$ & $-0.0067 * * *$ & 0.0035 \\
\hline Constant & -0.3627 & -0.7143 & -0.7822 & -0.5811 \\
\hline R-squared & 0.5964 & 0.6397 & 0.6265 & 0.6616 \\
\hline N. of observations & 2580 & 2580 & 2838 & 2838 \\
\hline
\end{tabular}

Notes: $* \mathrm{p}<0.10, * * \mathrm{p}<0.05$, $* * * \mathrm{p}<0.010$. In column 1 , only property damages from LA and TX are used on the right-hand side. In column 2, property damages in LA, TX, FL, AL, and MS are used. Coefficient estimates for variables associated with LA, TX, and FL are omitted from the table as they are not the paper's main interest. 
Table 2.C4. Estimation results when property damages from TX \& LA vs. all Gulf states are considered: Scenario 3 West and South

\begin{tabular}{|c|c|c|c|c|}
\hline & $\begin{array}{l}\text { West } \\
\text { (TX\&LA) }\end{array}$ & $\begin{array}{l}\text { West } \\
\text { (All 5) }\end{array}$ & $\begin{array}{l}\text { South } \\
(\mathrm{TX \& LA})\end{array}$ & $\begin{array}{l}\text { South } \\
\text { (All 5) }\end{array}$ \\
\hline Achieved RPS obligation & -0.0519 & -0.0397 & 0.0015 & -0.0074 \\
\hline Gulf Coast production share & $-1.5889 * * *$ & $-1.3656 * * *$ & $-0.8968 * * *$ & $-1.0000 * * *$ \\
\hline Cooling degree days & -0.0001 & -0.0001 & 0.0000 & 0.0001 \\
\hline Heating degree days & $0.0002 * * *$ & $0.0002 * * *$ & $0.0001 * *$ & $0.0001 * *$ \\
\hline $\log ($ State GDP $)$ & -0.0257 & -0.1523 & 0.3026 & -0.0416 \\
\hline VIX first difference & 0.0378 & 0.0236 & $0.0634 * * *$ & $0.0905 * * *$ \\
\hline Log(Oil price) & $0.5051 * * *$ & $0.5241 * * *$ & $0.4345 * * *$ & $0.4660 * * *$ \\
\hline $\mathrm{D}(=1$ if $Y$ ear $\geq 2010)$ & -0.0058 & -0.3969 & $-0.6263 * * *$ & -0.425 \\
\hline Log(In-state Dmg) & -0.0001 & 0.0001 & $0.0033 * *$ & $0.0034 *$ \\
\hline Log(In-state Dmg: Lag 1) & 0.0002 & 0.0007 & 0.0001 & -0.0006 \\
\hline Log(In-state Dmg: Lag 2) & -0.0012 & -0.0009 & 0.0015 & 0.001 \\
\hline Log(In-state Dmg: Lag 3) & $-0.0019 *$ & $-0.0017 *$ & $0.0027 * *$ & 0.0008 \\
\hline $\log ($ TX Dmg) & $0.0070 * * *$ & $0.0050 * * *$ & $0.0077 * * *$ & $0.0074 * * *$ \\
\hline Log(TX Dmg: Lag 1) & $0.0098 * * *$ & $0.0085 * * *$ & $0.0098 * * *$ & $0.0099 * * *$ \\
\hline Log(TX Dmg: Lag 2) & $0.0088 * * *$ & $0.0058 * * *$ & $0.0052 * * *$ & 0.0003 \\
\hline Log(TX Dmg: Lag 3) & $0.0058 * * *$ & 0.0020 & 0.0009 & $-0.0047 * *$ \\
\hline Log(TX Dmg: Lag 4) & 0.0010 & $-0.0037 * *$ & -0.0013 & $-0.0059 * * *$ \\
\hline Log(TX Dmg: Lag 5) & -0.0023 & $-0.0070 * * *$ & $-0.0086 * * *$ & $-0.0123 * * *$ \\
\hline Log(TX Dmg: Lag 6) & $-0.0093 * * *$ & $-0.0148 * * *$ & $-0.0082 * * *$ & $-0.0118 * * *$ \\
\hline $\log (\mathrm{LA} \mathrm{Dmg})$ & -0.0016 & 0.0000 & $-0.0035^{* *}$ & $-0.0044 * * *$ \\
\hline Log(LA Dmg: Lag 1) & -0.0023 & -0.0029 & 0.0012 & $0.0026 * *$ \\
\hline Log(LA Dmg: Lag 2) & $-0.0030 * *$ & $-0.0039 * *$ & -0.0013 & $-0.0029 *$ \\
\hline Log(LA Dmg: Lag 3) & 0.0018 & -0.0008 & $0.0027 * * *$ & 0.0006 \\
\hline Log(LA Dmg: Lag 4) & $0.0031 *$ & 0.0029 & $0.0029 * * *$ & 0.0008 \\
\hline Log(LA Dmg: Lag 5) & $0.0052 * * *$ & $0.0045 * *$ & $0.0085 * * *$ & $0.0089 * * *$ \\
\hline Log(LA Dmg: Lag 6) & $0.0092 * * *$ & $0.0093 * * *$ & $0.0090 * * *$ & $0.0052 * * *$ \\
\hline D * Log(In-State Dmg) & -0.0007 & -0.0021 & -0.0045 & -0.0072 \\
\hline D * Log(In-State Dmg: Lag 1) & 0.0000 & -0.0012 & -0.0030 & -0.0045 \\
\hline D * Log(In-State Dmg: Lag 2) & $0.0033^{*}$ & $0.0028 *$ & -0.0017 & -0.0048 \\
\hline D * Log(In-State Dmg: Lag 3) & 0.0016 & 0.0021 & -0.0059 & -0.0059 \\
\hline $\mathrm{D} * \log (\mathrm{TX}$ Dmg $)$ & $-0.0110 * * *$ & $-0.0151 * * *$ & $-0.0091 * * *$ & $-0.0150 * * *$ \\
\hline D * Log(TX Dmg: Lag 1) & $-0.0171 * * *$ & $-0.0147 * * *$ & $-0.0097 * * *$ & $-0.0110 * * *$ \\
\hline D * Log(TX Dmg: Lag 2) & $-0.0140 * * *$ & $-0.0143 * * *$ & -0.0034 & -0.0008 \\
\hline D * Log(TX Dmg: Lag 3) & $-0.0105 * * *$ & $-0.0116 * * *$ & 0.0007 & 0.0054 \\
\hline D * Log(TX Dmg: Lag 4) & -0.0021 & $-0.0066^{* * *}$ & $0.0038^{*}$ & 0.0042 \\
\hline D * Log(TX Dmg: Lag 5) & -0.0023 & -0.0033 & $0.0040 *$ & 0.0026 \\
\hline D * Log(TX Dmg: Lag 6) & -0.0013 & 0.0021 & -0.0004 & -0.0046 \\
\hline $\mathrm{D} * \log (\mathrm{LA} \mathrm{Dmg})$ & 0.0036 & $0.0050 * *$ & $0.0093 * * *$ & $0.0132 * * *$ \\
\hline $\mathrm{D} * \log (\mathrm{LA}$ Dmg: Lag 1$)$ & $0.0088 * * *$ & $0.0117 * * *$ & $0.0063 * * *$ & $0.0083^{* * *}$ \\
\hline $\mathrm{D} * \log (\mathrm{LA}$ Dmg: Lag 2$)$ & $0.0109 * * *$ & $0.0115 * * *$ & $0.0104 * * *$ & $0.0144 * * *$ \\
\hline D * Log(LA Dmg: Lag 3) & $0.0051 * * *$ & 0.0037 & $0.0041 * * *$ & -0.0034 \\
\hline D * Log(LA Dmg: Lag 4) & $0.0050 * * *$ & $0.0159 * * *$ & $0.0027 * * *$ & $0.0122 * * *$ \\
\hline D * Log(LA Dmg: Lag 5) & $0.0054 * * *$ & $0.0068 * * *$ & 0.0003 & $-0.0034 *$ \\
\hline D * Log(LA Dmg: Lag 6) & -0.0017 & $0.0054 * *$ & 0.0006 & $0.0124 * * *$ \\
\hline Constant & 0.3061 & 1.5498 & -3.3972 & 0.4420 \\
\hline R-squared & 0.6360 & 0.6690 & 0.6521 & 0.6830 \\
\hline N. of observations & 2838 & 2838 & 3612 & 2838 \\
\hline
\end{tabular}

Notes: $* \mathrm{p}<0.10, * * \mathrm{p}<0.05$, $* * * \mathrm{p}<0.010$. In column 1 , only property damages from LA and TX are used on the right-hand side. In column 2, property damages in LA, TX, FL, AL, and MS are used. Coefficient estimates for variables associated with LA, TX, and FL are omitted from the table as they are not the paper's main interest. 


\section{Chapter 3}

\section{Do Exploitations of Marcellus and Utica Shale Formations Improve Regional Economy in Ohio, Pennsylvania, and West Virginia? A Synthetic Control Analysis}

\subsection{Introduction}

In the late 1990s, the oil and gas industry in the United States (US) began to combine horizontal drilling and hydraulic fracturing techniques for commercial drilling in the Barnett shale play across the south-central states (Jacquet et al. 2018). Employment in the oil and gas sector started to rise in the early 2000s (Rickman and Wang 2020), with the production from shale plays in Colorado, Texas, and Wyoming underwent significant increases in subsequent years (Weber 2012). Not long after the initial success in the south-central US, the first natural gas well was drilled in the Marcellus play, which underlies parts of New York, Pennsylvania, Ohio, West Virginia, Maryland, and Virginia (IER, 2012). Following the success in the Marcellus play, wells were drilled in the Utica shale play, which lies under the Marcellus play in a much deeper stratum but contains a massive natural gas reserve (King 2019).

Most of the shale drilling activities in the Marcellus and Utica plays have taken place in Ohio (OH), Pennsylvania (PA), and West Virginia (WV). Although nationally, the shale boom started in the mid-2000s, natural gas production in these states did not begin to take off in the late 2000s (Figure 1). Figure 2 shows that the combined output from Marcellus and Utica plays accounted for only $1 \%$ of total shale gas production in November 2008, reaching $3 \%$ in August 2009 and over 5\% in April 2010. By the end of 2018, the monthly natural gas withdrawals in PA had reached a record of $450 \mathrm{Mmcf}$ (million cubic feet). Further calculation suggests that the average monthly natural gas production has increased by $889 \%, 2,174 \%$, and $393 \%$ from the preshale era (2002-2009) to the shale boom period (2010-2018) in OH, PA, and WV, receptively. In 
2018, about $69 \%$ of the total US natural gas production came from dry shale gas production, of which $43.7 \%$ was produced from the Marcellus and Utica plays (EIA, 2019a).

Natural resource extractions can create negative externalities to local communities such as air and water pollutions, forest and habitat fragmentation, property value declines, etc. Residents often expect drilling activities to generate economic benefits that could compensate for these negative impacts on the surrounding environments and communities (Sangaramoorthy et al. 2016; Jacquet et al. 2018). However, previous studies suggest that regions with abundant natural resources may suffer from a "natural resource curse" and "Dutch Disease" due to crowding-out effects on other industries (Rickman and Wang 2020). Moreover, energy development may increase the opportunity cost of education and reduce educational attainment (Rickman, Wang, and Winters 2017). From a policy perspective, it is essential to determine if the recent shale boom, one of the most important innovations in the US energy sector in the past few decades (Brown, 2014), indeed positively impacts the shale-producing regions. Such examinations also provide policymakers with the necessary information to evaluate/update the existing extractions-related regulations and incentive programs (Weber 2012).

The present paper aims to comprehensively assess the economic benefits of shale development to the Appalachian region in the United States, focusing on three states: Ohio, West Virginia, and Pennsylvania. Although various studies have assessed the economic and social impacts of shale development on states and counties with extensive drilling activities, the majority of these studies on Marcellus and Utica shale plays have focused on Pennsylvania, perhaps due to its relatively early drilling activities, growing significance in the natural gas industry, closer proximity to several large population centers, and a relatively larger-sized economy compared to the other two states. Although some previous studies on Marcellus and Utica plays do include $\mathrm{OH}$ and $\mathrm{WV}$, these analyses focus on the average impact in the region (e.g., Feyrer, Mansur, and Sacerdote (2017), Gittings and Roach (2020). Despite their rising shale production, less attention has been paid to the economic impact of shale development in $\mathrm{OH}$ and $\mathrm{WV}$, whose proved shale gas reserves in 2018 ranked \#5 and \#3 in the US, respectively (EIA, 2019b). Given the differences in demographic trends, economic structure, tax policies on oil and gas drilling, and geographic distribution of shale production in the Appalachia region, there is a clear need to examine the economic impacts of shale development in $\mathrm{OH}$ and $\mathrm{WV}$ separately. 
Furthermore, of the studies that evaluated the economic significance of the shale boom, the predominant approaches used in the literature are input-output (IO) models and the difference-in-differences (DiD) estimator. Kinnaman (2011) questions the validity of some of the assumptions used in IO studies and cautions that the positive economic impacts of shale gas extractions based on IO models may be overestimated. The conventional DID approach is criticized for its reliance on the researchers' subjective judgments when selecting the control group (Munasib and Rickman 2015). Further, the DiD approach assigns equal weight to all cross-sectional units in the comparison group (O’Neill et al. 2016), which may lead to biased estimates if some control units present greater similarities with the intervention than others.

In the present paper, we alternatively use the synthetic control method (SCM) of Abadie, Diamond, and Hainmueller (2010) to analyze the economic impact of the shale boom on the Marcellus and Utica Shale plays. The SCM overcomes some drawbacks associated with the IO and DiD approach by assigning heterogeneous weights to units in the control group and taking account of both positive and negative impacts of shale production impacts (Munasib and Rickman 2015). We consider several metrics, including employment growth, income growth, poverty rate, and population growth in $\mathrm{OH}, \mathrm{PA}$, and WV. Furthermore, we evaluate if the three states where shale production started later than other oil and gas states also suffer from the 20142016 energy price decline and industry bust found in Rickman and Wang (2020).

Using data from 2002 to 2017, we compare the economic outcomes in top oil and gas counties in $\mathrm{PA}, \mathrm{OH}$, and WV with their synthetic counterparts. We find that the shale boom has increased employment and income growth, and decreased the poverty rate in oil and gas counties in PA and WV in the short run. However, it has decreased the population growth in oil and gas regions in all three states, and this negative effect strengthens in the long run. For $\mathrm{OH}$, the shale development lowered population growth in the drilling counties, and failed to generate any significant positive impacts on other economic indicators. Given the heterogeneous results found for the three states, state-specific policies and regulations are needed to promote the continuing growth of and maximize the benefits from the shale industry.

The remainder of the paper is organized as follows. In section two, we review the relevant literature on the impact of shale development in the US. Sections three and four discuss 
the empirical method and data, respectively. Estimation results are presented in section five. The last section concludes the paper.

\subsection{Impact of Marcellus and Utica shale development}

Increased drilling activities and shale gas development have been shown to generate positive economic effects (such as income, employment, economic growth, etc.) to regions that experienced the boom (e.g., Agerton et al. 2017; Brown 2014; Munasib and Rickman 2015; Weber 2014, 2012), as well as to regions nearby (e.g., Feyrer, Mansur, and Sacerdote 2017) and related industries (Tsvetkova and Partridge 2016). For instance, Feyrer, Mansur, and Sacerdote (2017) find that regions within 100 miles of fracking retains approximately one-third of the new shale production revenue. James and Smith (2020) note that after excluding the potential overlapped inward spillover effects from nearby producing counties, the US fracking counties generated overall positive economic spillover effects to surrounding counties within 60 to 80 miles. Jacobsen (2019) finds that some shale counties experienced a rise in properties following the boom. However, along with the positive impacts, fracking also created negative externalities to shale-producing regions. Some of these externalities discussed in the literature include, among others, increased crime rate rising noise level, disruption to the wildlife, threats to the environment and health, and negative impacts on residents' well-beings and college completion rates (e.g., Jackson et al. 2013; James and Smith 2017; Komarek 2018; Lim 2018; Maguire and Winters 2017; Rich, Grover, and Sattler 2014; Rickman, Wang, and Winters 2017). Overall, results from the existing literature suggest that a comprehensive approach that accounts for various aspects of the economy is needed when evaluating the net impacts of shale development.

As noted in the previous section, studies on the shale boom in the Marcellus and Utica plays have predominately focused on PA (e.g., Hoy, Kelsey, and Shields 2017; Munasib and Rickman 2015; Considine, Watson, and Blumsack 2010; Hardy and Kelsey 2015). The existing

literature has paid relatively scant attention to the economic impacts of shale development in $\mathrm{OH}$ and WV, the two neighboring states of PA that have also experienced a dramatic shale boom over the past decade. As can be seen in figure 3.3, the geographic distribution of the coal and natural gas-producing counties in $\mathrm{OH}$ and WV differ significantly from that in PA-while the 
top gas-producing counties in $\mathrm{OH}$ and WV are within the 16-mile range (the average one-way commute distance for American workers) of or are overlapping with the coal counties, natural gas production is more spread apart throughout PA. The three states also differ significantly in demographic trends and economic structure (as discussed in the data section).

Furthermore, although there have been proposals to impose common shale taxation in the region, the three states differ in the tax policies toward oil and gas industries. For instance, severance taxes in WV are mainly determined by the gross value of energy, with the rate ranking in the middle range of the gas-producing states in the US (Kolesnikoff and Brown 2018). By contrast, $\mathrm{OH}$ imposes a production-based severance tax, which is considerably lower than that of WV. In PA, there was no extraction tax until 2012 when a small drilling impact fee (based on numbers and ages of wells, and energy prices) was imposed. ${ }^{10}$ Given the increasing importance of WV and $\mathrm{OH}$ in the US natural gas industry and the differences in demographic trends, economic structure, taxation policies, and geographic distribution of shale production, there is a clear need to examine the economic impacts of shale development in the two states.

Some studies on Marcellus and Utica plays include $\mathrm{OH}$ and WV. However, these analyses tend to focus on the average impact of fracking in the region, without considering the potential heterogeneous effects of drilling activities in the area. For instance, Paredes, Komarek, and Loveridge (2015) and Gittings and Roach (2020) show that shale development generates significant employment, but minimal income or spillover effects in the Marcellus play. Betz et al. (2015) fail to find evidence of a natural resource curse in the Appalachian region. Meanwhile, Komarek (2016) notes that fracking generated positive spillover effects to construction, transportation, and retail sectors in the area. Hoy et al. (2018) find shale gas development to exert little impact on agriculture in Marcellus drilling counties. However, the average effect found in these studies, as well as those in some nationwide studies (e.g., Feyrer, Mansur, and Sacerdote 2017; James and Smith 2020), may fail to represent the net impacts of fracking in $\mathrm{OH}$ and WV.

Of the few studies focusing on $\mathrm{OH}$ and WV's shale activities, the analyses are overall confined to the negative externalities of drilling on local communities. These include, among others, the quality of life, health of residents, inequality, and other environmental and social

\footnotetext{
${ }^{10}$ See http://www.multistateshale.org/three-state-severance-tax for further discussions, accessed on 4/19/2021.
} 
issues (e.g., Collins and Nkansah 2015; Fershee 2012; Sangaramoorthy et al. 2016; Willow 2014; Ogneva-Himmelberger and Huang 2015). In WV, Fershee (2012) finds that the wastewater from hydraulic fracturing poses potential environmental and health threats to residents in the state. Ogneva-Himmelberger and Huang (2015) note that a large portion of drilling activities in WV took place in regions with a high poverty rate, an aging population, and poor education outcomes, leading to further inequality issues for economically disadvantaged communities. These views are echoed in Sangaramoorthy et al. (2016), who contend that residents in WV often view fracking as economically beneficial but negatively affects health, environmental, and social outcomes in the region. Additionally, WV residents are concerned that a large proportion of the profits and benefits from extractions are acquired by out-of-state companies and workers, while most of the torments are suffered by residents (Fershee 2012).

In Ohio, Willow (2014) indicates that residents are concerned about the negative effect of drilling on health, water, and air quality. Residents in two Ohio fracking counties showed a lower level of psychological health due to fracking operations, some of whom were forced to tolerate or move away (Fisher et al. 2018). Jacquet et al. (2018) survey residents at four Ohio counties with either high existing or potential shale development, finding that participants overall have a positive attitude toward shale development. Although survey respondents are concerned about the adverse health and environmental impacts of shale development, those in counties with ongoing coal mining activities believe that the potential economic benefits would outweigh these health and environmental harms (Jacquet et al. 2018).

On the methodological front, a common approach used in the literature to analyze the impacts of shale development on regional economic outcomes is the input-output (IO) model. For instance, Considine et al. (2009) contend that spending by the shale gas extraction industry generated over $\$ 2$ billion in economic activities, almost 30,000 jobs, and approximately $\$ 238.5$ million in state and local taxes in PA in 2008. In an updated study, the same authors estimate that the economic impact of shale production to rise to $\$ 18.85$ billion in value-added, $\$ 1.87$ billion in state and local taxes, and about 212,000 jobs for PA in 2020 (Considine, Watson, and Blumsack 2010). Higginbotham et al. (2010) show that Marcellus shale development created almost 10,000 jobs for the energy sector in 2009. Michaud (2018) finds that in 2015 the shale industry contributed 23.34 billion to OH's economy and created 86,000 jobs. 
However, Brown, Weber, and Wojan (2013) argue that the estimated economic impacts of natural gas extractions based on IO models generally exceed the actual impacts due to three potential reasons. First, many IO models often ignore the crowding-out effect of drilling to other industries in the region; for example, the expansion of the shale sector may increase truck drivers' wages, negatively affecting other industries. Second, technology changes and innovations such as labor-saving methods usually are not reflected in IO models. Third, the industry expenditures accounted for in the IO models may be overestimated because part of the expenditures may go to the businesses outside the study region. Furthermore, Munasib and Rickman (2015) contend that IO models often overlook the potential adverse impacts of shale development in the region, leading to an upward bias in the estimation results. Empirically, Weber (2012) shows that the economic effects of Fayetteville and Marcellus shale plays based on IO models may be excessively large; in particular, the estimated job multipliers are sometimes well above the results found from other empirical models, since they rely on static assumptions and use only pre-intervention data to provide ex-ante projections.

Another common approach used in the empirical literature is the difference-in-differences (DiD) estimator, in which the effect of an exogenous change is estimated by comparing the outcomes of the treatment and control groups. However, the DiD method is often criticized for overstating the significance of an intervention (Bertrand, Duflo, and Mullainathan 2003), as well as the reliance on the researcher's subjective judgment when selecting the control or the comparison group (Munasib and Rickman 2015). Further, the standard DiD model assumes that the treatment and comparison groups trend together over time in the absence of the intervention, which can be problematic when there exist unobserved confounding factors and time-varying effects (Ryan, Burgess, and Dimick 2015). For instance, Cosgrove (2014) shows that fracking significantly improved economic outcomes in PA using counites in its neighboring state NY as the comparison group in DiD. Using border counties in a neighboring state as the control is fairly reasonable because 1) the outcome of the treatment and comparison groups likely trend together over time in the absence of an intervention, and 2) the treatment is subject to minimal unobserved confounding factors. However, most oil and gas counties in $\mathrm{OH}$ and $\mathrm{WV}$ are located at the border of the two states, making it impossible to find appropriate comparison groups that are not subject to the shale boom. Furthermore, the DiD approach assigns equal weight to all 
cross-sectional units in the comparison group (O’Neill et al. 2016), which may lead to biased estimates if some control units present greater similarities with the intervention than others.

Some studies analyze the impact of oil and gas development on employment and income using other econometric methods. For instance, Wang (2020) uses instrumental variable (IV) models to demonstrate that unconventional oil and gas development directly increased employment and income in the Permian Basin. Gittings and Roach (2020) find a positive relationship between oil and gas production value and employment in the counties exposed to Marcellus and Utica plays using OLS and IV approaches. A panel-fixed effects regression approach is adopted in Paredes, Komarek, and Loveridge (2015) and Feyrer, Mansur, and Sacerdote (2017).

In this study, we instead use the synthetic control method (SCM) to estimate the economic impacts of the shale boom in the Appalachian area, focusing on $\mathrm{OH}, \mathrm{PA}$, and WV. Compared to the IO approach, the SCM considers both positive and negative economic impacts, allowing for a more accurate estimation of the net impacts of shale development on various economic indicators. Furthermore, the SCM does not require the researchers to make many of the (sometimes problematic) assumptions as in IO models. Unlike the DiD estimator, the SCM assigns heterogeneous weights to units in the control group based on their similarities with the treatment using a data-driven approach, thus relaxing the restrictive parallel trend assumption of DiD (O’Neill et al. 2016; McClelland and Gault 2017). Compared to regression methods, the weighted average nature of SCM estimators and the sparsity of the optimal weights allow us to interpret the estimated counterfactuals in a straightforward manner (Abadie, Diamond, and Hainmueller 2015).

Two previous studies that estimate the net economic impacts of the shale boom on local economies using SCM include Munasib and Rickman (2015) and Rickman and Wang (2020). Munasib and Rickman (2015) find shale development to have generated mixed but overall positive impacts on population, income, employment, and poverty rate in shale-rich counties of Arkansas, North Dakota, and Pennsylvania. Rickman and Wang (2020) examine the effects of energy price booms and busts on top oil and gas producing states, including Louisiana, North Dakota, Oklahoma, and Wyoming. They find oil and gas development overall generated a 
positive long-run income effect in these states. However, neither studies consider Ohio or West Virginia, two shale-producing states with rising importance in the energy market.

\subsection{Empirical Methods}

The synthetic control method was first proposed by Abadie, Diamond, and Hainmueller (2010) to estimate the treatment effect of Proposition 99, a California tobacco control program implemented in 1988. Using a data-driven approach, it constructs a synthetic group based on units in the control group, to which the treatment group is compared. The outcome of the synthetic group, which approximates the characteristics of the treatment group in the pretreatment period, essentially represents what would have occurred to the treatment group if the treatment had not occurred. The SCM has since been used to analyze the impact of health policies (e.g., Kreif et al. 2016), natural disasters (e.g., Coffman and Noy 2012), regional policies (e.g., Gobillon and Magnac 2015), national monument (e.g., Jakus and Akhundjanov 2019), energy boom (e.g., Munasib and Rickman 2015), etc.

In our application, consider there exist $s+1$ aggregates of non-metropolitan counties (ANC) where the first ANC ( $s=1)$ experienced a shale boom (treatment) and the remaining ANCs $(s=2, \ldots S+1)$ did not. We follow Munasib and Rickman (2015) and construct treatment ANCs by aggregating top oil and gas non-metropolitan counties of $\mathrm{OH}, \mathrm{WV}$, and PA. Next, we construct donor ANCs, or the potential control units, by aggregating the nonmetropolitan counties of each non-boom state. The donor ANCs are further used to create a synthetic boom ANC that mimics the trajectory of the treatment ANC prior to the shale boom. The time periods considered in the analysis are denoted as $t=1, \ldots, T_{B} \ldots, T_{F}$, where $T_{B}$ is the year when the treatment or the shale boom occurred.

Let $Y_{s t}$ be the actual (observed) economic outcome (e.g., poverty rate) of ANC $s$ at time $t$. Let $Y_{s t}^{N}$ be the outcome for $s$ at time $t$ in the absence of shale gas boom. For the treatment ANC in the post-shale period, $Y_{s t}^{N}$ would be its economic output assuming the shale boom had not occurred. Let the binary variable $B_{s t}$ represent whether $s$ has experienced the shale boom. The observed economic outcome $Y_{s, t}$ can be written as: 


$$
Y_{s, t}=Y_{s, t}^{N}+B_{s, t} \alpha_{s, t},
$$

where $\alpha_{s, t}$ is the impact of the shale boom on the treatment ANC in the post-boom period. Abadie et al. (2010) suggest estimating $Y_{i, t}^{N}$ using a factor model:

$$
Y_{s, t}^{N}=\sigma_{t}+\beta_{t} Z_{s}+\lambda_{t} \mu_{s}+\varepsilon_{s, t},
$$

where $\sigma_{t}$ is an unknown common constant term across all ANCs at time $t, Z_{s}$ is a $(r \times 1)$ vector of observed covariates unaffected by the shale boom, $\beta_{t}$ is a $(1 \times r)$ vector of unknown parameters, $\mu_{s}$ is a $(F \times 1)$ vector of unobserved common factors, $\lambda_{t}$ is a $(1 \times F)$ vector of unknown common factor loadings, and $\varepsilon_{s, t}$ is the unobserved error term with zero mean.

We next construct a synthetic ANC by estimating an $(S \times 1)$ weighting vector $W=$ $\left(w_{2}, \ldots, w_{S+1}\right)^{\prime}$ that assigns weights to the donor ANCs. Following Abadie et al. (2010), we use the set of observed covariates (including both predictor and outcome variables) for all ANCs from the pre-boom period to match and find an optimal weighting vector $W^{*}=\left(w_{2}^{*}, \ldots, w_{S+1}^{*}\right)^{\prime}$. The $W^{*}$ is found by minimizing the discrepancy between an ANC's actual outcome $Y_{s, t}$ and synthetic outcome $Y_{s, t}^{N}$ in the pre-boom period. Detailed descriptions on estimating the weighting vector $W^{*}$ are documented in Abadie, Diamond, and Hainmueller (2010). The estimated impact of the boom on the shale ANC is then calculated as the difference between the actual outcome of the boom ANC and the outcome of the synthetic boom ANC in the post-boom period.

To determine the significance of the SCM results, we apply the placebo test by running the same model on each donor ANC, assuming it experienced the shale boom at the same time as the three treatment states. The single-year $p$-value for the treatment effect is defined as the proportion of placebo impacts for non-boom ANCs that exceed the estimated impact for the boom ANC in a given year. In other words, the proportion represents the probability that the estimated impact happened by chance and can be used to test the statistical significance of the SCM estimates (Galiani and Quistorff 2017). To evaluate the joint significance of the SCM estimates for the entire post-boom period, Abadie, Diamond, and Hainmueller (2010) suggest comparing the post-treatment outcome root mean square prediction error (RMSPE) of the treated ANC to the corresponding placebo RMSPEs in the post-treatment period. The joint $p$-value represents the proportion of placebo ANCs with a post-treatment outcome RMSPE equal or larger than those of the treated ANCs. As argued by Galiani and Quistorff (2017), this non- 
parametric approach of computing $\mathrm{p}$-value has the advantage that no assumption is needed for the distribution of the error term.

\subsection{Data}

We consider the non-metropolitan natural gas-producing counties in $\mathrm{PA}, \mathrm{OH}$, and WV that experienced the recent shale gas boom. These counties are likely to subject to fewer confounding factors where the economy is relatively small and the energy sector is relatively large (Weinstein 2019; Munasib and Rickman 2015). Following Munasib and Rickman (2015), we consider the top 4 and top 15 natural gas producing ANCs in the three states. In 2000-2011, the top 4 (15) counties accounted for $48 \%$ (91\%), 58\% (98\%), and $42 \%(91 \%)$ of total natural gas production in $\mathrm{OH}, \mathrm{PA}$, and $\mathrm{WV}$, respectively. The top 4 aggregation allows us to evaluate the direct impact of shale development on counties where most drilling activities took place. The top 15 aggregation, meanwhile, helps capture the potential effects of shale development on counties with different degrees of drilling intensiveness. ${ }^{11}$

The sample period spans from 2002 to 2017. We use the year 2009 to indicate when the shale gas boom occurred (treatment year). ${ }^{12}$ Previous studies suggest that the SCM results are not sensitive to small changes in the treatment year (Munasib and Rickman 2015; Rickman, Wang, and Winters 2017). For the donor pool, we start with the 30 non-energy states used in Rickman and Wang (2020) minus Ohio. We then remove New Jersey and Rhode Island from the donor pool because of the absence of non-metropolitan counties in these states. The final donor pool used consists of ANCs from 27 non-energy states in the US. ${ }^{13}$

We consider four outcome indicators: poverty rate, population growth, employment growth, and per capita personal income growth. Additional predictors used in constructing synthetic states are median household income, total wage growth, rural-urban code, natural

\footnotetext{
${ }^{11}$ We also consider top 3, top 5, top 10, and top 20 aggregations, whose results are qualitatively similar as the ones discussed in the paper. These results are available from the authors upon request.

${ }^{12}$ We also consider alternative treatment years, including 2008 and 2010. The results are qualitatively similar to those obtained using 2009 as the treatment year. These results are available from the authors upon request.

${ }^{13}$ The complete list of the donor pool includes ANCs from 27 non-energy states: AL, CA, CT, DE, FL, GA, IA, IL, IN, MA, MD, ME, MI, MN, MO, NC, NE, NH, NY, OR, SC, SD, TN, VA, VT, WA, and WI.
} 
amenities scale, percentages of employment in four sectors (agriculture, mining, manufacture, and retail), education levels, and median age. Rural-urban code classifies counties into 9 levels by their population and adjacency to a metro area, with a lower value indicating a more urbanized area. Natural amenity includes 7 levels, where a higher value indicates better environmental quality. The income, poverty rate, education level, rural-urban code, and natural amenities rank data are obtained from the Economic Research Service of the US Department of Agriculture. The population, median age, and employment by industry sector data are collected from the US Census.

All variables are computed as weighted averages based on the population. Due to data limitation, we use single-year data for rural-urban code (2003), natural amenities scale (1999), median age (2010), and education level (2000). However, due to changes in the population, these variables showed some small variations during the sample period. For all predictor variables, including the four outcome variables, the pre-boom period (2002 to 2009) average is used in the estimation. We also consider using the first, middle, and last year values of the outcome variable in the pre-boom period in the estimation, which generated similar results as using the average value of the outcome variable in the estimation.

Since the shale development period overlaps the 2008 Great Recession, it is difficult to completely discount the impact of the Great Recession from the observed treatment effect. In the estimation, we consider various predictor variables that allow the SCM to find the optimal synthetic for the treated region based on various characteristics. Given that the Great Recession affected all regions in the US (Deller and Watson 2016), the synthetic outcomes conducted using the non-energy donor pool should best mimic the scenario when the Great Recession occurred but shale development did not for the shale regions.

Table 3.1 presents the summary statistics of the predictor and outcome variables for the top 4 and 15 oil and gas ANCs in WV, OH, and PA, as well as the average across 27 donor ANCs during the pre-boom (2002-2009) and post-boom (2010-2017) periods. The economic and development indicators such as population, poverty rate, personal and household income, and graduation rates show that the top 4 and 15 oil and gas counties in WV all lag those of the same areas in $\mathrm{OH}$ and PA. The population growth is either stagnating or declining for the top oil and gas ANCs in the three states, whereas in the ANCs in the non-boom states, the population is 
overall rising. Furthermore, the three states' oil and gas ANCs show different levels of urbanization, with the most rural areas observed in WV and the most urban occurred for OH4. For natural amenities, the highest quality is observed in PA4, and the lowest in WV4, WV15, and $\mathrm{OH} 4$. The percentages of workers employed in the four sectors, especially in the manufacturing sector, show rather different industry structure in the three states.

Several interesting patterns emerge when comparing the numbers in the pre- and postboom periods. The percentages of mining employment increased in all three states' top 4 and top 15 oil and gas counties, while the population of all areas decreased in the post-boom period. Except for WV4, all other groups show an increase in poverty rates in the post-boom period. Interestingly, we find the income per capita increased in most oil and gas regions except for OH15 in the post-boom period. Overall, table 3.1 suggests that different demographic and socioeconomic patterns exist among the three states, highlighting the importance of empirically evaluating the impact of shale development on economic outcomes in specific regions.

\subsection{Empirical Results}

We estimate the impact of shale development on the four economic indicators: poverty rate, population growth, employment growth, and the growth rate of the per capita personal income in the top 4 and 15 oil and gas counties in PA, OH, and WV using the method described in section three. Figure 3.4 presents the weight matrices for the four outcome variables in each of the treated ANCs. As can be seen, only a sparse number of the ANCs is used when constructing the synthetic outcome. This is in sharp contrast to regression-based techniques (including DiD) where weights are placed on all possible control units. As an example, the employment growth of synthetic WV4 is calculated by the weighted average of actual total employment of the ANCs in MO, SD, VT, and WA, with the highest weights assigned to ANCs in VT and SD. For WV15 poverty rate, the highest weights are assigned to GA and VA ANCs. Given the geographic proximity between WV and VA, the ANCs in the two states likely share many similarities, which gives VA a high weight when constructing the synthetic outcome for WV indicators.

We apply the weight matrix to each corresponding outcome indicator and calculate their synthetic outcomes to obtain the SCM estimates of the shale effect. Before delving into the 
detailed estimation results, we follow Rickman and Wang (2020) to compare the synthetic control matching quality against the 27-ANC average in the donor pool, which is akin to the unweighted DiD. We calculate 1) the difference between the synthetic and actual values of the treated ANC, and 2) the difference between the 27-ANC average value and the actual value of the treated ANC. We then compute the percentage reduction in the two absolute differences for all outcome and predictor variables, as reported in table 3.2. A negative (positive) value indicates that the synthetic outcome is closer to (further away from) its actual outcome than the 27-ANC average. We further report the number of better matches made by SCM compared to the simple 27-ANC average for the 16 variables. As can be seen, the match quality for the synthetic groups performs at least as well as, and in most cases, outperforms the 27-ANC average.

Figures 3.5-3.7 plot the actual (solid line) and synthetic (dashed line) outcomes for various outcome indicators considered in the study. For comparison, we also plot the equalweighted outcomes based on the 27 donor ANCs (gray line). For most indicators, the 27-state average either do not trend together with the actual outcome or deviate further from the actual outcome than the synthetic outcome does in the pre-boom period.

For each SCM estimate of the shale effect obtained, we use the placebo test to check the statistical significance. Table 3.3 reports the pseudo $p$-values of the placebo test, or the proportion of donor states affected at least as much as the treatment ANCs by the shale boom for each outcome. As can be seen, the $p$-value for WV4 poverty rate is zero, suggesting high statistical significance as none of the donor state's poverty rate was affected as much as WV4 by the shale boom. For the other three WV4 indicators, the impact of the shale boom was at least as large as $85 \%$ of the donor states. In addition, the poverty rate in WV15 and PA4, the population growth in WV4, WV15, OH15, PA4, and PA15, the employment growth in WV4, WV15, PA4, and PA15, as well as personal income growth rate in WV4 and WV15 show statistical significance.

As a robustness check for our results, we implement the leave-one-out approach outlined in Abadie, Diamond, and Hainmueller (2015). Specifically, for each outcome variable, we drop the donor ANC which was assigned the highest weight from the donor pool and re-estimate the synthetic outcome. This procedure helps identify if an observed impact still exists when a dominant donor ANC is excluded. We repeat this procedure for five times (leave-five-out) and 
plot the synthetic (dot line) and actual outcomes (solid line) in the Appendix. Estimation results suggest that 1) most of the leave-one-out (up to leave-five-out) trends closely assemble the initial synthetic trend, 2) the estimated impacts are robust to the exclusion of dominant donor ANCs.

In the following sessions, we discuss the SCM results, focusing on the statistically significant indicators based on the placebo test. Further, we divide the post-boom period into two sub-periods (2010-2013 and 2014-2017) and report the average magnitude of impact during each sub-period, as well as during the entire post-boom period. Rickman and Wang (2020) find that the boom-and-bust cycle in the energy sector directly affects the local economy in oil and gasrich regions in $\mathrm{LA}, \mathrm{ND}, \mathrm{OK}$, and WY. In particular, they show that oil and gas employment declined significantly following the sharp energy price decline in 2014-2016. We evaluate whether a similar effect exists in the Marcellus and Utica shale plays.

\subsubsection{West Virginia}

Figures 3.5(a) and 3.5(b) present the estimation results for the poverty rate in WV4 and WV15, respectively. As can be seen, the actual and synthetic trends deviate in the early preboom period (2002-2005) but closely track each other in the later pre-boom episode (20062009). In the post-boom period, the trend for the actual poverty rate lies below its synthetic, suggesting that the poverty rate would have been higher if there were no shale development in these two regions. In table 3.4, we follow Jakus and Akhundjanov (2019) and Rickman and Wang (2020) report the average magnitudes of the impacts, or the difference between the synthetic and actual outcome. As can be seen, the average impacts on poverty rates of WV4 and WV15 are $-2.68 \%$ and $-0.58 \%$ in the entire post-boom period. The effect on WV4 is negative in both post-boom periods, while the impact on WV15 turns from negative (-0.70\%) to slightly positive $(0.05 \%)$ between the two episodes.

Consistent with the expectations of residents (Sangaramoorthy et al. 2016; Jacquet et al. 2018), our estimation results suggest that the increased drilling activities appear to have brought positive economic outcomes to the local communities by providing higher-paying job opportunities to lower-income residents, decreasing the poverty rate in oil and gas counties. This finding echoes the conclusion from previous studies such as Ogneva-Himmelberger and Huang (2015) who point out that a large portion of wells is clustered in high poverty regions in WV, as 
well as Higginbotham et al. (2010) who finds the Marcellus shale play to have created almost 10,000 jobs for the energy sector in 2009 alone. Alternatively, it may be possible that the shale boom increased the property values and living costs in drilling counties, forcing low-income households to move out of the boom counties and into areas with fewer drilling activities. The migration of low-income families may have decreased the poverty rate in WV4, while increasing the poverty rate in other regions. Indeed, Jacobsen (2019) finds that fracking increased house values and rental prices in boom areas in the US by $12.4 \%$ and $5.0 \%$, respectively.

However, the beneficial impact of the shale boom on the poverty rate appears to be of considerable small magnitude in WV15, which in fact disappeared in the latter post-boom period. The minimal impact of shale development on poverty rate in WV15 in the later boom period may be due to the post-2014 energy price decline and the boom-bust cycle in the energy sector. The lower government revenues from drilling, as well as the decreased incentive to drilling, may have limited the spillover effect of shale boom to counties with fewer drilling activities. This argument is consistent with the findings of Hardy and Kelsey (2015), who show that the economic benefits of shale drilling only benefited a small group of population in PA.

Figure 3.5 panels (c) and (d) plot the actual and synthetic population growth trends in WV4 and WV15. For both areas, the synthetic trend in the pre-boom period closely aligns with the actual trends, presenting a good pre-treatment match quality. The actual trend lies below the synthetic trend in the post-boom period, suggesting that the shale boom has decreased the population growth rate in these two regions. As shown in table 3.4, the negative impact of shale development on population growth has strengthened in both WV4 (-0.18 to -0.43) and WV15 ($0.20 \%$ to $-0.47 \%$ ) in the later post-boom period.

The negative impact of shale development on population growth is likely attributed to the outmigration due to higher property values, increased living costs, and other negative externalities associated with drilling activities. In addition to lower-income households, middleclass residents not actively engaged in the oil and gas sector may have also migrated out of the region due to the negative externalities and the lack of economic benefit from shale development. Results also indirectly echo the observation that many oil and gas workers are transient workers, instead of residents of the local communities as shown by the increased demand for hotel rooms in many shale-producing regions (Christopherson and Rightor 2012). 
Furthermore, shale development may have crowded out other sectors by increasing local wages and other input costs (Munasib and Rickman 2015). Indeed, table 3.1 shows that in both WV4 and WV15, the percentages of manufacture and retail employment decreased in the post-boom period while the mining employment increased. The lost jobs in other sectors may have led to outmigration and further population growth decline.

Evidence on the impact of the shale boom on employment growth (figures 3.5(e) and 3.5(f) and personal income per capita (figures 3.5(g) and 3.5(h)) in WV4 and WV15 is mixed. For both indicators, the actual and synthetic trends cross each other multiple times in the postboom period. Table 3.4 suggests that the average magnitudes of the effects were mostly positive in the early post-boom period, but turned negative in the later period. In addition to generating temporary jobs, increased drilling activities may produce spillover effects to downstream industries (e.g., service, financial, hotel, etc.), increasing the employment and income growth in oil and gas counties in the short run. As the drilling activities continue, however, it may crowd out other industries, leading to lower employment and income growth rates in oil and gas counties in the longer term. Since many of the oil and gas workers are commuters who tend to spend most of their income in places where they reside rather than where they work, the multiplier effect of increased drilling activities is likely to have declined over the years. Moreover, the 2014-2016 energy price decline and the boom-bust cycle in the energy sector (Rickman and Wang 2020) may have accelerated the exhaustion of short-term benefits in WV.

\subsubsection{Ohio}

The placebo test results indicate that the shale boom failed to generate a statistically significant impact on most of the outcome indicators considered in the study. The only exception is population growth, where the estimated effect in $\mathrm{OH} 15$ is larger than almost $90 \%$ of the placebo effects. As can be seen in figures 3.6(c) and 3.6(d), the synthetic population growth rate closely tracks the actual growth rate in the pre-boom period, suggesting a high match quality. In the post-boom period, the gap between the synthetic and actual trends is overall small. Indeed, table 3.4 shows that fracking has exerted a small negative effect on population growth in $\mathrm{OH} 15$, with the magnitude of the effect being $-0.03 \%$ in the early post-boom period, rising to $-0.06 \%$ in 
the later post-boom period. These negative impacts are considerably smaller than those for WV4 and WV15 that range between $-0.47 \%$ and $-0.18 \%$.

Figures 3.6(a) and 3.6(b) plot the estimation results for the poverty rates in the top 4 and top 15 oil and gas-producing counties in $\mathrm{OH}$. For 7 out of the 8 post-boom years, the synthetic trend of the poverty rate in $\mathrm{OH} 4$ lies below its actual trend, suggesting that the shale boom may have decreased the poverty rate in $\mathrm{OH} 4$. Figures 3.6(e) and 3.6(f) show that shale development may have slightly increased the employment growth in most post-boom years in $\mathrm{OH} 4$ and $\mathrm{OH} 15$. Interestingly, the positive impact of the shale boom on employment growth in $\mathrm{OH} 15$ is considerably larger than OH4 in 2010-2013; in 2014-2016, the relationship reverses. Finally, the actual trend crosses the synthetic trend multiple times throughout the post-boom period in figures 3.6(g) and 3.6(h), suggesting that the impact of the shale boom on the income growth in $\mathrm{OH}$ oil and gas counties may be mixed and vary year by year.

\subsubsection{Pennsylvania}

As shown in figures 3.7(a) and 3.7(b), the shale boom overall decreased poverty rates in both PA4 and PA15. However, the impacts diminished in the later post-boom years when energy prices were low, as also suggested by the magnitude of the average impact in table 3.4. Overall, shale development reduced the poverty rate by about $1 \%$ in PA4, and $-0.45 \%$ in PA15, which are smaller than those found for WV4 and WV15.

Figures 3.7(c) and 3.7(d) present the estimation results for the population growth rates in PA4 and PA15. The shale gas boom overall negatively affected the population growth rates in both regions. Table 3.4 suggests that the impact on population growth rate decreased from around $0.1 \%$ in the early post-boom period to around $-0.3 \%$ in the later post-boom period. This indicates that the negative impacts on population growth in PA4 and PA15 may last in the long run.

For employment growth, as can be seen in figures 3.7(e) and 3.7(f), the shale gas boom generated short-term positive impacts on employment growth in PA4 and PA15. However, the effects turned negative in the last few observed post-boom years. The average magnitudes of the impact in both regions switched from positive $(\mathrm{PA} 4=0.64 \%$; PA15 $=0.27 \%$ ) to negative (PA4 
$=-0.64 \%$; PA15 $=-0.42 \%$ ) in the later post-boom period, a finding consistent with the result of WV. For the entire post-boom period, however, the impact of fracking on employment growth in both regions is close to zero.

Figures 3.7(g) and 3.7(h) present the estimation results of the per capita personal income growth rate in PA4 and PA15. The actual income growth rate trend crosses the synthetic trend multiple times in the post-boom period. However, the pseudo $p$-values in table 3.3 indicate that the impacts are insignificant in both regions. Our findings in PA are consistent with the findings from the earlier SCM study of Munasib and Rickman (2015), who contend that the shale development might fail to generate detectable effects on employment and wage while producing negative impacts on population growth in PA oil and gas counties.

\subsection{Conclusions and Discussions}

Understanding the economic impacts of shale development on local communities remains an important issue that could provide valuable information to policymaking. This paper examines how the recent shale boom has affected several key economic indicators in the top oil and gas counties in PA, OH, and WV using the synthetic control method. We find mixed results depending on the regions and time periods considered, highlighting the importance of conducting region-specific analysis when evaluating the impact of the recent boom in the unconventional oil and gas sector. Our findings are overall consistent with previous studies that found increased drilling activities and shale gas developments to have improved the economic outcomes in the participating regions in the short-term (e.g., Agerton et al. 2017; J.P. Brown 2014; Munasib and Rickman 2015; Weber 2012, 2014), while negatively affects some economic measures in the long run (e.g., Jackson et al. 2013; Lim 2018; Maguire and Winters 2017; Rich, Grover, and Sattler 2014).

In $\mathrm{WV}$, the shale development significantly decreased the poverty rate, but the impact fails to persist in the long run. The average magnitude of the impact is $-2.68 \%$ in WV4 and $0.58 \%$ in WV15. The shale boom also created short-term positive effects on both employment growth rate and per capita personal income in the first few post-boom years (2010 to 2013), but 
the effects became negative in the later post-boom period (2014 to 2017). Furthermore, shale development negatively affected population growth in top oil and gas counties in WV, with the negative effect strengthens in the later post-boom period.

We find the shale gas boom to have created short-term economic benefits for WV, but the potential crowding-out effects on other industries and the outmigration due to negative externalities associated with the shale development may harm the state in the long run. The minimal long-run impact from shale development may also indicate that only a small portion of the profits from drilling activities had been reinvested in WV to promote economic growth in the region. Moreover, the oil and gas boom-bust cycle and decline of energy price in 2014-2016 that affected Louisiana, North Dakota, Oklahoma, and Wyoming (Rickman and Wang 2020) may be another key factor that most positive impacts in WV diminished in the 2014-2017 period.

In Ohio, the impact of shale development on the economic indicators considered is mostly non-significant. The only exception is population growth in OH15-fracking slightly decreased the population growth in OH15 by $0.05 \%$ between $2010-2017$, with the later postboom period (2014-2016) witnessed a slightly larger negative impact. Overall, counties with extensive drilling activities in $\mathrm{OH}$ fail to enjoy many economic benefits from shale development. Meanwhile, the negative externalities associated with shale drilling may have depressed the population growth rate in the region.

In Pennsylvania, the shale boom decreased the poverty rate in both PA4 and PA15, but as in WV the impact diminished in 2016. Estimation results further suggest that in 2010-2013, shale development increased population growth by $0.64 \%$ and $0.27 \%$ in PA4 and PA15, respectively. However, the impacts subsequently turned negative in the following years. For population growth, we again find shale drilling to exert a negative impact that persists and is enhanced in the long run. The estimated effects of shale development on PA economic outcomes are consistent with the findings from Munasib and Rickman (2015).

Some interesting patterns emerge when comparing the magnitudes of impact across the top oil and gas producing counties in the three states. While the shale development created some short-term positive impacts on the employment growth in WV and PA, the impacts weakened and in some cases turned negative following the energy price decline in 2014-2017. For the entire post-boom period, WV15 appeared to have suffered the highest negative impact on 
employment growth rate $(-0.35 \%)$, while in WV4 and PA4 the impact is close to zero. Moreover, shale development negatively affected population growth in all three states, with the negative impact most severe in WV and most minor in $\mathrm{OH}$. In addition to the crowd-out effect, the negative externalities due to increased drilling activities, such as increased crime rate, elevated noise level, lower education attainment, negative impacts on the well-being of the residents, and increased property values and living cost maybe the potential reasons that shale drilling has lowered population growth in regions with extensive drilling activities.

Overall, we find that the recent shale gas boom has generated heterogeneous impacts on regional economic outcomes in $\mathrm{PA}, \mathrm{OH}$, and WV's top oil and gas counties. The differential impacts can be partially attributed to heterogeneity between three states' economic factors and socio-characteristics. For instance, both the employment and population data show WV is the smallest economy among the three states. WV also has the highest poverty rate and the lowest high school graduation rate compared to $\mathrm{OH}$ and PA. The employment data shows that WV depends on the mining industry more than the other two states. Meanwhile, $\mathrm{OH}$ has the highest percentage of manufacturing employment, making it more robust to the boom-and-bust cycles in the energy sector.

The different taxation policies in the three states may be another key contributor to the heterogeneous results found in the study. Unlike $\mathrm{OH}$ and WV where severance taxes are imposed, PA did not tax the oil and gas industry until 2012, when the state started to impose a small impact fee based on the number of new wells, age of wells, and natural gas prices (Kolesnikoff and Brown 2018). While both $\mathrm{OH}$ and WV imposes severance taxes, the structure of the taxes is quite different. In WV, the severance tax is mainly determined by the gross value of energy ( $5 \%$ of the value), making the tax rate falls in the mid-range of all oil and gas producing states in the US. By contrast, the severance tax in $\mathrm{OH}$ is mainly determined by production, and is considerably lower than the tax in WV and many of the oil and gas producing states (Kolesnikoff and Brown 2018). Since the oil and gas tax rates in PA and WV both consider energy prices, the impact of shale development in the oil and gas producing regions in the two states is likely to be highly affected by energy price fluctuations. This may help explain why some of the positive impacts in PA and WV found in the early post-boom period either disappears or turns negative in the latter post boom years when the energy prices plunged. 
Given the heterogeneous economic impacts of shale development in WV, OH, and PA, a state-specific policy is needed to promote the continuing growth of and maximize the benefits from the unconventional oil and gas industry. For instance, policymakers in PA and WV may consider focusing on mitigating population outflows and extending the short-term economic benefits. Reinvestment into the drilling regions may be a key to the success of such efforts. Given the fast depletion rate of shale production from unconventional wells, Allred et al. (2015) show that the recovery of previously drilled land is much slower than the loss of land due to accelerated drilling in the US. Policy efforts may be directed to reclaiming the previously drilled land, in order to restore the ecosystem services in the boom counties and mitigate the negative externalities that may have caused outmigration and population growth decline. However, the current taxation policies on drilling in PA and WV make the oil and gas tax revenues sensitive to the boom-bust cycle in the energy sector and the volatility of energy prices, which may affect government reinvestment effort. For $\mathrm{OH}$, given the lack of significant economic impact and the slightly negative impact of drilling on population growth, policymakers may consider developing creative programs that focus on creating employment opportunities.

Overall, policymakers in the three states face the challenging task of navigating and finding solutions to mitigate the negative externalities and the population shifts due to shale drilling activities. The crowding-out effects of shale development and the lack of reinvestment from shale industries are also important issues that policymakers may wish to address. Finally, although considerable efforts have been proposed to enact a more uniform extraction tax structure in the three states, such discussions have not been successful. In the longer run, as advocated by several policy analysts, a more uniform tax policy may allow the states to spend more resources to address the impacts of drilling. ${ }^{14}$

There are several limitations of this study. First, the impact of shale development on four economic indicators was analyzed using SCM individually. The interrelationships between the economic indicators are not fully observed due to the nature of SCM and our model design. Second, a weighted average of the four indicators may provide further insights into the net impact of fracking. Third, housing prices were not considered in this study. Housing price is a

\footnotetext{
${ }^{14}$ See "Advocates from OH, PA, WV Urge Common Approach to Shale Taxation" http://www.multistateshale.org/three-state-severance-tax, accessed on 4/20/2021.
} 
good indicator reflecting the asset value and living cost. Along with the four economic indicators we evaluate, including housing prices in the analysis would provide a more comprehensive picture of the impact of the shale boom on regional economic outcomes. Future research may wish consider these aspects into the model design. 


\section{References}

Abadie, Alberto, Alexis Diamond, and Jens Hainmueller. 2010. "Synthetic Control Methods for Comparative Case Studies: Estimating the Effect of California's Tobacco Control Program." Journal of the American Statistical Association 105 (490): 493-505. https://EconPapers.repec.org/RePEc:bes:jnlasa:v:105:i:490:y:2010:p:493-505.

---. 2015. "Comparative politics and the synthetic control method." American Journal of Political Science 59 (2): 495-510.

Agerton, Mark, Peter R Hartley, Kenneth B Medlock III, and Ted Temzelides. 2017. "Employment impacts of upstream oil and gas investment in the United States." Energy Economics 62: 171-180.

Allred, B. W., Smith, W. K., Twidwell, D., Haggerty, J. H., Running, S. W., Naugle, D. E., and Fuhlendorf, S. D. 2015. "Ecosystem services lost to oil and gas in North America." Science, 348(6233), 401-402.

Bertrand, Marianne, Esther Duflo, and Sendhil Mullainathan. 2003. "How Much Should We Trust Differences-In-Differences Estimates?” The Quarterly Journal of Economics 119: 249-275. https://doi.org/10.1162/003355304772839588.

Betz, Michael R, Mark D Partridge, Michael Farren, and Linda Lobao. 2015. "Coal mining, economic development, and the natural resources curse." Energy Economics 50: 105-116.

Brown, Jason P. 2014. "Production of natural gas from shale in local economies: a resource blessing or curse?" Economic Review-Federal Reserve Bank of Kansas City: 5.

Brown, Jason, Jeremy G Weber, and Timothy R Wojan. 2013. "Emerging energy industries and rural growth." United States Department of Agriculture, Economic Research Service Report November 2013.

Christopherson, Susan, and Ned Rightor. 2012. "How shale gas extraction affects drilling localities: Lessons for regional and city policy makers." Journal of Town and City Management 2 (4): 1-20. 
Coffman, Makena, and Ilan Noy. 2012. "Hurricane Iniki: measuring the long-term economic impact of a natural disaster using synthetic control." Environment and Development Economics 17 (2): 187-205.

Collins, Alan R, and Kofi Nkansah. 2015. "Divided rights, expanded conflict: the impact of split estates in natural gas production." Land Economics 91 (4): 688-703.

Considine, Timothy, Robert Watson, and Seth Blumsack. 2010. "The economic impacts of the Pennsylvania Marcellus shale natural gas play: an update." The Pennsylvania State University, Department of Energy and Mineral Engineering.

Considine, Timothy, Robert Watson, Rebecca Entler, and Jeffrey Sparks. 2009. An emerging giant: prospects and economic impacts of developing the Marcellus Shale natural gas play. The Pennsylvania State University, Department of Energy and Mineral Engineering.

Cosgrove, Brendan. 2014. "The Economic Impact of Shale Gas Development: A Natural Experiment along the New York and Pennsylvania Border." Honors Theses 871.

Deller, Steven, and Philip Watson. 2016. "Did regional economic diversity influence the effects of the great recession?" Economic Inquiry 54 (4): 1824-1838.

Fershee, Joshua. 2012. "The Oil and Gas Evolution: Learning from the Hydraulic Fracturing Experiences in North Dakota and West Virginia.” Texas Wesleyan Law Review 19 (1). https://doi.org/10.2139/ssrn.2175798.

Feyrer, James, Erin T Mansur, and Bruce Sacerdote. 2017. "Geographic dispersion of economic shocks: Evidence from the fracking revolution." American Economic Review 107 (4): 1313-34.

Fisher, Michael P, Alex Mayer, Kaitlin Vollet, Elaine L Hill, and Erin Haynes. 2018. "Psychosocial implications of unconventional natural gas development: Quality of life in Ohio's Guernsey and Noble Counties." Journal of Environmental Psychology 55: 90-98.

Galiani, Sebastian, and Brian Quistorff. 2017. "The synth_runner package: Utilities to automate synthetic control estimation using synth.” The Stata Journal 17 (4): 834-849. 
Gittings, R Kaj, and Travis Roach. 2020. "Who benefits from a resource boom? Evidence from the Marcellus and Utica shale plays.” Energy Economics 87: 104489.

Gobillon, Laurent, and Thierry Magnac. 2015. "Regional Policy Evaluation: Interactive Fixed Effects and Synthetic Controls." The Review of Economics and Statistics 98 (3): 535-551. https://doi.org/10.1162/REST_a_00537.

Hardy, Kirsten, and Timothy W. Kelsey. 2015. "Local income related to Marcellus shale activity in Pennsylvania.” Community Development 46 (4): 329-340. https://doi.org/10.1080/15575330.2015.1059351.

Higginbotham, Amy, Adam Pellillo, Tami Gurley-Calvez, and Tom S Witt. 2010. The economic impact of the natural gas industry and the Marcellus shale development in West Virginia in 2009. Bureau of Business and Economic Research, College of Business and Economics, West Virginia University. https://energyspeakswv.com/Resources/Docs/Studies/Economic\%20Impact\%20of\%20the \%20Marcellus\%20Shale\%202009\%20FINAL.pdf.

Hoy, Kyle A, Timothy W Kelsey, and Martin Shields. 2017. "An economic impact report of shale gas extraction in Pennsylvania with stricter assumptions." Ecological economics 138: $178-185$.

Hoy, Kyle A, Irene M Xiarchos, Timothy W Kelsey, Kathryn J Brasier, and Leland L Glenna. 2018. "Marcellus shale gas development and farming." Agricultural and Resource Economics Review 47 (3): 634-664.

Institute for Energy Research (IER). 2012. "The Hard Facts bout U.S. Shale Oild and Gas." https://www.instituteforenergyresearch.org/fossil-fuels/gas-and-oil/the-hard-facts-aboutu-s-shale-energy/.

Jackson, Robert B, Avner Vengosh, Thomas H Darrah, Nathaniel R Warner, Adrian Down, Robert J Poreda, Stephen G Osborn, Kaiguang Zhao, and Jonathan D Karr. 2013. "Increased stray gas abundance in a subset of drinking water wells near Marcellus shale gas extraction." Proceedings of the National Academy of Sciences 110 (28): 1125011255. 
Jacobsen, Grant D. 2019. "Who wins in an energy boom? Evidence from wage rates and housing.” Economic Inquiry 57 (1): 9-32.

Jacquet, Jeffrey B., Anne N. Junod, Dylan Bugden, Grace Wildermuth, Joshua T. Fergen, Kirk Jalbert, Brian Rahm, Paige Hagley, Kathryn J. Brasier, Kai Schafft, Leland Glenna, Timothy Kelsey, Joshua Fershee, David L. Kay, Richard C. Stedman, and James Ladlee. 2018. "A decade of Marcellus Shale: Impacts to people, policy, and culture from 2008 to 2018 in the Greater Mid-Atlantic region of the United States.” The Extractive Industries and Society 5 (4): 596-609. https://doi.org/https://doi.org/10.1016/j.exis.2018.06.006.

Jakus, Paul M, and Sherzod B Akhundjanov. 2019. "The Antiquities Act, national monuments, and the regional economy." Journal of Environmental Economics and Management 95: 102-117.

James, Alexander, and Brock Smith. 2017. "There will be blood: Crime rates in shale-rich US counties.” Journal of Environmental Economics and Management 84: 125-152.

---. 2020. “Geographic Dispersion of Economic Shocks: Evidence from the Fracking Revolution: Comment." American Economic Review 110 (6): 1905-13. https://doi.org/10.1257/aer.20180888.

King, Hobart M. . 2019. "Marcellus Shale - Appalachian Basin Natural Gas Play.” Geology.com. https://geology.com/articles/marcellus-shale.shtml.

Kinnaman, Thomas C. 2011. "The economic impact of shale gas extraction: A review of existing studies.” Ecological Economics 70 (7): 1243-1249. https://EconPapers.repec.org/RePEc:eee:ecolec:v:70:y:2011:i:7:p:1243-1249.

Kolesnikoff, Anne, and Cassarah Brown. 2018. "State Oil and Gas Severance Taxes." National Conference of State Legislatures. https://www.ncsl.org/research/energy/oil-and-gasseverance-taxes.aspx.

Komarek, Timothy M. 2016. "Labor market dynamics and the unconventional natural gas boom: Evidence from the Marcellus region." Resource and Energy Economics 45: 1-17. https://doi.org/https://doi.org/10.1016/j.reseneeco.2016.03.004.

---. 2018. "Crime and natural resource booms: evidence from unconventional natural gas production." The Annals of Regional Science 61 (1): 113-137. 
Kreif, Noémi, Richard Grieve, Dominik Hangartner, Alex James Turner, Silviya Nikolova, and Matt Sutton. 2016. "Examination of the synthetic control method for evaluating health policies with multiple treated units." Health economics 25 (12): 1514-1528.

Lim, Siew Hoon. 2018. "Does Shale Energy Development Mean More Crime? The Case of the Bakken Oil Boom." Growth and Change 49 (3): 413-441.

Maguire, Karen, and John V Winters. 2017. "Energy Boom and Gloom? Local Effects of Oil and Natural Gas Drilling on Subjective Well-Being." Growth and Change 48 (4): 590-610.

McClelland, Robert, and Sarah Gault. 2017. The synthetic control method as a tool to understand state policy. Urban Institute.

Michaud, Gilbert. 2018. "Shale industry's economic contribution in Ohio, USA: Implication for future activity in the state.” Regional Science Inquiry 10 (2): 163-171.

Munasib, Abdul, and Dan S. Rickman. 2015. "Regional economic impacts of the shale gas and tight oil boom: A synthetic control analysis." Regional Science and Urban Economics 50: $1-17$.

O’Neill, Stephen, Noémi Kreif, Richard Grieve, Matthew Sutton, and Jasjeet S Sekhon. 2016. "Estimating causal effects: considering three alternatives to difference-in-differences estimation." Health Services and Outcomes Research Methodology 16 (1-2): 1-21.

Ogneva-Himmelberger, Yelena, and Liyao Huang. 2015. "Spatial distribution of unconventional gas wells and human populations in the Marcellus Shale in the United States: Vulnerability analysis.” Applied Geography 60: 165-174. https://doi.org/https://doi.org/10.1016/j.apgeog.2015.03.011.

Paredes, Dusan, Timothy Komarek, and Scott Loveridge. 2015. "Income and employment effects of shale gas extraction windfalls: Evidence from the Marcellus region.” Energy Economics 47: 112-120. https://doi.org/https://doi.org/10.1016/j.eneco.2014.09.025.

Rich, Alisa, James P Grover, and Melanie L Sattler. 2014. “An exploratory study of air emissions associated with shale gas development and production in the Barnett Shale." Journal of the Air \& Waste Management Association 64 (1): 61-72. 
Rickman, Dan, and Hongbo Wang. 2020. "What goes up must come down? The recent economic cycles of the four most oil and gas dominated states in the US." Energy Economics 86: 104665.

Rickman, Dan, Hongbo Wang, and John V Winters. 2017. "Is shale development drilling holes in the human capital pipeline?" Energy Economics 62: 283-290.

Ryan, Andrew M, James F Burgess Jr, and Justin B Dimick. 2015. "Why we should not be indifferent to specification choices for difference-in-differences." Health services research 50 (4): 1211-1235.

Sangaramoorthy, Thurka, Amelia M. Jamison, Meleah D. Boyle, Devon C. Payne-Sturges, Amir Sapkota, Donald K. Milton, and Sacoby M. Wilson. 2016. "Place-based perceptions of the impacts of fracking along the Marcellus Shale." Social Science \& Medicine 151: 2737. https://doi.org/https://doi.org/10.1016/j.socscimed.2016.01.002.

Tsvetkova, Alexandra, and Mark D Partridge. 2016. "Economics of modern energy boomtowns: do oil and gas shocks differ from shocks in the rest of the economy?" Energy Economics 59: 81-95.

Wang, Haoying. 2020. "The economic impact of oil and gas development in the Permian Basin: Local and spillover effects." Resources Policy 66: 101599.

Weber, Jeremy G. 2012. "The effects of a natural gas boom on employment and income in Colorado, Texas, and Wyoming." Energy Economics 34 (5): 1580-1588. https://EconPapers.repec.org/RePEc:eee:eneeco:v:34:y:2012:i:5:p:1580-1588.

---. 2014. "A decade of natural gas development: The makings of a resource curse?" Resource and Energy Economics 37: 168-183. https://doi.org/https://doi.org/10.1016/j.reseneeco.2013.11.013.

Weinstein, Amanda. 2019. The Economic Value of Shale Natural Gas in Ohio. Swank Program in Rural-Urban Policy.

Willow, Anna. 2014. "The new politics of environmental degradation: Un/expected landscapes of disempowerment and vulnerability." Journal of Political Ecology 21: 237-257. https://doi.org/10.2458/v21i1.21135. 


\section{Tables and Figures}

Table 3.1. Summary Statistics: West Virginia, Ohio, and Pennsylvania Top 4 and 15 Oil \& Gas Aggregates of Nonmetropolitan Counties (ANC) and 27-Donor ANCs

\begin{tabular}{|c|c|c|c|c|c|c|c|c|c|c|c|c|c|c|}
\hline & \multicolumn{7}{|c|}{ Pre-boom period: $2002-2009$} & \multicolumn{7}{|c|}{ Post-boom period: $2010-2017$} \\
\hline & 27 Donor & WV4 & WV15 & OH4 & OH15 & PA4 & PA15 & 27 Donor & WV4 & WV15 & OH4 & OH15 & PA4 & PA15 \\
\hline \multicolumn{15}{|c|}{ Outcome variables (before transformation) } \\
\hline Population $(1,000)$ & 1058.5 & 124 & 331 & 394.1 & 829.9 & 233.8 & 754.5 & 1077.3 & 120.3 & 324.6 & 393.4 & 827.8 & 229.3 & 737.8 \\
\hline Total employment $(1,000)$ & 540.6 & 57.9 & 141.3 & 205.2 & 395.2 & 108.4 & 365.7 & 539.1 & 60.9 & 144.3 & 202.6 & 398 & 117.2 & 371.3 \\
\hline Personal income per capita $(1,000 \$)$ & 31.4 & 26.6 & 17 & 28.2 & 28.8 & 27.5 & 28.3 & 40.6 & 35.4 & 22.5 & 36.1 & 28.1 & 36.1 & 36.8 \\
\hline \multicolumn{15}{|l|}{ Outcome variables } \\
\hline Poverty Rate $(\%)$ & $13.3 \%$ & $22.1 \%$ & $15.7 \%$ & $12.5 \%$ & $14.2 \%$ & $14.6 \%$ & $13.9 \%$ & $15.5 \%$ & $21.1 \%$ & $16.5 \%$ & $15.7 \%$ & $17.2 \%$ & $15.2 \%$ & $15.3 \%$ \\
\hline Population growth (\%) & $0.3 \%$ & $-0.1 \%$ & $-0.1 \%$ & $0.0 \%$ & $0.0 \%$ & $0.0 \%$ & $0.0 \%$ & $0.1 \%$ & $-0.3 \%$ & $-0.3 \%$ & $0.0 \%$ & $0.0 \%$ & $-0.2 \%$ & $-0.2 \%$ \\
\hline Employment growth (\%) & $0.1 \%$ & $0.2 \%$ & $0.1 \%$ & $-0.4 \%$ & $-0.4 \%$ & $0.3 \%$ & $-0.1 \%$ & $0.3 \%$ & $0.2 \%$ & $-0.1 \%$ & $0.4 \%$ & $0.4 \%$ & $0.1 \%$ & $0.1 \%$ \\
\hline Personal income per capita growth $(\%)$ & $1.4 \%$ & $1.8 \%$ & $1.1 \%$ & $1.1 \%$ & $1.1 \%$ & $1.4 \%$ & $1.5 \%$ & $1.4 \%$ & $1.2 \%$ & $1.5 \%$ & $1.5 \%$ & $1.5 \%$ & $1.4 \%$ & $1.3 \%$ \\
\hline \multicolumn{15}{|l|}{ Predictor variables } \\
\hline Total wage growth (\%) & $1 \%$ & $2.0 \%$ & $1.80 \%$ & $0.5 \%$ & $0.6 \%$ & $1.6 \%$ & $1.1 \%$ & $1.3 \%$ & $1.4 \%$ & $0.8 \%$ & $1.7 \%$ & $1.6 \%$ & $1.2 \%$ & $1.10 \%$ \\
\hline Rural-Urban code, 2003 & 5.7 & 6.0 & 5.4 & 4.0 & 5.5 & 5.2 & 5.4 & 5.7 & 6.0 & 5.0 & 4.0 & 5.1 & 5.2 & 5.4 \\
\hline Median household income $(1,000 \$)$ & 41.3 & 30.9 & 22.4 & 40.3 & 39.4 & 36.6 & 36.3 & 47.6 & 38.6 & 26.9 & 45.0 & 39.4 & 45.7 & 44 \\
\hline Median Age, 2010 & 41.1 & 42.2 & 31.4 & 39.6 & 39.2 & 40.8 & 41.5 & 41.1 & 42.0 & 31.4 & 39.4 & 39.4 & 40.8 & 41.5 \\
\hline$\%$ with high school grad, 2000 & $35.0 \%$ & $39.3 \%$ & $30.3 \%$ & $44.9 \%$ & $45.0 \%$ & $46.9 \%$ & $48.4 \%$ & $35.0 \%$ & $39.5 \%$ & $30.3 \%$ & $44.9 \%$ & $45.2 \%$ & $46.9 \%$ & $48.4 \%$ \\
\hline$\%$ with associate degree, 2000 & $26.6 \%$ & $18.1 \%$ & $13.1 \%$ & $21.8 \%$ & $19.6 \%$ & $18.6 \%$ & $18.9 \%$ & $26.6 \%$ & $18.5 \%$ & $13.1 \%$ & $21.8 \%$ & $21.6 \%$ & $18.8 \%$ & $18.9 \%$ \\
\hline$\%$ with bachelor's degree, 2000 & $17.7 \%$ & $12.1 \%$ & $7.8 \%$ & $13.5 \%$ & $10.5 \%$ & $14.9 \%$ & $13.8 \%$ & $17.7 \%$ & $12.3 \%$ & $7.8 \%$ & $13.5 \%$ & $13.3 \%$ & $14.9 \%$ & $13.8 \%$ \\
\hline$\%$ of agricultural employment & $0.1 \%$ & $0.0 \%$ & $0.0 \%$ & $0.0 \%$ & $0.0 \%$ & $0.0 \%$ & $0.0 \%$ & $0.1 \%$ & $0.0 \%$ & $0.0 \%$ & $0.0 \%$ & $0.0 \%$ & $0.0 \%$ & $0.0 \%$ \\
\hline$\%$ of mining employment & $1.7 \%$ & $9.1 \%$ & $9.5 \%$ & $1.0 \%$ & $1.0 \%$ & $5.4 \%$ & $2.4 \%$ & $1.3 \%$ & $9.1 \%$ & $9.9 \%$ & $1.2 \%$ & $1.2 \%$ & $8.8 \%$ & $4.2 \%$ \\
\hline$\%$ of manufacture employment & $14.2 \%$ & $4.9 \%$ & $9.1 \%$ & $27.1 \%$ & $23.5 \%$ & $15.8 \%$ & $22.4 \%$ & $13.0 \%$ & $3.7 \%$ & $6.1 \%$ & $23.1 \%$ & $20.9 \%$ & $10.6 \%$ & $18.8 \%$ \\
\hline$\%$ of retail employment & $15.6 \%$ & $19.2 \%$ & $18.0 \%$ & $14.8 \%$ & $15.4 \%$ & $17.9 \%$ & $16.6 \%$ & $15.8 \%$ & $17.4 \%$ & $16.4 \%$ & $14.6 \%$ & $15.0 \%$ & $17.7 \%$ & $16.0 \%$ \\
\hline Natural amenity rank, 1999 & 3.5 & 2.9 & 2.9 & 2.9 & 3.0 & 4.0 & 3.5 & 3.5 & 2.9 & 2.9 & 2.9 & 3.0 & 4.0 & 3.5 \\
\hline
\end{tabular}

Notes: The entire sample period consists of 16 years, with the pre-boom period being 2002-2009, and the post-boom period being 2010-2017. All data are weighted average by population in each county. The 27 units in the donor pool combined include 30,176 (1,886 nonmetropolitan counties) observations in 2002-2017, while the top 4 and 15 aggregates of nonmetropolitan counties in WV, PA, and $\mathrm{OH}$ include data for the top 4 and 15 oil and gas-producing counties in each state, respectively. The income, poverty rate, education level, rural-urban code, and natural amenities rank data are

obtained from the Economic Research Service of the US Department of Agriculture. The population, median age, and employment by industry sector data are collected from the US Census. 
Table 3.2. Match Quality of All Variables (Comparison with 27-state Average)

\begin{tabular}{|c|c|c|c|c|c|c|c|c|c|c|c|c|c|c|}
\hline & \multicolumn{3}{|c|}{ Poverty Rate } & \multicolumn{5}{|c|}{ Population Growth } & \multicolumn{4}{|c|}{ Employment Growth } & \multicolumn{2}{|c|}{ Personal Income } \\
\hline & WV4 & WV15 & PA4 & WV4 & WV15 & $\mathrm{OH} 15$ & PA4 & PA15 & WV4 & WV15 & PA4 & PA15 & WV4 & WV15 \\
\hline Poverty rate & $-27 \%$ & $-40 \%$ & $-40 \%$ & $3 \%$ & $-32 \%$ & $-21 \%$ & $-27 \%$ & $-22 \%$ & $-2 \%$ & $-36 \%$ & $-34 \%$ & $-30 \%$ & $2 \%$ & $-39 \%$ \\
\hline Employment growth rate & $-1 \%$ & $9 \%$ & $10 \%$ & $38 \%$ & $23 \%$ & $35 \%$ & $23 \%$ & $119 \%$ & $2 \%$ & $-5 \%$ & $-2 \%$ & $17 \%$ & $33 \%$ & $-4 \%$ \\
\hline Personal income per capita growth & $20 \%$ & $-16 \%$ & $-19 \%$ & $-17 \%$ & $-6 \%$ & $133 \%$ & $-11 \%$ & $-20 \%$ & $-15 \%$ & $-16 \%$ & $-19 \%$ & $-14 \%$ & $22 \%$ & $-20 \%$ \\
\hline Population growth rate & $120 \%$ & $473 \%$ & $703 \%$ & $-183 \%$ & $-120 \%$ & $-243 \%$ & $-68 \%$ & $-186 \%$ & $-82 \%$ & $-242 \%$ & $425 \%$ & $41 \%$ & $-204 \%$ & $534 \%$ \\
\hline Total wage & $11 \%$ & $-6 \%$ & $-21 \%$ & $-11 \%$ & $-13 \%$ & $-15 \%$ & $-20 \%$ & $-25 \%$ & $-7 \%$ & $-23 \%$ & $-21 \%$ & $-23 \%$ & $16 \%$ & $-10 \%$ \\
\hline Rural-Urban code & $-5 \%$ & $-1 \%$ & $13 \%$ & $7 \%$ & $-3 \%$ & $0 \%$ & $5 \%$ & $7 \%$ & $3 \%$ & $-2 \%$ & $4 \%$ & $5 \%$ & $36 \%$ & $-2 \%$ \\
\hline Median household income & $7 \%$ & $6 \%$ & $11 \%$ & $1 \%$ & $2 \%$ & $10 \%$ & $5 \%$ & $5 \%$ & $3 \%$ & $3 \%$ & $5 \%$ & $1 \%$ & $41 \%$ & $4 \%$ \\
\hline Median age & $9 \%$ & $26 \%$ & $0 \%$ & $3 \%$ & $24 \%$ & $9 \%$ & $-2 \%$ & $0 \%$ & $1 \%$ & $2 \%$ & $-1 \%$ & $1 \%$ & $40 \%$ & $24 \%$ \\
\hline$\%$ with high school graduate & $-1 \%$ & $3 \%$ & $5 \%$ & $-1 \%$ & $3 \%$ & $-7 \%$ & $8 \%$ & $5 \%$ & $-1 \%$ & $-7 \%$ & $8 \%$ & $5 \%$ & $31 \%$ & $0 \%$ \\
\hline$\%$ with associate degree & $-33 \%$ & $27 \%$ & $-22 \%$ & $20 \%$ & $68 \%$ & $-31 \%$ & $-6 \%$ & $-9 \%$ & $-5 \%$ & $-42 \%$ & $-15 \%$ & $-17 \%$ & $-4 \%$ & $57 \%$ \\
\hline$\%$ with bachelor degree & $-41 \%$ & $45 \%$ & $-45 \%$ & $3 \%$ & $71 \%$ & $-36 \%$ & $-31 \%$ & $-32 \%$ & $24 \%$ & $-42 \%$ & $-34 \%$ & $-40 \%$ & $-4 \%$ & $66 \%$ \\
\hline$\%$ ag employment & - & - & - & - & - & - & - & - & - & - & - & - & - & - \\
\hline$\%$ mining employment & $9 \%$ & $-3 \%$ & $-5 \%$ & $18 \%$ & $18 \%$ & $-71 \%$ & $-11 \%$ & $-33 \%$ & $-16 \%$ & $-77 \%$ & $-12 \%$ & $-15 \%$ & $-39 \%$ & $-28 \%$ \\
\hline$\%$ manufacture employment & $-22 \%$ & $-169 \%$ & $-159 \%$ & $-117 \%$ & $-162 \%$ & $-162 \%$ & $-185 \%$ & $-184 \%$ & $-39 \%$ & $-182 \%$ & $-167 \%$ & $-182 \%$ & $-144 \%$ & $-178 \%$ \\
\hline$\%$ retail employment & $1 \%$ & $-3 \%$ & $-14 \%$ & $1 \%$ & $-7 \%$ & $-9 \%$ & $2 \%$ & $-3 \%$ & $-7 \%$ & $-14 \%$ & $-5 \%$ & $-11 \%$ & $24 \%$ & $-3 \%$ \\
\hline Natural amenity scale & $4 \%$ & $-6 \%$ & $-2 \%$ & $-20 \%$ & $-17 \%$ & $-6 \%$ & $7 \%$ & $7 \%$ & $-11 \%$ & $-17 \%$ & $-1 \%$ & $-3 \%$ & $21 \%$ & $5 \%$ \\
\hline \# of better match out of 16 variables & 8 & 9 & 10 & 7 & 9 & 11 & 10 & 10 & 11 & 14 & 12 & 10 & 6 & 9 \\
\hline
\end{tabular}

Notes: the estimated impacts that fail to pass the placebo test are excluded in the table. We follow the procedure that Rickman and Wang (2020) introduced to provide assessments of match quality in terms of all variables. Each percentage indicates the reduction in the difference in the match between the synthetic and the actual outcomes to the match

between the 27-donor average and the actual outcome. A negative number indicates the synthetic control better match the treated unit than the 27 -donor average does. The last row represents numbers of better match that synthetic control makes out of 16 variables. The $\%$ of ag employment in the treated ANCs are $0 \%$. The SCM was able to construct a synthetic outcome of $0 \%$ ag employment which is 0 difference with the actual outcome. The $\%$ of ag employment in the 27 -donor is $0.1 \%$. The reduction in the difference is calculated as: $(0-0.001) / 0=$ Undefined. However, we do know that the synthetic control outperforms the 27 -donor average in terms of the $\%$ of ag employment. 
Table 3.3. Joint Impact P-values for Post-boom period, 2010-2017

\begin{tabular}{lcccc}
\hline Area & $\begin{array}{c}\text { Poverty } \\
\text { Rate }\end{array}$ & Population Growth & Employment Growth & $\begin{array}{c}\text { Personal Income per } \\
\text { Capita Growth }\end{array}$ \\
\hline Pseudo P-values & & & \\
WV4 & $0^{* * *}$ & $0.037^{* *}$ & $0^{* * *}$ & $0.1111^{\wedge}$ \\
WV15 & $0.0741^{*}$ & $0.1111^{\wedge}$ & $0.0741^{*}$ & $0.1111^{\wedge}$ \\
OH4 & 0.2963 & 0.5556 & 0.7407 & 1 \\
OH15 & 0.963 & $0.1111^{\wedge}$ & 0.7037 & 0.5556 \\
PA4 & $0.0741^{*}$ & $0.0741^{*}$ & $0^{* * *}$ & 0.4444 \\
PA15 & 0.3333 & $0.1111^{\wedge}$ & $0.1481^{\wedge}$ & 0.5926 \\
\hline
\end{tabular}

Notes: The $p$-values indicate the proportions of placebo post-treatment impacts on the non-boom states that are greater or equal to the post-treatment impact on the boom state. For instance, 0 indicates none of the placebo impacts is greater or equal to the impact on the boom state, 0.5 indicates $50 \%$ of the placebo impacts from the non-boom states are greater or equal to the impact on the boom state, and 1 indicates all placebo impacts are greater or equal to the impact on the boom state. ${ }^{* *},{ }^{* *},{ }^{*}$, and ${ }^{\wedge}$ indicates statistical significance at $0.01,0.05,0.10$, and 0.15 , respectively. 
Table 3.4. Estimated Impacts of Shale Boom on Top Oil \& Gas Counties in PA, OH, and WV

\begin{tabular}{lcccccccccccccc}
\hline & \multicolumn{3}{c}{ Poverty Rate } & \multicolumn{2}{c}{ Population Growth } & \multicolumn{2}{c}{ Employment Growth } & \multicolumn{2}{c}{ Income per Capita Growth } \\
\hline & $\mathbf{2 0 1 0 - 2 0 1 7}$ & $\mathbf{2 0 1 0 - 2 0 1 3}$ & $\mathbf{2 0 1 4 - 2 0 1 7}$ & $\mathbf{2 0 1 0 - 2 0 1 7}$ & $\mathbf{2 0 1 0 - 2 0 1 3}$ & $\mathbf{2 0 1 4 - 2 0 1 7}$ & $\mathbf{2 0 1 0 - 2 0 1 7}$ & $\mathbf{2 0 1 0 - 2 0 1 3}$ & $\mathbf{2 0 1 4 - 2 0 1 7}$ & $\mathbf{2 0 1 0 - 2 0 1 7}$ & $\mathbf{2 0 1 0 - 2 0 1 3}$ & $\mathbf{2 0 1 4 - 2 0 1 7}$ \\
\hline WV4 & $-2.68 \%$ & $-2.44 \%$ & $-2.93 \%$ & $-0.30 \%$ & $-0.18 \%$ & $-0.43 \%$ & $0.04 \%$ & $0.27 \%$ & $-0.19 \%$ & $-0.49 \%$ & $0.23 \%$ & $-1.21 \%$ \\
WV15 & $-0.58 \%$ & $-1.09 \%$ & $-0.07 \%$ & $-0.33 \%$ & $-0.20 \%$ & $-0.47 \%$ & $-0.35 \%$ & $0.20 \%$ & $-0.90 \%$ & $-0.76 \%$ & $-0.12 \%$ & $-1.40 \%$ \\
\hline OH4 & $0.46 \%$ & $-0.26 \%$ & $-0.66 \%$ & $0.00 \%$ & $0.00 \%$ & $0.00 \%$ & $0.13 \%$ & $0.14 \%$ & $0.12 \%$ & $0.13 \%$ & $0.01 \%$ & $0.25 \%$ \\
OH15 & $-0.09 \%$ & $-0.34 \%$ & $-0.16 \%$ & $-0.05 \%$ & $-0.03 \%$ & $-0.06 \%$ & $0.15 \%$ & $0.24 \%$ & $0.06 \%$ & $0.14 \%$ & $0.11 \%$ & $0.16 \%$ \\
\hline PA4 & $-1.01 \%$ & $-1.35 \%$ & $-0.67 \%$ & $-0.20 \%$ & $-0.10 \%$ & $-0.30 \%$ & $0.00 \%$ & $0.64 \%$ & $-0.64 \%$ & $0.28 \%$ & $0.06 \%$ & $0.50 \%$ \\
PA15 & $-0.45 \%$ & $-0.64 \%$ & $-0.26 \%$ & $-0.21 \%$ & $-0.12 \%$ & $-0.31 \%$ & $-0.08 \%$ & $0.27 \%$ & $-0.42 \%$ & $-0.23 \%$ & $-0.44 \%$ & $-0.01 \%$
\end{tabular}

Notes: numbers reported in the table are estimated impacts of shale boom in the post-boom period (2010-2017) in each study area using the synthetic control method. The pre-boom period is 2002-2009. In addition to the average impact during the entire post-boom period (2010-2017), we consider the average impacts in early post-boom (2010-2013) and later post-boom (2014-2017) periods. 


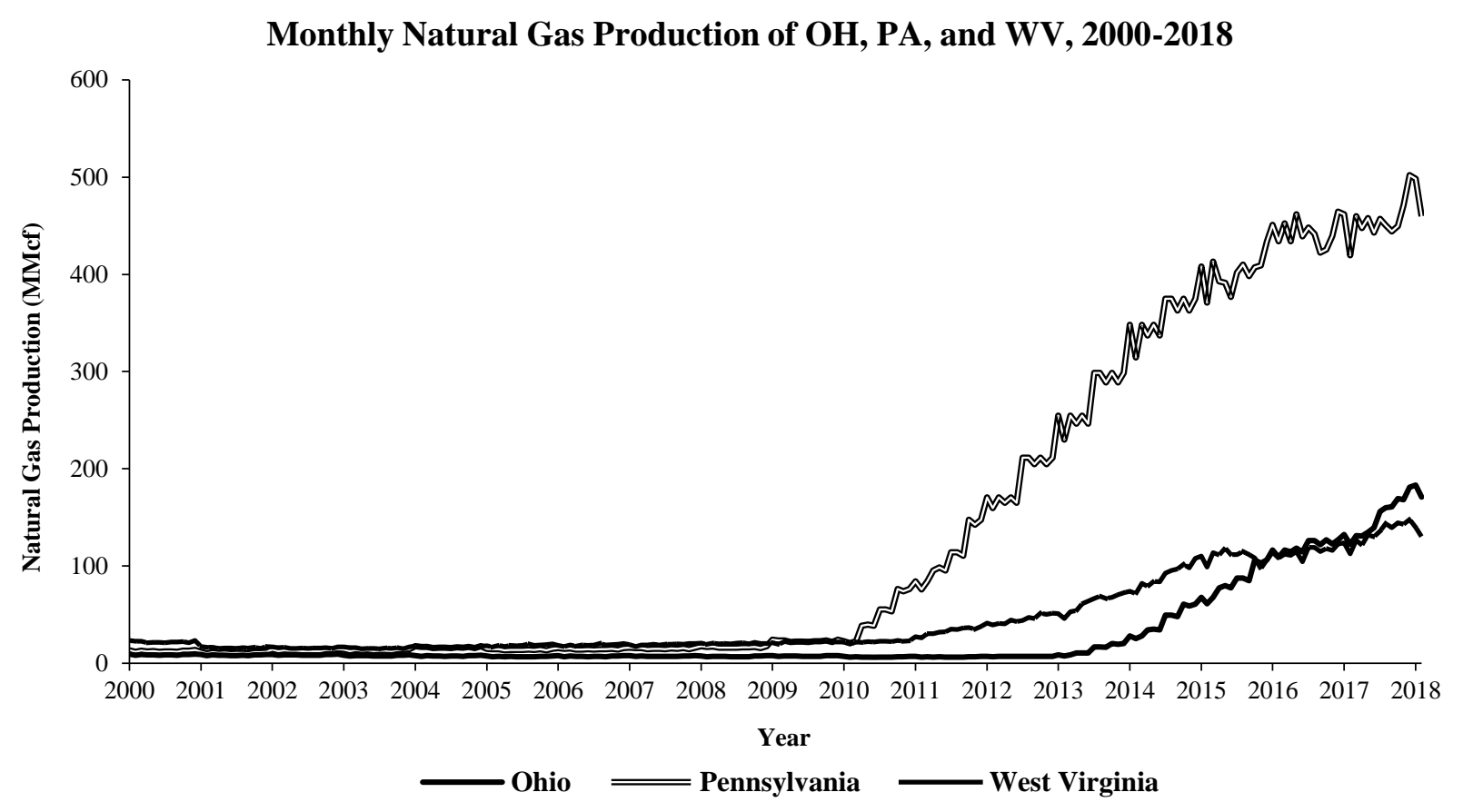

Source: US EIA, 2018a

Figure 3.1. Monthly Natural Gas Production of Ohio, Pennsylvania, and West Virginia, 2000-2018 


\section{Production by Shale Play and Marcellus \& Utica Production Share}

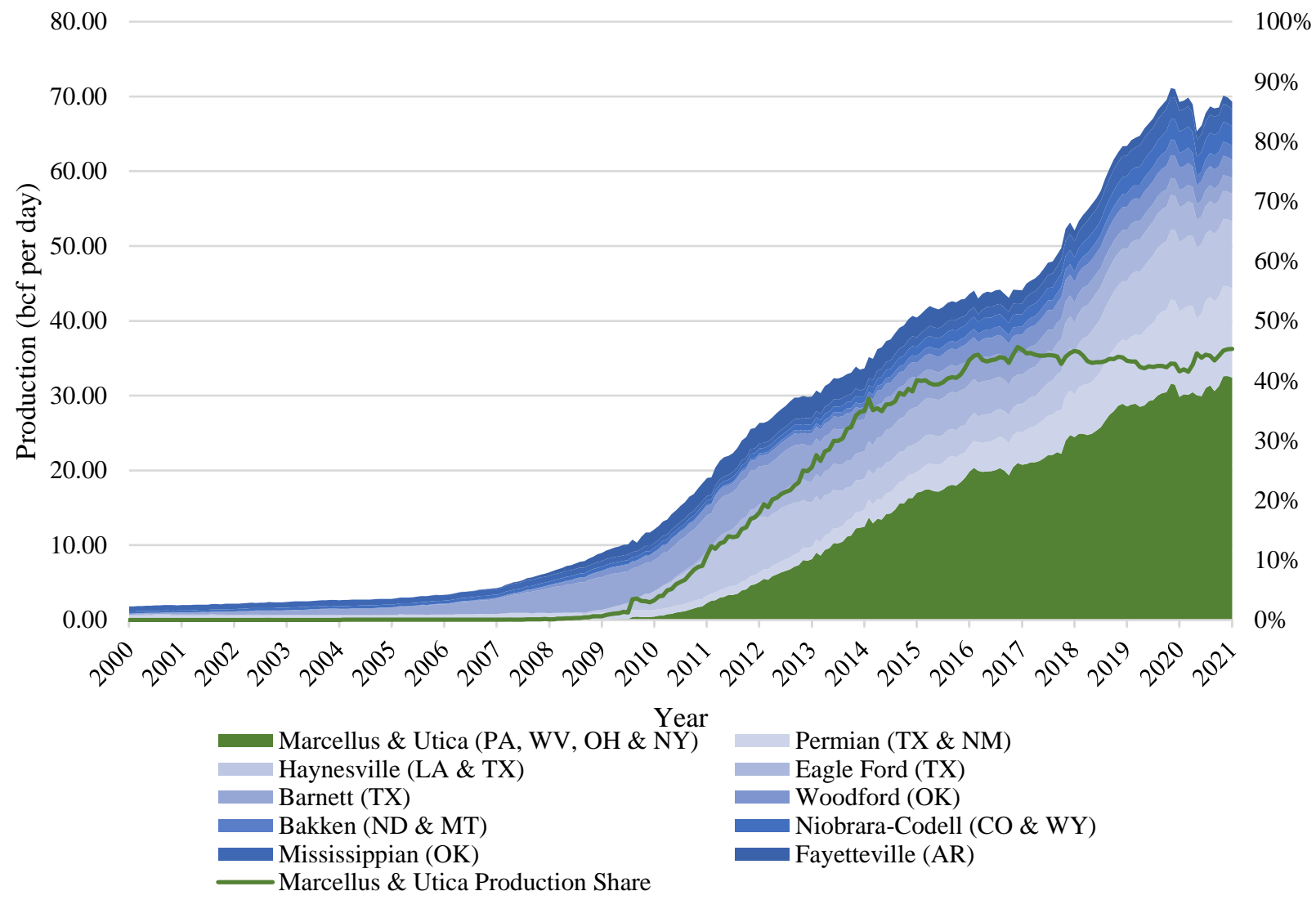

Source: US EIA

Figure 3.2. Production by Shale Play and Marcellus \& Utica Production Share 

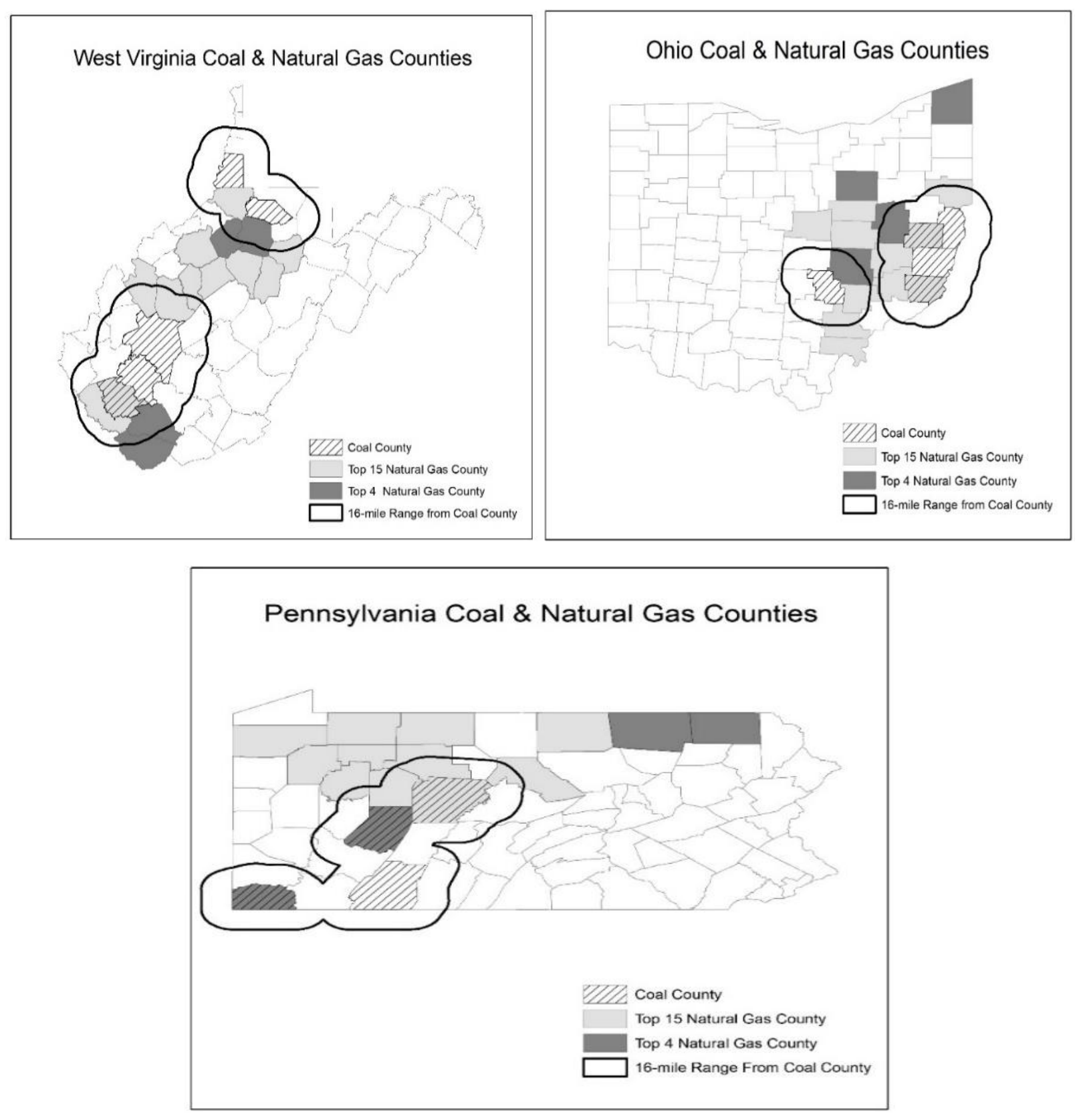

Figure 3.3. West Virginia (upper left), Ohio (upper right), and Pennsylvania (low) Top Coal and Oil \& Gas Counties 
WV4 Poverty Rate

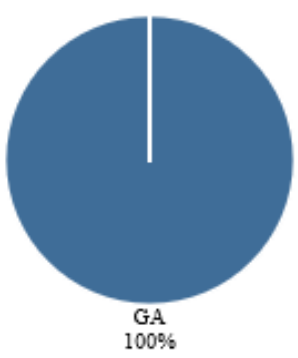

WV15 Poverty Rate $\begin{array}{lll}\text { IN } & \text { SD } \\ 5 \% & 2 \%\end{array}$ $9 \%$

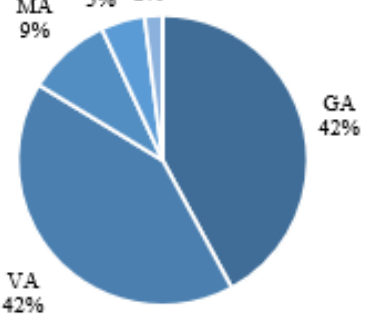

$42 \%$

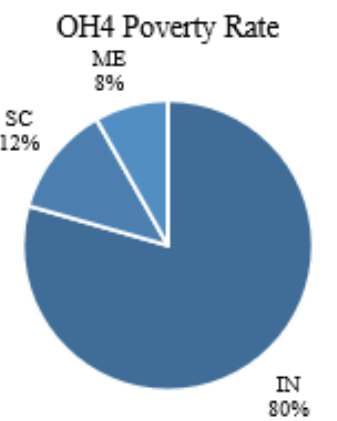

WV4 Population Growth

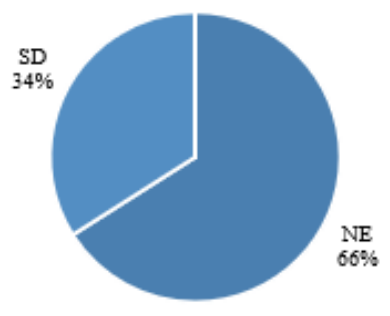

WV15 Population Growth

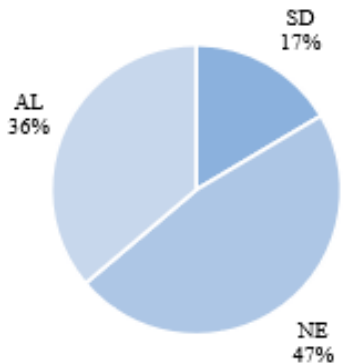

$\underset{47 \%}{\mathrm{NE}}$

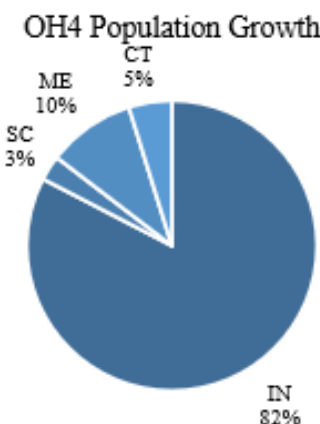

SD
WV4 Employment Growth

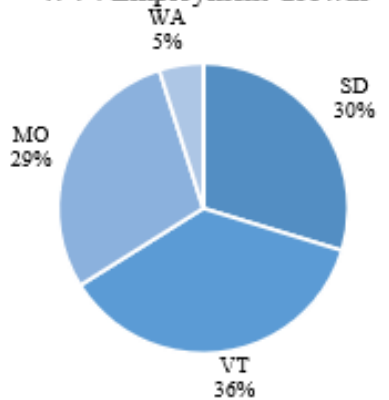

WV15 Employment Growth

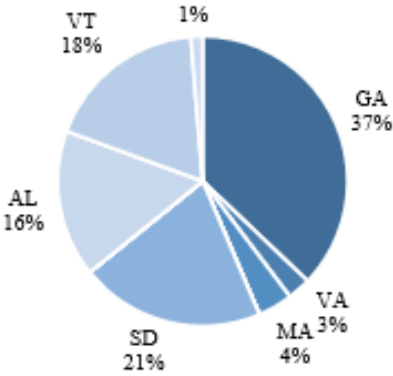

OH4 Employment Growth

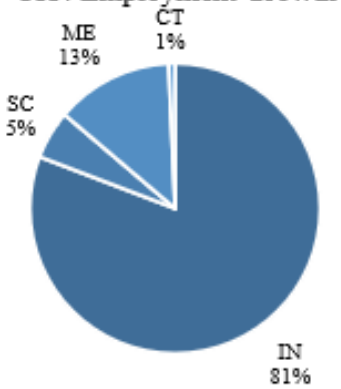

WV4 Personal Income per Capita Growth

VA

WA

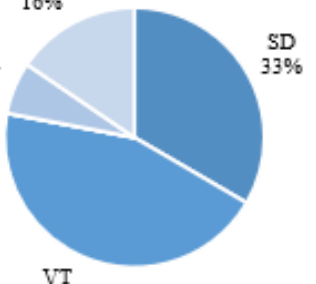

${ }_{45 \%}^{\mathrm{VT}}$

WV15 Personal Income pes Capita Growth

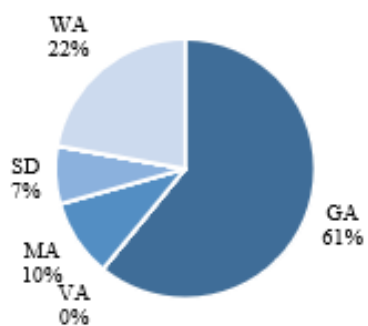

OH4 Personal Income per Capita Growth $\underset{13 \%}{\mathrm{CT}}$

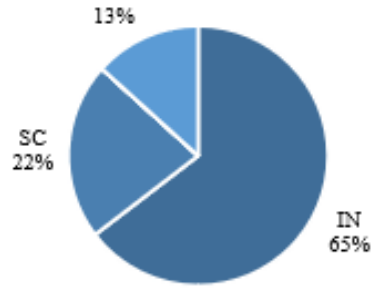

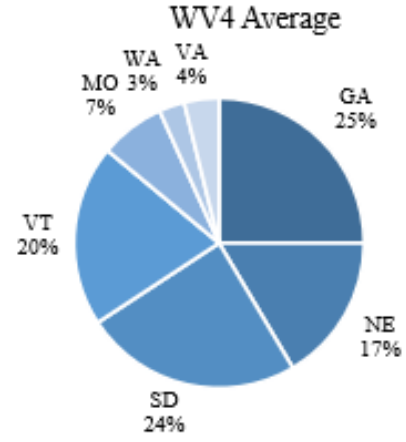

WV15 Average VT $6 \%$

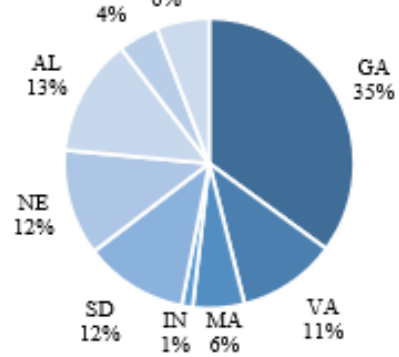

OH4 Average

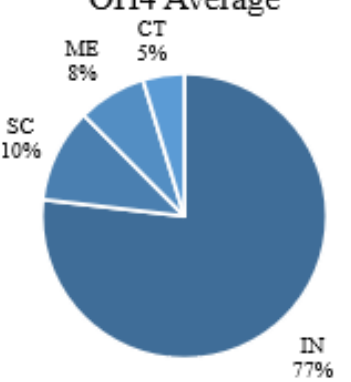

Figure 3.4. Optimal Weight Matrix for Top Oil and Gas Producing Counties in WV, OH, and PA. 

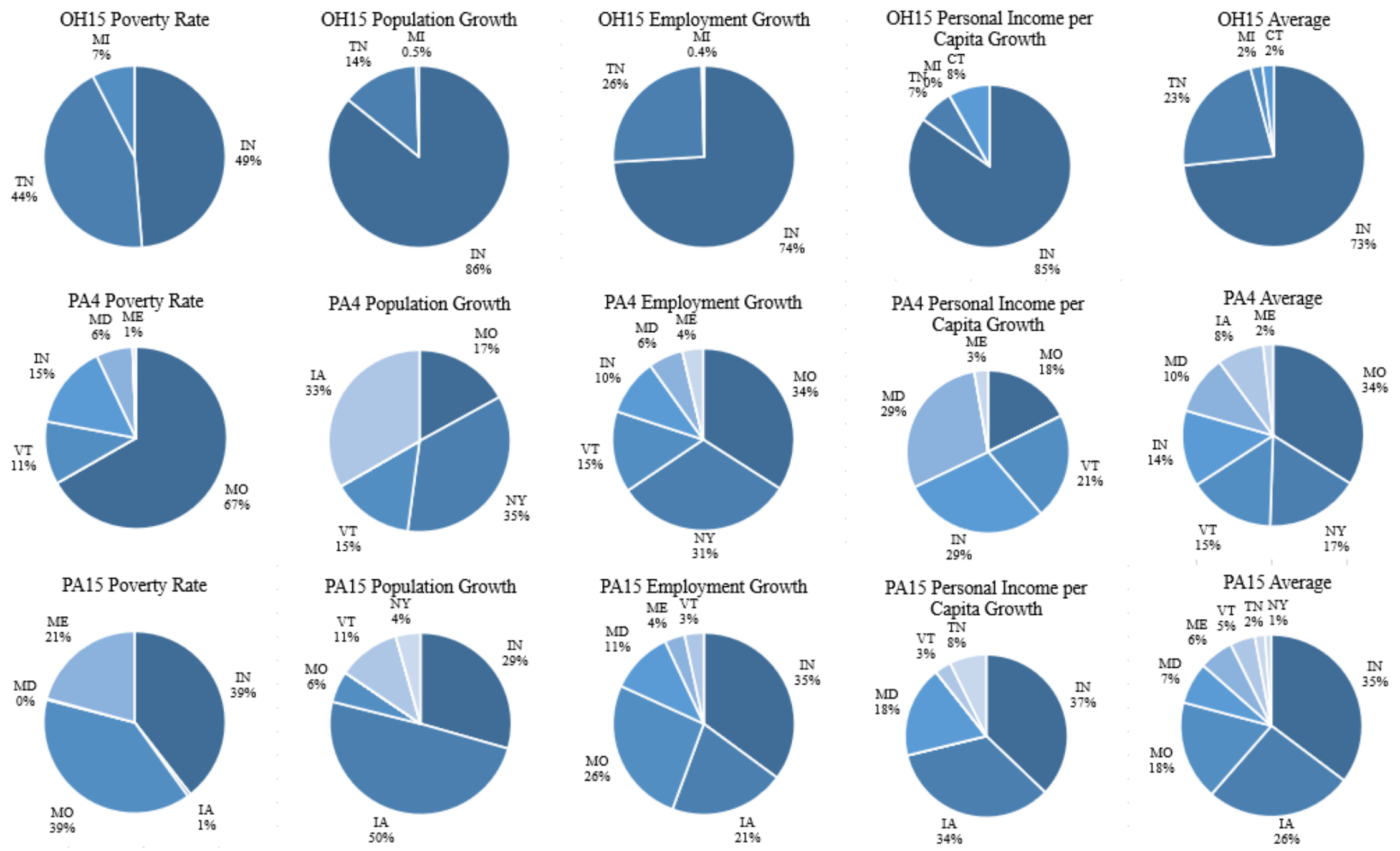

Figure 3.4 (continued). Optimal Weight Matrix for Top Oil and Gas Producing Counties in WV, OH, and PA. 


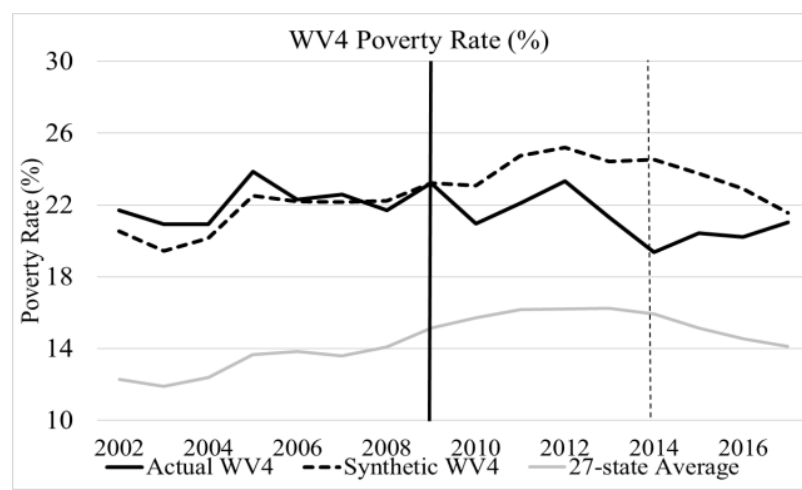

a. WV top 4 poverty rate

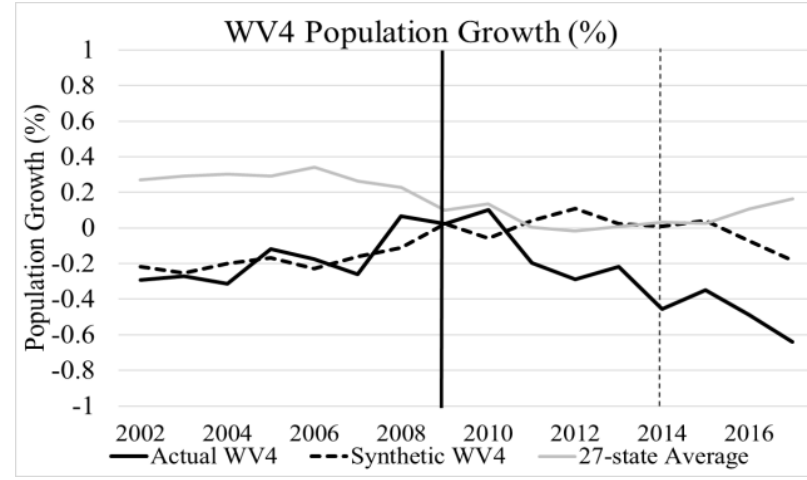

c. WV top 4 population growth

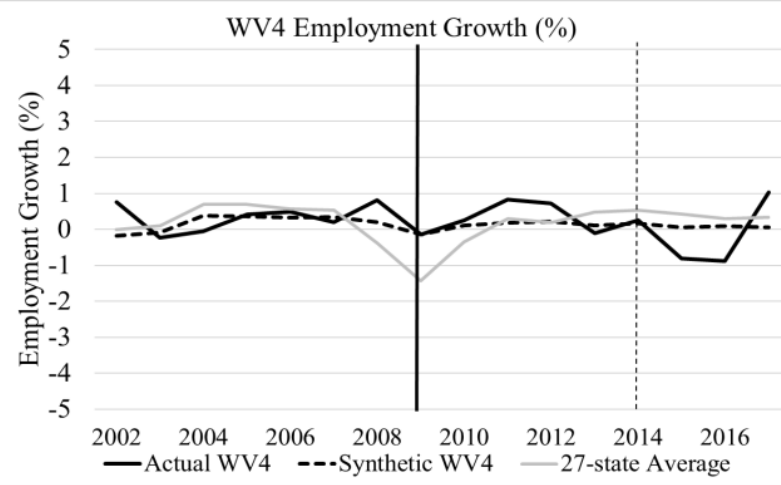

e. WV top 4 employment growth

WV4 Personal Income per Capita Growth (\%)

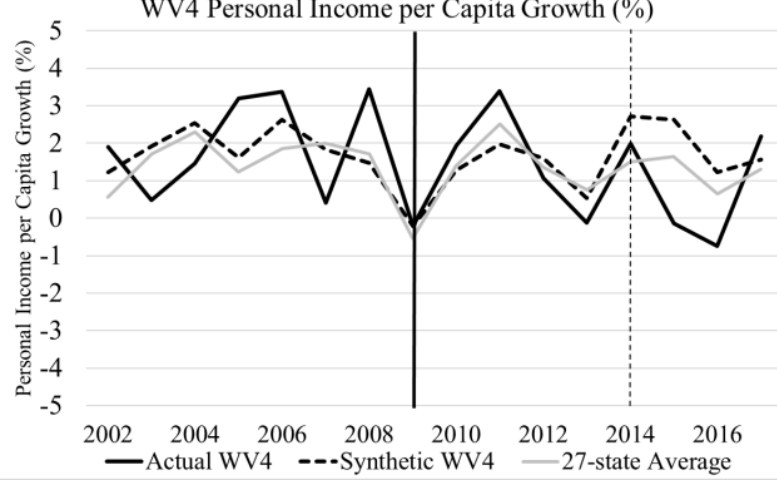

g. WV top 4 income per capita growth

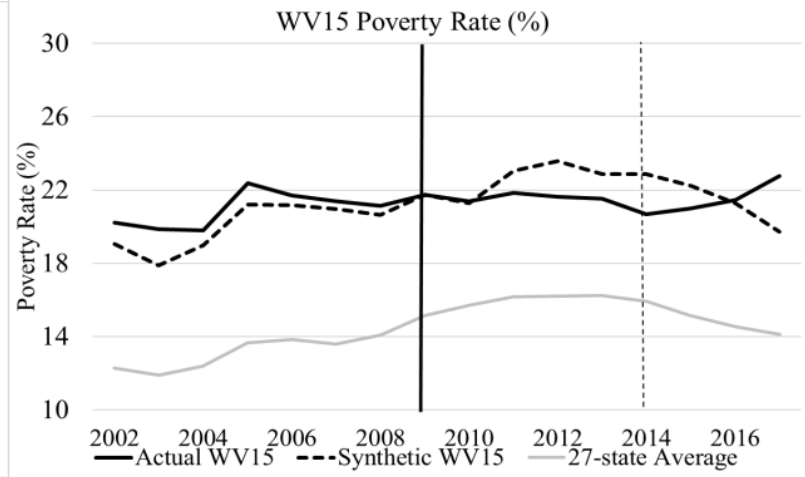

b. WV top 15 poverty rate

WV15 Population Growth (\%)

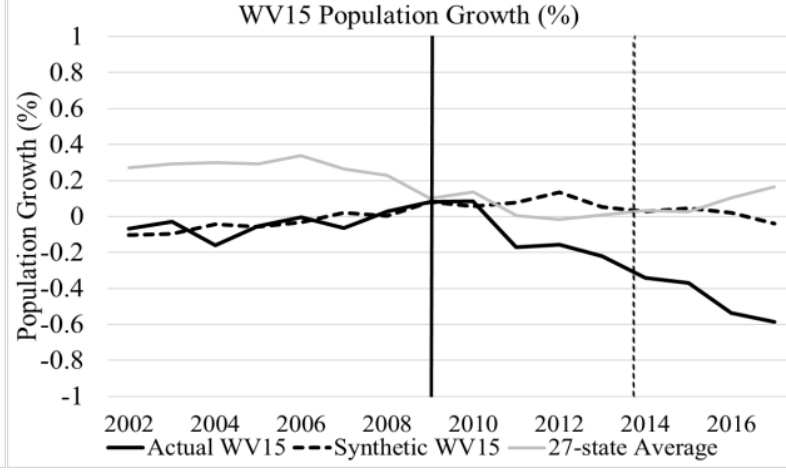

d. WV top 15 population growth

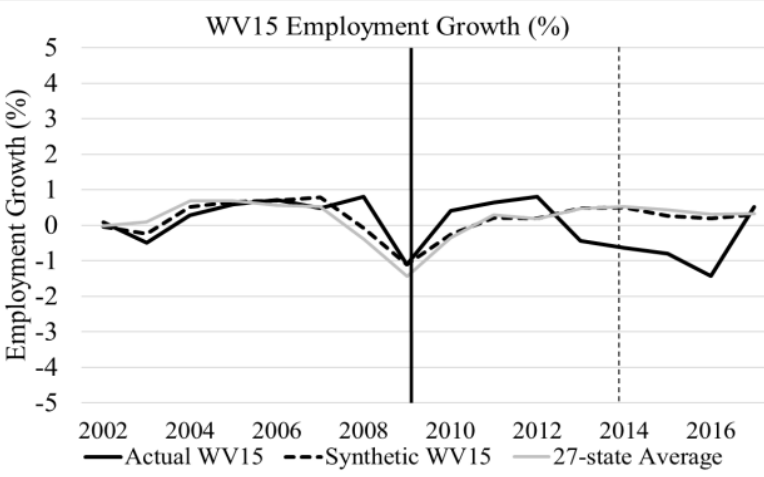

f. WV top 15 employment growth

WV15 Personal Income per Capita Growth (\%)

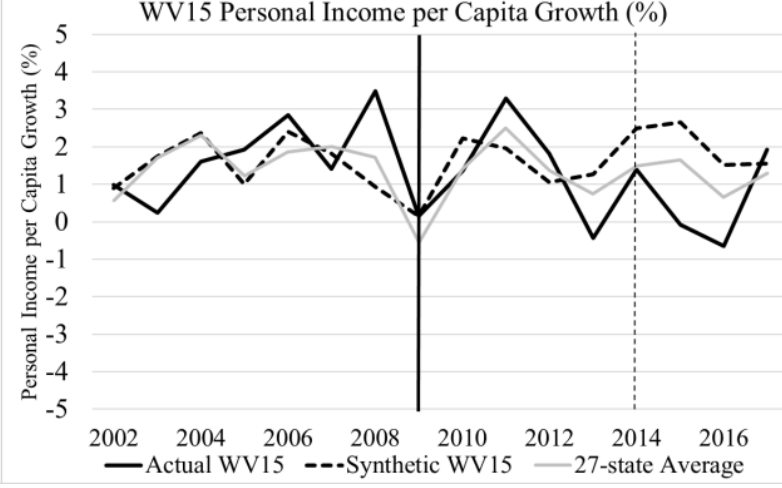

h. WV top 15 income per capita growth

Figure 3.5. Estimated Impacts of Shale Boom on Top Oil \& Gas Counties in West Virginia 


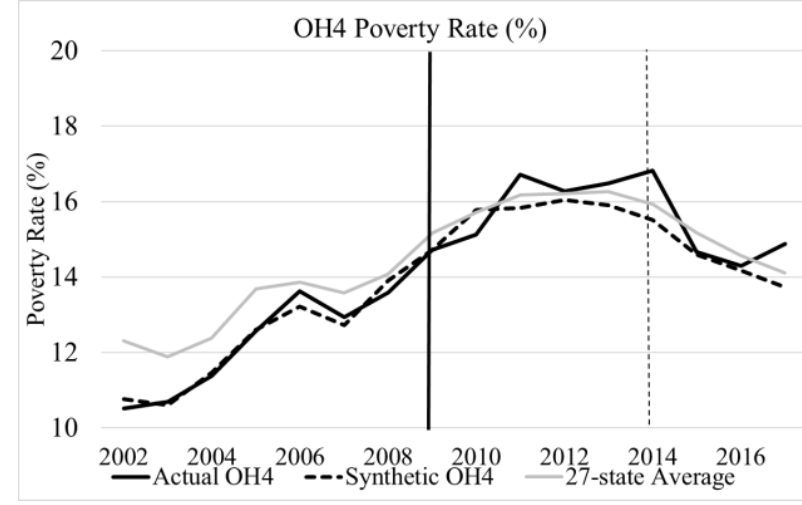

a. OH top 4 poverty rate

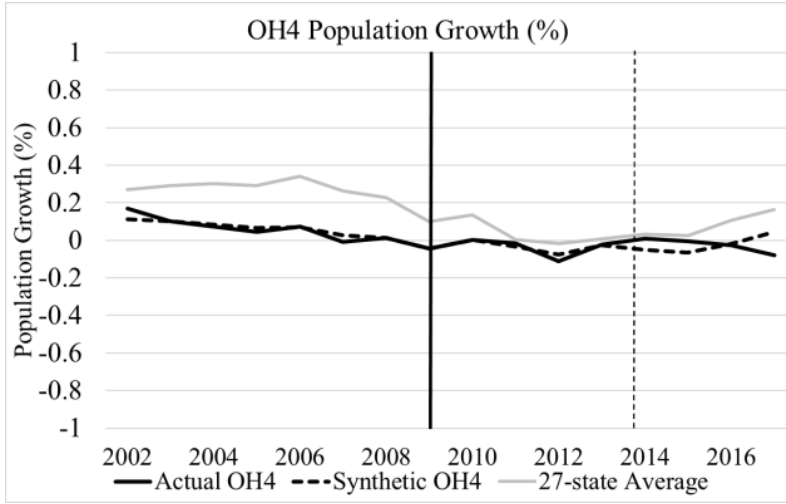

c. $\mathrm{OH}$ top 4 population growth

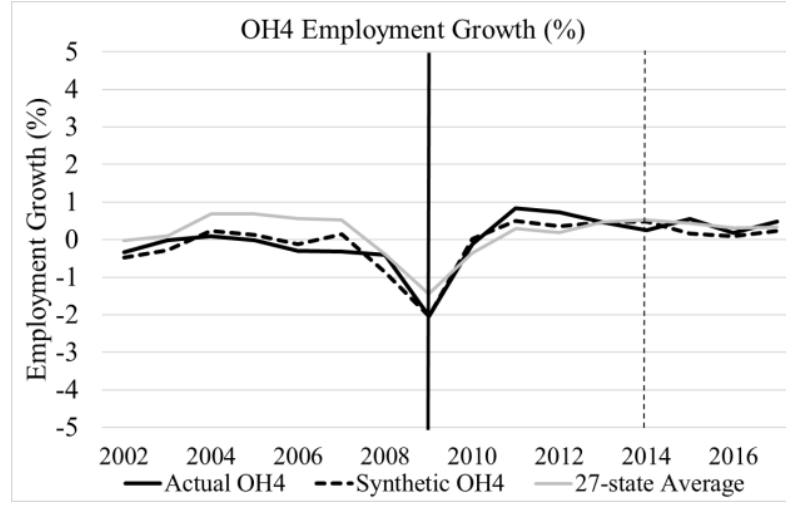

e. OH top 4 employment growth

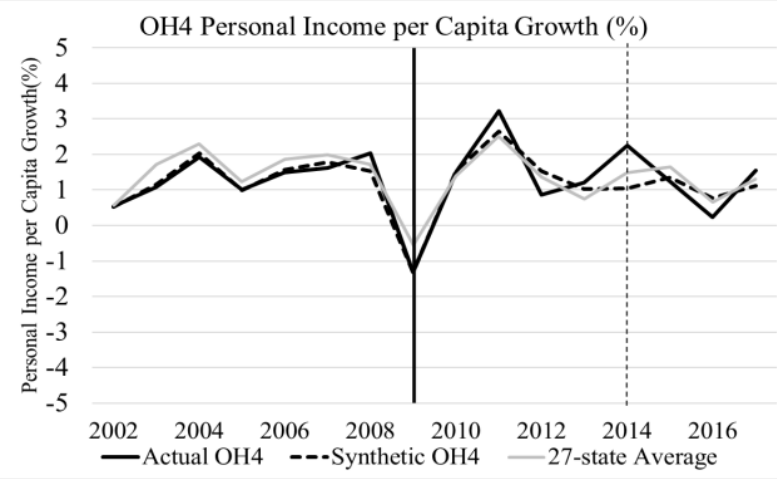

g. OH top 4 income per capita growth

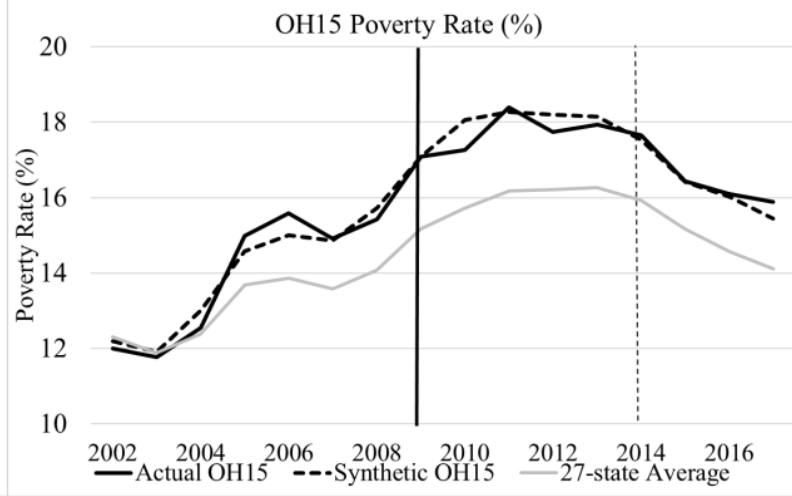

b. OH top 15 poverty rate

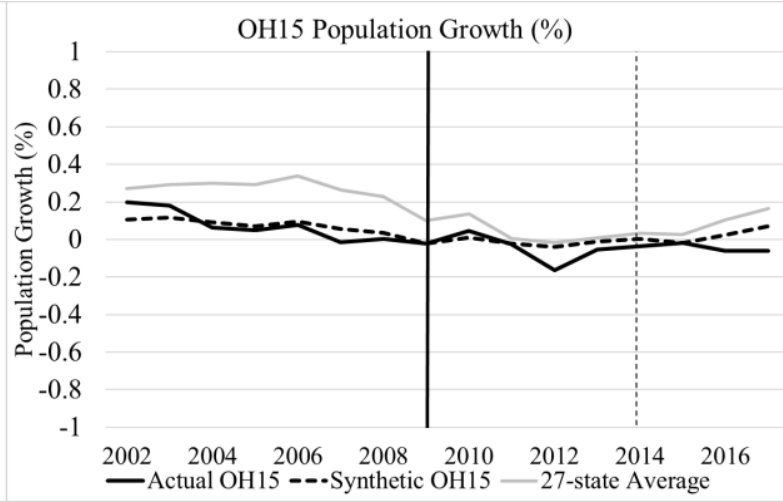

d. OH top 15 population growth

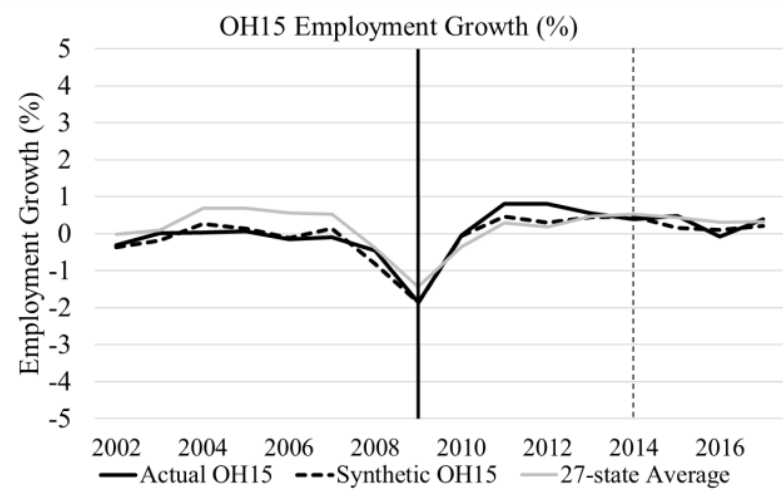

f. OH top 15 employment growth

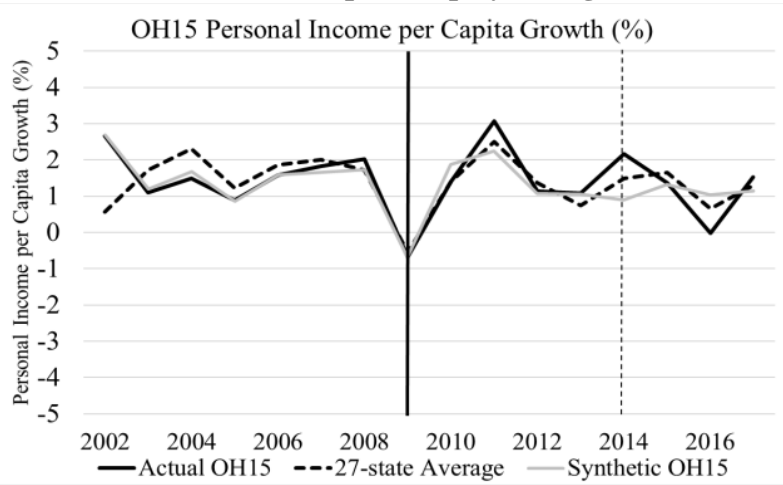

h. OH top 15 income per capita growth

Figure 3.6. Estimated Impacts of Shale Boom on Top Oil \& Gas Counties in Ohio 


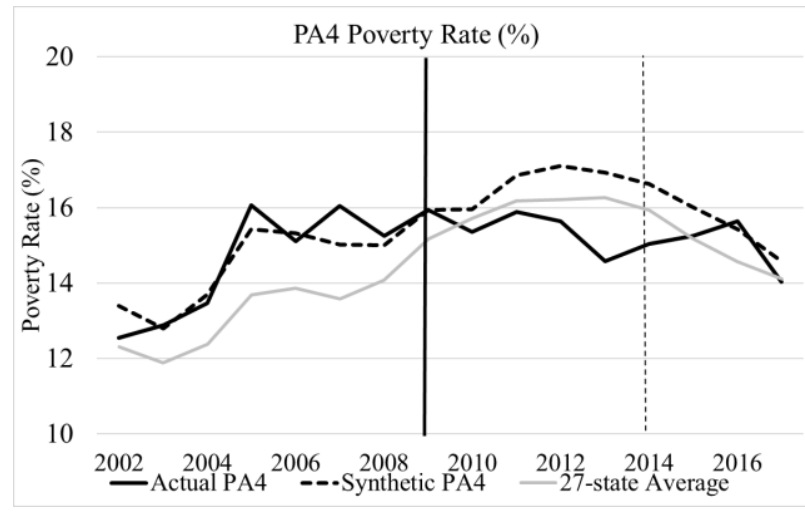

a. PA top 4 poverty rate

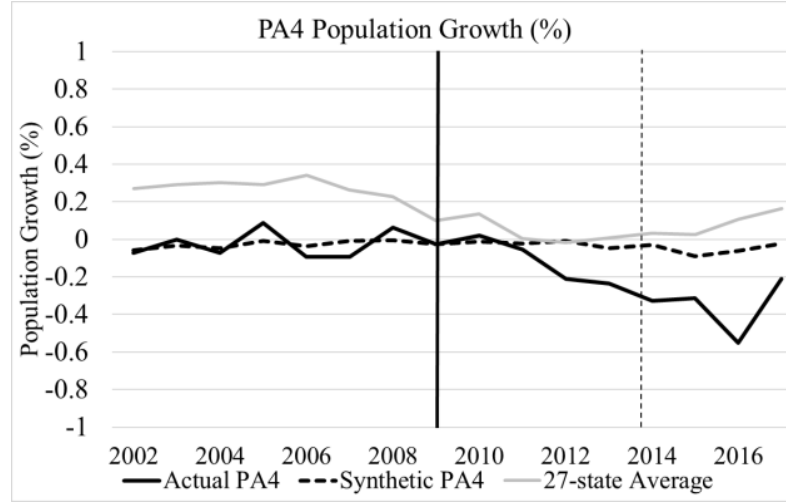

c. PA top 4 population growth

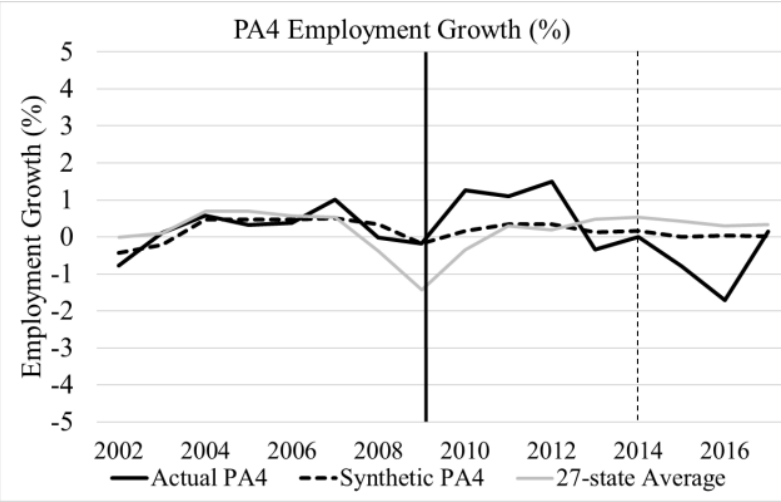

e. PA top 4 employment growth

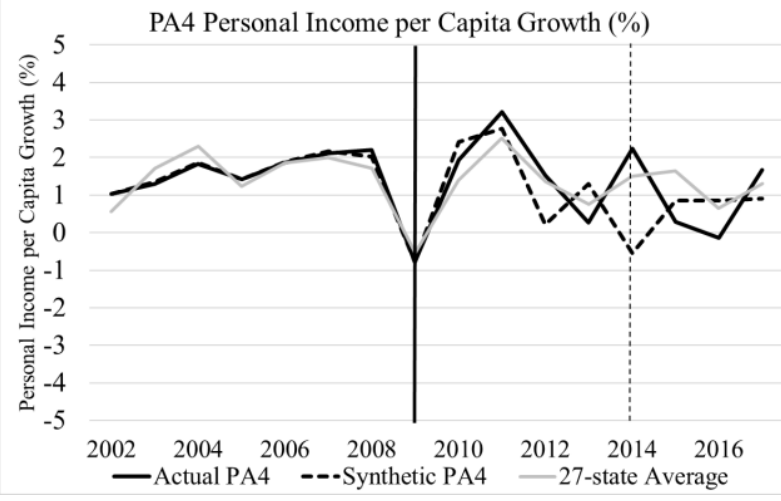

g. PA top 4 income growth

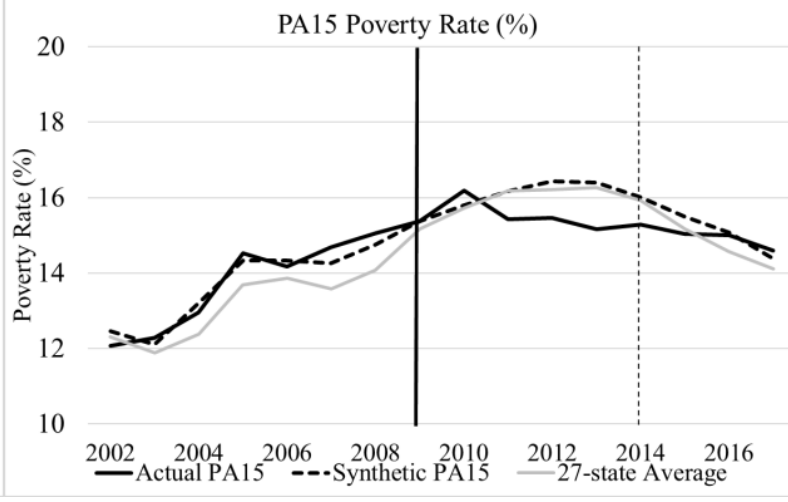

b. PA top 15 poverty rate

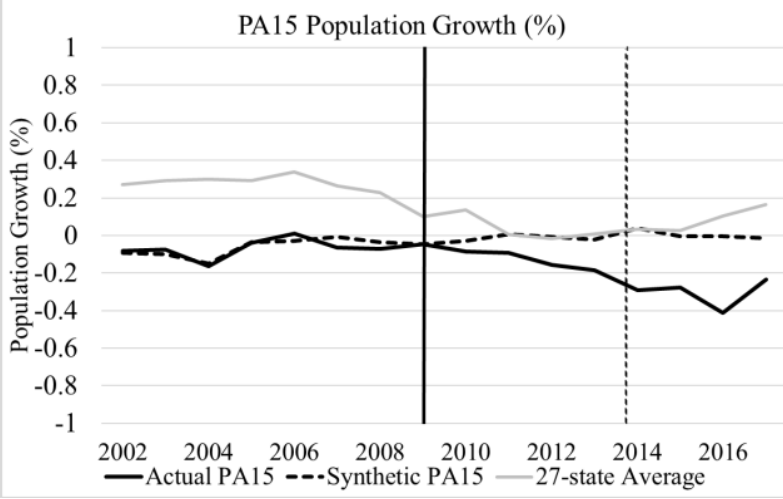

d. PA top 15 population growth

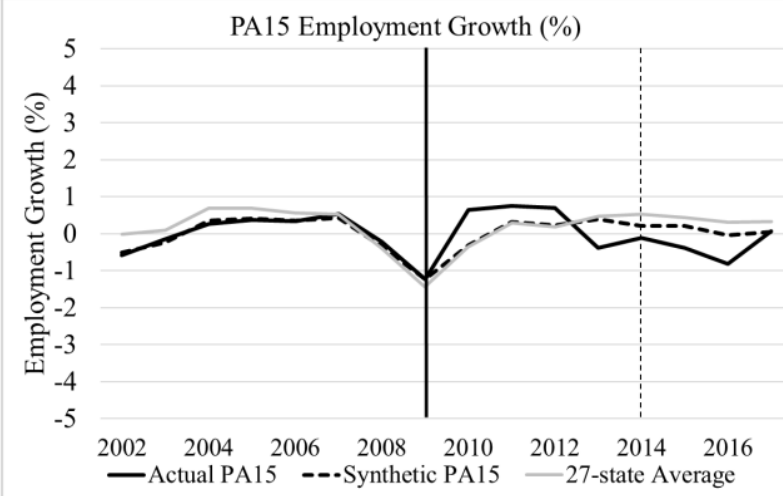

f. PA top 15 employment growth

PA15 Personal Income per Capita Growth (\%)

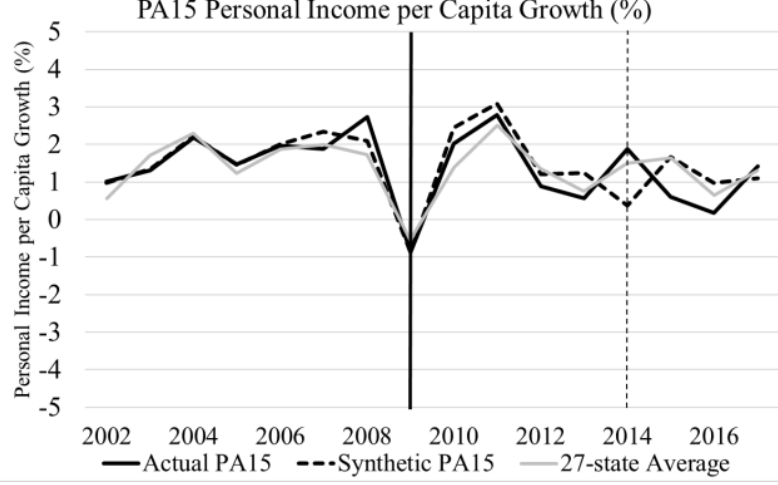

h. PA top 15 income growth

Figure 3.7. Estimated Impacts of Shale Boom on Top Oil \& Gas Counties in Pennsylvania 


\section{Appendix A}

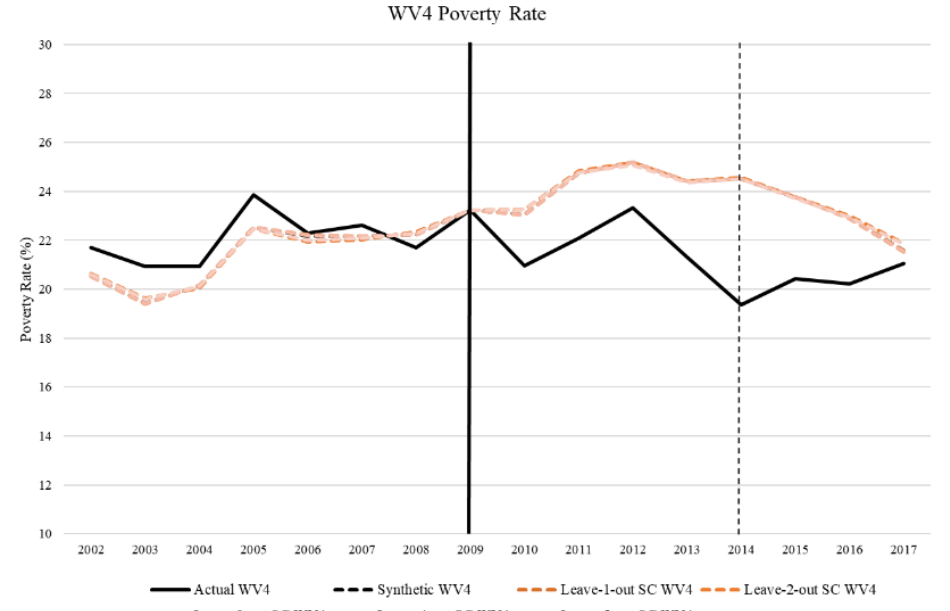

a. WV top 4 poverty rate

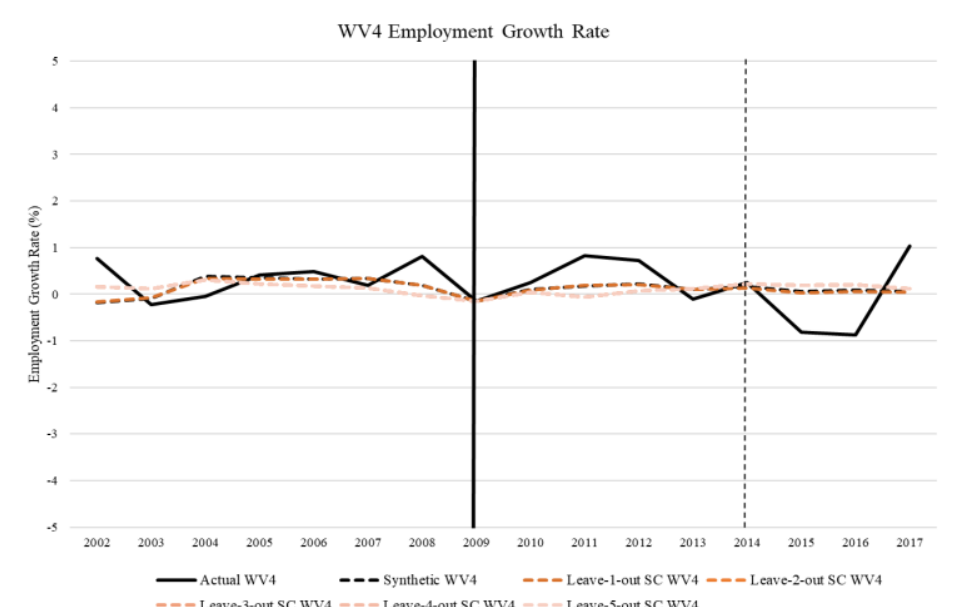

c. WV top 4 employment growth

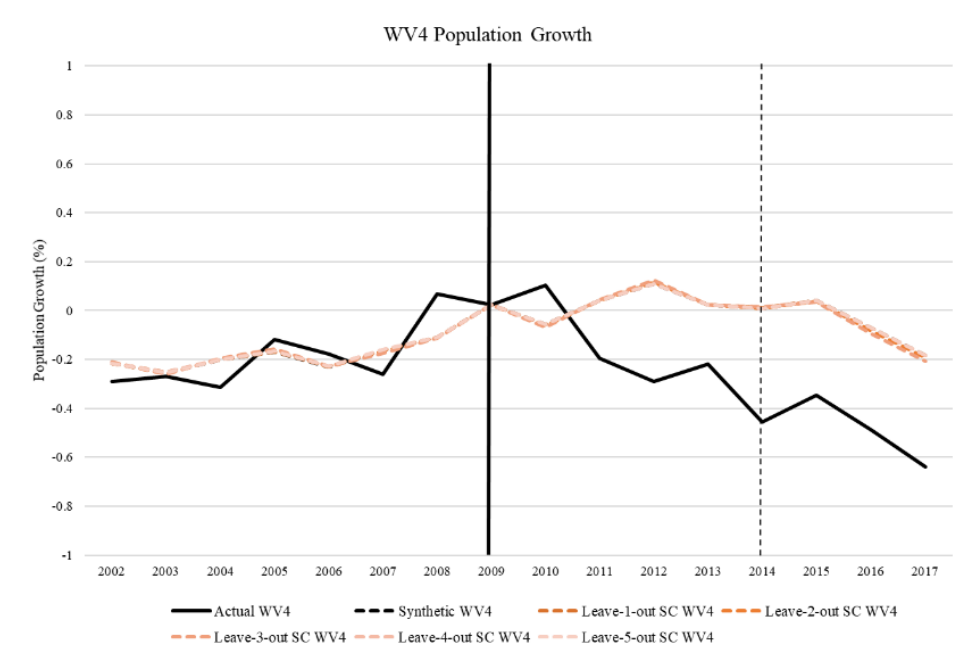

b. WV top 4 population growth

WV4 Personal Income per Capita

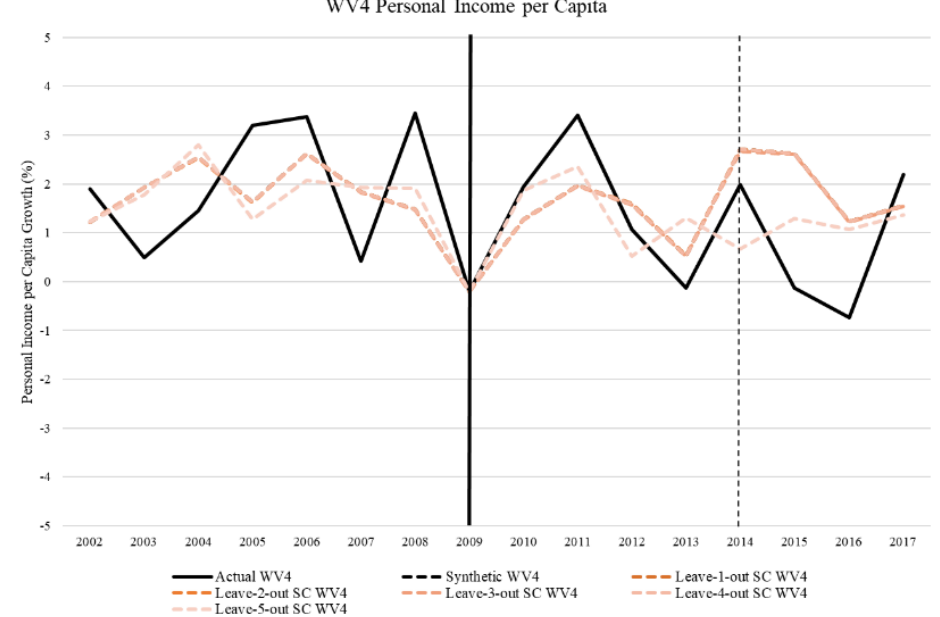

d. WV top 4 income growth

Figure 3.A1. Leave-one-out Robustness Test Results for WV4 


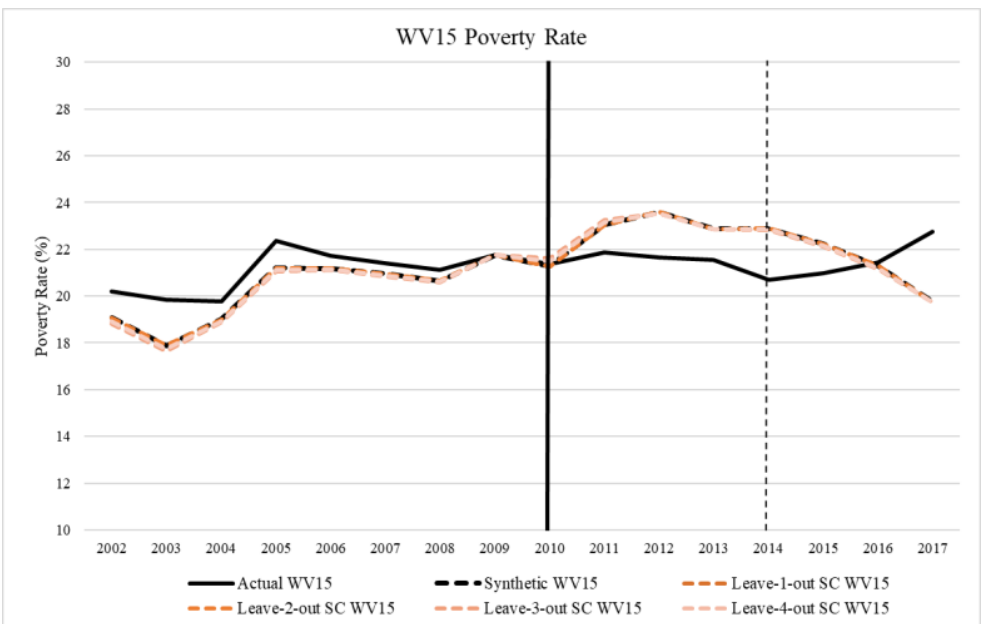

a. WV top 15 poverty rate

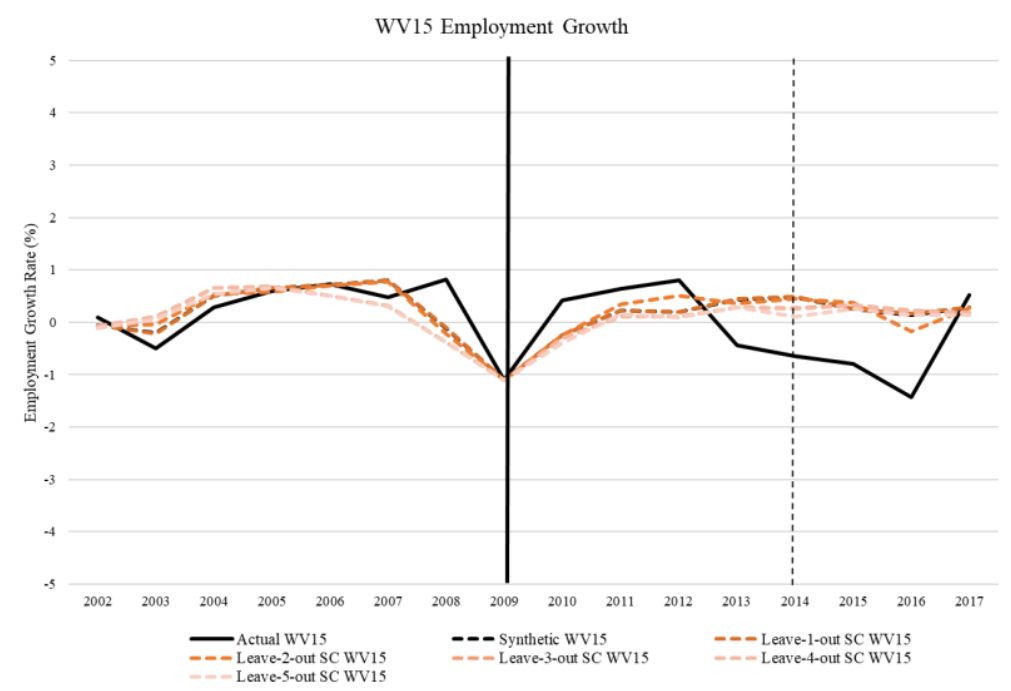

c. WV top 15 employment growth

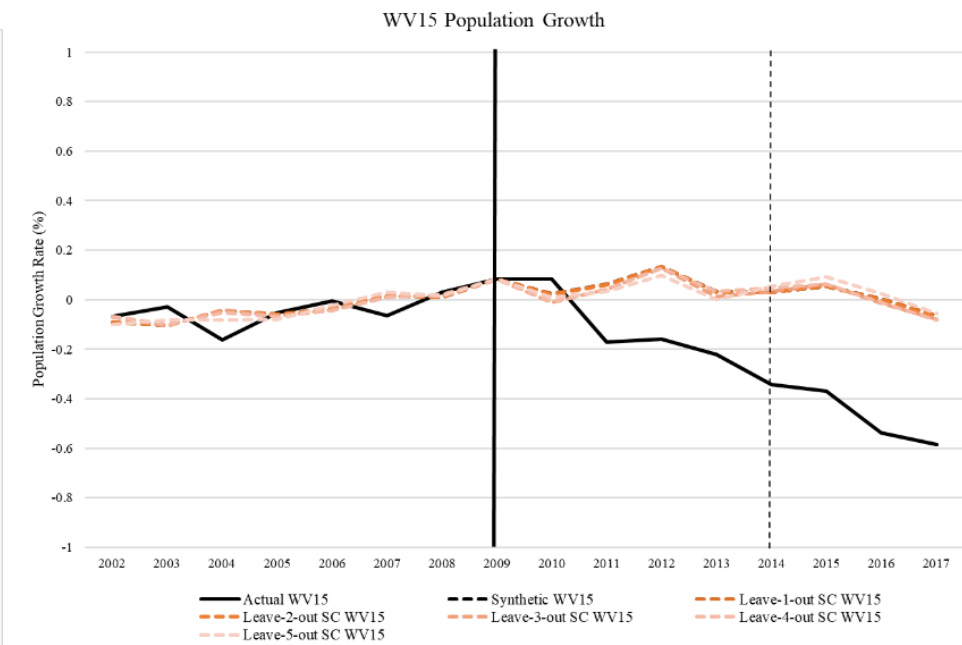

b. WV top 15 population growth

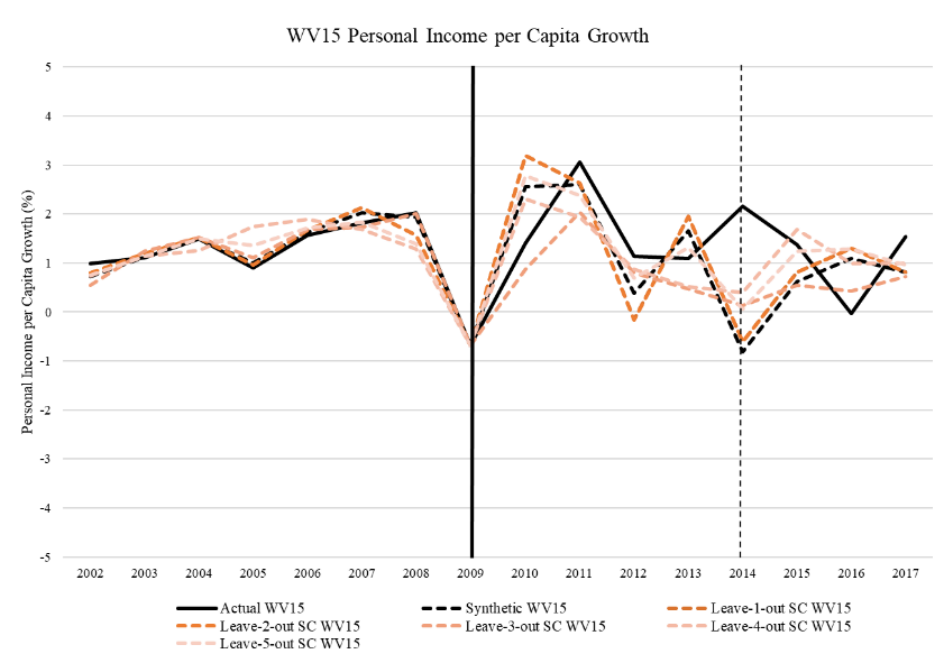

d. WV top 15 income growth

Figure 3.A2. Leave-one-out Robustness Test Results for WV15 


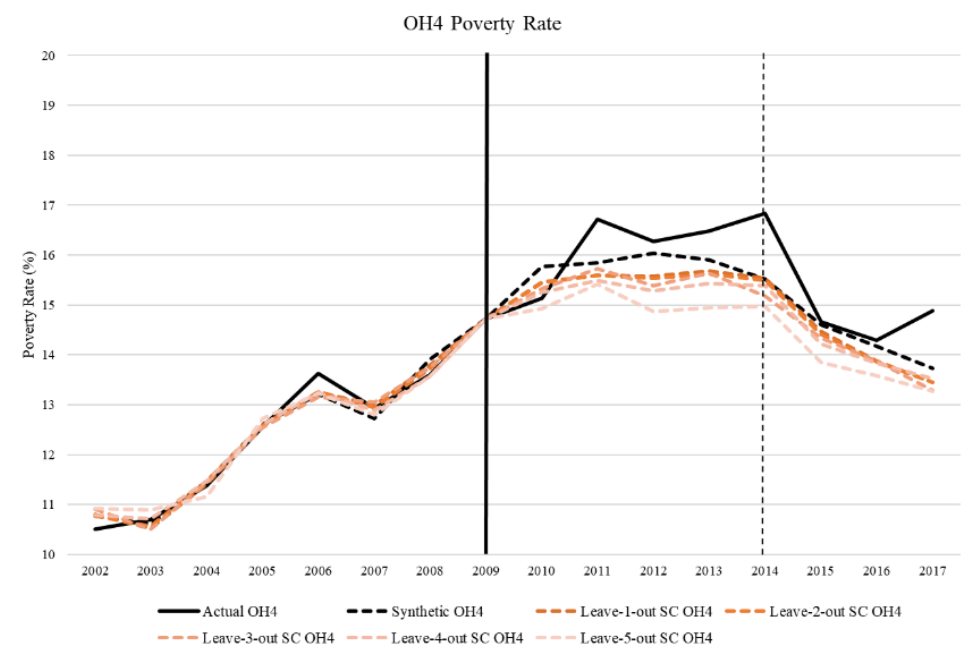

a. OH top 4 poverty rate

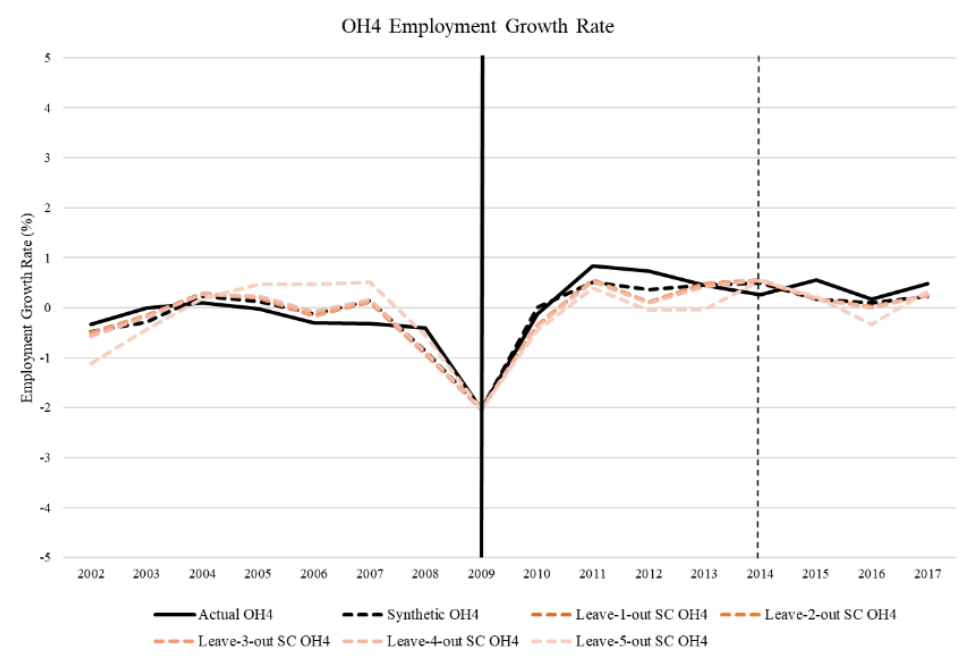

c. OH top 4 employment growth

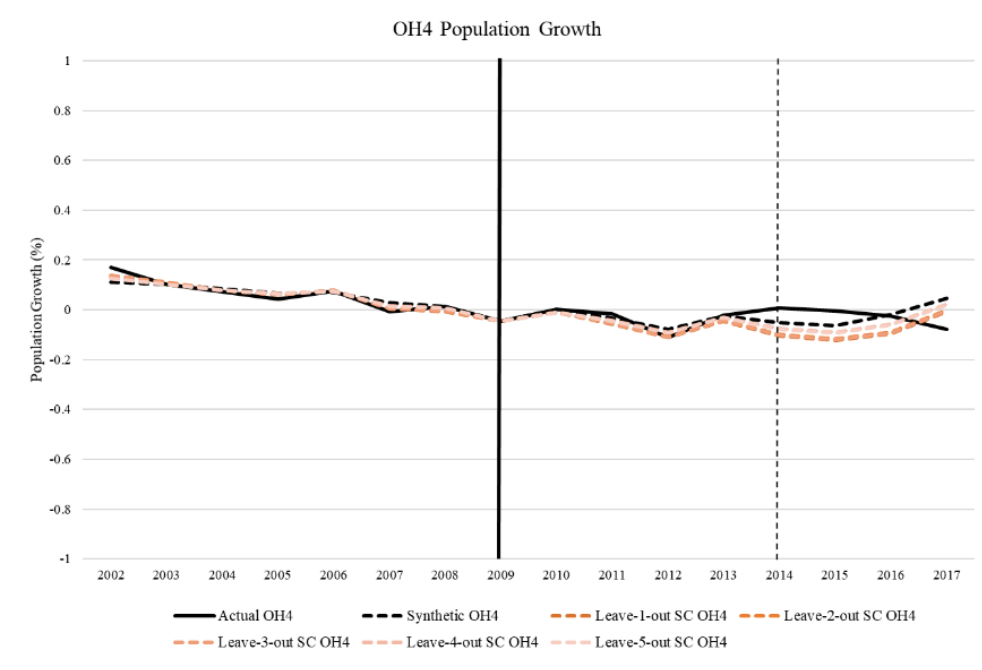

b. $\mathrm{OH}$ top 4 population growth

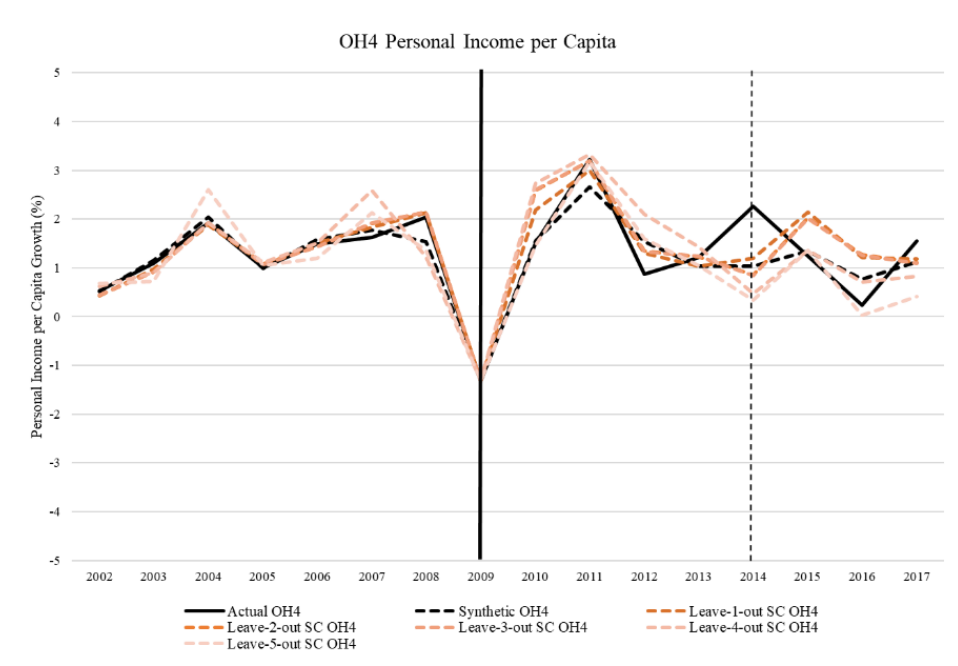

d. OH top 4 income growth

Figure 3.A3. Leave-one-out Robustness Test Results for $\mathrm{OH} 4$ 


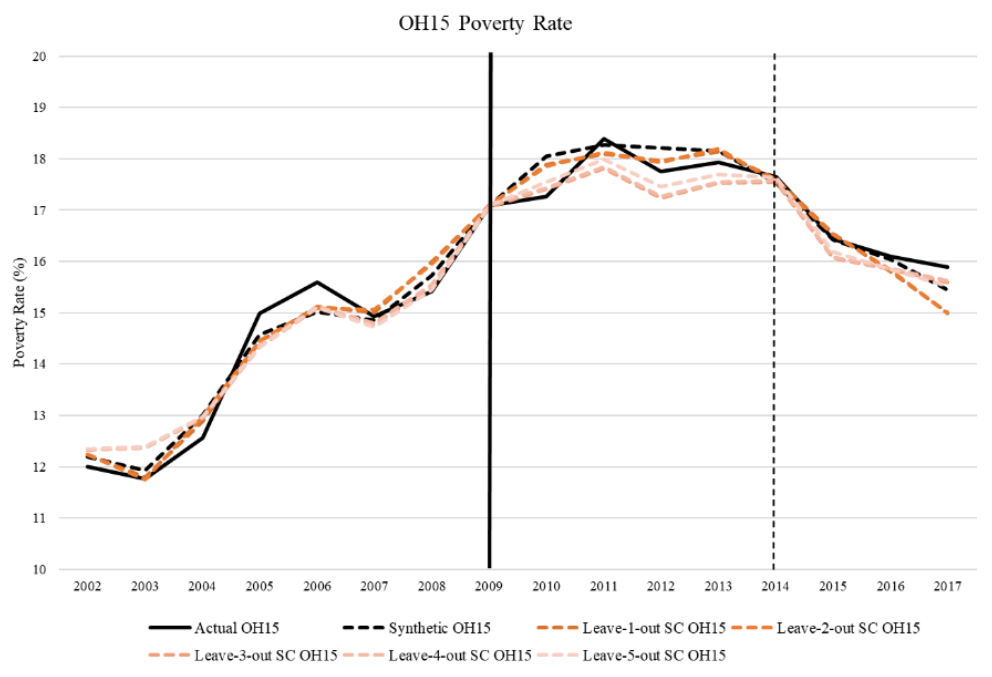

a. OH top 15 poverty rate

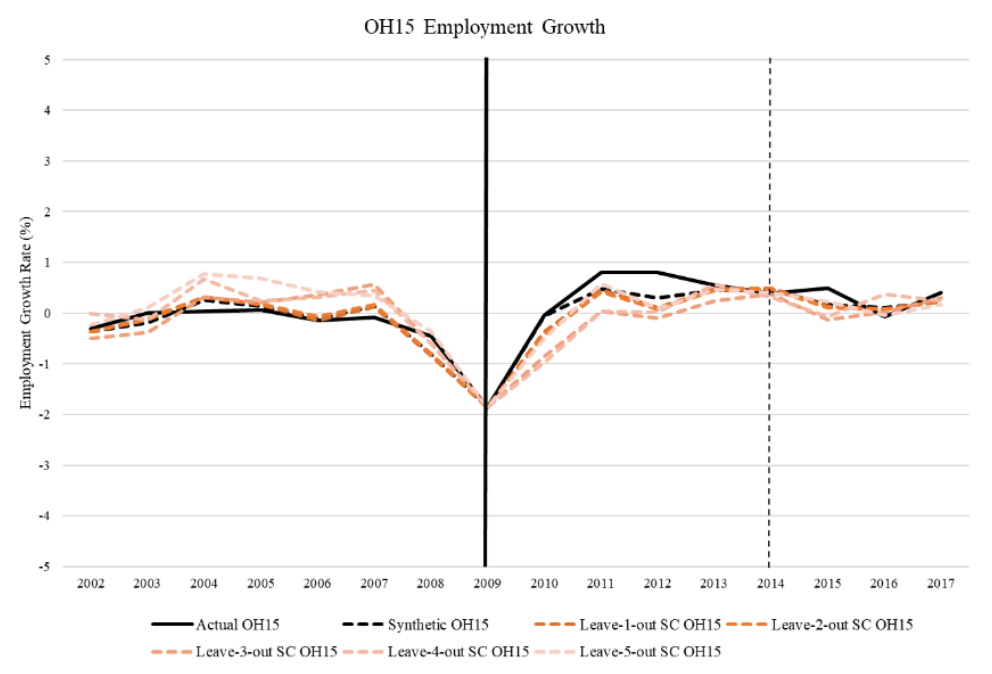

c. OH top 15 employment growth

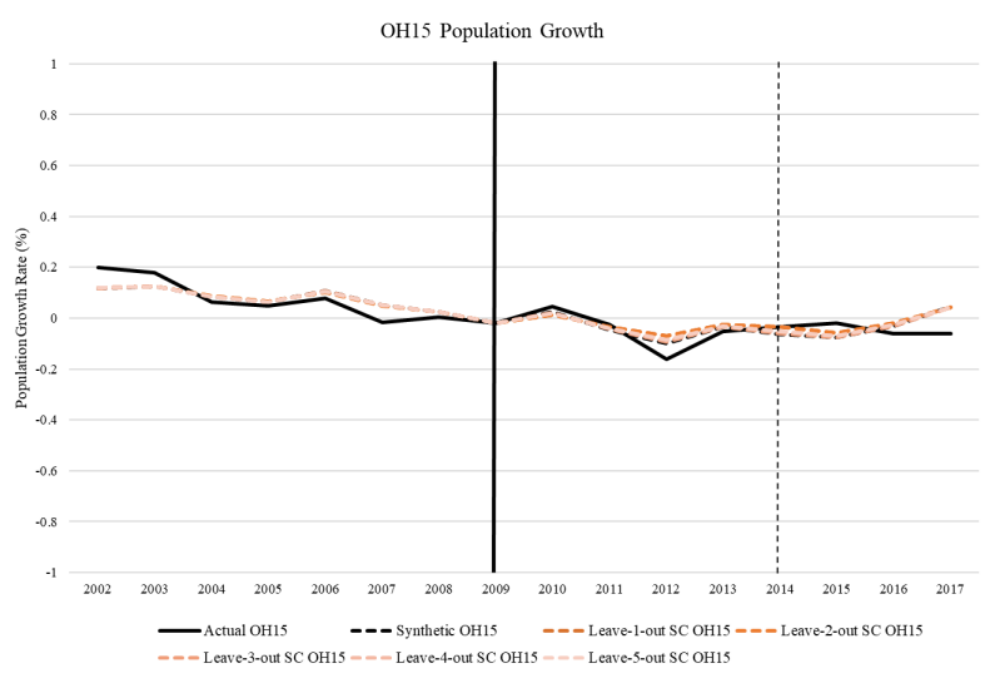

b. OH top 15 population growth

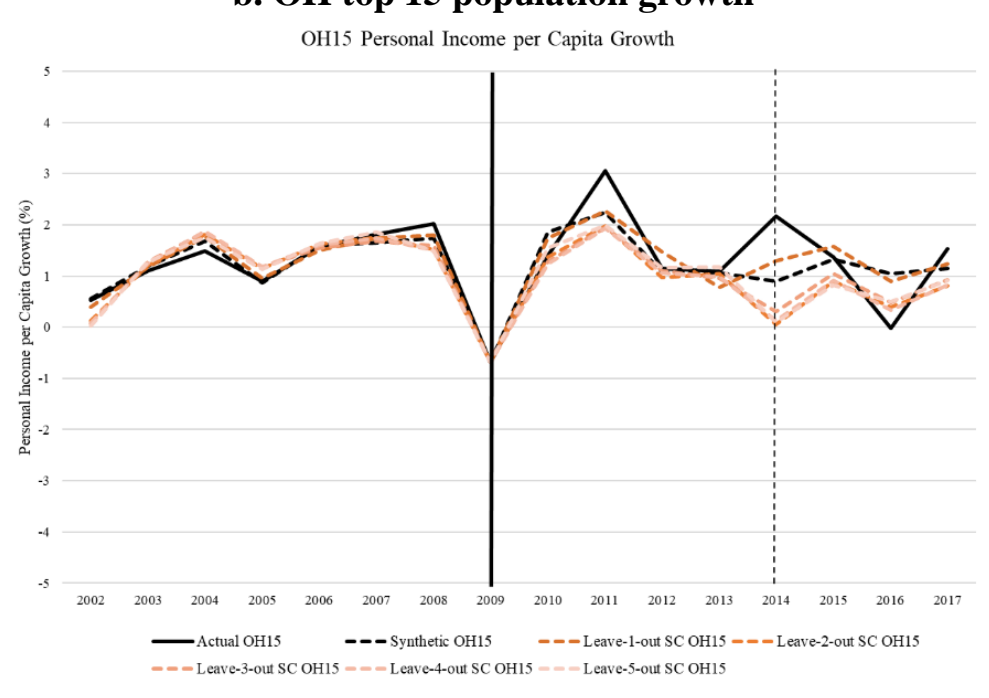

d. OH top 15 income growth

Figure 3.A4. Leave-one-out Robustness Test Results for OH15 


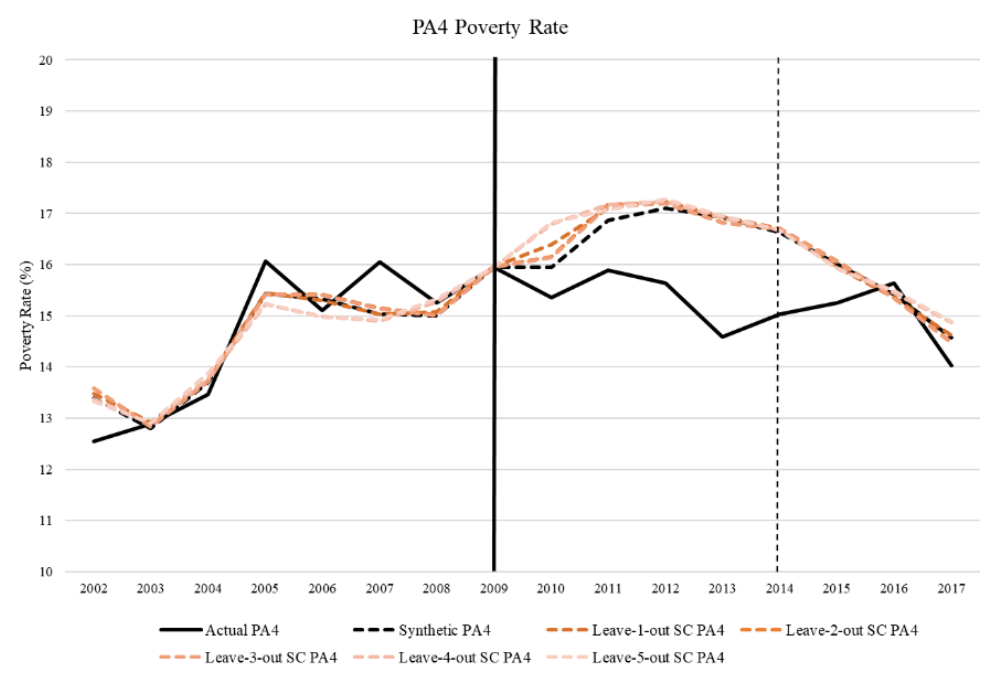

a. PA top 4 poverty rate

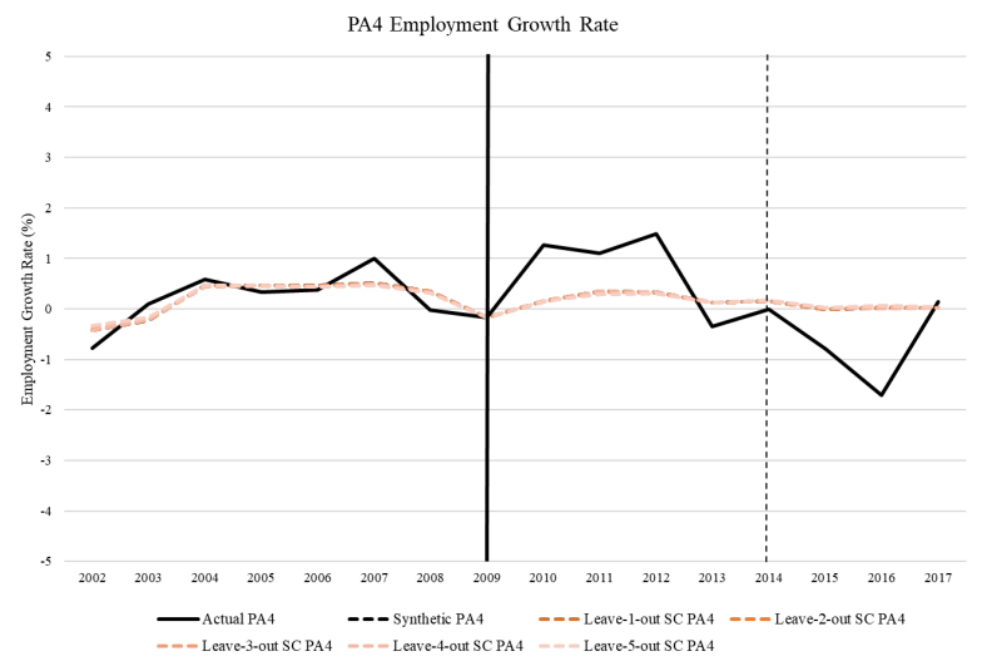

c. PA top 4 employment growth

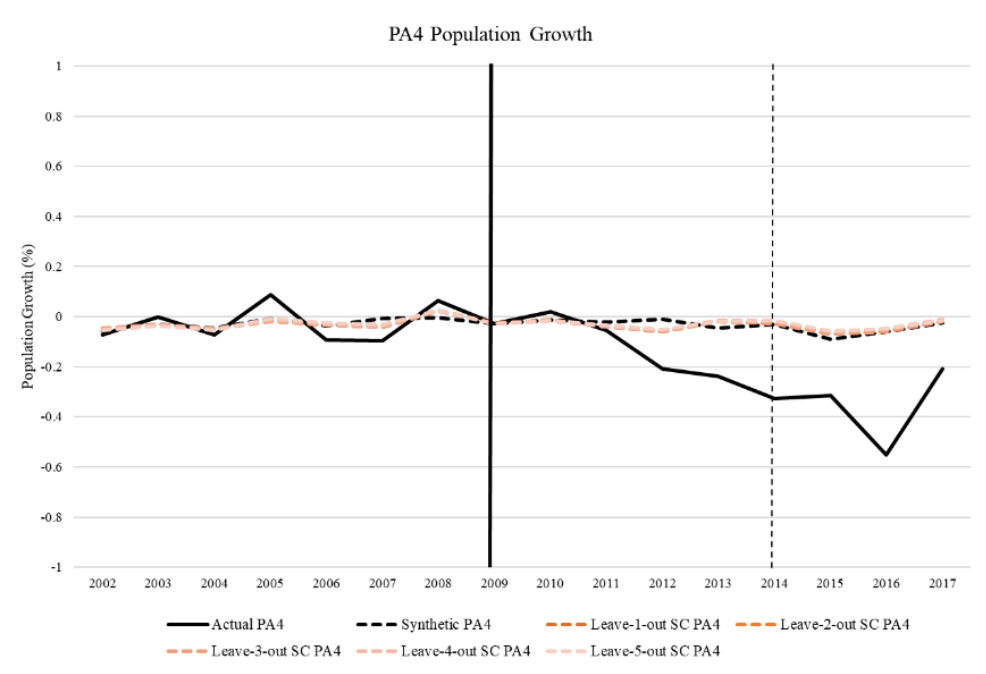

b. PA top 4 population growth

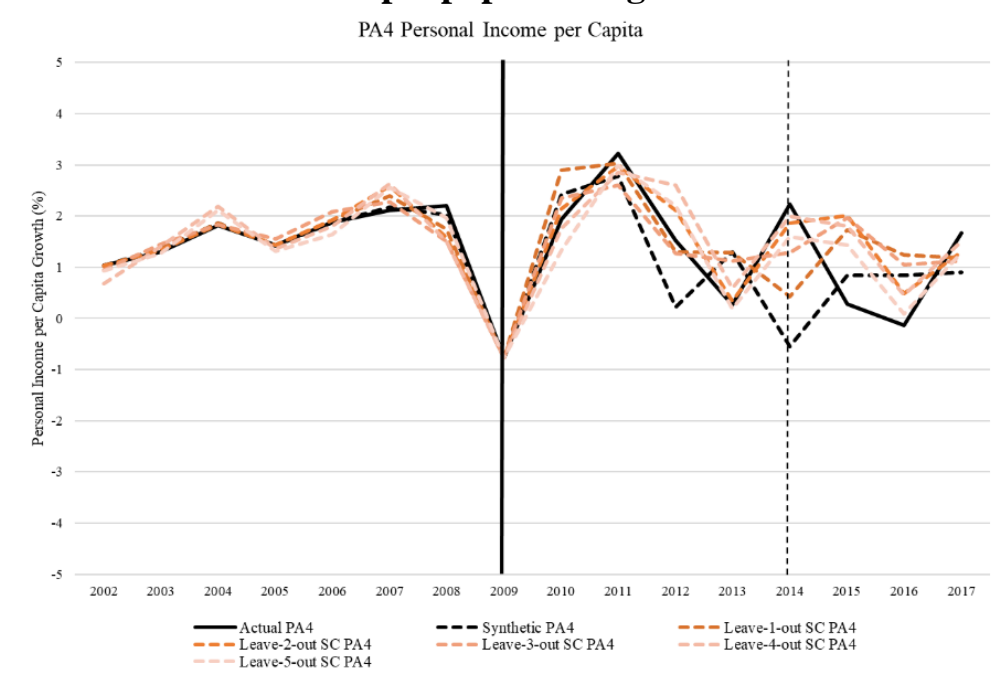

d. PA top 4 income growth

Figure 3.A5. Leave-one-out Robustness Test Results for PA4 


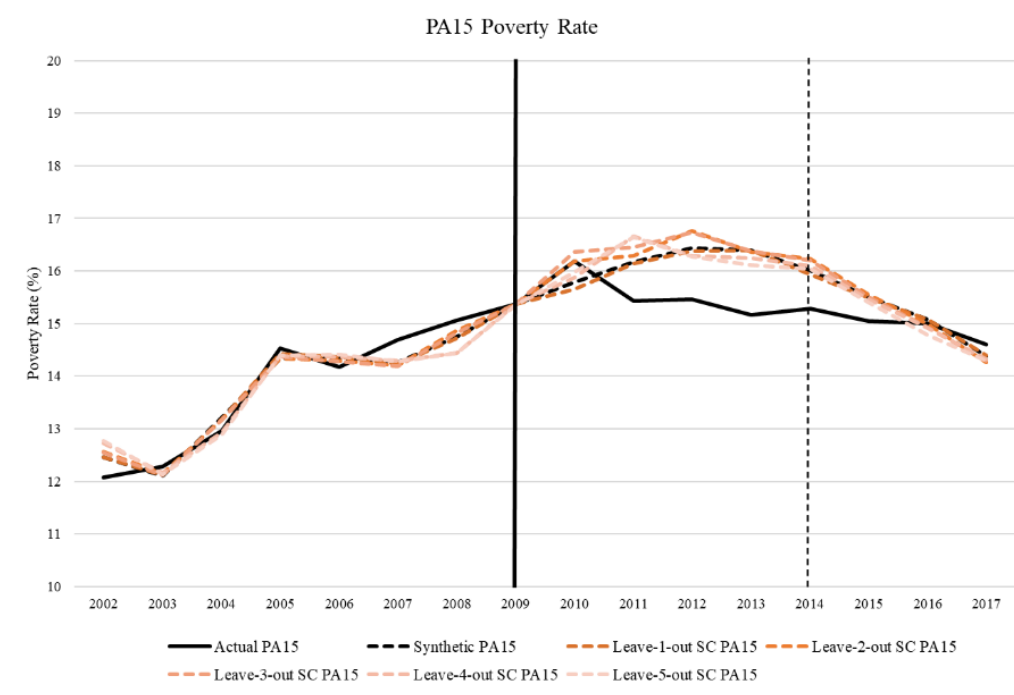

a. PA top 15 poverty rate

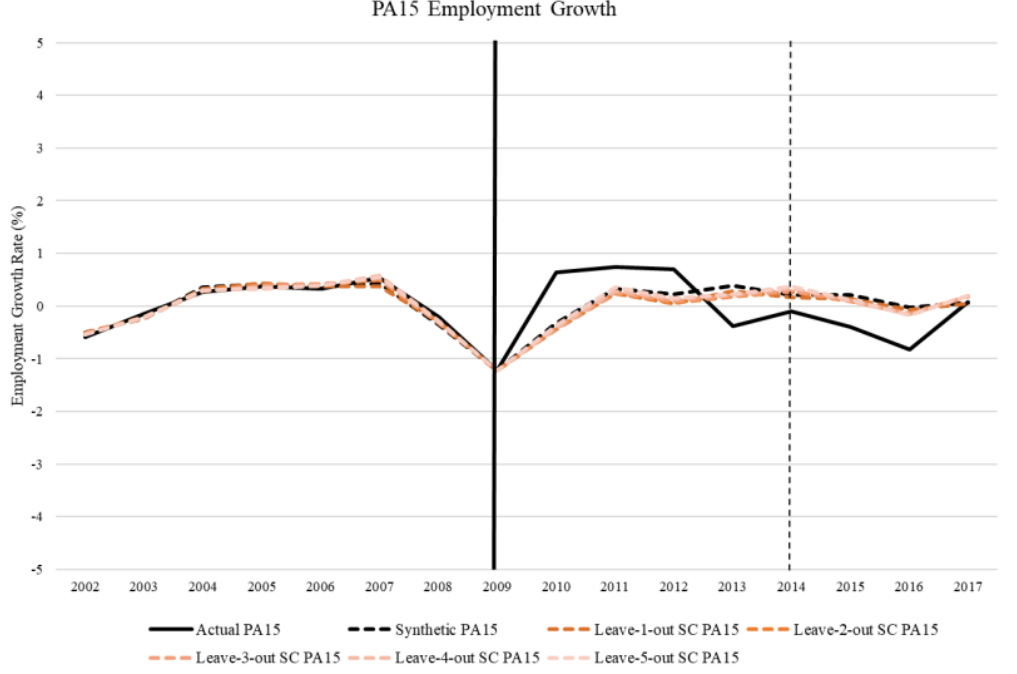

c. PA top 15 employment growth

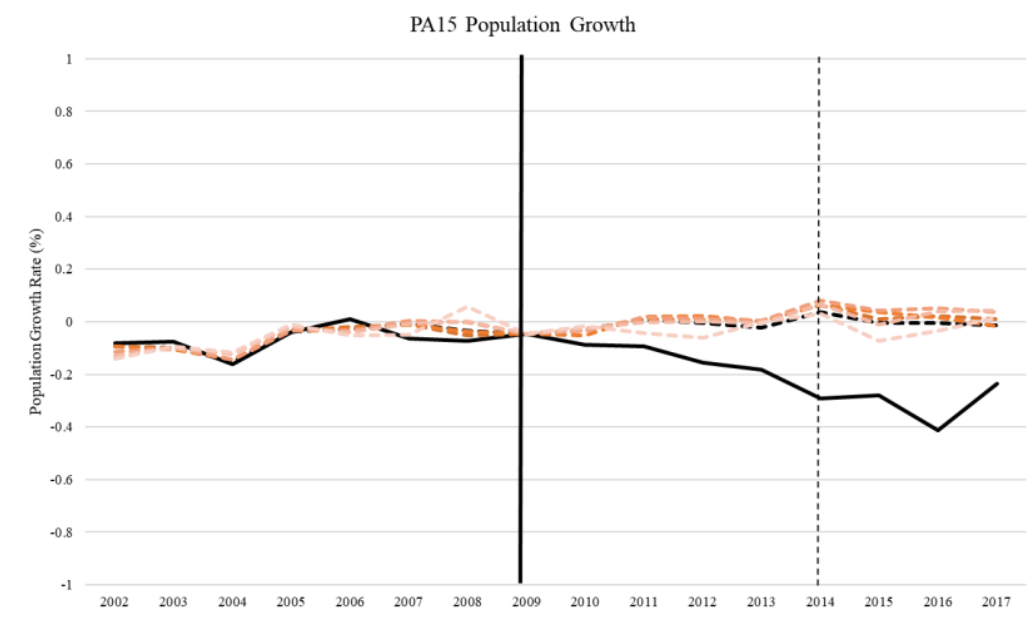

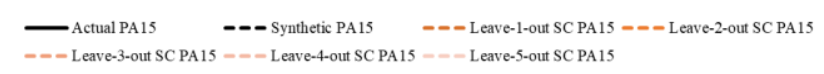

b. PA top 15 population growth PA15 Personal Income per Capita Growth

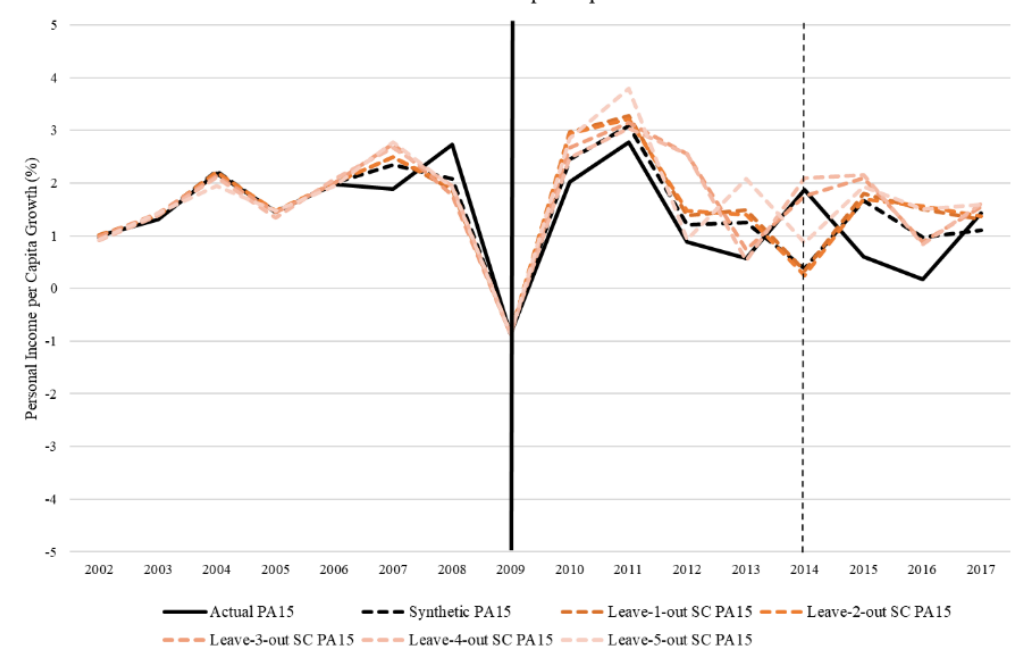

d. PA top 15 income growth

Figure 3.A6. Leave-one-out Robustness Test Results for PA15 


\section{Chapter 4}

\section{How Did Covid-19 Impact US Household Food Spending? An Analysis Six Months In}

\subsection{Introduction}

The Covid-19 pandemic has caused enormous disruptions to the global economy. At the beginning of the pandemic, concerns about food shortage led to panic buying as consumers stocked up on groceries (Mead et al. 2020; Melo 2020; Knotek II et al. 2020). During Covid-19, the closure and limited access to restaurant dining, as well as the lifestyle changes (e.g., working from home), have led consumers to change their grocery shopping habits (e.g., Ellison et al. Forthcoming; Mead et al. 2020). Consumers are also facing higher food prices due to issues in the supply chain such as labor shortage (Richards and Rickard 2020; Thilmany et al. Forthcoming) and reduced shipments (Peña-Lévano et al. 2020).

Amid this backdrop, we estimate how Covid-19 has affected US household grocery spending behavior, in particular fresh produce and local food purchase and factors driving such changes. Previous studies show that sudden exogenous events, including the 2011 Tohoku Earthquake (Hori and Iwamoto 2014), the 9/11 terrorist attacks (Dube and Black 2010), Gulf Coast Deepwater Oil Spill (Levy and Gopalakrishnan 2010), Fukushima Nuclear Accident (Frank and Schvaneveldt 2014), and infectious diseases (Funk et al. 2015), often led to subsequent changes in short-term consumption behavior. Overall, changes in consumption patterns differ depending on the types of events, consumer income, information sources, as well as consumer experience and levels of knowledge. Increased food expenditures due to stockpiling and irrational panic buying are frequently observed at the beginning of extreme events. Consumers consider over-purchasing food, cleaning products, and other necessities as an insurance mechanism to mitigate future uncertainty (Melo 2020; Kim et al. Forthcoming; Hori and Iwamoto 2014). Meanwhile, decreased food expenditures after a sudden exogenous event may also occur if the event leads to increased contamination risks, higher health concerns, reduced income, or lower availability of food (e.g., Vilar-Compte et al. 2015; Çakır, Li, and Yang Forthcoming). 
Given the scope and length of the Covid-19 episode, changes in household purchasing behavior may differ significantly from those observed in previous sudden exogenous events. First, Covid-19 is a global outbreak that affected almost every country in the world, fueling uncertainty across all sectors of the economy. Second, the economic lockdown and lifestyle changes have led to the closures of many businesses, causing unemployment problems and loss of income (Nicola et al. 2020). Third, production and supply chain disruptions led to limited availabilities and increased retail prices of groceries and necessities (Farnsworth 2020; Richards and Rickard 2020; Kim et al. Forthcoming). In particular, the U.S. Bureau of Labor Statistics reported the August 2020 food at home and vegetable and fruits price indexes increased 3.7\% (U.S. Bureau of Labor Statistics 2020b) and 3\% (U.S. Bureau of Labor Statistics 2020c) respectively in comparison to January 2020. Lastly, eligible US households and individuals received stimulus payments that increased their unanticipated income and overall expenditures (Lai et al. 2020; Baker et al. 2020b).

These issues created both positive (i.e., stockpiling behaviors, changes of lifestyle, and stimulus payments) and negative (i.e., limited availabilities, loss of income, concerns of health risks) impacts on consumer spending. At the beginning of the pandemic, card and grocery spending increased by approximately 50\% from February 26 to March 11 due to consumer panic buying behaviors (Peña-Lévano et al. 2020; Melo 2020). Baker et al. (2020a) analyzed transaction-level financial data from August 2016 to March 2020 and found that consumers increased spending on retail and food items in the early stage of the pandemic (from late-February to mid-March) and that the grocery spending at the end of March remained 7.5\% higher relative to early 2020. They also indicated that the stimulus payment recipients' first-month spending increased by $\$ 0.30$ per dollar of the stimulus (Baker et al. 2020b). In spite of the overall reported increased spending, Ahn and Norwood (25) show that compared to 2016 and 2017, three percentage points more households with children were classified as food insecure in May 2020, and Gundersen et al. (Forthcoming) estimate that 17 million more Americans were food insecure in 2020 compared to 2019.

In addition to overall grocery consumption, fresh produce consumption during the pandemic is another issue worthy of investigation. Fresh produce prices are highly sensitive to supply changes, and given the supply disruptions during Covid-19, the price volatility of fresh produce is likely to be high during the pandemic (Mead et al. 2020). Meanwhile, layoffs and reduced incomes due to lockdowns and other restrictions in the short term are exacerbating existing food and nutrition insecurity in many contexts, further reducing the affordability of fresh produce 
for low-income households (Gundersen et al. Forthcoming; FAO et al. 2020; Ahn and Norwood Forthcoming). Ellison et al. (Forthcoming) survey conducted in mid-March to late April shows that households tend to value nutrition less during the pandemic. The Global Alliance for Improved Nutrition (38) notes that lower-income families tend to choose food with lower safety and quality levels and lower nutritional value during the pandemic. A survey study conducted in the later period, between April and June, by Enriquez and Goldstein (2020) found that low-income and benefits-eligible families faced increased financial difficulties and food insecurities during the lockdown period. The food safety concerns and nutrition insecurity problems in the initial lockdown period created greater negative impacts on vulnerable individuals such as young children and pregnant women in the household (Pérez-Escamilla, Cunningham, and Moran 2020; FAO et al. 2020).

Farmers markets may provide a solution for food and nutrition insecurity by providing access to fresh produce and local products. In 2018, $72 \%$ of counties reported having at least one farmers' market, and 32\% of counties reported having at least one farmers' market accepting SNAP (U.S. Department of Agriculture 2020a). In 2019, the number of registered farmers' markets had reached 8,140 , with an average market day sales of $\$ 14,547$ and daily household visits of 916 per market (U.S. Department of Agriculture 2020b). Furthermore, 99.6\% of farmers markets sold fruits and vegetables and, $84.7 \%$ of markets carried locally grown labeled products (U.S. Department of Agriculture 2020b). Since farmers markets are a popular outlet for consumers to shop fresh produce and local products, their closure or limited access during the pandemic would certainly limit consumers' choices and disrupt the local food supply chain. In addition, the closures or reduced business hours of farmers markets would create negative impacts on the local economies and rural communities.

This paper examines the changes in food grocery expenditure, fresh produce expenses, the purchasing behavior of locally grown fresh produce during a later stage of the pandemic and explores the potential factors driving such changes. Most of the recent survey studies on Covid-19 were conducted between February and June 2020, a period generally considered to be the early pandemic phase (e.g., Ellison et al. Forthcoming; Ahn and Norwood Forthcoming; Enriquez and Goldstein 2020). In contrast, our online survey was conducted at a later stage of Covid-19 from August 12 to August 18, 2020. 
An important factor that may lead to distinguishing changes in consumption behavior between the early and the later stages of the Covid-19 is the government assistance program. Onetime or temporary government stimulus programs such as the $\$ 1,200$ stimulus check, and the $\$ 600$ per week enhanced unemployment benefits, provided short-term financial reliefs to the households and individuals in need, but the absence of continuing programs may leave vulnerable population unprotected after the expirations of these programs (Han, Meyer, and Sullivan 2020). Indeed, previous findings using data before July 2020 (e.g., FAO et al. 2020; Pérez-Escamilla, Cunningham, and Moran 2020) show that households and families with young children and pregnant and lactating women suffered the most from the negative impacts such as food and nutrition insecurity in the early phase of the pandemic and the aftershocks may last for years. Moreover, the low-income households (defined as household income $<130 \%$ of the federal poverty level) were suffering from food insecurity from April to June 2020 (26). Since no further stimulus programs or bills passed after the Coronavirus Aid, Relief, and Economic Security (CARES) Act before August 2020 (at the federal level), we expect the households with lower income or vulnerable members to continue suffering from food insecurity after the initial phase. Moreover, we expect the percentage of locally fresh produce purchased to decrease due to the operating restrictions of farmers markets.

We contribute to the literature by analyzing household purchasing trends in August 2020 when the economy had partially reopened, and consumers had different spending opportunities but might have already exhausted their extra income from the first round of government financial assistance, in comparison to the early Covid-19 months. The first-round financial assistance program refers to the CARES Act which includes an over $\$ 2$ trillion economic relief package was passed and signed into law on March 27, 2020. Using a nationwide survey on 514 primary grocery shoppers, we record household spending on food grocery and fresh produce in dollar amount, and the percentage of locally grown fresh produce purchased before and six months after Covid-19 was declared as a pandemic (i.e. August 2020). Shopping behaviors are categorized into three groups: decreased, unchanged, and increased consumption. Using ordered Probit models, we find that: 1) compared to higher income households, households with income below $\$ 50,000$ and those with income between $\$ 50,000$ and $\$ 99,999$ are less likely to increase their overall food grocery and fresh produce spending during the pandemic; 2) household demographics such as age and family composition (with kids and elderly) play an important role in household grocery and fresh 
produce purchasing behavior; 3) Covid-19 severity level, as measured by number of cumulative Covid-19 cases per 100 people, and food accessibility, as measured by the number of farmers markets and the number of grocery stores and supercenters per 10,000 population significantly affects consumer grocery consumption.

Our results show that both low-income and middle-class households suffered from higher food expenditure problems in the middle stage of the pandemic. The finding implies that the food spending problems that households faced in the early pandemic period identified in previous studies continue. Our results provide support for the issuance of financial assistance and stimulus bills that consider low-income and middle-class households and those with vulnerable members. Furthermore, assisting local farmers in adopting new sales channels may help mitigate the loss of businesses due to the closures of physical farmers' markets during the pandemic.

\subsection{Survey Questionnaire}

An online survey on household grocery consumption behavior was conducted through Qualtrics from August 12 to August 18, 2020. All questions and procedures were approved by the West Virginia University Institutional Review Board before the survey was distributed. Our sample quotas and distribution mirrored the five-year average income, education, and age distributions presented in the US Census Bureau 2018 American Community Survey (see appendix I for the detailed quotas). In total, 514 valid responses from the primary grocery shopper of the household were collected. The advantage of surveying the primary food shopper is that they have first-hand knowledge of the food budget and can best understanding the food expenditures among all other household members. We believe this minimizes potential measurement errors caused by recalling and self-reporting expenditures.

To understand how household grocery consumption has changed due to Covid-19, we asked primary grocery shoppers to answer the following questions for periods both before Covid19 (before) and during the Covid-19 (August 2020):

i. What was/has been your (or your household's) typical weekly expenses for food purchased during grocery shopping? 
ii. What was/has been your (or your household's) typical weekly expenses for fresh vegetables and fruits?

iii. Of the fresh fruits and vegetables you purchased, approximately what percentage was locally grown?

Following Lusk (2013) 's food demand survey, we provide respondents with ranges of dollar amounts and ask them to select the one that best describes their purchasing behavior. Based on the average household grocery spending in 2019 (Statista 2020), we divide the weekly food grocery expenses into ten categories starting at \$0, and then with a \$25 increment, up until \$201 or more. Based on the 2018 weekly fruit and vegetable expenditure as reported by the U.S. Bureau of Labor Statistics (2020a), we split weekly fresh produce expenses into twelve categories: \$0, \$1-\$5, \$6$\$ 10, \ldots, \$ 46-\$ 50$, and $\$ 51$ and more. Individuals that selected a non-zero category in the fresh produce consumption question were asked the percentage of fresh produce purchased that was grown locally. A total of six numeric options (0\%, 1-20\%, 21-40\%, 41-60\%, 61- 80\%, and 81\% or more) and an opt-out option ("I don't know") were given. We include the opt-out option to account for the possibility that respondents may be unaware of the origin of the products they purchased. In total, out of the 514 valid responses, 133 respondents chose the opt-out option in at least one period. In follow-up questions, respondents indicated whether there was a change in fresh produce purchasing behavior and, if so, why the change occurred. Only a small percentage of respondents responded to these questions.

\subsection{Data}

The detailed demographic information of the surveyed primary food shoppers and variable descriptions are reported in table 4.1. Our key explanatory variable, the annual household income level, was categorized into four levels: less than $\$ 50,000, \$ 50,000$ to $\$ 99,999, \$ 100,000$ to $\$ 149,000$, and $\$ 150,000$ or more. In our discussion of the results, the "base income group" will refer to the households with income below $\$ 50,000$, the "middle income group" will refer to the households with income between $\$ 50,000$ to $\$ 99,999$, and the "higher income groups" will refer to the two household groups of $\$ 100,000$ to $\$ 149,000$ and $\$ 150,000$ or more throughout this paper. Out of the 514 respondents, respondents in each income level from the lowest to the highest 
accounted for $41.25 \%, 30.93 \%, 14.98 \%$, and $12.84 \%$ of the sample, respectively. $27.6 \%$ of respondents were Supplemental Nutrition Assistance Program (SNAP) participants. The average household size was 3.14 members. $42.22 \%$ and $29.96 \%$ of households in the sample have at least member under 18 and at least one member older than 64, respectively. Furthermore, $42.4 \%$ of respondents were employed either full-time or part-time.

The respondents were divided into metropolitan and non-metropolitan residents using the zip code information. The majority of the respondents (85\%) were living in metropolitan areas. By matching respondents' zip codes with the USDA Food Access Research Atlas dataset, we constructed household food accessibility measures. We measure household food accessibility by the number of farmers markets selling fresh produce per 10,000 people in 2018 and, the number of supercenters and grocery stores per 10,000 people in 2016 at the zip code level. As shown in table 4.1, the number of farmers markets selling fresh produce and the number of supercenters and grocery stores per 10,000 people averaged 0.18 and 2.34, respectively. The Covid-19 severity level is measured by the accumulated Covid-19 cases per 100 people on August 12 (first day of survey) at the county level, based on respondent's zip code. The number of cases per 100 people averaged 1.53. Furthermore, approximately $42 \%$ of respondents owned a personal garden at the time of the survey. The data was retrieved from USA Facts. ${ }^{15}$

Respondents were further asked to self-report their health status on a scale of 1 to 5 (1 indicates extremely unhealthy and 5 indicates extremely healthy). The average self-reported health status was 3.76 (i.e., between fair and good conditions). Given the concern of food contamination risks during Covid-19, we asked the respondents about their food handling practices. Following the food safety guidance suggested in Dietary Guidelines for Americans 2015-2020 (U.S. Department of Agriculture and U.S. Department of Health and Human Services 2015), respondents were asked to rate on a scale of 0 to 3 ( 0 is never/almost never and 3 is always/almost always) on the frequencies of practicing the following food handling procedures: i) washing hands with soap and running water before handling food, ii) sanitizing kitchen surface and cutting boards, iii) using one cutting board for fresh produce and separate one for raw meat, iv) rinsing fresh produce under running water just before cutting, eating, or cooking and v) refrigerating or freezing perishables within two hours of purchase during Covid-19 restrictions. An index reflecting each respondent's

${ }^{15}$ USA Facts Webpage: https://usafacts.org/visualizations/coronavirus-covid-19-spread-map 
food safety practice levels was computed by summing up the five scores. The index may also indirectly, to some degree, reflect the respondent's level of concern about the pandemic. The food handling index averages 12.27 , out of a 15-point maximum.

We next use interval regressions with only a constant, as in Lusk (2013), to estimate average household consumption levels before and during Covid-19. Figure 4.1 shows the estimated mean expenditures on food grocery, fresh produce spending, and share of locally grown fresh produce purchased. The mean food grocery expenditure increased across all income levels during Covid-19. The average food grocery spending of the two higher household income (HHI) groups increased $10.2 \%$ and $9.7 \%$, respectively, while for the base and middle income groups, average food grocery expenditures increased by $3.9 \%$ and $6.8 \%$, respectively (figure $4.1 \mathrm{a})$. These numbers are higher than or close to the food at home price increase from January to August 2020, which ranged around $3.7 \%$ as reported by the U.S. Bureau of Labor Statistics (2020b).

We further find that the average fresh produce spending of the two higher-income groups increased more than 5\%, whereas the average fresh produce expenditure of the base and middle income groups remained almost unchanged (figure 4.1b). Given the price index of fruits and vegetables increased approximately 3\% from January to August 2020 (U.S. Bureau of Labor Statistics 2020c), this may suggest that base and middle income households have had to sacrifice the amount of fresh produce bought to stay within budget. Hence, they could be sacrificing the nutritional value of the food.

Figure 4.1c shows that higher-income households have on average spent more on local produce than the base and middle income households during the pandemic - while the average percentage of locally grown fresh produce purchased increased by $3.6 \%(\$ 100,000$ to $\$ 149,999)$ and $1.5 \%$ (> $\$ 149,999)$, it decreased in the base income group by $0.8 \%(<\$ 50,000)$ and middle income group $2.2 \%$ ( $\$ 50,000$ to $\$ 99,999)$. Respondents could opt-out of this question by choosing "I don't know" if they are unaware of the origin of the fresh produce they purchase. 133 out of 514 respondents opted-out from this question. As shown in appendix I, the distribution of the income, age, and education levels of the respondents are still representative and match the quotas and the allocations set in the full sample.

To construct the dependent variable for the empirical analysis, we compare the surveyed primary food shoppers' answers with respect to their expenditure level before and during Covid- 
19 restrictions. We define the household expenditure to have either "increased," "decreased," or "remained the same" when a higher, lower, or the same dollar category was selected for the Covid19 period. By setting up the dependent variable, expenditure changes that remain within an expenditure category are categorized as "remained the same". To account for increments smaller than the expenditure interval, we incorporate the earlier reported interval regression results into our result discussions.

As shown in table 4.2, 19.65\%, 40.66\%, and 39.69\% of respondents reported a decrease, no change, and an increase, respectively, in their weekly household spending on food grocery shopping. For fresh produce expenditures, $48.83 \%$ of the respondents reported no change to the level of spending during Covid-19, while $20.82 \%$ and $30.35 \%$ of respondents had decreased and increased their spending, respectively. About half of the respondents $(50.39 \%)$ purchased the same percentage of locally grown fresh produce during the pandemic, and about $25 \%$ of the respondents either increased or decreased the portion of locally grown fresh produce in their food expenditure.

\subsection{Empirical Framework and Results}

To determine what factors drive household food expenditure change during the Covid-19 restrictions, we model survey data using the ordered Probit model, a method frequently employed in previous studies to analyze ordered categorical data (e.g., Greene and Hensher 2010; Cranfield and Magnusson 2003). The benefit of using the ordered Probit model is that it takes the latent continuous relationship among the ordinal responses into account and its result indicates how changes in a predictor affect the probability of observing a particular ordinal outcome (Greene and Hensher 2010). Specifically, the vector of the latent continuous dependent variable, $\boldsymbol{y}^{*}$, is specified in equation (1) as a linear combination of independent variables,

$$
y^{*}=x \beta+e, \quad e \sim N I I D[0,1]
$$

where $\boldsymbol{x}$, is a vector of independent variables, $\boldsymbol{\beta}$ is a vector of parameters, and $\boldsymbol{e}$ the iid normally distributed error term. The observed ordinal variable, $y$, takes on values 1,2 and 3 based on the relationship between $y^{*}$ and the thresholds $\left(\mu_{1}, \mu_{2}\right)$ : 


$$
y=j \leftrightarrow \mu_{j-1}<y^{*} \leq \mu_{j}, \quad \text { where } j=1,2,3
$$

Parameter estimates are obtained by maximizing the log-likelihood function. The sign of an estimated parameter indicates the direction of the response associated with a change in the independent variable. Since it is difficult to interpret the magnitude of the estimated parameters directly, we compute the marginal effects associated with each independent variable, while holding other variables at the sample mean values (Greene and Hensher 2010).

Table 4.3 reports the estimation results for each dependent variable, including changes in household overall food grocery consumption, overall fresh produce expenditure, and the percentage of fresh produce purchased that is grown locally. Results suggest that household income and member characteristics are important determinants for both overall food grocery and fresh produce expenses. For instance, households with an income of $\$ 100,000$ or more, with elderly members or with kids, and where the primary food shopper is employed or is female are more likely to increase their spending on food grocery. Expenditures on food grocery during the pandemic are also more likely to increase as the primary food shopper's age and household safety practice level increase, when there are more farmers markets nearby, when there are more Covid19 cases, and when the household does not own a personal garden. Estimation results further suggest that household income, the presence of kids at home, the age of the primary grocery shopper, and the family's safe handling index are positively linked to the likelihood of fresh produce expenditure during Covid-19.

We find that income does not help explain changes in local fresh produce purchasing behavior. Meanwhile, when the primary grocery shopper is male, employed, or at least one household member is aged over 64, households tend to increase the share of locally grown fresh produce purchased during the pandemic. Furthermore, households without a garden, or are more aware of safety practices, or those living in a neighborhood with more grocery stores and supercenters and/or with more severe Covid-19 condition, are more likely to purchase a higher percentage of locally grown fresh produce during the pandemic.

We next compute the marginal effects of the independent variables for changes in the three ordinal dependent variables, as shown in table 4.4. Compared to the base income group $(<\$ 50,000)$, households with an annual income exceeding $\$ 99,999$ and $\$ 149,999$ are about 8 and 9.4 percentage points more likely to increase their food grocery expenditure during Covid-19. A similar 
magnitude of the impact is found for households with at least one child and where the primary grocery shopper is employed. Households with at least one elderly family member are 5 percentage points more likely to increase their food grocery spending. Meanwhile, households with a garden, or whose primary grocery shopper is male, are 4.4 and 5.8 percentage points more likely to decrease spending on food groceries than other households, respectively.

Since age and the safe handling index are discrete ordinal variables, their marginal effects can be interpreted as the percentage points that the household is more/less likely to increase/decrease their food grocery expenditure when the variable of interest increases by one unit. The marginal effects of age indicate that an increase in age level (total of six age groups) of the primary food shopper makes the household 3.5 percentage points more likely to increase overall food grocery spending. Furthermore, when the level of safe handling index increases by one point, the household is 1.2 percentage points more likely to increase its food grocery expenditure. Compared to households living in a region without a farmers' market, a primary food shopper living in area with 1 farmers market per 1 million population is 1 percentage point more likely to increase his/her food grocery spending. Compared to households living in a county without any Covid-19 cases, a primary food shopper living in a county with average one Covid19 cases per 100 population is $5 \%$ more likely to increase his/her food grocery expenditure.

For fresh produce consumption, table 4.4 suggests that compared to the base group, households whose incomes fall between $\$ 100,000$ and $\$ 149,999$ and those that exceed $\$ 150,000$ are respectively 13.1 and 8 percentage points more likely to increase their expenditures. A household with kids is 9.2 percentage points more likely to increase their spending on fresh produce compared to those without kids. Furthermore, an increase in the primary grocery shopper's age level make the household 3.3 percentage points more likely to increase fresh produce expenditure. Compared to households living in a county without any Covid-19 cases, a primary food shopper living in a county with average one Covid-19 cases per 100 population is $2.4 \%$ more likely to increase his/her fresh produce expenditure.

The last two columns of table 4.4 display the marginal effects for variables affecting the share of local fresh produce over the total fresh produce purchase. The largest marginal effect comes from the presence of elderly members - households with at least one member older than 64 are 7.5 percentage points more likely to increase the share of locally grown fresh produce 
consumption. When the level of safe handling index increases by one point, the household is 0.8 percentage points more likely to increase its share of local fresh produce consumption. Employed shoppers also tend to be $2.8 \%$ more likely to increase their local fresh produce share. Owning a garden, on the other hand, makes the household 4.9 percentage points more likely to purchase less locally grown fresh produce. Regarding the accessibility to food outlets, when the number of grocery stores and supercenters per 10,000 population in the neighborhood increases by 1 , households are 14.3 percentage points more likely to increase the share of local fresh produce consumption. Last, compared to households living in a county without any Covid-19 cases, a primary food shopper living in a county with average one Covid-19 cases per 100 population is $4.9 \%$ more likely to increase his/her local fresh produce share.

\subsection{Discussions and Conclusions}

Existing studies on the impact of Covid-19 on consumers' food shopping behaviors and insecurity problems mostly focus on the early stage of the pandemic, i.e., March to June 2020 (e.g., Ellison et al. Forthcoming; Gundersen et al. Forthcoming; Ziliak Forthcoming). Given the changes in the economic conditions, expirations of governmental assistant programs, and potential changes in food systems, it is essential to conduct a study focusing on consumers' shopping behaviors and identify the vulnerable groups in later stages of the pandemic, when most enhanced benefits packages expired. We contribute to this necessity by analyzing the purchasing trends of households in August 2020. Using a nationwide survey, we investigate how Covid-19 has affected US household grocery spending behavior, in particular fresh produce and local food purchase and factors driving such changes. Out of 514 responses, about $40 \%$ and $30 \%$ of the households reported increased overall food grocery and fresh produce expenditures, respectively, while about $20 \%$ of the households decreased the spending on these two categories. About one-fourth of the households reduced the share of locally grown fresh produce over the total fresh produce purchase, while more than half of the sample reported no change in local fresh produce shopping behavior.

The interval regression results show that average food grocery spending of the two higher household groups increased $10.2 \%$ and $9.7 \%$, respectively, while for the base and middle income 
groups, average food grocery expenditures only increased by $3.9 \%$ and $6.8 \%$, respectively. We further use the ordered Probit models to show that higher-income households are between 9 and 9.6 percentage points more likely to increase their spending compared to the base income group. This finding aligns with the results reported by the Global Alliance for Improved Nutrition (2020) that households with lower income are faced with more financial constraints, limiting how much they can increase their spending to cover inflated food prices and forcing them to compromise for lower food quality/or quantity. Other recent studies also show that many households suffered from food hardship and insecurity during the pandemic (Ziliak Forthcoming; Enriquez and Goldstein 2020; Gundersen et al. Forthcoming). Our results further show that these limitations also apply to middle-class families.

The interval regression results show that average fresh produce spending of the two higher household groups increased $14.2 \%$ and $5.2 \%$, respectively, while for both the base and middle income groups, average food grocery expenditures only increased by less than $1 \%$. We further use the ordered Probit models to show that higher-income households are 13.1 and 8 percentage points more likely to increase their spending compared to the base income group, respectively. Indeed, in our follow-up questions on why expenditure on fresh produce decreased, some respondents from the base and middle income groups indicated that they suffered from income losses and, thus, had to replace fresh produce consumption with less expensive food.

All else equal, households with kids or elderly are significantly more likely to increase their expenditure on food groceries during the pandemic than other households, perhaps due to the higher nutrition and quality demand of kids and older adults. Frank and Schvaneveldt (2016) reported that households with young children paid more attention to food quality after the Fukushima nuclear accident. In our case, we find that the presence of kids has positively impacted household spending on fresh produce, a highly nutritious type of food during Covid-19. However, having an elderly at home does not significantly affect household fresh produce spending. One possible explanation is that the elderly may take vitamin or fiber supplements to fulfill the needs of these key nutrition supplied by fresh produce, while parents may prefer offering kids fresh produce over nutrition supplements.

Furthermore, the older population may have a stronger bond with the local business and food suppliers, including the local farmers and vendors. During the pandemic, many local 
businesses, including the local fresh produce suppliers, have faced extremely severe negative shocks and suffered long-term or permanent loss of business and customers. In the meantime, the elderly and seniors may have had more difficulty shifting to online shopping, which has become a popular venue for shopping among the younger population. The less frequent in-person shopping trips may have limited the quantity purchased or the expenditure spent on perishable fresh produce. Meanwhile, the strong bonds between the elders and communities may have driven households to purchase more local fresh produce to support local businesses. Indeed, we find that households with at least one elderly are $7.5 \%$ more likely to increase the share of local fresh produce over total fresh produce expenditures than families without older members. Since the pandemic started, wellknown businesses such as Google, American Express, Grubhub made campaigns to promote local and small businesses by providing local/small business maps, statement credits, or coupons. Our result would suggest that these campaigns may have a greater effect when targeted towards the older population.

Characteristics of the primary household food shoppers such as age, gender, and employment status significantly affect food purchasing behavior during Covid-19. We find that households whose primary grocery shopper is male are more likely to decrease their food grocery expenses during the pandemic, perhaps due to the higher likelihood of ordering take-out of males. The significant positive marginal effects of age on increasing both food grocery and fresh produce expenditures may suggest that primary food shoppers care more about the nutrition content and quality of food as they get older. This result is consistent with the finding in Hori and Iwamoto (2014) that the age of the primary grocery shopper positively affected grocery expenditures among Japanese households after the Tohoku Earthquake. Households whose primary grocery shopper is employed are more likely to increase the overall food grocery expense and the local fresh produce percentage than those whose primary grocery shopper were unemployed. Employed food shoppers may have fewer financial constraints, allowing the households to maintain their food quantity and quality standard at a higher price during the pandemic. The adequate and stable income sources of the employed food shoppers may further allow them to choose more locally grown fresh produce which is often considered to be fresher, superior in quality, and more beneficial to local communities (Darby et al. 2006), and is less likely to pose risk concerns due to a shorter supply chain. 
The probability of higher household expenditure on food grocery is positively related to the household's safe handling index. This indicates that individuals who follow food safety guidance, and practice safety procedures frequently, are willing to spend more on food quality and/or quantity. These food shoppers also tend to have a higher probability of increasing the share of local fresh produce purchased during the pandemic. A possible explanation is that consumers might consider local produce a safer option, presenting lower Covid-19 contamination or food safety risks than the conventional products sourced from other regions and often subject to longer supply chains. Households may also have had more information about the origin of the local food and, thus have been willing to purchase more locally grown produce during the pandemic. This result is consistent with the finding of Peña-Lévano et al. (2020) that consumers tend to value food safety and local food attributes more in the long-run.

Lastly, we find that households are more likely to increase overall food grocery expenditure, spending on fresh produce, and local fresh produce share during the pandemic in counties with more severe Covid-19 conditions. A reasonable explanation is that consumers tend to consume more handmade meals and/or be more willing spend on food quality when the risk of dining out is relatively higher in his/her area. Consumers may also focus more on the nutritional content of food by consuming healthier food, to lower their risk of getting sick from Covid-19 risks. Moreover, consumers may consider the shorter supply chain of local fresh produce lowers Covid-19 contamination risks. However, most of the farmers markets have been forced to close temporarily or to operate under more restrictions during Covid-19 (Thilmany et al. Forthcoming). The closure of farmers' markets may have pushed primary household shoppers to buy local fresh produce from other retail sources or even online. Even when farmers markets resumed their regular services, some households who frequently shopped there before the pandemic may have opted for online shopping or delivery through conventional grocery stores and supercenters to minimize social contact. In a survey conducted by Peña-Lévano et al. (2020), the authors find that consumers have been more likely to purchase food groceries online during the pandemic. This may cause local farmers who do not have experience selling products online nor connections with conventional outlets face difficulties in the long-run.

Our findings show that the food insecurity problems in the early pandemic stage that were identified in previous studies (Gundersen et al. Forthcoming; Ziliak Forthcoming) continue. In addition to the families with missing or low income, many middle-class households were also 
experiencing food insecurity problems for the first time (Baskin 2020). Moreover, we find that households with children or elderlies, who tend to require higher food quality and nutrition intakes, have a higher probability of increasing their spending. These two findings indicate that base and middle income households with vulnerable members may be enduring extremely heavy financial burdens in mid-August when most of the enhanced benefits packages had expired. The food insecurity problem among the base and middle income households may be further exacerbated by the permanent increase in fresh fruit and vegetable prices compared to the pre-pandemic period due to higher production costs, labor shortages, and structural changes in the food industry (PeñaLévano et al. 2020; Richards and Rickard 2020). Given the significant impact of Covid-19 on food access, policymakers may wish to expedite passing new rounds of stimulus plans to provide additional financial support to households with vulnerable members and facing financial hardship. On the retail side, the decreased shop local behaviors would create severe financial difficulties for local farmers and businesses who do not have experience setting up online stores or even access to the Internet, adversely affecting the local economy. It is essential for the policymakers to develop programs to increase broadband access and to train local farmers on developing alternative sales channels and innovative approaches such as 1) providing farm-to-home delivery; 2) offering online purchasing options, 3) diversifying retail outlets, 4) following social distancing measures at farmers markets.

There are some limitations of this study. First, we surveyed the consumers' income but not the wealth and the recent loss of income. Debt and loss of income may affect a consumer's food shopping behaviors significantly. Since such information was not included in the survey, we were not able to identify how debt and net wealth may have affected our estimation results. Second, we surveyed whether a respondent is a SNAP recipient, but we did not ask for information about his/her eligibility on new Covid-19 food and financial assistance programs provided by either federal or local governments. The type of assistance program and the amount of benefit received may affect consumers' food shopping behaviors differently. Last, the survey did not consider household member lifestyle change during Covid-19. For instance, we may observe a large increase in food expenditures from the households who dine out frequently before the pandemic. Moreover, the families with more members switched to remote working or learning may also be subject to a more rapid increase in food grocery expenses. This factor might be partially accounted for by the binary variable which indicates if there is at least one under 18 members in the household. 
Nonetheless, the variable does not represent the adults who switched to remote working or college students who switched to online education. 


\section{References}

Ahn, Sunjin, and F Bailey Norwood. Forthcoming. "Measuring Food Insecurity during the Covid-19 Pandemic of Spring 2020." Applied Economic Perspectives and Policy.

Baker, Scott R, Robert A Farrokhnia, Steffen Meyer, Michaela Pagel, and Constantine Yannelis. 2020a. How does household spending respond to an epidemic? consumption during the 2020 covid-19 pandemic. Working Paper 26949, National Bureau of Economic Research.

---. 2020b. Income, liquidity, and the consumption response to the 2020 economic stimulus payments. (Working Paper 27097, National Bureau of Economic Research).

Baskin, Kara. 2020. "Food Insecurity in the Age of COVID-19." Thufts Now. https://now.tufts.edu/articles/food-insecurity-age-covid-19.

Çakır, Metin, Qingxiao Li, and Xiaoli Yang. Forthcoming. "COVID-19 and Fresh Produce Markets in the United States and China." Applied Economic Perspectives and Policy.

Cranfield, John AL, and Erik Magnusson. 2003. "Canadian consumer's willingness-to-pay for pesticide free food products: an ordered probit analysis." International Food and Agribusiness Management Review 6 (4): 1-18.

Darby, Kim, Marvin T Batte, Stanley C Ernst, and Brian E Roe. 2006. Willingness to pay for locally produced foods: A customer intercept study of direct market and grocery store shoppers. (Paper presented at the 2006 American Agricultural Economics Association Annual Meeting).

Dube, Leon F, and Gregory S Black. 2010. "Impact of national traumatic events on consumer purchasing." International Journal of Consumer Studies 34 (3): 333-338.

Ellison, Brenna, Brandon McFadden, Bradley J Rickard, and Norbert Wilson. Forthcoming. "Examining food purchase behavior and food values during the COVID-19 pandemic." Applied Economic Perspectives and Policy.

Enriquez, Diana, and Adam Goldstein. 2020. "COVID-19's Socioeconomic Impact on LowIncome Benefit Recipients: Early Evidence from Tracking Surveys." Socius: Sociological Research for a Dynamic World 6: 1-17.

FAO, IFAD, UNICEF, WFP, and WHO. 2020. "In Brief to The State of Food Security and Nutrition in the World 2020. Transforming food systems for affordable healthy diets.". Rome, FAO. Accessed December 2020. https://doi.org/10.4060/ca9699en. 
Farnsworth, Derek. 2020. "US COVID-19 Policy Affecting Agricultural Labor." Choices 35 (3). Frank, Björn, and Shane J Schvaneveldt. 2014. "Self-Preservation vs. Collective Resilience as Consumer Responses to National Disasters: A Study on Radioactive Product Contamination." Journal of Contingencies and Crisis Management 22 (4): 197-208.

---. 2016. "Understanding consumer reactions to product contamination risks after national disasters: The roles of knowledge, experience, and information sources." Journal of Retailing and Consumer Services 28: 199-208.

Funk, Sebastian, Shweta Bansal, Chris T Bauch, Ken TD Eames, W John Edmunds, Alison P Galvani, and Petra Klepac. 2015. "Nine challenges in incorporating the dynamics of behaviour in infectious diseases models." Epidemics 10: 21-25.

Global Alliance for Improved Nutrition. 2020. "The COVID-19 Crisis and Food Systems: probable impacts and potential mitigation and adaptation responses.". Accessed December 2020. https://www.gainhealth.org/sites/default/files/news/documents/covid19-crisis-and-food-systems-probable-impacts-and-potentialmitigation-and-adaptationresponses.pdf.

Greene, William H, and David A Hensher. 2010. Modeling Ordered Choice.: Cambridge University Press.

Gundersen, Craig, Monica Hake, Adam Dewey, and Emily Engelhard. Forthcoming. "Food Insecurity during COVID-19." Applied Economic Perspectives and Policy.

Han, Jeehoon, Bruce D Meyer, and James X Sullivan. 2020. Income and Poverty in the COVID19 Pandemic. Working Paper 27729, National Bureau of Economic Research.

Hori, Masahiro, and Koichiro Iwamoto. 2014. "The run on daily foods and goods after the 2011 Tohoku earthquake: a fact finding analysis based on homescan data." The Japanese Political Economy 40 (1): 69-113.

Kim, Jungkeun, Marilyn Giroux, Jae-Eun Kim, Yung Kyun Choi, Hector Gonzalez-Jimenez, Jacob C Lee, Jooyoung Park, Seongsoo Jang, and Seongseop Sam Kim. Forthcoming. "The moderating role of childhood socioeconomic status on the impact of nudging on the perceived threat of coronavirus and stockpiling intention." Journal of Retailing and Consumer Services 59.

Knotek II, Edward S, Raphael Schoenle, Alexander Dietrich, Keith Kuester, Gernot Müller, Kristian Ove R Myrseth, and Michael Weber. 2020. "Consumers and COVID-19: A 
Real-Time Survey." Economic Commentary, Federal Reserve Bank of Cleveland 2020 (08): $1-6$.

Lai, John, Stephen Morgan, Bachir Kassas, Jaclyn Kropp, and Zhifeng Gao. 2020. "Spending of Economic Stimulus Payments and Changes in Food Purchasing During the COVID-19 Pandemic." Choices 35 (3). https://www.choicesmagazine.org/choicesmagazine/submitted-articles/spending-of-economic-stimulus-payments-and-changes-infood-purchasing-during-the-covid-19-pandemic.

Levy, Jason K, and Chennat Gopalakrishnan. 2010. "Promoting ecological sustainability and community resilience in the US Gulf Coast after the 2010 Deepwater Horizon oil spill." Journal of Natural Resources Policy Research 2 (3): 297-315.

Lusk, Jayson. 2013. "Food Demand Survey (FooDS)-Technical Information on Survey Questions and Methods." Accessed June 2020. http://agecon.okstate.edu/files/Survey\%20Info\%20(pdf4556).pdf.

Mead, Dave, Karen Ransom, Stephen B Reed, and Scott Sager. 2020. The impact of the COVID19 pandemic on food price indexes and data collection. (U.S. Bureau of Labor Statistics Monthly Lab Review (August 2020)).

Melo, Grace. 2020. "The Path Forward: US Consumer and Food Retail Responses to COVID19." Choices 35 (3).

Nicola, Maria, Zaid Alsafi, Catrin Sohrabi, Ahmed Kerwan, Ahmed Al-Jabir, Christos Iosifidis, Maliha Agha, and Riaz Agha. 2020. "The socio-economic implications of the coronavirus and COVID-19 pandemic: a review." International Journal of Surgery 78: 185-193.

Peña-Lévano, Luis, Shaheer Burney, Grace Melo, and Cesar Escalante. 2020. "COVID-19: Effects on US Labor, Supply Chains and Consumption Imagery Article." Choices 35 (3). Pérez-Escamilla, Rafael, Kenda Cunningham, and Victoria Hall Moran. 2020. "COVID-19 and maternal and child food and nutrition insecurity: a complex syndemic." Maternal and Child Nutrition 16 (3).

Richards, Timothy J, and Bradley Rickard. 2020. "COVID-19 impact on fruit and vegetable markets." Canadian Journal of Agricultural Economics 68 (2): 189-194.

Statista. 2020. "Weekly household grocery spending in the United States 2019, by household type." Accessed December 2020. https://www.statista.com/statistics/240595/weekly-ushousehold-grocery-expenditure-by-household-type/. 
Thilmany, Dawn, Elizabeth Canales, Sarah A Low, and Kathryn Boys. Forthcoming. "Local Food Supply Chain Dynamics and Resilience during COVID-19." Applied Economic Perspectives and Policy.

U.S. Bureau of Labor Statistics. 2020a. "Consumer Expenditures in 2018." Accessed December 2020. https://www.bls.gov/opub/reports/consumer-expenditures/2018/home.htm.

---. 2020b. Consumer Price Index for All Urban Consumers: Food at Home in U.S. City Average retrieved from Federal Reserve Bank of St. Louis; https://fred.stlouisfed.org/series/CUSR0000SAF11.

---. 2020c. Consumer Price Index for All Urban Consumers: Fruits and Vegetables in U.S. City Average. retrieved from Federal Reserve Bank of St. Louis; https://fred.stlouisfed.org/series/CUSR0000SAF113.

U.S. Department of Agriculture. 2020a. "One-third of U.S. counties in 2018 had one or more farmers markets that accepted SNAP benefits." Accessed December 2020. https://www.ers.usda.gov/data-products/chart-gallery/gallery/chartdetail/?chartId=99829.

---. 2020b. "USDA 2019 National Farmers Market Managers Survey." Accessed December 2020. https://downloads.usda.library.cornell.edu/usdaesmis/files/pz50hd694/gx41n598k/jd473j98z/nfar0820.pdf.

U.S. Department of Agriculture and U.S. Department of Health and Human Services. 2015. "Dietary guidelines for Americans 2015-2020. 8th Edition.". Accessed December 2020. http://health.gov/dietaryguidelines/2015/guidelines/.

Vilar-Compte, Mireya, Sebastian Sandoval-Olascoaga, Ana Bernal-Stuart, Sandhya Shimoga, and Arturo Vargas-Bustamante. 2015. "The impact of the 2008 financial crisis on food security and food expenditures in Mexico: a disproportionate effect on the vulnerable." Public Health Nutrition 18 (16): 2934-2942.

Ziliak, James P. Forthcoming. "Food Hardship during the Covid-19 Pandemic and Great Recession." Applied Economic Perspectives and Policy. 


\section{Tables and Figures}

Table 4.1. Demographic information of the survey respondents and descriptions of the variables

\begin{tabular}{|c|c|c|c|c|c|}
\hline Variable definitions & Obs. & $\%$ & Variable definitions & Obs. & $\%$ \\
\hline \multicolumn{3}{|l|}{ Household income } & \multicolumn{3}{|l|}{ Age of primary food shopper } \\
\hline$<\$ 50,000$ & 212 & $41.25 \%$ & 18 to $24=1$ & 51 & $9.92 \%$ \\
\hline$\$ 50,000-\$ 99,999$ & 159 & $30.93 \%$ & 25 to $34=2$ & 106 & $20.62 \%$ \\
\hline$\$ 100,000-\$ 149,999$ & 77 & $14.98 \%$ & 35 to $44=3$ & 122 & $23.74 \%$ \\
\hline$\$ 150,000$ or more & 66 & $12.84 \%$ & 45 to $54=4$ & 47 & $9.14 \%$ \\
\hline SNAP Participant & 142 & $27.63 \%$ & 55 to $64=5$ & 97 & $18.87 \%$ \\
\hline Education of primary shopper & 514 & & 65 or above $=6$ & 91 & $17.70 \%$ \\
\hline Less than high school & 60 & $11.67 \%$ & Employed (full/ part time) & 218 & $42.41 \%$ \\
\hline High school & 144 & $28.02 \%$ & With at least one kid under 18 & 216 & $42.22 \%$ \\
\hline Some college (no degree) & 115 & $22.37 \%$ & With at least one member $>64$ & 154 & $29.96 \%$ \\
\hline Associate's degree & 48 & $9.34 \%$ & Metropolitan area $=1$ & 437 & $85.02 \%$ \\
\hline Bachelor's degree & 95 & $18.48 \%$ & Owns garden $=1$ & 215 & $41.83 \%$ \\
\hline Graduate/prof. degree & 52 & $10.12 \%$ & Male $=1$ & 166 & $32.30 \%$ \\
\hline \multicolumn{4}{|l|}{ Variable definitions } & Mean & Std. \\
\hline \multicolumn{4}{|c|}{ Self-report health level, $\min ($ extremely bad $)=1 ; \max =5$} & 3.76 & 0.88 \\
\hline \multicolumn{4}{|c|}{ Safe practice level, $\min$ (not following any food safety procedures) $=0 ; \max =15$} & 12.27 & 3.05 \\
\hline \multicolumn{4}{|c|}{ Household family size, $\min =1 ; \max =12$} & 3.14 & 1.86 \\
\hline \multicolumn{4}{|c|}{$\#$ of FM selling fresh produce per 10,000 pop, $\min =0 ; \max =4.8$} & 0.18 & 0.3 \\
\hline \multicolumn{4}{|c|}{$\#$ of grocery stores \& supercenters per 10,000 pop, $\min =0.7 ; \max =9.4$} & 2.34 & 1.47 \\
\hline \multicolumn{4}{|c|}{$\#$ of Covid-19 cases per 100 pop, $\min =0.05 ; \max =5.13$} & 1.53 & 0.82 \\
\hline
\end{tabular}


Table 4.2. Summary of Dependent Variable: Changes in Consumption Pattern

\begin{tabular}{lllllll}
\hline Dependent variables & No. obs & $\begin{array}{l}\text { Decrease } \\
\text { (value =1) }\end{array}$ & $\begin{array}{l}\text { Same } \\
\text { (value =2) }\end{array}$ & $\begin{array}{l}\text { Increase } \\
\text { (value =3) }\end{array}$ & Mean & Std. Dev. \\
\hline $\begin{array}{l}\text { Weekly spending on } \\
\text { food grocery }\end{array}$ & 514 & $\begin{array}{l}101 \\
(19.65 \%)\end{array}$ & $\begin{array}{l}209 \\
(40.66 \%)\end{array}$ & $\begin{array}{l}204 \\
(39.69 \%)\end{array}$ & 2.20 & 0.75 \\
$\begin{array}{l}\text { Weekly spending on } \\
\text { fresh produce }\end{array}$ & 514 & $\begin{array}{l}107 \\
(20.82 \%)\end{array}$ & $\begin{array}{l}(48.83 \%) \\
(30.35 \%)\end{array}$ & & \\
$\begin{array}{l}\text { Percentage of local fresh } \\
\text { produce }\end{array}$ & 381 & 94 & 192 & 95 & 2.10 & 0.71 \\
& & $(24.67 \%)$ & $(50.39 \%)$ & $(24.93 \%)$ & & \\
\hline
\end{tabular}

Notes: The number of observations for local fresh produce is 381 instead of 514 because the respondents who chose the opt-out option "I don't know" were excluded from the analysis of local fresh produce purchase behaviors. 
Table 4.3: Ordered Probit Estimation Results

\begin{tabular}{|c|c|c|c|c|c|c|}
\hline \multirow[b]{2}{*}{ HHI $\$ 50,000-\$ 99,999^{a}$} & \multicolumn{2}{|c|}{$\begin{array}{l}\text { Overall food grocery } \\
\text { expenditure }\end{array}$} & \multicolumn{2}{|c|}{ Fresh produce expenditure } & \multicolumn{2}{|c|}{$\begin{array}{l}\% \text { of fresh produce } \\
\text { locally grown }\end{array}$} \\
\hline & -0.004 & $(0.074)$ & -0.017 & $(0.053)$ & -0.163 & $(0.104)$ \\
\hline HHI $\$ 100,000-\$ 149,999^{a}$ & $0.213^{*}$ & $(0.123)$ & $0.371 * * *$ & $(0.103)$ & 0.125 & $(0.239)$ \\
\hline HHI $>\$ 149,999^{a}$ & $0.251 *$ & $(0.146)$ & $0.232 *$ & $(0.123)$ & 0.128 & $(0.265)$ \\
\hline SNAP $^{a}$ & 0.123 & $(0.222)$ & -0.046 & $(0.145)$ & -0.101 & $(0.125)$ \\
\hline male $^{a}$ & $-0.219 * * *$ & $(0.081)$ & -0.048 & $(0.125)$ & $0.045^{*}$ & $(0.027)$ \\
\hline household size & -0.021 & $(0.045)$ & -0.013 & $(0.008)$ & 0.009 & $(0.036)$ \\
\hline kid at home $^{a}$ & $0.246^{* *}$ & $(0.111)$ & $0.274 * * *$ & $(0.054)$ & 0.021 & $(0.201)$ \\
\hline elder at home ${ }^{a}$ & $0.136 * * *$ & $(0.044)$ & -0.006 & $(0.186)$ & $0.262 * *$ & $(0.129)$ \\
\hline employed $^{\text {a }}$ & $0.218 * * *$ & $(0.071)$ & 0.105 & $(0.091)$ & $0.099 * * *$ & $(0.029)$ \\
\hline age & $0.096 * * *$ & $(0.017)$ & $0.098 * * *$ & $(0.036)$ & -0.003 & $(0.031)$ \\
\hline education & 0.02 & $(0.057)$ & -0.037 & $(0.043)$ & 0.016 & $(0.079)$ \\
\hline health condition & 0.057 & $(0.087)$ & 0.104 & $(0.123)$ & -0.076 & $(0.075)$ \\
\hline owns garden ${ }^{\mathrm{a}}$ & $-0.167^{*}$ & $(0.098)$ & -0.115 & $(0.126)$ & $-0.166^{* * *}$ & $(0.061)$ \\
\hline live in metro ${ }^{\mathrm{a}}$ & 0.088 & $(0.189)$ & -0.047 & $(0.252)$ & 0.066 & $(0.154)$ \\
\hline safe handling index & $0.031 * * *$ & $(0.011)$ & $0.036^{*}$ & $(0.021)$ & $0.029 *$ & $(0.015)$ \\
\hline \# farmers market & $2.767 * *$ & $(1.231)$ & -0.639 & $(1.373)$ & -0.313 & $(0.601)$ \\
\hline \# grocery \& supercenters & -0.477 & $(0.396)$ & -0.392 & $(0.463)$ & $0.499^{*}$ & $(0.269)$ \\
\hline Covid-19 cases per 100 & $0.137 * * *$ & $(0.049)$ & $0.070^{* * *}$ & $(0.027)$ & $0.171 * * *$ & $(0.053)$ \\
\hline cut 1 & $0.4654 *$ & $(0.272)$ & $0.301 *$ & $(0.162)$ & -0.171 & $(0.262)$ \\
\hline cut 2 & $1.637 * * *$ & $(0.251)$ & $1.681 * * *$ & $(0.124)$ & $1.368 * * *$ & $(0.174)$ \\
\hline Pseudo R-squared & 0.035 & & 0.030 & & 0.030 & \\
\hline No. observations & 514 & & 514 & & 381 & \\
\hline
\end{tabular}

Notes: ${ }^{\text {a }}$ denotes binary variables. Robust standard errors in parentheses. A joint test (see Greene and Hensher (2010)) for the statistical significance of the two cut points was performed for all three models, and testing results show the two cut points are significantly different (p-value: 0.0000) in all models. One, two, and three asterisks represent statistical significance at $10 \%, 5 \%$, and $1 \%$, respectively. 
Table 4.4. Marginal Effects of Variables on Overall Food Grocery Spending, Fresh Produce Expenditure, and Share of Locally Grown Fresh Produce Purchased

\begin{tabular}{|c|c|c|c|c|c|c|}
\hline \multirow[b]{2}{*}{ Variables } & \multicolumn{2}{|c|}{ Overall food grocery expenditure } & \multicolumn{2}{|c|}{ Fresh produce expenditure } & \multicolumn{2}{|c|}{ \% of fresh produce locally grown } \\
\hline & $\begin{array}{l}\text { Prob } \\
\text { (Decrease) }\end{array}$ & $\begin{array}{l}\text { Prob } \\
\text { (Increase) }\end{array}$ & $\begin{array}{l}\text { Prob } \\
\text { (Decrease) }\end{array}$ & $\begin{array}{l}\text { Prob } \\
\text { (Increase) }\end{array}$ & $\begin{array}{l}\text { Prob } \\
\text { (Decrease) }\end{array}$ & $\begin{array}{l}\text { Prob } \\
\text { (Increase) }\end{array}$ \\
\hline income $\$ 100,000-\$ 149,999^{a}$ & $-0.054 *$ & $0.080 *$ & $-0.094 * * *$ & $0.131 * * *$ & & \\
\hline income $>\$ 149,999^{a}$ & $-0.063 * * *$ & $0.094 *$ & $-0.062 *$ & $0.08 *$ & & \\
\hline male $^{\mathrm{a}}$ & $0.058 * * *$ & $-0.081 * * *$ & & & & \\
\hline kid at home ${ }^{a}$ & $-0.065^{* *}$ & $0.091 * *$ & $-0.075 * * *$ & $0.092 * * *$ & & \\
\hline elder at home ${ }^{a}$ & $-0.036 * * *$ & $0.050 * * *$ & & & $-0.078 *$ & $0.075^{*}$ \\
\hline employed $^{\text {a }}$ & $-0.058 * * *$ & $0.08 * * *$ & & & $-0.029 * * *$ & $0.028 * * *$ \\
\hline age $* * *$ & $-0.025 * * *$ & $0.035^{* *}$ & $-0.027 * * *$ & $0.033 * * *$ & & \\
\hline owns garden ${ }^{\mathrm{a}}$ & $0.044^{*}$ & $-0.061 *$ & & & $0.049 * * *$ & $-0.048 * * *$ \\
\hline safe handling index $* * *$ & $-0.008 * * *$ & $0.012 * * *$ & & & $-0.009 * *$ & $0.008 * *$ \\
\hline \# farmers market $* * *$ & $-0.731 * *$ & $1.018 * *$ & & & & \\
\hline \# grocery \& supercenters & & & & & $-0.148 *$ & $0.143 *$ \\
\hline Covid-19 cases & $-0.036 * * *$ & $0.05 * * *$ & $-0.019 * * *$ & $0.024 * * *$ & $-0.051 * * *$ & $0.049 * * *$ \\
\hline
\end{tabular}

Notes: ${ }^{a}$ denotes binary variables. One, two, and three asterisks represent statistical significance at $10 \%, 5 \%$, and $1 \%$, respectively. Marginal effects are only computed for variables that are statistically significant in the ordered Probit model. The probability of no change, which equals 1probability of increase - probability of decrease is omitted in the table. 
(a) Weekly Spending on Overall Food Gorcery: Before vs. During COVID-19

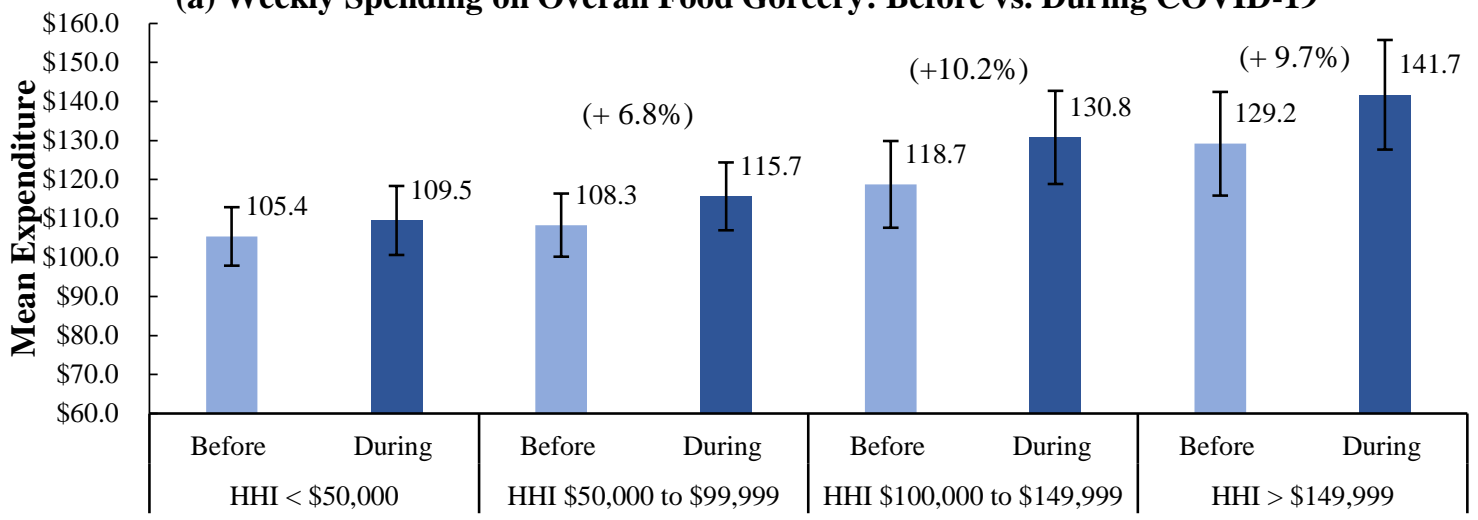

(b) Weekly Spending on Fresh Produce: Before vs. During COVID-19

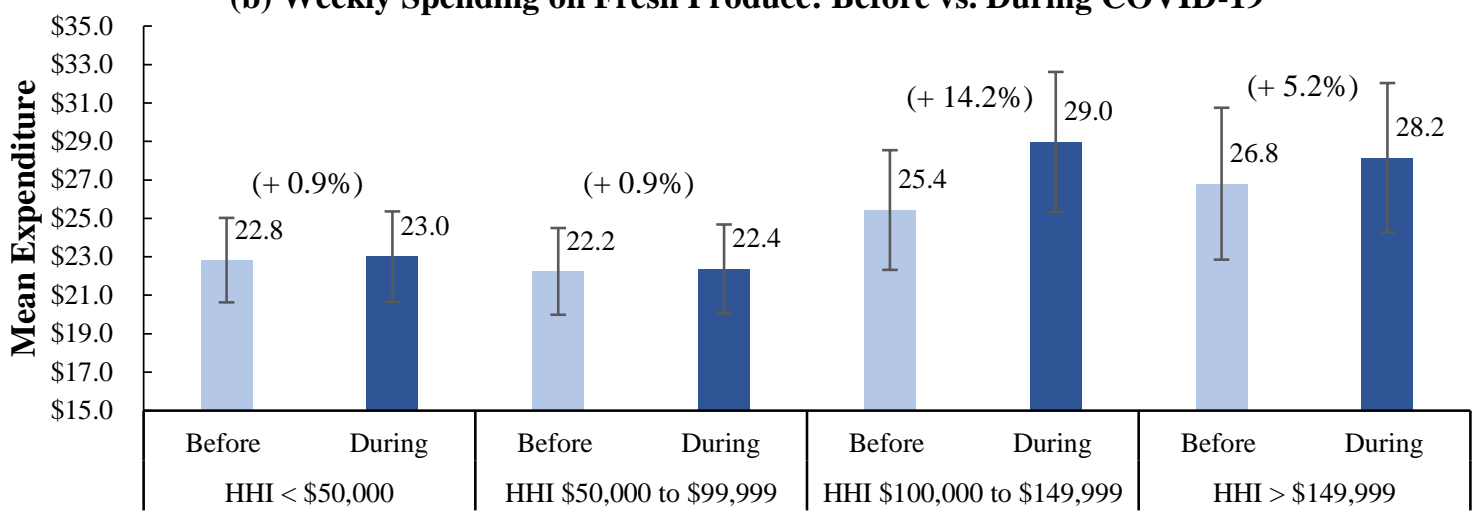

(c) Percentage of Fresh Produce Purchased that is Locally Grown: Before vs.

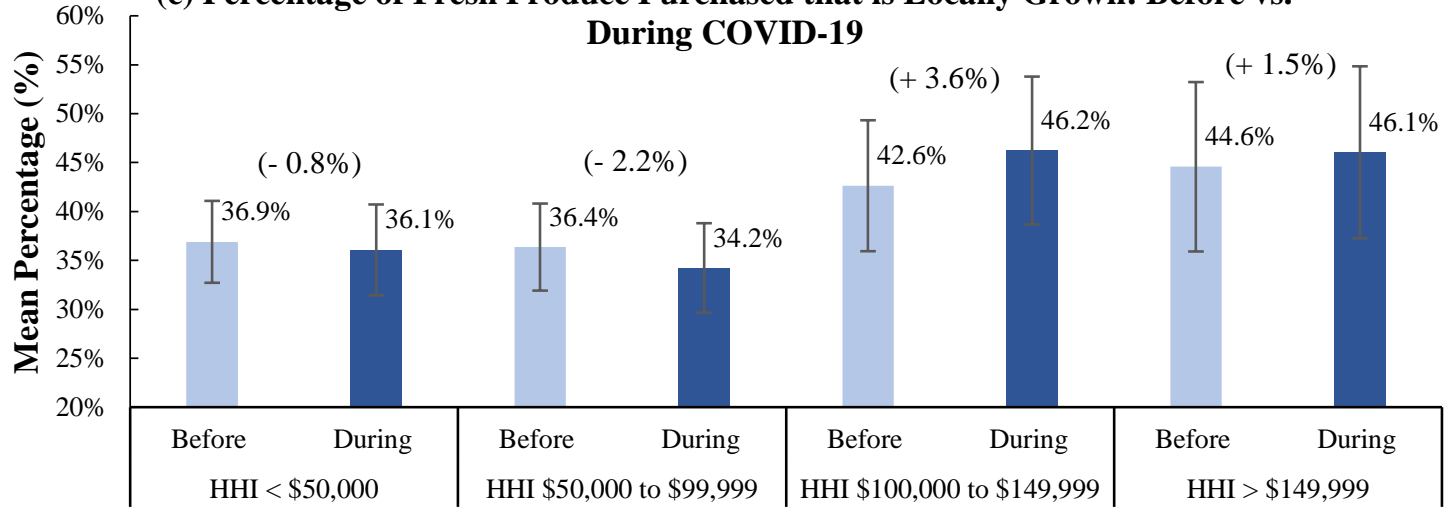

Note 1: Responses are recorded in ranges. Interval censored regressions are used to calculate the mean numbers. The range of a bar indicates the $95 \%$ confidence interval of the mean based on the censored regression.

Note 2: The numbers in parenthesis indicate the percentage changes of the means between the two periods.

Note 3: The U.S. Bureau of Labor Statistics reported the August 2020 food at home and vegetable and fruits price indexes increased $3.7 \%$ and $3 \%$ respectively in comparison to January 2020.

Figure 4.1. Grocery shopping and fresh produce expenses, and the share of locally grown fresh produce purchased by income level: Before vs. During Covid-19 


\section{Appendix}

Table 4.A1: Quota Used in the Survey

\begin{tabular}{|c|c|c|c|}
\hline & $\begin{array}{l}\text { US 5-year } \\
\text { average }^{a} \\
\text { (Quota) }\end{array}$ & $\begin{array}{l}\text { Full sample } \\
\quad(n=514)\end{array}$ & $\begin{array}{l}\text { Opt-outs } \\
\text { dropped } \\
(n=381)\end{array}$ \\
\hline \multicolumn{4}{|l|}{ Household income } \\
\hline$<\$ 50,000$ & $42 \%$ & $41.25 \%$ & $40.42 \%$ \\
\hline$\$ 50,000$ to $\$ 99,999$ & $30 \%$ & $30.93 \%$ & $31.50 \%$ \\
\hline$\$ 100,000$ to $\$ 149,999$ & $15 \%$ & $14.98 \%$ & $16.01 \%$ \\
\hline$\$ 150,000$ or more & $13 \%$ & $12.84 \%$ & $12.08 \%$ \\
\hline \multicolumn{4}{|l|}{ Education level } \\
\hline Less than high school & $12 \%$ & $11.67 \%$ & $9.71 \%$ \\
\hline High school & $28 \%$ & $28.02 \%$ & $28.61 \%$ \\
\hline $\begin{array}{l}\text { Some college or Associate's } \\
\text { degree }\end{array}$ & $31 \%$ & $31.71 \%$ & $31.76 \%$ \\
\hline Bachelor's degree & $18 \%$ & $18.48 \%$ & $19.42 \%$ \\
\hline $\begin{array}{l}\text { Graduate or professional } \\
\text { degree }\end{array}$ & $11 \%$ & $10.12 \%$ & $10.50 \%$ \\
\hline \multicolumn{4}{|l|}{ Age } \\
\hline 18 to 34 & $30 \%$ & $30.54 \%$ & $30.97 \%$ \\
\hline 35 to 54 & $34 \%$ & $32.88 \%$ & $37.01 \%$ \\
\hline 55 or above & $36 \%$ & $36.57 \%$ & $32.02 \%$ \\
\hline
\end{tabular}

Notes: a: American Community Survey 2014-2018 5-Year Average Estimate

Source: U.S. Census Bureau 


\section{Chapter 5}

\section{Concluding Remarks}

Understanding how the recent shale boom has affected the energy market and the local economy in the United States is critical given the significance of the energy sector to the US economy. In the first essay of this dissertation, I analyze how natural hazard events affect statelevel natural gas prices in the United States and how the relationship has changed in light of the inland shale revolution. In the second essay, I examine how the recent shale boom has affected several key economic indicators in the top oil and gas counties in Pennsylvania, Ohio, and West Virginia.

In 2020, the global economy experienced the biggest sudden exogenous shocks in the past decade, the Covid-19 pandemic. In March 2020, the Covid-19 was declared as a global pandemic by the World Health Organization. Later that month, President Trump declared a national emergency in the US and states started to issue stay-at-home orders. By the end of May 2020, the Covid-19 death reached 100,000 in the US. The daily new cases in the US spiked to over 50,000 in July. In my third essay, using a nationwide survey of primary grocery shoppers conducted in August 2020, I examine household food spending when the economy had partially reopened, using interval and Order Probit regressions.

Several limitations exist for the dissertation. In essay one, we use property damages due to natural hazards to represent supply and demand disruptions. However, not all natural disasters necessarily lead to disruptions in the natural gas market. Given the measurement errors in our key independent variable, the estimates provided in the study, therefore, represent a lower bound of the impact of natural disasters on natural gas prices. In essay two, we did not consider housing prices, nor many other important economic indicators. Moreover, the intercorrelations among the economic indicators were not accounted for due to the nature of the synthetic control method and the model design. In the third essay, we fail to consider household wealth, debt, loss of income, and change of lifestyles, in the survey. These may be important factors that affect households' food shopping behaviors. Future research may wish to address these limitations of the dissertation. 